\title{
THE IMPACT OF NON-MONETARY PERFORMANCE MEASURES UPON BUDGETARY DECISION MAKING IN THE PUBLIC SECTOR
}

D IS SERTATION

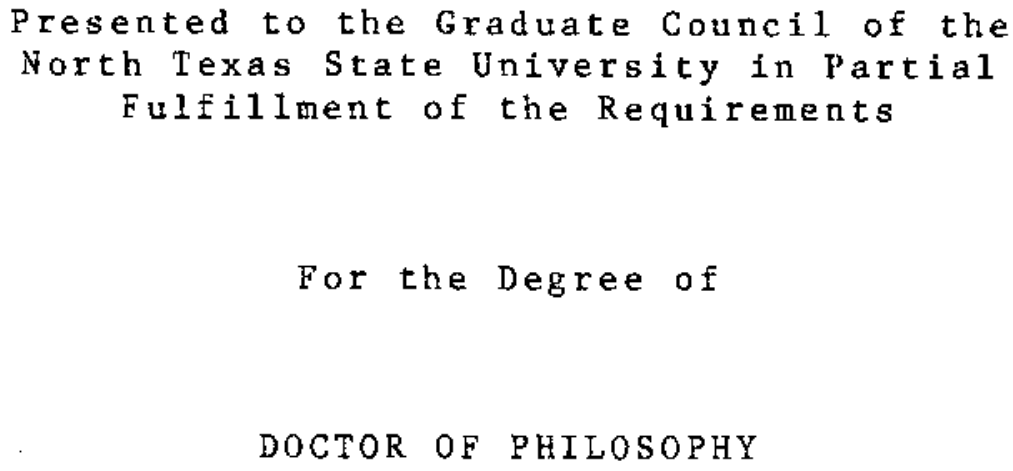


Reed, Sarah A., The Impact of Non-Monetary Performance Measures Upon Budgetary Decision Making in the Public Sector. Doctor of Philosophy (Accounting), May, 1984, 394 pp., 94 tables, bibliography, 102 titles. Public policy decision makers must make complex resource a1location decisions. They not only need feedback concerning the efficiency with which organizational inputs were converted into outputs in the form of goods and services, but also require data concerning the outcome of a program and its impact upon society.

This study addresses in an exploratory fashion the following questions.

1. Would non-monetary performance measures grouped into a statement of public efforts and accomplishments significantly reduce the uncertainty of decision makers concerning past entity performance?

2. Would knowledge of such data alter their resultant budgetary decisions?

The research was carried out in two phases. First, a descriptive quasi-experiment was conducted. An actual program was examined to determine the effect of the project activities upon the target. Chi-square analyses of secondary data and interrupted time series analysis was utfized to evaluate past program results. 
After the evaluation phase was completed, effectiveness cues were developed for intrusion in a laboratory experiment. Regression models were developed to test research hypotheses pertaining to the informational content of performance cues and the impact of these measures upon budgetary decisions.

The major findings of this study are as follows.

1. Existing not-for-profit entity financial statements do not convey adequate information pertaining to both past efforts and accomplishments. Thus a new statement of organizational performance, which compares the dollar resources utilized in a particular project with non-monetary measures of performance should be developed.

2. The evaluation of a particular program in terms of goods or services produced, program outcomes and societal impact encompassed to a satisfactory degree all levels of accomplishment.

3. In a budgeting setting, the provision of cues pertaining to program outcomes and societal impacts significantly altered both the decision makers' certainty of past performance and the resultant budgetary decision. However, subjective biases, created by gender, work experlence, age, education and perception of the severity of local crime, were not completely removed from the process. 


\section{THE IMPACT OF NON-MONETARY PERFORMANCE MEASURES UPON BUDGETARY DECISION MAKING IN THE PUBLIC SECTOR}

D IS SERTATION

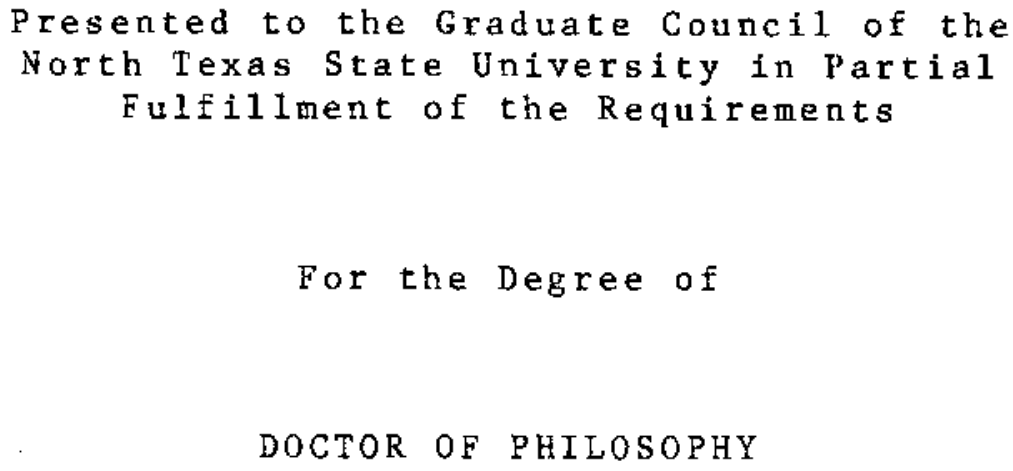




\section{Copyright by \\ Sarah Auman Reed \\ 1984}


TABLE OF CONTENTS

$\underline{\text { Page }}$

LIST OF TABLES.$\cdot \cdot \cdot \cdot \cdot \cdot \cdot \cdot \cdot \cdot \cdot \cdot \cdot \cdot \cdot \cdot \cdot \cdot \cdot \cdot$ $\cdot \cdot \mathrm{v}$

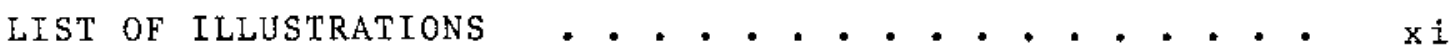

Chapter

I. THE PROBLEM . . . . . . . . . . . . . . . . . 1

Background and Significance of the Problem . . . I 1

Statement of the Problem . . . . . . . . . . 3

Statement of the Conceptual Hypotheses . . . . . 4

Conclusions................. . . . 5

organization of the study . . . . . . . . . . 6

II. THEORETICAL MODEL . . . . . . . . . . . . . 7

Public Sector Economic Model . . . . . . . . . . 7

Agency Relationship Model . . . . . . . . . 17

Political Conflict Model . . . . . . . . . 20

Budgeting Cycle Model . . . . . . . . . . 27

Information Production,

Use and Evaluation Model . . . . . . . . . 29

Human Information Processing Model . . . . . . . 33

Public Sector Information Needs Model . . . . . 37

Public Entity Organizational

Performance Model . . . . . . . . . 39

III. REVIEW OF RELAted literature . . . . . . . . . . 43

Criteria for Judging Performance Indicators . . 43

Measurement Problems . . . . . . . . . . 50

Cost-Effectiveness Measurement Techniques . . . 64

Conclusions... . . . . . . . . . . 66

IV. RESEARCH METHODOLOGY . . . . . . . . . . . 69

Description of Research... . . . . . . . . 69

Quasi-Experiment Research Design . . . . . . 69

Lab Experiment Research Design . . . . . . . 93

V. RESEARCH FINDINGS . • . . . . . . . . . . 108

Quasi-Experiment . ............. 108

Lab Experiment . . . . . . . . . . . . 122 
VI. CONCLUSIONS AND RECOMMENDATIONS FOR

FUTURE RESEARCH . . . . . . . . . " . . . 160

Conclusions . . . . . . . . . . . . . . 160

Recommendations for Future Research . . . . . 161

APPENDIX

A. URBAN CRIME-DESCRIPTION AND PREVENTION * • • • • 163

Introduction . . . . . . . . . . . . . . 164

Determinants of Crime . . . . . . . . . 165

Crime Prevention Policies . . . . . . . . . 180

Crime Prevention Model . . . . . . . . . . 187

B. LAB EXPERIMENT CASES AND RESEARCH INSTRUMENT . . . 193

Background Case Material . . . . . . . . . . 194

Past Program Outputs . . . . . . . . . . . . 199

Past Program Outcomes-Failure Case . . . . . 200

Past Program Outcomes--Successful Case . . . . 201

Past Program Impacts-Failure Case... . . . . 202

Past Program Impacts--Successful Case . . . . . 203

Research Instrument . . . . . . . . . . . 204

C. PROGRAM OUTCOMES . . . . . . . . . . . . 207

Recall of Advertising ............. 209

Crime Prevention Techniques . . . . . . . . 214

Conclusion................. 277

D. IMPACT ASSESSMENT . . . . . . . . . . . . . 279

Data . . . . . . . . . . . . . . 280

Model Building.................. 282

Impact Assessment . . . . . . . . . . . . 354

Conclusion . . . . . . . . . . . . . . 369

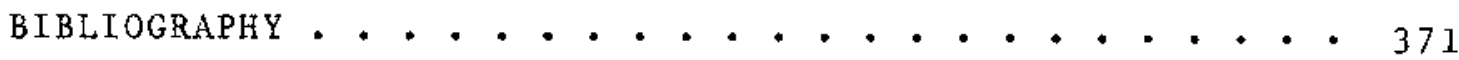




\section{LIST OF TABLES}

Table

I Sample and Population Characteristics. . . . 75

II Persona1, Household and Commercial Crimes-Per Cent of Victimizations Reported to the Police.............. 84

II Percentage Change in Crime-Dallas and Houston . . . . . . . . . 93

IV Experimental Subjects . . . . . . . . 103

$\checkmark$ Dallas Victimization Rates for Persons Age 12 and 01 der . . . . . . . . . 112

VI Crime Time Series Models . . . . . . . 117

VII Crime Prevention Advertising Progran Impact • • 118

VIII Statement of Organizational Performance . . . . 123

IX Correlation Coefficients Between Uncertainty Reduction and Independent Variables............. 130

$X$ Hierarchical Regression CoefficientsUncertainty Reduction . . . . . . . . . 132

XI Summary of Direct, Indirect and Spurious Effects of Each Independent Variable on Uncertainty Reduction . . . . . . 133

XII Estimations of Experimenta1 ResultsUncertainty Reduction . . . . . . . . . . 135

XIII Descriptive Statistics - Experiment . . . . . 137

XIV Mean Difference Research Results . . . . . . 141

XV Correlation Coefficients Between the Dependent and Independent Variables . . . . 142

XVI Hierarchical Regression Coefficients Successful Experiment... . . . . . . 145

XVII Summary of Direct, Indirect and Spurious Effects on Each Independent Variable - Successful Experiment . . . . . 146 
XVIII Hierarchical Regression Coefficients -

Failure Experiment . . . . . . . . . 147

XIX Summary of Direct, Indirect and

Spurious Effects of Each Independent

Variable - Failure Experiment . . . . . . 148

XX Model Estimates............... . 158

XXI Analysis of Variance - Experimental

Variables.............. . 159

XXII Criminal Victimization Rates . . . . . . . 166

XXIII Personal Criminal Victimization Rates . . . . 169

XXIV Household Criminal Victimization Rates . . . 169

XXV Respondents Indicating Feax for

Personal Safety . . . . . . . . . . . 173

XXVI Perceived Neighborhood Crime Problem . . . . . 173

XXVII Recall of Crime Prevention Advertising by Period . . . . . . . . . 211

XXVIII Recall of Crime Prevention Advertising

By Socio-Economic Group........... 212

XXIX Recal1 of Location of Advertising By Period . . 213

XXX Recall of Crime Prevention Pamphlets

By Period................ . 215

XXXI Recall of Crime Prevention Pamphlets

By Socio-Economic Group........... 216

XXXII Home Security Measures--Total Opinion

by Period................. . 217

XXXIII Home Security Measures-opinion

by Area Crime Rate . . . . . . . . . 220

XXXIV Home Security Measures--Heavy Crime Area

Opinion by Period............... 221

XXXV Home Security Measures--Low Crime Area

opinion by Period.............. 222

XXXVI Home Security Measures--Importance of

Techniques-Opinjon by Gender . . . . . . . 222 
XXXVII Home Security Measures--Importance of Techniques-Gender Opinion by Period . . . . . 224

XXXVIII Home Security Measures--Likelihood of Using Techniques-0pinion by Gender . . . . . 224

XXXIX Home Security Measures--Likelihood of Using Techniques--Gender Opinion by Period . . . . . . . . . . . . 225

XL Home Security Measures--Importance of Techniques--Opinion by Ethnic Group . . . . . 227

XLI Home Security Measures--Importance of Techniques--Ethnic Group Opinion by Period............... . . 227

XLII Home Security Measures--Likelihood of Using Techniques--Opinion by Ethnic Group . . 228

XLIII Home Security Measures--Likelihood of Using Techniques--Ethnic Group Opinion by Period................. 229

XLIV Home Security Measures--Importance of Techniques--Opinion by Age . . . . . . . . 231

XLV Home Security Measures--Importance of Techniques--Age Opinion by Period . . . . . 231

XLVI Home Security Measures--Likelihood of Using Techniques--Age Opinfon by Period. . . 232

XLVII Home Security Measurea--0pinion by Marital Status . . . . . . . . . . . 234

XLVIII Home Security Measures--Single opinion by Period . . . . . . . . . . . . 234

XLIX Hore Security Yeasures--Married Opinion by Period . . . . . . . . . . . . 236

$L$ Home Security Measures--Importance of Techniques--Opinion by Tenure . . . . . . 236

LI Home Security Measures--Importance of Techniques--Tenure Opinion by Period . . . . 237

LII Home Security Measures--Likelihood of Using Techniques--Opinton by Tenure . . . . 237 
LIII Home Security Measuresmilkelthood of

Using Techniques-Tenure Opinion

by Period . . . . . . . . . . . . 238

LIV Home Security Measures--Importance of

Techniques--Opinion by Income . . . . . . 240

LV Home Security Measures--Importance of

Techniques--Income Opinion by Period . . . . 240

LVI Home Security Measures--Likelihood of

Using Techniques--0pinion by Income • • . • 241

LVII Home Security Measures-mikelihood of

Using Techniques--Income Opinion

by Period . . . . . . . . . . . .24I

LVIII Vehicular Security Measures--Total

opinion by Period.. . . . . . . . . . . 243

LIX Vehicular Security Measures--Importance

of Techniques--Opinion by Area Crime Rate. . 243

LX Vehicular Security Measures--Importance

of Techniques--Area Crime Rate opinion

by Period................ 245

LXI Vehicular Security Measures--Likelihood

of Using Techniques--Area Crime Rate

opinion by Period............ . . 245

LXII Vehicular Secur1ty Measures--Female

opinion by Period. . . . . . . . . . . . 247

LXIII Vehicular Security Measures--Male Opinion

by Period... . . . . . . . . . . 2 247

LXIV Vehicular Security Measures--Importance of

Techniques--Opinion by Ethnic Group . . . . 248

LXV Vehicular Security Meastures--Importance of Techniques--Ethnic Group Opinion by Period * . 248

LXVI Vehicular Security Measures--Likelihood of Using Techniques--0pinion by Ethnic Group . . 250

LXVII Vehicular Security Measures--Likelihood of Using Techniques-Dthnic Group by Period . . 250

LXVIII Vehicular Security Measures--Opinion by Age • . 251 
LXIX Vehicular Security Measures--Age Opinion

by Period... . . . . . . . . . . . 253

LXX Vehicular Security Measures--0pinion

by Marital Status.... . . . . . . . 253

LXXI Vehicular Security Measures--Married

Opinion by Period.... . . . . . . . 255

LXXII Vehicular Security Measures--Single

opinion by Period.... . . . . . . . . 255

LXXIII Vehicular Security Measures--Importance of

Techniques--Opinion by Tenure... . . . . 255

LXXIV Vehicular Security Measures--Likelihood of

Using Techniques--Tenure Opinion by Period . 257

LXXV Vehicular Security Measures-opinion

by Income . . . . . . . . . . . . 257

LXXVI Vehicular Security Measures--Income

opinion by Perlod . . . . . . . . . . 259

LXXVII Personal Security Measures--Total

opinion by Period.. . . . . . . . . . 260

LXXVII Personal Security Measures--Importance of

Techniques--0pinion by Area Crime Rate . . . 262

LXXIX Personal Security Measures--Importance of

Techniques--Area Crime Rate Opinion

by Period............... . . 262

LXXX Personal Secur1ty Measures--Likelihood

of Using Techniques--High Crime Area

opinion by Period.. . . . . . . . . . 263

LXXXI Personal Security Measures--Importance of Techniques--Opinion by Gender . . . . . . 265

IXXXII Personal Security Measures--Importance of Techniques--Gender Opinion by Period . . . 265

LXXXIII Personal Security Measures--Likelihood of Using Techniques--Opinion by Gender . . . 266

LXXXIV Personal Security Measures--Likelihood of Using Techniques--Gender Opinion

by Period................ 2 266 
LXXXV Personal Security Measures--Importance of Techniques--opinion by Ethnic Group . . . 267

LXXXVI Personal Security Measures--Importance of Techniques--Black Opinion by Period . . . 267

LXXXVII Personal Security Measures--Likelihood of Using Techniques-Opinion by Ethnic Group ............... 269

LXXXVIII Personal Security Measures--Likelihood of Using Techniques--Ethnic Group opinion by Period . . . . . . . . . . . 269

LXXXIX Personal Security Measures--Importance of Techniques-opinion by Age . . . . . . 270

XC Personal Security Measures--Importance of Techniques--Age Opinion by Period . . . . 270

XCI Personal Security Measures--Importance of Techniques--Opinion by Marital Status . . 272

XCII Personal Security Measures--Importance of Techniques--Marital Status Opinion by Period................. 272

XCIII Personal Security Measures-Likelihood of Using Techniques--Single Opinion

by Period................. 273

XCIV Personal Security Measures--Importance of Techniques-opinion by Tenure ......, 275

XCV Personal Security Measures--Likelihood of Using Techniques--Tenure Opinion by Period.... . . . . . . . . . 275

XCVI Personal Security Measures--Importance of Techniques-opinion by Income . . . . . 276

XCVII Personal Security Measures--Importance of Techniques-Income Opinion by Period . . . 278

XCVIII Personal Security Measures--Likelihood of Using Techniques--Opinion by Income . . . 278

XCIX Reported Crime--Dallas, January, 1971 December, 1981 ............. 281 


\section{LIST OF ILLUSTRATIONS}

Figure

Page

1 Private Market Sector Model . . . . . . . . . . 8

2 Public Sector Model . . . . . . . . . . . . 12

3 Economic Model . . . . . . . . . . . . . 14

4 Political Conflict Model . . . . . . . . . . 23

5 Budget Cycle . . . . . . . . . . . . . 27

6 Information Process . . . . . . . . . . . . 30

7 Information Production and Use . . . . . . . . . 31

8 Brunswick's Lens Model . . . . . . . . . . . . 34

9 Organizational Performance Model . . . . . . . . 40

10 Reported Murder--Dallas and Houston . . . . . . . 85

11 Reported Rape--Dallas and Houston . . . . . . . . 86

12 Reported Robbery--Dallas and Houston . . . . . . . 87

13 Reported Assault--Dallas and Houston . . . . . . 92

14 Reported Burglary--Dallas and Houston . . . . . . 93

15 Reported Larceny--Dallas and Houston . . . . . . 94

16 Reported Auto Theft--Dallas and Houston . . . . . . 95

17 Certainty of Event outcomes . . . . . . . . . 96

18 Factorial Research Design . . . . . . . . . . 101

19 Summary of Impact of Dallas Crime Prevention Advertising Program Upon Citizens"Attitudes ... . Ilo

20 Interaction of Gender and Work Experience with Effectiveness Certainty-Failure Experiment . . . . . . . . . . . 153

21 Interaction of Gender and Education with Budget-Fallure Experiment . . . . . . . . . . . . 154

22 Interaction of Gender and Impact Cue with Effectiveness Certainty- Failure Experiment . . . . 
23 Dallas Reported Crime--Murder--Average Monthly Incidences 1971-1981 . . . . . . . . . . . . . . 283

24 Dallas Reported Crime--Rape--Average Monthly Incidences 1971-1981 . . . . . . " . . . . 284

25 Dallas Reported Crime--Assault--Average Monthly Incidences 1971-1981 . . . . . . . . . . . . . 285

26 Da11as Reported Crime--Robbery--Average Month1y Incidences 1971-1981 . . . . . . . . . . . . 286

27 Dallas Reported Crime--Auto Theft--Average Monthly Incidences 1971-1981 . . . . . . . . . 287

28 Dallas Reported Crime--Burglary--Average Month1y Incidences 1971-1981 . . . . . . . . * 288

29 Dallas Reported Crime--Larceny--Average Monthly Incidences 1971-1981 .......... 289

30 Murder Time Series--Unlogged Data, 1971-1981 • . . . 291

31 Murder Time Series--Logged Data, 1971-1981 . . . . . 292

32 Murder Time Series Residuals-Unlogged Data (000), 1971-1981 .......... 293

33 Murder Time Series Residuals-Unlogged Data (010), 1971-1981 . . . . . . . . 294

34 Murder Time Series Residuals--Unlogged (011), $1971-1981$. . . . . . . . . . . . . . 296

35 Murder Time Series Residuals--Unlogged (010)(010)12,

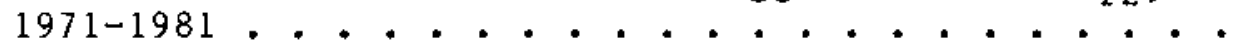

36 Murder Time Series Residuals--Unlogged (111)(111) 12 , 1971-1981................... . . .

37 Murder Time Series Residuals plot-Unlogged $(111)(111)_{12}, 1971-1981$. . . . . . 301

38 Rape Time Series--Unlogged Data, 1971-1981 . . . . . 302

39 Rape Time Series--Logged Data, 1971-1981 . . . . . 303

40 Rape Time Series Residuals--Logged Data (000),

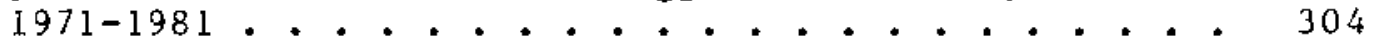


41 Rape Time Series Residuals--Logged (010)(010) 12 ,

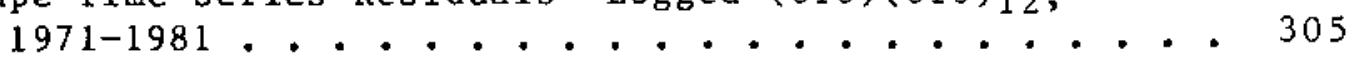

42 Rape Time Series Residuals--Logged (011)(011)12,

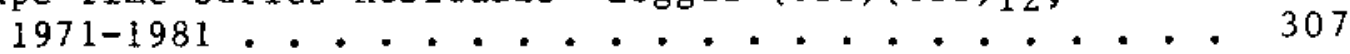

43 Rape Time Series Residuals Plot--Logged (011)(011) 12,

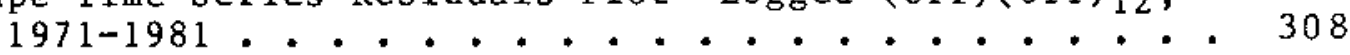

44 Assault Time Series--Unlogged Data, 1971-1981 . . . 309

45 Assault Time Series--Logged Data, 1971-1981 . . . . 310

46 Assault Time Series Residuals--Logged (000), 1971-1981................... . . 311

47 Assault Time Series Residuals--Logged (010),

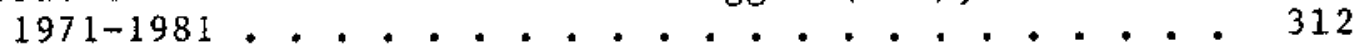

48 Assault Time Series Residuals--Logged (010)(010) 12, 1971-1981.................. 314

49 Assault Time Series Residuals-Logged $(011)(001)_{8}(011)_{12,1971-1981}$. . . . . . 316

50 Assault Time Series Residuals Plot-Logged $(011)(001)_{8}(011)_{12}, 1971-1981 . . . . . .317$

51 Robbery Time Series--Unlogged Data, 1971-1981 . . . 318

52 Robbery Time Series--Logged Data, 1971-1981. . . . . 319

53 Robbery Time Serles Residuals-Unlogged $(000), 1971-1981 . . . . . . . . .320$

54 Robbery Time Series Residuals-Unlogged (010), 1971-1981............

55 Robbery Time Series Residuals-Unlogged $(111)(001)_{6}(001)_{8}(101)_{12}, 1971-1981 \ldots$

56 Robbery Time Series Residuals Plot-Unlogged $(111)(001)_{6}(001)_{8}(101)_{12}, 1971-1981$. . 326

57 Auto Theft Time Series--Unlogged Data, 1971-1981 . • 327

58 Auto Theft Time Series--Logged Data, 1971-1981 . . . 328 
59 Auto Theft Time Series Residuals--Unlogged (000),

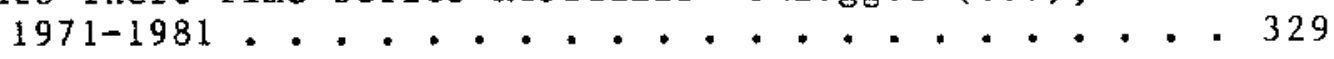

60 Auto Theft Time Series Residuals--

Unlogged (010), 1971-1981... . . . . . . . 330

61 Auto Theft Time Series Residuals--

Unlogged (010)(010) $12,1971-1981$. . . . . . . 331

62 Auto Theft Time Series Residuals--

Unlogged $(011)(011)_{12}, 1971-1981$. . . . . . 333

63 Auto Theft Time Series Residuals Plot--

Unlogged (011)(011)12,1971-1981 . . ". . . . 334

64 Burglary Time Series--Unlogged Data, 1971-1.981 • • . 335

65 Burglary Time Serles--Logged Data, 1971-1981 • • . • 336

66 Burglary Time Series Residuals--

Logged (000), 1971-1981 . . . . . . . . . 338

67 Burglary Time Series Residuals--

Logged (010), 1971-1981 . . . . . . . . . 339

68 Burglary Time Series Residuals--

Logged $(010)(010)_{12}, 1971-1981$. . . . . . 340

69 Burglary Time Series Residua1s--

Logged $(011)(011)_{12}, 1971-1981$. . . . . . . 341

70 Burglary Time Series Residuals--

Logged (111)(011)12,1971-1981 . . . . . . . 343

71 Burglary Time Series Residuals Plot--

Logged (111)(011)12,1971-1981 . . . . . . . 345

72. Larceny Time Series- Unlogged Data, 1971-1981 . • . 346

73 Larceny Time Series--Logged Data, 1971-1981 . . . . 347

74 Larceny Time Series Residuals--

Logged (000), 1971-1981 . . . . . . . . . . . 348

75 Larceny Time Series Residuals--

Logged (010), 1971-1981 . . . . . . . . . 349

76 Larceny Time Series Residuals--

Logged $(010)(010)_{6}(010)_{12}, 1971-1981 . . . . . .350$ 
77 Larceny Time Series Residuals--

Logged $(011)(011)_{6}(011)_{12}, 1971-1981 \ldots . . . . . .352$

78 Larceny Time Series Residuals Plot--

Logged $(011)(011)_{6}(011)_{12}, 1971-1981 . . . . . .353$

79 Rape Interrupted Time Series Residuals--

Abrupt, Permanent Intervention--

Logged $(011)(011)_{12}, 1971-1981$. . . . . . .

80 Assault Interrupted Time Series Residuals -.

Abrupt, Permanent Intervention--

Logged $(011)(001)_{8}(011)_{12}, 1971-1981 \ldots . . . .$.

81 Robbery Interrupted Time Series Residuals--

Abrupt, Permanent Intervention--

Unlogged (111)(001) $6(001)_{8}(101)_{12}, 1971-1981$. . 361

82 Auto Theft Interrupted Time Series Residuals--

Abrupt, Permanent Intervention--

Unlogged $(011)(011)_{12}, 1971-1981 . . . . . . . .364$

83 Burglary Interrupted T1me Series Residuals--

Abrupt, Permanent Intervention--

Logged (111)(011)12,1971-1981 . . . . . . 366

84 Larceny Interrupted Time Series Residuals--

Abrupt, Permanent Intervention $\rightarrow$

Logged $(011)(011)_{6}(011)_{12}, 1971-1981$. . . . 370 
CHAPTER I

THE PROBLEM

Background and Significance of the Problem

In 1976, public expenditures accounted for 34 per cent of the Gross National Product. This represents a 48.7 per cent increase since 1949. The tax burden placed upon the middle income family has also become greater. In 1953, 11.8 per cent of a household's income was transferred to the public sector. This increased to 22.7 per cent in 1975.2 Public polisy decision makers must make complex resource allocation decisions. Yet, the accounting information system utilized in the public sector has not adequately adapted to meet these complex needs. Public policy decision makers interact in an environment where numerous interests compete for scarce resources. They must weigh the costs of foregoing certain opportunities against the benefits to be obtained from implementing other programs. One source of information utillzed in this process comes from the accounting system. At the present, however, only two general purpose external financial statements are provided. One describes a public entity's assets, liabilities, and related (Englewood Cliffs, $1979 \overline{\text { ), P. } 245 . ~}$

2 Ibid. p. 245 . 
fund balances at a particular point in time and the other depicts resource inflows and outflows by type and fund for a period of time.

This information is useful in determining entity accountability and liquidity. However, more data is needed to estimate past organizational performance. Decision makers not only need feedback concerning the efficiency with which organizational inputs were converted into outputs in the form of goods and services, but they also require data concerning the outcome of a program and its impact upon society.

Three questions must be answered to adequately weigh the costs and benefits of various programs competing for scarce resources.

1. Were past resources utilized in an efficient and economical manner to produce a given output?

2. Did the output generated have the desired effect upon the target population?

3. Did the program ultimately impact the perceived societal problem in the predicted fashion?

At the present only the efficiency question is being addressed within the accounting system. Thus, a need exists to develop valid, reliable, relevant and economical effectiveness measures. 
Statement of the Problem

This study addresses in an exploratory fashion the following questions.

1. Would non-monetary performance measures grouped into a statement of public efforts and accomplishments significantly reduce the uncertainty of decision makers concerning past entity performance?

2. Would knowledge of such data alter their resultant budgetary decisions?

Theoretically, data on service efforts and accomplishments should allow decision makers to better evaluate an entity's past performance and to assess its ability to continue such services. However, the current state of the art of measuring and reporting entity effectiveness is inadequate. 3

The purpose of this study was to investigate whether performance measures would reduce user uncertainty and impact budgetary decision making. The research was carried out in two phases. First, a descriptive quasi-experiment was conducted. An actual program was examined to determine the effect of the project activities upon the target. After the evaluation phase was completed, effectiveness cues were developed for intrusion in a laboratory

3Harold $I$. Steinberg and Paul K. Brace, "Pinancial Accounting Standards Board Study of Service Efforts and Accomplishments", Government Accountants Journal, XXX 
experiment. Research hypotheses pertaining to the impact of the performance information upon uncertalnty and budgetary decisions were then tested. Statement of the Conceptual Hypotheses The conceptual hypotheses tested in this study are as follows :

$\mathrm{H}_{1}$ : The Statement of Organizational Performance that compares public efforts with public accomplishments will significantly increase the information available to decision makers concerning the outcome of a program or activity.

$\mathrm{H}_{2}$ : The Statement of organizational Performance that compares public efforts with public accomplishments will significantly increase the information avallable to decision makers concerning the impact of a program or activity upon society.

$\mathrm{H}_{3}$ : The Statement of Organizational Performance that compares public efforts with public accomplishments will significantly reduce an individual decision maker's uncertainty pertaining to past program outcomes.

$\mathrm{H}_{4}$ : The Statement of Organizational Performance that compares public efforts with public accomplishments will significantly reduce an individual decision maker's uncertainty pertaining to past program impacts.

H5: As uncertainty concerning past program outcomes is reduced, judgment variability among decision makers will decline.

$\mathrm{H}_{6}$ : As uncertainty concerning past program impacts is reduced, judgment variability among decision makers will decline. 
Conclusions

The major findings of this study are as follows.

1. Existing not-for-profit entity financial statements do not convey adequate information pertaining to both past efforts and accomplishments. Thus a new statement of organizational Performance, which compares the dollar resources utilized in a particular project with non-monetary measures of performance should be developed.

2. The evaluation of a particular program in terms of goods or services produced, program outcomes and societal impact encompassed to a satisfactory degree all levels of accomplishment.

3. In a budgeting setting, the provision of cues pertaining to program outcomes and societal impacts significantly altered both the decision makers' certainty of past performance and the resultant budgetary decision. However, subjective biases, created by gender, work experience, age, education and perception of the severity of local crime, were not completely removed from the process. 


\section{Organization of the Study}

Chapter I has introduced the study. A background of the toplc was included, the problem was stated, the research methodology was introduced, the conceptual hypotheses were presented, and the conclusions were outlined.

Chapter II contains the theoretical model underlying this research. The forces impacting the problem are discussed in detail and postulates are developed.

Chapter II presents a review of the related literature. It demonstrates what is currently known about the problem.

Chapter IV provides a detailed discussion of the research methodology employed. The model is specified and the research design is described. The methods of data collection and data analysis are also explained.

Chapter $V$ presents the research findings.

Chapter VI sumarizes the study. It includes the 1imitations and major contributions of this endeavor and suggests areas of potential future research.

Appendix A contains a brief discussion of the current crime prevention literature.

Appendix $B$ includes copies of the cases and the instrument utilized in the laboratory experiment. Appendices $C$ and $D$ present detalled analyses of the program outcome and impact, respectively. 


\section{Chapter II}

THEORETICAL MODEL

Public Sector Economic Model

Politico-economic systems attempt to organize cooperation and control behavior to achieve two fundamental social goals: efficiency and equity. Econolic efficiency concerns the allocation of productive resources to their best use and, given this, the technical creation of these commodities at the least possible cost. Distributional equity involves judgments about the division ot the output of goods and services among the citizenry.l Al1 politico-economic systems employ two mechanisms--exchange and authority--to achieve these social goals.

Exchanges occur in three markets. Individuals possess a linited quantity of the three basic factors of production-land, labor, and capital. They enter the factor market where these productive assets and energies are offered to business enterprises in exchange for money in the form of rents, wages, or interest. Businesses possess the technology by which these factor inputs are converted into

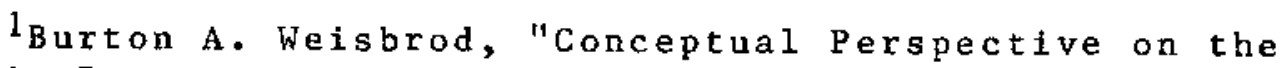
Public Interest: An Economic Analysis", Public Interest Law (University of California Press 1982), pp. 4-5. 
new goods or services possessing additional utility. An intermediate market exists where business enterprises exchange among themselves money for intermediate factors needed to create the final outputs. Individual households then enter the consumer market to exchange money for desired goods and services. 2 Figure 1 depicts this process pictorially.

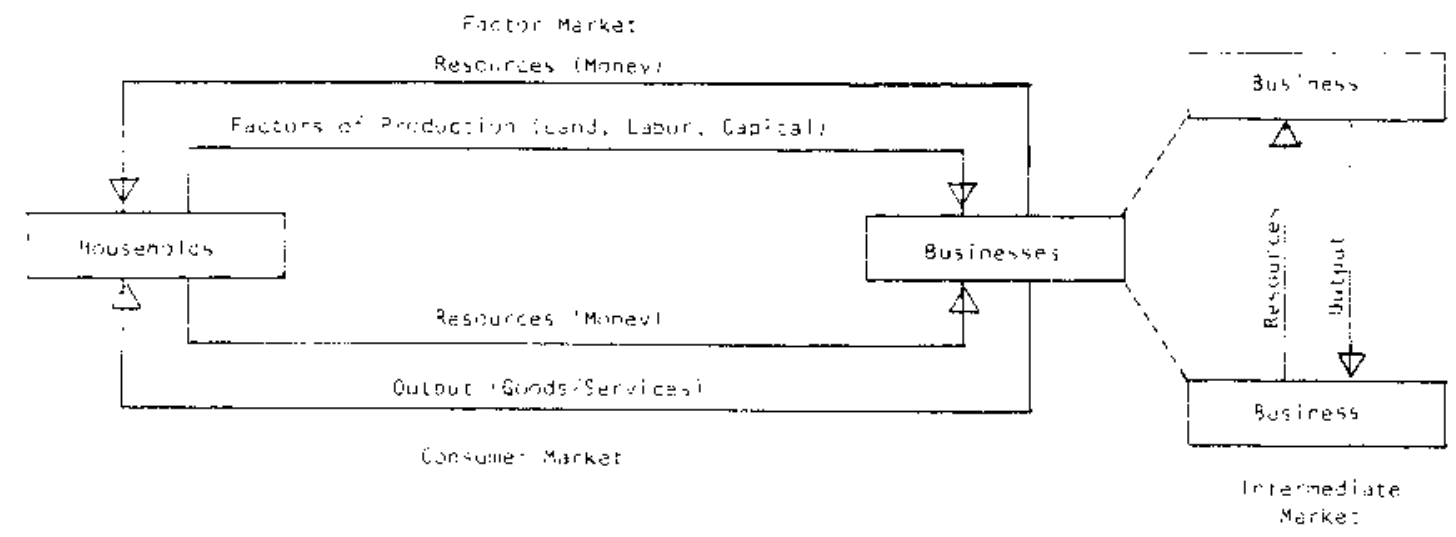

Fig. 1--Private Market Sector Model

The market exchange system performs three functions. It establishes (1) what is to be produced, (2) how the productive process will be organized, and ( 3 ) to whom the products will be distributed. 3 A perfect market, characterized by competition among individuals, acts first to channel resources into industries producing outputs

${ }^{2}$ Charles E. Lindblom, Politics and Markets (New York, $1977), \mathrm{p} .37$.

${ }^{3}$ Robert $H$. Haveman, The Economics of the Public sector (Santa Barbara, 1976), p. 27 . 
desired by consuming households and, secondly, into those Individual firms that can make the most efficient use of these resources. Distribution of the resultant market exchange output is determined by the dollars comanded by individual households. This depends, in turn, upon the quantities of the factors of production that each initially controls and the prices received for them.

For an exchange market to operate efficiently in allocating input factors to the production of goods and services demanded by consumers, certain conditions must necessarily exist. First, all traders in the market must be price takers. 4 only if each actor is so small relative to the aggregate market that he can not manipulate the price of the item being exchanged, will prices be established by the impersonal forces of supply and demand and reflect economic value.

Secondly, all participants must possess full knowledge of all available alternatives and be completely mobile. 5 Market prices must inform both the buyer and the seller of not only the benefits of any transactions undertaken, but also the costs of the foregone opportunities. It must also be possible to alter consumer and producer actions quickly as market signals change. If immobility, uncertainty, and

${ }^{4} \mathrm{Ibid} .$, p. 23.

${ }^{5}$ Charles L. Schultze, The Public Use of Private Interest (Washington, 1977), p. 36 . 
information costs are too high, the efficiency of the market wi11 be 1 mpeded.

Finally, no externalities can exist. 6 No benefits or costs should spill over to third parties not directly involved in the exchange transaction. Individual participants evaluate their private costs and benefits when appraising the possible resource allocation alternatives. Ideally, resultant exchange dollar prices should reflect total societal costs and benefits. In reality, however, this is not the case.

Some commodities impose spillover costs. Others create spillover benefits. Positive or negative externalities will cause inappropriate amounts of resources to be allocated to the production of a particular comodity by the private sector.

Public goods represent the extreme case of a commodity with positive externalities. 7 In this instance, a commodity generates almost entirely indirect benefits. For example, when a quantity of national defense is produced, benefits are automatically available to all soctetal members. Consumption by one individual does not significantly reduce the amount of the good or service available to others.

6 Jack Hirshleifer, Price Theory and Applications (Englewood Cliffs, $1 9 7 6 \longdiv { \text { ), P. } }$ 449.

${ }^{7}$ Robert H. Haveman, The Economics of the public sector (Santa Barbara, 1976), p. 41 . 
Since no one can be barred from receiving benefits, there is little incentive for any member of the community to voluntarily contribute toward the costs of production. Thus, households will refuse to pay for a public good and businesses will refuse to produce it.

Even if the exchange market experiences no fallures and all market demands are efficlently satisfled, equity as perceived by societal members may not be achieved. The market mechanism can only give value for value received. It automatically awards income to the participants based upon what each contributes to the productive process in the form of land, labor, and capital. Household income variations then arise from differences in the kinds and quantities of resources owned by individuals and the prices paid by businesses employing these resources. Thus, Individual income differences are largely a result of chance and beyond the control of household participants. 8

When the necessary conditions for efficient market operations are not present or when society subjectively determines that the resultant market distribution of income is not equitable, collective action is required to alter the existing situation. The public sector provides a mechanism for this activity.

${ }^{8}$ Richard H. Leftwich, The Price System and Resource

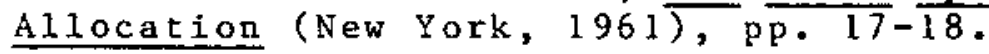


Public entities act as an authority network. For any given population, a government exists when one organization exercises authority over every other organization without challenge from rival clatmants. Authority generally operates through law and other prescriptive rules.9 The interactive process that occurs between the public and private sectors is displayed in Figure 2 .

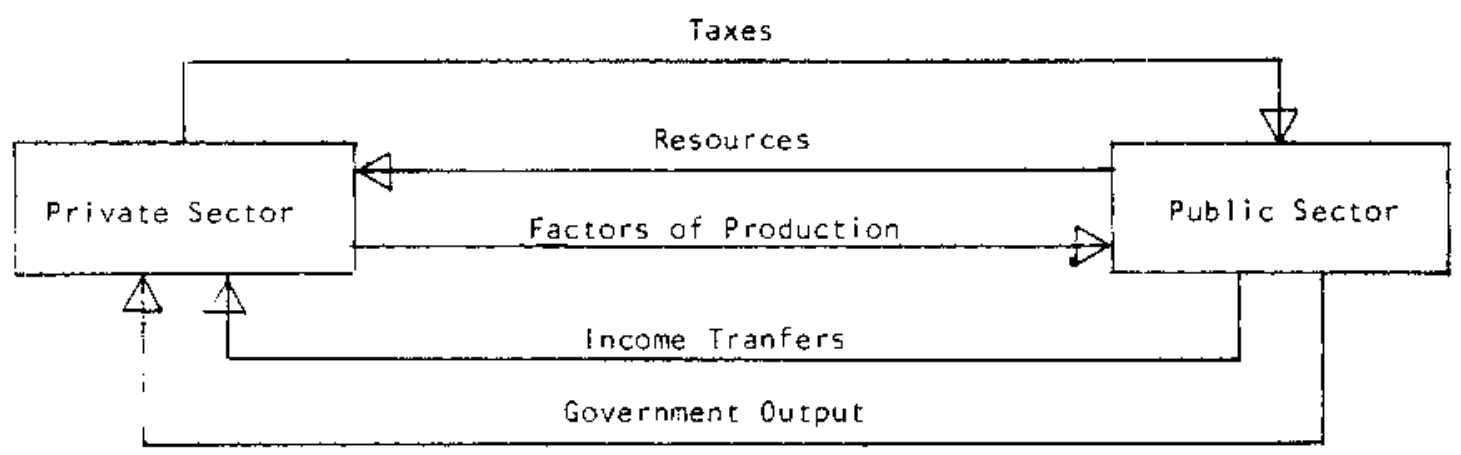

Fig. 2 - Public Sector Model

The public sector obtains operating resources from the private sector through taxation. The funds would have otherwise been utllized in the privace sector to achieve greater personal benefits. A societal cost, therefore,

${ }^{9}$ Charles E. Lindblom, Politics and Markets (New York, 1977), PP. 21-22. 
occurs equal to the resultant decline in individual wants satisfaction.

Public funds are utilized to perform two functions. To alleviate private market inefficlencies, the government utilizes taxes to purchase factors of production in the private market. These, in turn, are converted into public outputs which are then supplied to the private sector for consumption. Societal equity considerations are implemented through income redistribution. Here, public resources are directly transferred to certain qualifying households or businesses in the private sector. Purchasing power is taken from some through taxation and given to others whom society has deemed more needy. Figure 3 contains the complete economic mode1.

Before developing propositions concerning the economic environment in which public entities operate, certain simplifying assumptions must be made. (1) For most goods, the private sector exchange market operates efficientiy. Thus, factors of production are allocated efficiently to create the output desired by individual households. There are certain goods or services that the private sector can not produce. These commodities, termed public goods, must by necessity be provided in some manner through collective action by the public sector. (3) The public sector obtains all of its resources through taxation. The social cost of diverting resources from the private to 


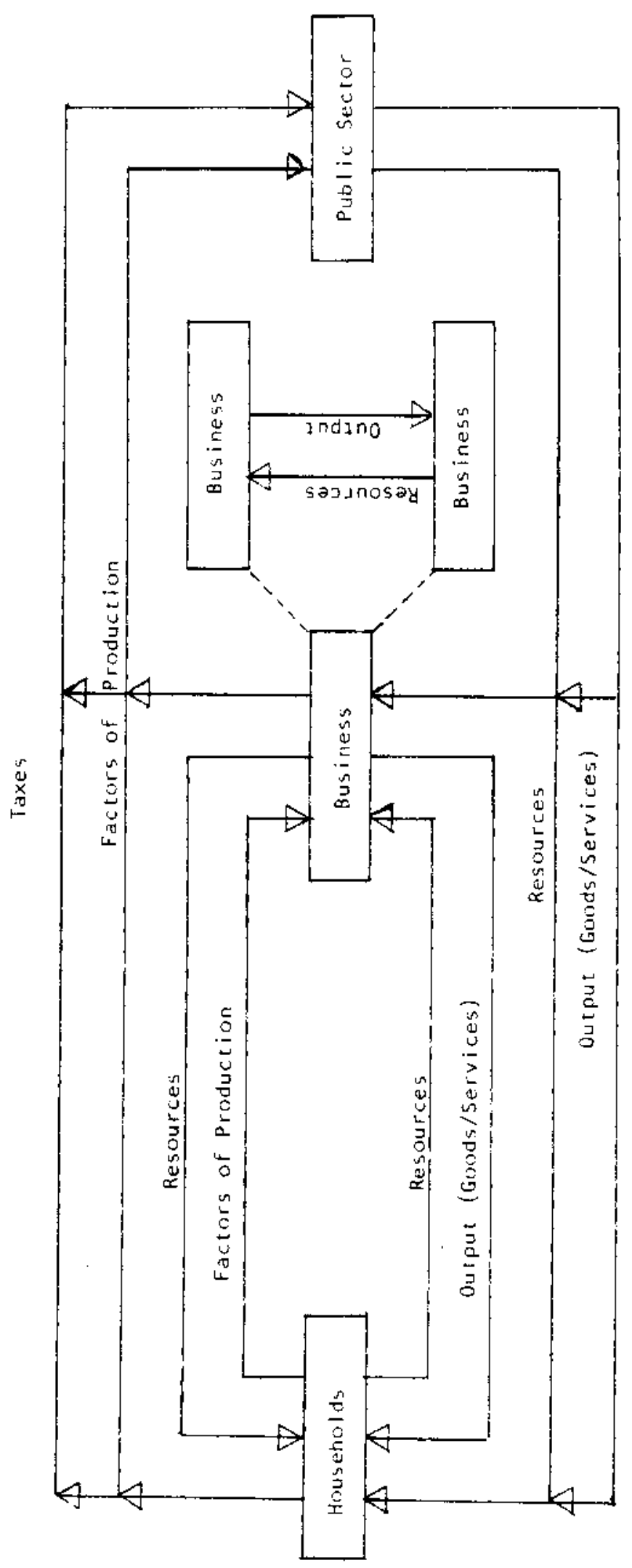

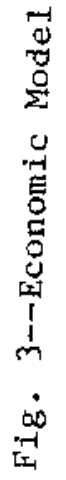


the public sector through taxation is known. (5) All public goods can be evaluated and the social benefft to be obtatned from each additional unit produced is known. (6) The public sector and the private sector agree in their respective evaluation of social benefits and social costs. (7) No equity decisions will be made.

Social benefits are achieved when the wants of the consuming populace are satisfied. Thus, as the quantity of the public sector output increases, more public wants are satisfied and total social benefits increase. However, benefits are obtained at a dimintshing rate. As additional public goods or services are consumed, less incremental individual unsatisfied wants are gratified. In contrast, the social costs created by taxation increase at an increasing rate. These costs may be defined as the loss of individual opportunities to achieve wants satisfaction in the private sector. As each individual transfers increasingly more valuable resources to the public sector, he must forego increasingly thore valuable wants satisfaction in the private sector. Therefore, the marginal social cost resulting from each additional unit of public output reduces the wants satisfaction of the consuning public at an increasing rate.

The optimal efficient size of the public sector is achieved when the marginal social benefit of the last unit of public output produced equals the marginal social cost of 
creating such a product. Only then is wants satisfaction fully maximized.10 This is summarized in the following proposition.

Proposition 1A: Resources are efficiently allocated between the public and private sectors when the marginal social benefit derived from the last dollar of public expenditures equals the marginal social cost imposed by diverting that dollar from the private sector through taxes.

At a minimum, no public activity should be implemented where prospective social gains from the undertaking will not exceed social costs.11 Public resources should be allocated among projects so that the excess of total social gains over total social costs for all activities is maximized. Efficiency is achieved and public satisfaction maximized if the marginal social benefit for each activity equals the marginal social cost. Thus, if wants satisfaction is maximized for each public project, total public market efficiency will be obtained.

Proposition lB: Resources are efficiently allocated to a public project when the marginal social benefit derived from the last dollar of public expenditures applied to that project equals the marginal social cost imposed by diverting that dollar from the private sector through taxes.

${ }^{10}$ Robert $H$. Haveman, The Economics of the Public sector (Santa Barbara, 1976), pp.49-59.

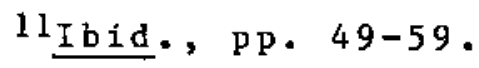


Agency Relationship Model

Since only human needs supported by dollar voting will be satisfied by the exchange market in the private sector, sone form of collective action must be superimposed upon the market structure to achieve the mix of goods and services deemed appropriate by society. It every citizen participated in each collective decision, not only would large bureaucratic costs be fncurred, but many would shirk the task of becoming well informed on every issue since any losses associated with bad decisions would be spread over all societal members. More effective control of collective action is achieved by transferring decision authority to a smaller group.12 Thus, society grants authority to the public sector to act on its behalf in certain matters. An agency relationship exists between any particular governing authority and the individuals it purports to represent. An agency relationship can be defined as "a contract under which one or more persons (the principal(s)) engage another person (the agent) to perform some service on

12 Armen A. Alchian and Harold Demsetz, "Production, Information Costs, and Economic organization", The American Economic Review, LXII (December, 1972), p. 188 . 
their behalf which involves delegating some decision making authority to the agent." 13

A control system is created. Principals seek to control the behavior of their agents and agents seek to control their environment so that principals are satisfied. For this control mechanism to be operational, a principal must commuicate his preferences to the agent, monitor the agent's performance, and prevent and/or correct any deviation observed from the desired performance. The agent, on the other hand, must ascertain the principal's preferences, and implement these endeavors. 14

If all individuals are assumed to be utility maximizers, then it is probable that in some instances, the agent will attempt to 1mprove his own personal welfare at the principal's expense. To limit these divergences, the principal will establish agent incentive devices and incur monitoring costs. Furthermore, the agent will create bonding arrangements to reduce the likelihood that he will actualiy perform acts harmful to the principal or to compensate the principal if such actions are selected. However, some reduction in principal welfare will still be

13 Michael C. Jensen and William H. Meckling, "Theory of the Firm: Managerial Behavior, Agency Costs and Ownership Structure", Journal of Financial Economics, III (October, 1976), p. 308 .

14Barry M. Mitnick, "Regulation and the Theory of Agency", Orbis, P. 446 . 
experienced. This residual loss creates the third element of the total cost of creating an agency relationship.15 The magnitude of agency costs will depend upon the divergence between the principal's and the agent's tastes and the difficulty with which agent performance can be measured and evaluated.

In this instance, the collective society (the principal) and the public sector (the agent) are geographically separated. Therefore, the principals can not directly observe the agent's behavior. Principals must also relay their individual preferences to agents at widely spaced intervals through the ballot process. Here, varied, vague, and even conflicting desires are glven public volce. Even after some consensus of public sentiment is achieved, agents find it difficult, if not impossible, to implement these perceived preferences. The goods and services created by the agent are those that the exchange market is either unwilling or unable to produce in the quantities desired by the populace. Therefore, market prices can not be utilized as a convenient common denominator for judging the costs and benefits of alternative courses of action. Since accomplishments are

15 Michael C. Jensen and William H. Meckling, "Theory of the Firm: Managerial Behavior, Agency Costs and Ownership Structure,", Journal of Financial Economics, III (October, 1976), p. 308 . 
not readily quantifiable, inputs and processes are more likely to be controlled rather than output. The public sector resource allocation system in general and the budget in particular are utilized by the principal to monitor agent actions and control deviant behavior.

Proposition 2: In the principal and agent relationship that exists between the society and the public sector, resources are expended to create a control system that will more closely identify the opportunities available to the agent's interests with those of the principals.

\section{Political Conflict Mode1}

Governmental policies determine where tax dollars are allocated. Policy implementation begins with the adoption of a budget. The term "budget" originally referred to the money bag or the public purse which served as a receptacle for revenue of the state.16 However, through the centuries it has evolved into a plan that monetarily expresses the relationship between the expenditure of funds and the accomplishment of objectives.

Governmental budgets focus attention upon the planning, managemt, and control of the use of public resources. planning involves the determination of objectives, the evaluation of alternative courses of action for their effectiveness in accomplishment of desired aims, and the

16 Jesse Burkhead, Governmental Budgeting (New York, $1956)$, p. 2 . 


\begin{abstract}
allocation of scarce resources among the avallable
alternatives. Management is concerned with the conversion of approved programs into specific activities, the design and staffing of the administrative units needed to carry out the established activities, and the efficient and effective utilization of resources in the accomplishment of stated objectives. Control refers to the process of assuring that specific tasks are carried out according to specified guidelines. 17
\end{abstract}

Ideally, budgetary decisions should encompass six activities: (1) definition of the operational goals to be achieved, (2) establishment of an inventory of available resources and constraining values, (3) inventory of all available alternatives for meeting goals, (4) determination of the costs and benefits of each alternative, (5) calculation of the net benefits or costs of each alternative, and (6) selection and implementation of the alternative with the highest net expectations.18

Wildavsky (1979) argues that several assumptions, implicit in this normative model, make "rational" decision making imposible.ig First, the model assumes that there is

17 Allen Schick, Perspectives on Budgeting (Washington, $1980)$, p. 47 .

18 Thomas D. Lynch, Public Budgeting 1n America (Englewood Cliffs, 1979 ), p. 23 .

${ }^{19}$ Aaron Wildavsky, The Politics of the Budgetary Process (Boston, 1979). 
consensus among the budget participants concerning the goals to be achieved. In our pluralistic society, a powerfully elite group does not establish goals. 20 Numerous factions with differing goal perceptions, compete for scarce resources.

Secondly, even if general agreement car be generated for a specific objective, considerable disagreement may remain on the implementation of sub-objectives. When multiple values must be considered as criteria for a decision, they frequently conflict. Furthermore, they may not remain stable over time. Therefore, an administrator can not objectively rank values prior to analysis of alternatives.

Thirdly, the rational model assumes that the decision maker is a completely rational person. However, time and information constraints, coupled with a human being's limited cognitive capabilities, make it imperative that problems be simplified and satisficing occur. The search for a solution is halted when an acceptable solution is uncovered. Thus, all available alternatives are never examined and certain possible consequences of public activities are ignored.

20 For an alternative view, see C. Wright Mills, The Power Elite. 
Finally, the rational model assumes that policy making is a positive-sum game in which everyone gains and no one loses. In reality, however, budgeting requires that one take from one group and give to another. Pollcy making thus deals with the consideration of who will actually pay and who will benefit.21 The political conflict model depicted in Figure 4 provides a more accurate description of the budgetary decision process.

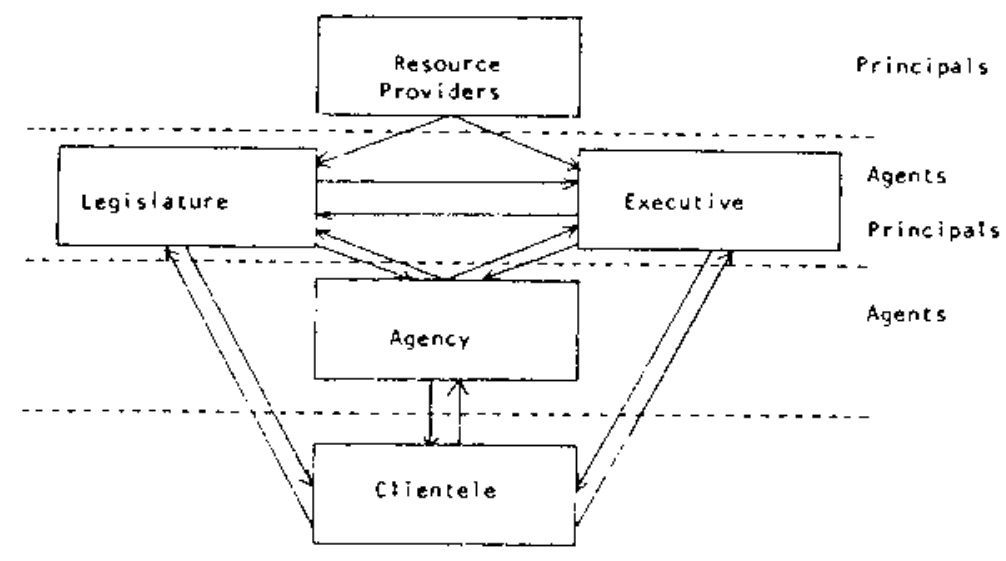

Fig. 4--Positive Conflict Model

The budgetary process occurs in a political arena where five groups engage in organized conflict. whe system is one of checks and balances in which the chief executive, agencies, the legislature, clientele groups, and resource providers enact distinct roles.

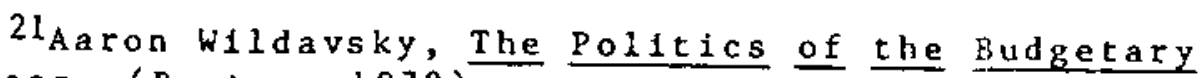
Process, (Boston, 1979 ). 
The chief executive plays the role of the overseer.22 Budgets serve many concurrent purposes. They are utilized as a main instrument in the national attempt to ensure economic growth, full employment, and price stability. Futhermore, they provide a conduit through which scarce resources are funneled to activities and programs designed to ameliorate conditions of market inefficiency and inequity. Finally, budgets serve as a political symbol of executive leadership. 23 The chief executive must weigh the inherent conflicts among the fiscal, allocative, and political objectives and base his decisions upon the complete picture.

Agencies are charged with implementing policy. They play the role of the advocate and defender of specific public programs. Belief in the fundamental worth of their particular activities will naturaliy lead agency personel to favor program expansion to fulfill the perceived unmet needs of their clientele. Expansionist tendencies are dampened only by the knowledge that resources are scarce and that excessively large requests may be arbitrarily cut. Therefore, agencies generally limit budget requests to only

\footnotetext{
${ }^{22}$ Lance T. Leloup, Budgetary Politics (Brunswick, 1980), p. 14 . ${ }^{23}$ Ibid., p. 6.
} 
those critical areas displaying jointly the greatest perceived need and the largest external support. 24

The legislature serves as the guardian of the purse. Without operating resources, no activity will occur. only here, can dollars actually be appropriated for any particular purpose. Duties performed fnclude reviewing, questioning, and modifying departmental requests to meet overall policy requirements. The guardianship and review roles adopted by the legislature assure that excessive agency requests are systematically eliminated.25

External feedback is provided by the clientele or cltizens who are affected by the implemented programs. Activities are only worthwhile if useful results are achieved. Thus lobbying by interested parties provides valuable information to the public participants concerning the effectiveness of past policy decisions and the posstble political and social implications of current alternatives under consideration. 26

Citizens furnish the resources with which public activities are carried out through the taxation process. Resource providers do not directly determine public policy but rather indirectly vote for delegates who will make these

24Aaron Wildavsky, The Politics of the Budgetary Process (Boston, 1979), Pp. 18-31.

25 Ibid., pp. 47-56.

26 Thomas D. Lynch, Public Budgeting in America (Englewood Cliffs, 1979 ), PP. $86-91$. 
cructal chotces. Political candidates offer packages of societal benefits at certain societal costs in the form of taxes. If citizens are not subsequently satisfied with policy results they can exercise ultimate control by voting the offending party out of office. Thus, public policy actors are constrained by the political reality of what society is actually wiling to accept as a public activity. The division of labor, based upon mutual expectations, reduces the exceedingly complex budgetary decision-making process to manageable proportions. Since each public program impacts numerous societal segments, it is impossible for administrators and program experts to view their activities from a comprehensive perspective that details all possible implications of the policy under consideration. The maintenance of institutional roles and the inclusion of many parties in the decision-making process lessens uncertainty, insures that a wider range of perspectives and constraints will be considered, and improves the coordinative capacity of the system. The values neglected by one group may be the major concern of another competing group. Where decision makers representing a variety of attitudes, goals, and perspectives, engage in political give and take, satisficing, and ultimately compromise, the resultant decisions will be efficient in terms of the general interest of the country. Proposition 3 sumarizes the political conflict model. 
Proposition 3: Five groups of participants--the chief executive, agencies, the legislature, clientele, and resource providers-competitively interact within the political environment to create and implement public policy.

\section{Budgeting Cycle Model}

Despite the fact that the political budgetary process is speciallzed and fragmented, as well as incremental and sequential, it encompasses a cyclical pattern of activities. Figure 5 outlines the sequence of events in a budget cycle.

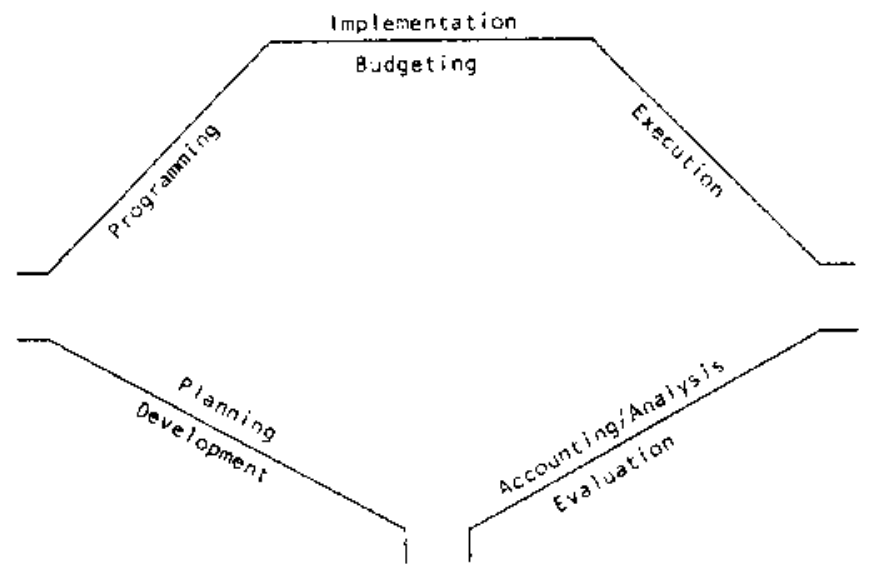

Fig. 5--Budget Cycle

Every budget is formulated, enacted, administered, and evaluated in a regular cycle of events. In the planning stage strategic policy concerning the optimal distribution of scarce resources among competing functions is formulated. Policy positions are then operationalized into various activities and programs. At the lowest level, the technical work to be accomplished is determined. Then functional unit 
administrators combine the local estimates into budget requests. 27

Planning and programing are continuous transactive processes. The public planner provides expertise concerning the broader aspects of a particular problem and knowledge of tools that are avallable to attack it. The program administrator inputs an awareness of the specific local environment within which a program must operate. The blending of these two types of information in an innovative fashion occurs during the planning and programing stages of the policy cycle. Funds are subsequently appropriated by the legislative enactment of an operating budget. Legislators generally maintain a short-term tactical perspective of maximal responsiveness to the immediate needs of their constituents in addition to playing the role as guardian of the purse. 28

Since the development of any public policy is the result of goal competition and compromise, a mechanism has been created to alter previously formulated goals when conditions warrant it. Data is collected during the execution stage. This feedback is subsequently evaluated and analyzed to determine the worthwhileness of a program

27 Freemont $J$. Lyden and Ernest G. Miller, Public Budgeting Program Planning and Implementation (Englewood C1iffs, 1982), p. 151 . ${ }^{28}$ I bid., p. 151 . 
and to ascertain if any unexpected consequences have resulted from its implementation. After the specific problem solutions have been evaluated, the problem is reformulated, new techniques are devised, and resources are allocated in the next budget.

The five actors concerned with the development and implementation of public policy compete within this sequential, cyclical and political structure. Even though they enter the conflict with different perspectives, they display one commonality of interest. All need information concerning the actual services provided by the public sector.29 Feedback concerning past events obtained in the evaluative stage of the budgeting process is one source of such information. Thus, political judgment and analysis of past events are blended in the budget formulation process. Proposition 4: Data describing the past results of extant programs and activities provides useful information to decision makers concerned with the creation and implementation of public policy.

Information Production, Use and Evaluation Model Current information systems can generate voluminous feedback for budgetary actors. Evaluative criteria must be

${ }^{29}$ American Institute of Certified Public Accountants, "Objectives of Financial Reporting by Nonbusiness Organizations", Statement of Financial Accounting Concepts No. 4, (New York, AICPA, December, 1980), p. 16 . 
developed to ascertain the dectsion usefulness of particular messages. The system should be parsimonious.

Environmental stimuli are constantiy bombarding the decision makers. However, not all messages are actually recelved by the reciplent. Stimuli pass through a cognitive filtering device that ignores most messages and allows relatively few to impact a particular decision and elicit a response. This process is diagramed in Figure 6.30

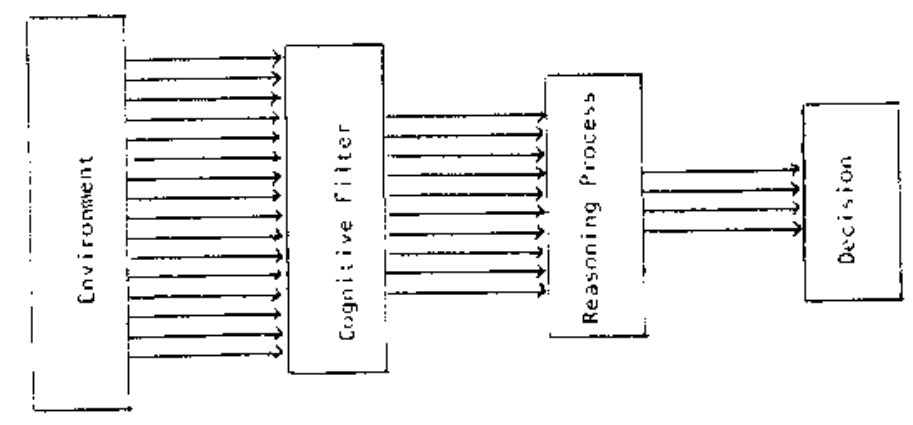

Fig. 6--Information Process

Only messages that impact the decision making process can be termed information. A message is a verbal or symbolic representation of some aspect of perceived reality. 31 Absolute precision is unattainable due to the limitations inherent in the measuring instrument. However, to the extent that perceptions gained from the message

${ }^{30}$ Robert R. Sterling, Theory of the Measurement of Enterprise Income (Lawrence, 1970), p. $4 \overline{7}$.

$31_{\text {I bid. . p. } 41 .}$ 
actually deplct the event being described, reality is present and information results.

A measurement scale is the most effictent device avallable to communicate the relationships that empirically exist among objects and events. A model of the production and use of finformation is provided in Eigure 7.32

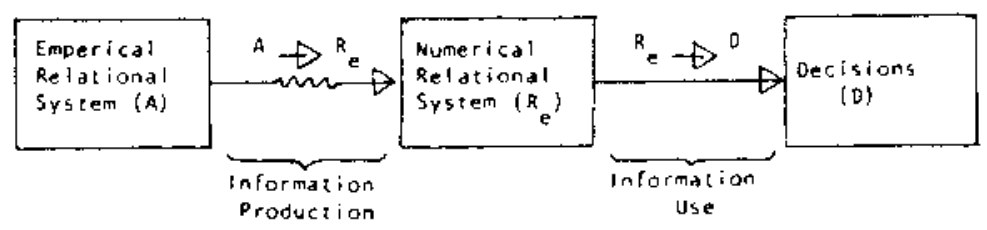

Fíg. 7--Information Production and Use

A measurement scale can be evaluated at three levels: factual, empirical and purposive. At the factual level, three formal criteria are useful in the evaluation of a measurement scale: representation, uniqueness, and meaningfulness. First, a measurement scale must be representative. The predefined relationships that are created among the assigned numbers in the numerical relational system must represent the equivalent relationships that exist among the weasured attributes

32 Theodore $J$. Mock, Measurement and Account1ng

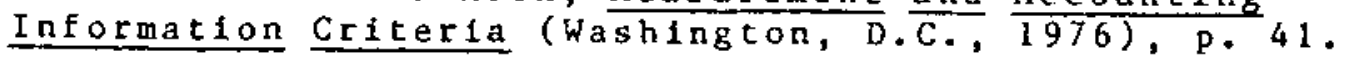


in the empirical relational system. Mapping must be homomorphic. 33

The uniqueness of a measurement scale is determined by the weaning that can be attached to the numerical assignments and the admissible mathematical transformations that can be performed on the numerical relational system. Numerical transformations must be homomorphic with the transformations permissible in the empirical relational system. 34

Finally, the inferences that can be logically drawn from the mathematical and statistical processing of the numerical measures should be meaningful. Certain sets of transformations are only meaningful for specific scales.35

A measurement scale may also be evaluated empirically in terms of reliability and valldity. A measurement is reliable when it yields a referent that is consistent. No measurement system will ever be completely free of error, but repeated attempts to measure the same set of objects with the same measuring instrument should produce stable, accurate results.36 If too much noise is contained in the measurement, the results will be uninterpretable.

${ }^{33}$ I bid. , p. 15

${ }^{34}$ Ibid., pp. $16-17$.

35 Ibid., p. 23 .

36 Fred N. Kerlinger, Foundations of Behavioral Research (New York, 1973), P. 443 . 
Measurement validity is concerned with the extent to which the assigned scale numbers actually reflect the true magnitude of the events being reported. Numerical assignments should be representative ot the universe being measured, should reflect or predict something beyond the lmmediate environs of the test, and should correlate with previously developed theoretical constructs. 37

Pragmatically, certain numerical assignments may adequately meet the factual and empirical criteria, and yet not be acceptable systems. Unless a measurement system timely produces data that is relevant within a particular decision context, the information has little value. Public policy decision makers need information concerning an agency's ability to provide services. To create valuable information, a system therefore tust produce reliable, valid and relevant indicators of performance in a timely fashion. Proposition 5: The timely provision of reliable, valid and relevant information to decision makers charged with allocating scarce resources is useful in the creation of effective and efficient public policy decisions.

\section{Human Information Processing Model}

The purpose of an information system is to provide information to individuals that is useful in making judgments about the current state or predictions concerning 
some future state of an event of interest. Humans form these judgments in an atmosphere of uncertainty. The declstion maker is separated from the event being measured by time and space and is faced with multiple overlapping cues which are imperfect predictions of the environmental state. Thus he must probabilisticaliy combine fmperfect cues to form a judgment concerning some criterion event. 38 The human process of observing the environment through lens of imperfect cues can be modeled as follows.39

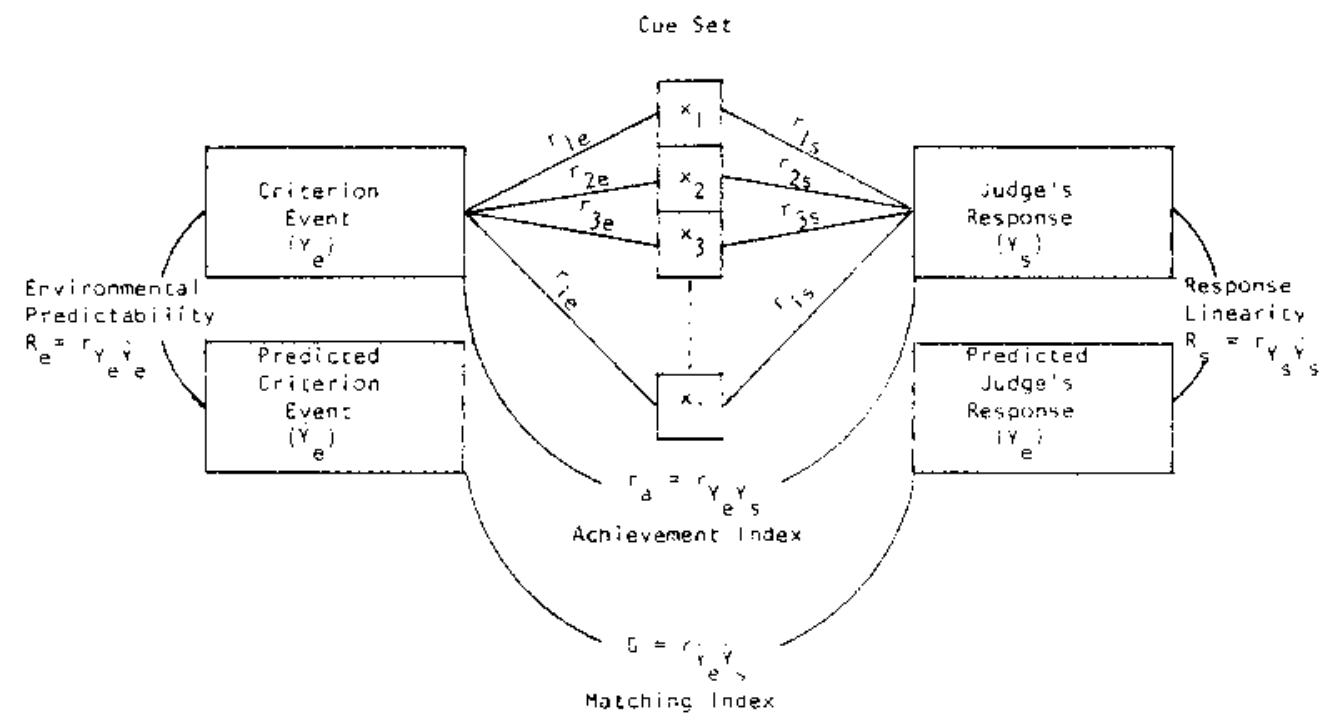

Fig. 8--Brunswick's Lens Model

${ }^{38}$ Robert Libby, Accounting and Human Information $\frac{\text { Processing: }}{1981), \text { PP. }} 5-\frac{\text { Theory }}{6 \text {. }}$ and Appilcations(Englewood Cifffs, ${ }^{39} \mathrm{Ibid} ., \mathrm{p} .19$. 
There are three basic elements of the system.40 The criterion event ( $\left.Y_{e}\right)$ is the variable with which an individual is concerned. He way wish to either judge its current value or to predict the future value. Cues $\left(x_{i}\right)$ are items of information used to judge or predict the criterion variable. Ys denotes the individual's estimate of the event. $Y_{e}$ and $Y_{s}$ values will differ if the statistical relationship between the criterion event and the cue set is less than perfect ( $r_{e i}$ ) or the individual's use of the cue set in forming his judgment is less than perfect ( $\left.s_{i}\right) .41$ The optimal use of the cues in predicting the criterion event $Y_{e}$ is denoted as follows.42 2.1) $\hat{y}_{e}=a_{e}+b_{1 e} x_{1}+b_{2} e^{x_{2}}+\cdot \cdot \cdot b_{k n} x_{n}$ The decision maker's predicted optimal reliance on individual cues is determined in a similar manner. 43 2.2) $\hat{\mathrm{Y}}_{\mathrm{s}}=\mathrm{a}_{\mathrm{s}}+\mathrm{b}_{1 \mathrm{~s}} \mathrm{X}_{1}+\mathrm{b}_{2} \mathrm{~s}_{2}+\cdot \cdot \cdot+\mathrm{b}_{\mathrm{kn}} \mathrm{X}_{\mathrm{n}}$ Four indices of judgment have been derived from the Lens Mode1.44 $\mathrm{R}_{\mathrm{e}}$ is a measure of the environmental or task predictability. It indicates the degree to which the complete cue set of $x_{i}$ variables can be utilized to predict

40 Robert H. Ashton, Human Information processing in Accounting, (Washington, 1982 , p. 14 .

$41_{\text {I bid. }}$, p. 15 .

42 Robert Libby, Accounting and Human Information Processing: Theory and Applications (Englewood Cliffs, 43 Ibid. , p. 20 ${ }^{44}$ Ibid., p. 20 . 
$Y_{e} \cdot R_{S}$ on the other hand, measures the individual's consistency of judgment. The matching fndex (G) shows the degree to which the optimal individual cue weightings match the environmental optimal relationships. Thus it measures the accuracy of cue weighting and utilization. The achievement index ( $r_{a}$ ) measures the correspondence between the subject's actual response and the environment event and denotes his accuracy in judging criterion values.

Generally, judgment accuracy is affected by three factors: the process of acquiring knowledge, the application of this knowledge in deriving a decision, and the enviromental state with which the decision maker is confronted.45 Thus:

2.3) $r_{a}=G R_{e} R_{s}$

The correlation of the environmental and individual optimal equations (G) denotes the extent to which the individual detects the essential properties of the judgment task through his cue weighting. The predictability of the environmental properties $\left(R_{e}\right)$ indicates the extent to which these criterion can actually be predicted with the available cues. Finally, $R_{S}$ measures the extent to which the decision maker consistently applies his judgment policy.46 Thus, judgment accuracy could be increased either by improving the

45 Robert H. Ashton, Human Information Processing in

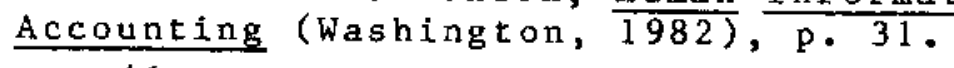

$46_{\text {I bid. }}$, p. 31 . 
decision maker's acquisition and processing of information and/or by improving the set of cues which he must manipulate.

Proposition 6: Information consisting of a set of cues that adequately deplcts the environmental state which the decision maker is attempting to judge or predict is useful in the creation of effective and efficient public policy decisions.

Public Sector Information Needs Model

one function of accounting is to provide quantitative information, primarily financial in nature, about economic entities that is intended to be useful in making economic decisions--in making reasoned choices among alternative courses of action.47 Thus, general purpose external flnancial statements derived from an entity's accounting system provide a vehicle through which valuable information can be communicated to interested parties. In general, financial reporting attempts to measure the effects of historical economic transactions in terms of units of money. This information, at best, is only a tool. Policy making participants must blend this data with a thorough knowledge of agency activities and an understanding of the surrounding political, economic, and social environment to achieve an informed decision.

\footnotetext{
${ }^{47}$ American Institute of Certified Public Accountants, "Objectives of Financial Reporting by Business Enterprises", $\frac{\text { Statement }}{\text { York, } 1978 \text { ), Financial Accounting Concepts, No. 1, (New }}$
} 
Proposition 7A: Financial reporting by public entities provides information that is useful to decision makers concerned with the allocation of resources to these organizations.

Each governmental organtzation is considered an entity in its own right. Operating activities include the redistribution of wealth and the provision of goods and services that are not available through the private market mechanism. Each entity operates as an integrated whole to generate benefits. Decision makers are interested in information that would be useful in assessing the extent to which the entity is successful in carrying out its operating objective.

Current activities are conditioned by prior operations and in turn condition those of the future. Thus, an evaluation of past accomplishments relative to past efforts enables the decision maker to form a judgment about anticipated future service delivery.

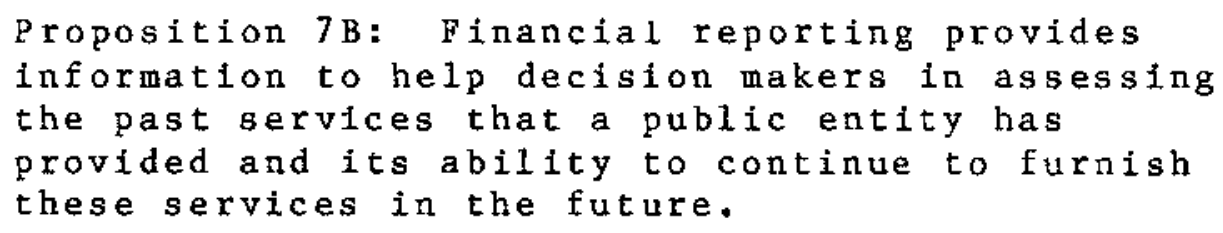

Public entities own or control supplies of resources that were obtained through the budgeting process. Agency management determines within a particular appropriation category how these resources can be utilized in the most efficient and effective manner. Since individuals external 
to the agency interact in the public policy formulation process, feedback is needed to evaluate agency performance. Decision makers are concerned with such issues as the proper safeguarding of assets, compliance with statutory and contractual obligations, and appropriate resource utilization. At present, only two general purpose financial statements are furnished to decision makers. One identifies the organization's economic resources, obligations, and related fund balances at a point in time. The other depicts the nature and relationship between resource inflows and outflows over a period of time. While these are useful in assessing a governmental entity's financial strengths and weaknesses and its liquidity, no information is currently provided concerning past organizational performance.

Public Entity Organizational Performance Model

Organizational performance can be ascertained by answering the simple question, "Are we doing the right thing?" Conceptually, organizational performance may be divided into two basic categories: efforts and accomplishments. This is displayed schematically below. 


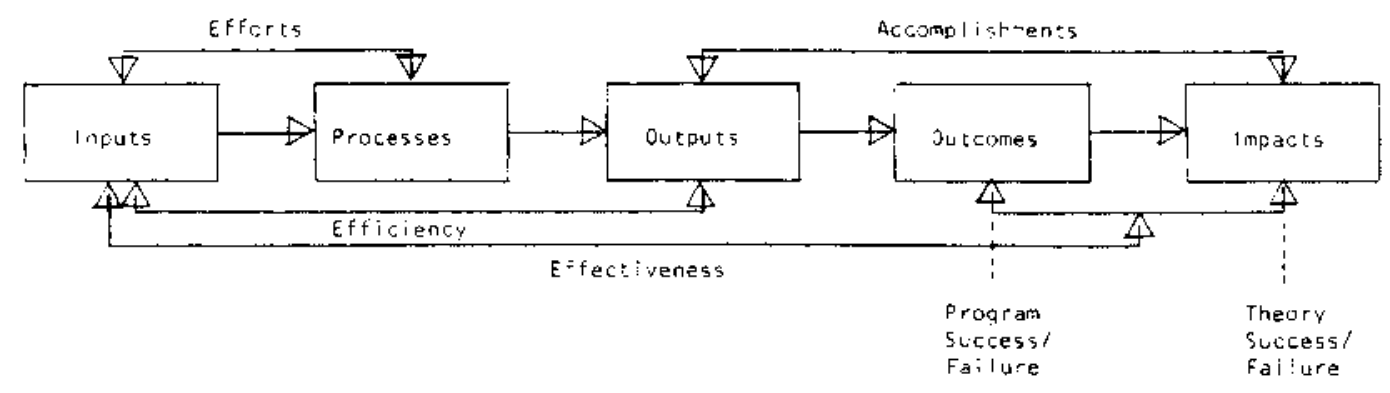

Fig. 9--organizational Performance Model

A particular organizational entity interacts with its surrounding environment to convert human, physical, and capital resources into public goods and services. This internal process is termed organizational efforts. Inputs indicate the amounts of resources applied to the productive process. Not only money, but also facilities and equipment usage, personnel hours, and quantities of materials utilized might be measured.

Processes describe the ways resources are applied to create output. Data on the size and needs of the target population as well as other pertinent environmental information should be created.

Organizational accomplishments describe in general what happens as a result of the internal processes or mixing of resources. Outputs are defined as the goods or services produced by the internal process. Outcomes measure the 
changes in perceived conditions of the direct targets as a result of the organizational activities. Aiterations may occur in the target's physical, mental, or emotional state. Iapacts reflect the effects of the organizational activities on broader social conditions.

Organizational performance basically has two dimensions: efficiency and effectiveness. Efficiency refers to the relative economy with which factors of production are converted into outputs. Effectiveness is concerned with the extent to which the goals and objectives of the entity are met.48 Efficiency compares inputs with outputs, while effectiveness contrasts inputs with outcomes or impacts. Effecttveness measures that contain outcomes focus upon program success or failure. Impact comparisons examine the theory underlying a program and judge its success or failure.

Performance is a function of the quantity of resources used (efforts) and the effectiveness of the results produced (accomplishments). Thus:

2.4) Organizational Performance $=f($ Efforts, Accomplishments $)$

Efforts activities consist mainly of the exchange of dollars for the factors of production--labor, materials, and capital--in the private market place. The scale utilized to 
measure efforts is the consideration given in the exchange process. This expresses the mutual valuation of the item by the buyer and seller at the moment of exchange. Thus, the money price is a convenient common denominator by which these diverse inputs can be expressed homogeneously.

The governmental entity furnishes benefits to the public that the private market sector is either unable or unwlling to provide in the appropriate quantities. Valuation of these benefits, expressed quantitatively as price aggregates derived from the market mechanism, is unavalable. No private pricing system exists to perform this service objectively and efficiently. Therefore, accomplishments must be measured in terms of nonmonetary measurement scales. Program outputs, outcomes, and impacts will be detafled.

The Statement of Organizational Performance will provide information concerning past efforts and accomplishments. It will contain numerous nonmonetary indicators of efficiency and effectiveness and will compare these with the dollar costs of the activity in question.

Proposition 8: A Statement of Organizational Performance that compares public accomplishments with public efforts is useful to decision makers in assessing past entity performance. 
Chapter III

\section{REVIEW OF RELATED LITERATURE}

A review of the social science and accounting literature provides numerous examples of normative solutions to the problems inherent in nonmonetary performance measurement. However little empirical research has been reported in this field to date. Consequently, this survey of the literature displays a strong normative tone. First, the criteria that can be utilized to judge performance indicators are presented. A discussion of the measurement problems that are encountered follows. Then a brief description of the cost-effectiveness technique that forms the framework for the Statement of organizational performance is provided. Pertinent empirical studies are sumarized where applicable.

$$
\text { Criteria for Judging Performance Indicators }
$$

Performance is a function of the quantity of resources used and the effectiveness of the results produced. Input, process, output, outcome, and impact indicators must be carefully selected to assure that organizational performance is being actually measured. Each individual measure should be assessed against several criteria to ascertain if it is useful. 
These criteria may be grouped into four basic categories that answer the following questions: (1) What is being measured? (Validity), (2) How is it being measured? (Reliability), (3) Does the resultant measurement influence human actions? (Relevance), and (4) Does the cost of obtaining a measure outweigh the benefits to be derived from it? (Cost/Benefit) Accountants and other social scientists have addressed these four questions independently, and wtth one notable exception, have arrived at similar conclusions.

\section{Cost/Benefit}

There is general consensus among all disciplines that the benefits achieved from a particular measure must outweigh the costs. Ultimately, the value of the performance measure in improving decision making wust be greater than the cost to collect and analyze the data.1 The costs of providing information include the costs of collecting and processing the data, costs of disseminating It to the users, costs of user's time, costs associated with the dangers of litigation, and possibly the costs of a loss of competitive advantage. 2

Harry P. Hatry, "Performance Measurement Principles and Techniques", Public Productivity Review, IV (December, 1980), p. 314 .

2American Institute of Certified Public Accountants, "Qualitative Characteristics of Accounting Information", Statement of Financial Accounting Concepts No. 2, (New York, 1980), par 137. 


\section{$\underline{\text { Reliability }}$}

The importance of reliability is also generally acknowledged. However, it is viewed from a slightly different perspective by each group. According to accountants, an indicator must measure something meaningful and "must represent the phenomenon that it purports to represent."3 It should be both verifiable and neutral. The data must be stable enough that a measurement consensus can be obtained among several people analyzing similar data with similar measuring instruments. Furthermore, the obtained results should be free from systematic bias. There must also be representational faithfulness or agreement between the measure and the property being measured. Other social scientists have likewise utilized stability and accuracy as synonyms for reliability. First, any performance indicator must be capable of assuming a metric value. It should be unequivocal and reproductble, so that it is impossible to misinterpret the resultant value assigned to the measure. Furthermore, if performance is measured in a simflar situation, the outcome should not be spurious, but should provide similar results. 4

3Ibid., par. 59.

${ }^{4}$ E. Gerald Hurst, "Attributes of Performance Measures", Public Productivity Review, IV (March, 1980), pp. 44-45. 
The measure must be reasonably accurate. It must be precise and sensitive to the factors being measured.5 An accurate measure should not be subject to random or systematic biases. Bias may be defined as the tendency of a measure to fall more often on one side than the other of what it represents.6

Social scientists have also defined reliability in terms of the amount of random errors that result from use of a measuring instrument. Any measure has a true component and an error component. Therefore, the total variance obtained from any set of measures is composed of systematic variance measuring the true component and error variance resulting from random off-setting impulses. Reliability is defined as the proportion of true vartance to the total obtained variance.7

Accounting measurements are based upon completed monetary transactions. These indicators are very precise and are not subject to significant random error. However, the same is not true in the allocation phase where dollar values are spread over numerous reporting periods.

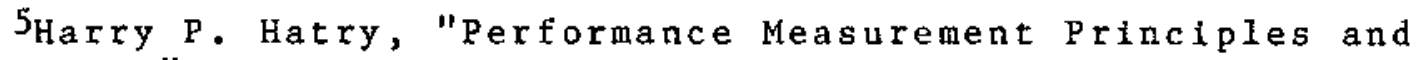
Techniques", Publ1c Productivity Review, IV (December, $1980)$, p. 313 .

6E. Gerald Hurst, "Attributes of Performance Measures", Public Productivity Review, IV (March, 1980), p. 45.

${ }^{7}$ Fred V. Kerlinger, Foundations of Behavioral Research, (New York, 1973), pp. 445-450. 
Arbitrary and subjective allocations of costs can lead to material random errors. Thus, the measuring error of this particular measuring instrument may lead to unreliable indicators.

\section{Relevance}

Accountants and other social scientists view relevance from slightly different perspectives. Accountants define relevance solely from the view of the decision maker. However, social scientists are also concerned with the effect of the measuring process upon the entity being measured.

$$
\text { According to accountants, a measurement "must be }
$$
capable of making a difference in a dectsion by helping users to form predictions about the outcomes or correct expectations." Information that reduces uncertainty about past activities should improve estimates of the consequences of related future endeavors. The measure must contain predictive value or feedback information. It should provide data that people wish to know when actually making decisions or allow a decision maker to make explicit judgments about past decisions. The information must also be available

8 American Institute of Certified Public Accountants, "Qualitative Characteristics of Accounting Information", Statement of Financial Accounting Concepts No.2, (New York, 1980), par. 47 . 
to decision makers on a timely basis. It must be accessible when a decision needs to be made.

Soctal scientists agree that decision usefulness is of prime importance. However, they also point out that the measuring process itself can influence organizational

behavior. Each measure used to gauge organizational performance must relate to factors controlled by the entity whose performance is being measured. Only in this way can entity personnel be held accountable for the results.9 However, the measure must not result in behavior that is contraxy to the objectives of the organization.10 External environmental factors aiso intrude on individual performance. Where possible, these uncontrollables should be separated from the controllables. 11

Measures should be understandable both by the decision maker and by the person being measured. Measures that are overly technical or involve complex combinations of elements will be of limited use in evaluating performance. 12 Furthermore, if no causal relationship between performance and its measurement can be perceived by the individual actor, the indicator wil1 not motivate. 13

$9_{E}$. Gerald Hurst, "Attributes of Performance Measures", Public Productivity Review, IV (March, 1980), p. 43.

10 Harry p. Hatry, "Performance Measurement Principles and Techniques", Public Productivity Review, IV (December, $1980), \mathrm{p} .313$.

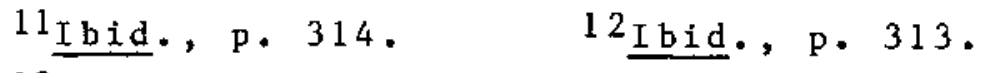

$13 \mathrm{E}$. Gerald Hurst, "Attributes of Performance Measures", Public Productivity Review, IV (March, 1980), p. 45. 


\section{$\underline{\text { Validity }}$}

Validity at the simplest level may be determined by answering the question of whether the measure is representative of the universe being measured.14 Each measure should uncover some lmportant aspect of performance that 1 s not revealed elsewhere. Care should be taken to prevent overlapping, duplicative measures.15 At the same time, the set of measures must cover all of the performance aspects of the organization.16 This will necessitate the creation of multiple measures rather than a single indicator.

At a more basic level, validity is concerned with determining what properties explain the variance in a particular measure. Here, one examines the properties being measured and attempts to validate the theory behind the measure.17 Educators, psychologists, and sociologists are particularly 1nterested in this aspect of validity. Accountants have emphasized the economic theory of a

14 Fred N. Kerlinger, Foundations of Behavioral Research, (New York, 1973), pp. 457-459.

15 Harry P. Hatry, "Performance Measurement Principles and Techniques", Public Productivity Review, IV (December 1980), P. 313 .

16 Ibid., P. 314.

17 Fred $N$. Kerlinger, Foundations of Behavioral Research, (New York, 1973), Pp. 461-462. 
perfectly competitive market and have made it the cornerstone for accounting statements. Thus, the validity of current accounting measurements is based upon the assumption that all benefits and all costs are impacted in the monetary indicators currently in use. When the assumptions of this theory are relaxed, however, the validity of these measures falters. Monetary indicators do not indicate social value and social cost.

$$
\text { Measurement Problems }
$$

Several difficulties exist in obtaining performance measures that meet the desired criteria. Some of these problems are discussed below in terms of how they affect the investigation of organizational performance.

\section{Construct Validity}

Effectiveness is a construct. It is an abstraction formed by generalization from particulars with the added meaning, however, of having been "deliberately and consciously invented or adopted for a special scientific purpose."18 It is "based on the hypothesis that several varlables will consistently covary or fit together to form a unified whole." 19

18 I bid., P. 29.

19 Richard M. Steers, "Problems in the Measurement of Organizational Effectiveness", Administrative Science Quarterly, XX (December, 1975 ), P. 551 . 
Since effectiveness is an abstraction made up to give meaning to an idea, the indicators of effectiveness must be defined. To do this, one must first determine the boundaries of the construct space. 20 Presently, there is little consensus among researchers as to what criteria should be included in the effectiveness domain. Selection of the appropriate criteria is based upon the evaluator's frame of reference. No one model has captured the total meaning of effectiveness.

\section{Multiple goals}

A second property of effectiveness that contributes to confusion is its basis in individual values. Organizational effectiveness is "inherently subjective and is grounded in the values and preferences of strategic constituencies."2l Groups that have a substantial stake in the organization include resource providers, consumers, employees, groups whose cooperation is essential to the organization's survival, or those whose lives are affected by the organization.

The basis for evaluating effectiveness in a particular organization depends on the Individual preferences of the

$20_{\mathrm{K}}$. Cameron, "Construct Space and Subjectivity Problems in Organizational Effectiveness", Public Productivity Review, $V$ (June, 1981 ), p. 108 .

$$
21_{\text {Ibid., p. } 112 .}
$$


constituencies. However, individual goals are not consensual and may even conflict. Thus, it is difficult to identify criteria that fit the preferences of more than one constituency.

To illustrate this point, the goals of two groups-management and society--are contrasted. Managenent is concerned with the organization's vitality. Quinn suggests that administrators comonly pursue six objectives in trying to improve their organization.

(1) Output process or effectiveness reflects an improvement in the quantity, quality, and timeliness of outputs or services, and also a resulting increase in the satisfaction of output recipients.

(2) Coordination means an improvement in decision making, communication, planning, the integration of subunits, and relationships with other units.

(3) Motivational climate has to do with the orlentation of unit members; it is reflected by an improvement in initiative, involvement, satisfaction, identification with the unit, cooperation, creativity and interpersonal relations.

(4) Stability--equilibrium is improved as stratn and pressure are reduced, as stability or balance is increased, and as work-force retention tmproves.

(5) Savings simply means economizing. Savings increase as money and other resources are conserved. 
(6) Resource acquisition is reflected by increasing revenues or profits, growth in size of the unit and a generally increased ability to acquire resources. 22

In contrast, the general public is concerned with measuring the achievement of national goals. Societal members are interested in the efficient utilization of scarce resources that are not adequately priced in the market place. Thus, the economic power of business entities resulting from concentration is of interest, as well as some Indication of externalities resulting from market activity. The state of the national physical and mental health as reflected by unemployment, underemployment, 11 Inesses, addfctions, crime, and strikes concerns citizens, as does the utilization of national land, water, mineral, and game resources. 23

Multiple-objective functions are also prevalent in the public sector. Public agencies, legislators, the executive branch, special interest groups, clientele, and the general citizenry all engage in partisan mutual adjustment. As a result, policies, whose implementation must subsequently be assessed, are influenced by a broad range of participants

22Robert E. Quinn, "Productivity and the Process of Organizational Improvement: Why We Cannot Talk to Each other", Public Administrative Review, (January/February, $1978)$, p. 43 .

${ }^{23}$ Committee on Non-Financial Measures of Effectiveness, Comittee Report, Accounting Review, XLVI (1971), p. 187 . 
with widely varying goals and interests. 24 what is perceived as effective by one group is deemed unimportant or a hindrance to another.

Friedlander and Pickle explored the interactions between an organization and groups upon which 1 t was dependent for survival and growth. The findings of their study indicated that there was only a moderate relationship between the degree to which the entity concurrently fulfills the needs of its Internal subsystem component (1ts employees), its owner, and the components of the larger environment (the communty, government, customers, suppliers and creditors). They concluded that "organizations find it difficult to fulfill simultaneously the variety of demands made upon them. . It is probable that organizations do not strive to maximize fulfiliment of any one system component, but operate in accordance with a policy of satisficing several system components."25

Whetten used an integrated macro and micro organizational behavior perspective to focus on the difficulty that directors of public agencies have satisfying multiple interest groups. At the macro level, interested groups

${ }^{24}$ Charles E. Lindblom, "Still Muddling, Not Yet Through", Public Administrative Review, (November/December, 1979), pp. 522-23.

25 Frank Friedlander and Hal Pickle, "Components of Effectiveness in Small organizations", Administrative Science Quarterly, XIII (1968), pp. 302-303. 
within a policy subsystem affect the distribution of both the political and economic resources needed by agencies. Politically, these groups control legitimacy and power which are important for an entity's long term survival. They also influence the division of labor among agencies and the allocation of other economic resources to them. Macro theory acknowledges that the environment is composed of conflicting interests and emphasizes the importance of controlling environmental resources.

The micro approach examines the internal conflicts experienced by organizational leaders who may be termed boundary spanners. The level of role conflict is measured, but little effort is made to trace it back to the larger organizational context.

Data were collected on 67 manpower agencies to examine these two models.26 Relevent interest groups included the organization staff, local community leaders, and the central regional administrator. Correlational analysis indicated that there was a negative relationship between the staffs' ratings and agency output. Analysis suggested that conflict resulted in unpredictable agency director roles and many job related problems. This, coupled with long delays in

26David A. Whetten, "Coping with Incomplete Expectation: An Integrated View of Role Conflict", Administrative Sclence Quarterly, XXIII (June, 1978), p. 257 . 
feedback, resulted in the need for extensive long range planning.

\section{Criterion Ambiguity}

If effectiveness is to be based upon attainment of goals, the organizational goals must be clear, specific, and measurable. Goals, however, tend to be stated in ambiguous terms "to mask underlying divergencies 1 n intent." 27 Weiss offers four approaches that are available to a researcher to develop usable goals.

(1) He can pose the question and wait for progran personnel to reach a consensus . . [However], he should bring books to the office to read while wating for them to agree...

(2) Another thing he can do is read everything about the program he can find, talk to practitioners at length, observe the program in operation, and then sit down and frame the statement of goals himself. .

(3) He can set up a collaborative effort in goal formulation. This is probably the best approach. Sitting with the program people, the evaluator can offer successive approximations of goal statements. The program staff modifies them, and the discussion continues until agreement is reached.

(4) He can table the question of goals, and enter not upon evaluation in the traditional sense, but on a more exploratory, open-ended study. 28

Weiss concludes by adding, "the experienced evaluator also searches for the hidden agenda, the covert goals of the

${ }^{27}$ Carol H. Weiss, Evaluation Research, (Englewood Cliffs, 1972), P. 27 .

${ }^{28}$ I bid., p. 28 . 
project that are unlikely to be articulated, but whose achievement sometimes determines success or failure no matter what else happens." 29

\section{Criterion stability}

Organizations operate in an action setting. They are fluld, nonstationary systems. Therefore, performance criteria that are suitable at one point in time, become outmoded and new problems emerge that require new indicators. 30 While growth may be the aim in good economic times, retrenchment and the minimization of losses is called for under poor economic conditions. Steers suggests one possible solution to this dilema. Researchers should "develop contingency models capable of accounting for changes in environmental conditions or shifts in goal preferences as they relate to organizational effectiveness."31

\section{Fractiona1 Measurement}

Since multiple goals tend to be operative in the organizational setting, multidimensional measurement results. Care must be taken that the fractional measurement is not dysfunctional. Development of an overall index requires

\section{Ibid. , p. 29.}

${ }^{30} \mathrm{Committee}$ on Measures of Effectiveness for Social Programs, Comittee Report, Accounting Review, XlVII, $(1972)$, p. 348 .

3lRichard M. Steers, "Problems in the Measurement of organizational Effectiveness", Administrative Science Quarterly, XX (December, 1975), pp.552-553. 
"(1) weighting the relative importance of the various dimensions and Indicators and (2) choosing the statistical procedures that represent the relative value of the various dimensions and indicators." 32 This may result in a misleading measure. Contradictory changes in dimensions may cancel each other and the overall index remain unchanged.

\section{Measurement Precision}

Measurement consists of rules or procedures for assigning numbers to attributes to represent them quantitative1y.33 In the private sector, competition and market forces encourage businesses to operate efficiently and effectively so that they can provide the goods the public desires at prices consumers are willing to pay. However, these forces will not affect the delivery of public goods.

Public goods possess peculiar demand characteristics that make measurement difficult. These may be labeled non-exclusion and non-rivalry.34 No one is excluded from enjoying the benefits resulting from an expenditure for a pure public good, regardless of their willingness to pay for

32Comittee on Measures of Effectiveness for Social Programs, Committee Report, Accounting Review, XlviI (1972), p. 348 .

33 Richard M. Steers, "Problems in the Measurement of organizational Effectiveness", Administrative Science Quarterly, Xx (December, 1975), pp. 553 .

$34 \mathrm{Jes}$ se Burkhead and P.J. Hennigan, "Productivity Analysis: A Search for Definition and Order", Public Administrative Review, (January/February, 1978 ), p. $\overline{3}_{4}$. 
the particular product. Furthermore, all citizens can jointly consume or enjoy a given supply of public goods.

Much of the activity in the public sector deals with the implementation of social programs. These may be defined as "a plan of action, an experiment introduced into society for the purpose of producing a change in the status of the society or some of its members." 35 A measurement difficulty arises in these cases. There is no concrete output that can be identified. Thus, surrogate measures must be developed. An additional problem hampering precise measurement, particularly in the public sector, concerns the gathering of data. Avalable information is gathered for formal units such as cities, counties, or states. Particular programs, however, may not have similar boundaries. This results in measurements being confounded by external factors. 36

\section{Time Perspective}

Different perspectives can be taken in viewing organizational performance. In many cases, the ultimate outcome of a program will not be known for some time. Thus, short run or process objectives must be developed and measured that will indicate the progress toward long run organizational goals. Process variables are concerned with the

${ }^{35}$ Comittee on Measures of Effectiveness for social Programs, Committee Report, Accounting Review, XLVII (1972), p. 349 . 
relationship between expected and actual inputs and outputs. These can be quite useful for control purposes.

Sizer advocates the development of progress measures. 37

These would focus on trends with strategic actions being classified as growth, consolidation, and planned withdrawal and redeployment. Organizational performance would be assessed in terms of its responsiveness to the changing needs of society.

He offered the following steps for implementation of such a strategy. An organization should

(1) examine systematically the future environment in which it will be operating. . to identify threats and opportunities;

(2) understand and communicate the implications of this future environment to the institution's constituencies;

(3) evaluate the institution's. . . critical resources;

(4) agree through consensus building techniques [on] the goals and objectives for the institution and its constituent parts, and the measures for monitoring progress towards achieving these goals and objectives;

(5) develop

(a) a set of alternative long-term strategies and operating plans including a strategy for long-term resource mobility; (b) a strategy for medium-term financial mobility and short-term emergencies;

${ }^{37}$ John Sizer, "Performance Assessment in Institutions of Higher Education Under Conditions of Financial stringency, Contraction and Changing Needs: A Management Accounting Perspective", Accounting and Business Research, (Sumer, 1981), pp. 233-234. 
(c) resource allocation procedures consistent with the institution's long-term objectives; and

(d) a short-term planning and control system based on measurable information and performance indicators. 38

Such a plan of attack should improve resource mobility. Furthermore, greater congruence between goals and activities should be achieved.

\section{Generalizability}

When performance criteria are being created, concern must be shown for the degree to which they are consistent with the goals and purposes of the organization under study. Functional specialization, however, causes a problem in generalizability. What is relevant for one entity may be useless in another setting. 39

Two researchers have performed studies aimed at assessing the effectiveness of particular entities. Mahoney examined business organizations.40 Managers first described their subordinate units in terms of 114 effectiveness indicators. Then, they made judgments about the overall effectiveness of these units. Using factor analysis and a multiple regression model, the indicators were combined into

\section{Ibid., p. 240 .}

${ }^{39}$ Richard M. Steers, "Problems in the Measurement of organizationa 1 Effectiveness", Adminlstrative Science Quarterly, XX (December, 1975 ), P. 554 .

40 Thomas A. Mahoney, "Managerial Perception of organizational Effectiveness", Management Science, XIV (1967), pp. B76-91. 
dimensions of a general effectiveness construct. Four dimensions (productivity-support-utilization, planning, reliability, and initiative) accounted for 56 per cent of the variance in the managers' perceptions of the effectiveness of their organizations.

Webb explored the development of effectiveness measures for the institutional church.4l A list of 28 church goals was initially given to 181 church members to obtain their opinions of the relative degree of importance given to each item by their congregation. Five factors were developed from the responses to be subsequently utilized as an index of effectiveness. A second questionnaire was distributed to 569 church members to ascertain particular organizational characteristics and to gather independent judgments of the effectiveness of church operations based upon the index derived from the factor analysis. A multiple regression model was then developed. Four indicators (cohesion, efficiency, adaptability, and support) accounted for 45 per cent of the variance in the independent judgments of the church members.

As can be seen from these two studies, appropriate performance indicators for one entity may be irrelevant for

41Rona1d J. Webb, "Organizational Effectiveness and the Voluntary Organization", Academy of Management Journal, (December, 1974), pp. 663-677. 
another. Without empirical support obtained through replication, generalizability will be impossible.

The problems inherent in developing suitable performance measures necessitate a careful development of appopriate indicators. Steers offers three suggestions that could improve the precision of such measures.

[First], a clear understanding of an organization's functional and environmental uniqueness is a prerequisite to assessing 1 ts effectiveness. Thus, it would appear that attempts to measure effectiveness should be made with reference to the operative goals that an organization is pursuing; that is, criterion specification should be flexible enough to account for diversity in goal preferences..

Second, new attempts at model-building could include efforts to account for differential weights on the various evaluation criteria to reflect different valences attached to each goal. Few organizations pursue their numerous operative goals with equal vigor or resources...

Third, this more flexible, contingency approach to the measurement of organizational effectiveness should allow for the explicit acknowledgement in the model of certain irreducible constraints that necessartly obstruct criteria maximization. Such constraints can be found in the structure, technology, environment, and membership of a given organization. 42

42Richard M. Steers, "Problems in the Measurement of organizational Effectiveness", Administrative Science Quarterly, XX (December, 1975), pp. S55-556. 
Cost-Effectiveness Measurement Techniques

Sorenson and Grove describe the cost-effectiveness methodology.43 First, the objective to be achleved for a specific target group is identified. The goals must be explicitly defined. Next, alternative treatment programs or opposing strategies are specified. Third, relevant measurable performance indicators are developed. Fourth, the amounts of service rendered, the costs of each program, and the cost per untt of service are determined. Then, the effect or outcome of the program intervention on the target group is assessed. Finaliy, cost and outcome data are combined to produce cost-effectiveness information.

Hatry points out that appropriate data may be collected in many ways. Existing record data is an attractive source of information. Since it is already collected, little cost is added. However, because data were originally accumulated for another purpose, it may need modification. Furthermore, accuracy of the records may vary considerably. 44

43James E. Sorenson and Hugh D. Grove, "Cost-Outcome and Cost-Effectiveness Analysis: Emerging Nonprofit Performance Evaluation Techniques", The Accounting Review, LII (July, 1977 ), P. 663 .

${ }^{44}$ Harry P. Hatry, "Performance Measurement Principles and Techniques", Public Productivity Review, IV (December, 1980), pp. 312-339. 
An observer can be trained to assess the physical

characteristics of some service outcomes. To assure

accurate measurements certain steps should be followed. The administrator should:

(1) Provide some type of anchored scale spectfic as to what each grade of the scale represents, so that different observers, seeing a range of conditions at different points in time, would generally provide the same rating...

(2) Test the procedure before full use. Have different observers rate a number of different conditions to see whether their ratings are sufficiently close to be reliable.

(3) Choose raters who are independent of the unit whose work is being rated to avoid the potential for, or appearance of, bias.

(4) Periodically check each observer's ratings for possible deterioration in the ratings quality -.

(5) Train new raters in the procedures and retrain current observers when periodic checks indicate rating problems.45

Surveys of the general citizenry or clients are also useful in evaluating the quality of service. However, Stipak warns that policy makers may misinterpret such information because expressed citizen satisfaction may not 
reflect actual service performance.46 The level of overall satisfaction may result instead from an unknown mixture of different perceptions, expectations, and types of evaluation processes. 47

Once performance indicators have been developed and related to the cost of operations, some basis must be found for comparison. Hatry describes several ways this may be accomplished.48 Actual performance can be compared against performance standards or pre-set and planned targets. Current performance could be compared to indicators developed in previous time periods. Different service units performing essentially the same activities and outcomes for various client groups within one jurisdiction also may provide useful comparisons.

\section{Conclusions}

Even though efficiency and effectiveness measures would be useful to decision makers, development of these important indicators is still in its embryonic stage. In 1975, a mail survey was conducted to obtain opinions from state budget

46 Brian Stipak, "Citizen Satisfaction with Urban Services: Potential Misuse as a Performance Indicator",

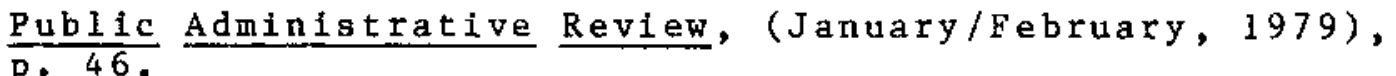

47 I bid., p. 49.

48 Harry P. Hatry, "Performance Measurement Principles and Techniques", Public Productivity Review, IV (December, $1980)$, , pp. 336-337. 
officers as to the adequacy of existing performance measures. Responses from 32 states indicated that 47 per cent rated efficiency measures and 91 per cent rated effectiveness measures as only barely adequate or inadequate. 49 Five years later, a FASB study of state and local reports concluded that "the state of the art in reporting inputs, processes, outputs, and efficiency is probably adequate for the enhancement of financial reporting. However, results, and therefore effectiveness, have not yet reached that level." 50

The Amertcan Institute of Certified Public Accountants has briefly discussed the desirability of providing information about program benefits.

Information about service accomplishments in terms of goods or services produced (outputs) and of program results may enhance significantly the value of information provided about service efforts. However, the ability to measure service accomplishments, particularly program results, is generally undeveloped. . . Research should be conducted to determine if measures of service accomplishment with the requisite characteristics of relevance, reliability, comparability,

${ }^{49}$ Harry P. Hatry, "The Status of Productivity Measurement in the Public Sector", Public Administrative Review, (January/February, 1978), p. 29 .

50 Harold I. Steinberg and Paul K. Brace, "Financial Accounting Standards Board Study of Service Efforts and Accomp1ishments", Government Accountants Journal, XXX (Spring, 1981), p. 9. 


$$
\begin{aligned}
& \text { veriflabiltty, and neutrality can be developed, } \\
& \text { they should be included in financial reports.5 }
\end{aligned}
$$

Accountants should broaden thefr horizons to fill this void. The totality of organizational performance can not be determined by compiling and analyzing only monetary measures. Non-monetary indicators provide the flavor needed to accurately assess performance.

Churchman charges that if accountants are to be of service to soclety in this field, they must "be stubborn but not necessarily humorless." Once accountants give up the "silly notion that numbers have the final answers", they "can really enjoy themselves now and then."52

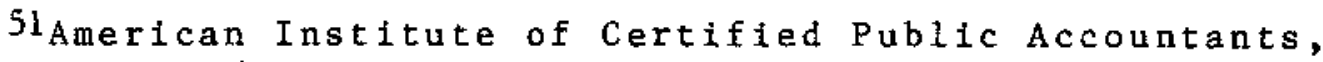
"Objectives of Financial Reporting by Nonbusiness organizations", Statement of Financial Accounting Concepts No. 4 , (New York, December, 1980), pp. 25-26.

${ }^{52} \mathrm{C}$. West Churchman, "On the Facility, Felicity and Morality of Measuring Social Change", Accounting Review, XLVI (January, 1971), p. 34 . 
CHAPTER IV

RESEARCH METHODOLOGY

Description of Research

To test the six conceptual hypotheses, the following research was conducted. First, a descriptive quasi-experiment was performed on an actual program to determine if it was feasible to create a Statement of organizational Performance. Second, an experiment, utilizing the data obtained in the first stage, was conducted to ascertain if this statement significantly increased the information available to decision makers concerning program outcomes and program impacts and/or altered budget decisions.

$$
\text { Quasi-Experiment Research Design }
$$

On May 15, 1975, the Dallas police department initiated a ten month general media advertising campaign directed at potential crime victims. Utilizing the theme, "Don't Ask for It", commercials were aired on prime viewing-time television and prime drive-time radio spots. In addition, ads were placed in area newspapers and on city buses. The police department hoped through this program to increase cltizen awareness of crime prevention techniques and to 
motivate the populace to take simple precautions to protect themselves and their properties. (See Appendix A for a discussion of crime prevention literature.)

A Statement of Organizational Performance was created to describe the output, outcome, and impact of this program. The program dollar costs accumulated by activity rather than by object class depicted the efforts. The accomplishments were described in three ways: products created (program outputs), effect on citizen behavior (program outcomes), and effect on reported crime (program impact).

\section{Program outputs}

Program outputs describe the physical goods or services produced by the internal process. A numerical count of the various advertising products created provided the data needed for the workload measures of accomplishment. This data was readily available from the existing records and is normally supplied to deciston makers.

\section{Program outcomes}

\section{Procedures.--Program outcomes measure the changes in} the perceived conditions of the direct targets as a result of the organizational activities. To ascertain the program outcome, secondary data from a public opinion survey conducted by Louls, Bowles and Grove, Inc. was analyzed. Eight hundred face-to-face interviews were conducted at 
three different points in time: prior to, at the mid-point, and within two weeks after the campalgn was concluded. Survey questions pertained to citizen awareness of crime prevention techniques in general and of the police advertising canpalgn in particular. In addition, information concerning reported changes in cltizen behavior during the program period was gathered.

Survey results were presented to the Dallas police department in crossbreak form. A crossbreak is defined as a "numerical tabular presentation of data, usually in frequency or percentage form, in which variables are cross-partitioned in order to study relations between them."1 Extensive tables of percentages were created in which responses were cross-tabulated with various socio-economic indices on a temporal basis. However, no statistical tests of significance were performed.

Therefore, the initial step of the quasi-experiment was to conduct chi-square tests on the survey results to ascertain if the obtalned frequencies in the program surveys departed from the frequencies expected by chance in a statistically significant manner.

The chi-square formula is:

4.1) $x_{k-1}^{2}=\sum_{i=1}^{k} \frac{\left(O_{i}-E_{i}\right)^{2}}{E_{i}}$

1Fred V. Kerlinger, Foundations of Behavioral Research, (New York, 1973), pp. 159-160. 


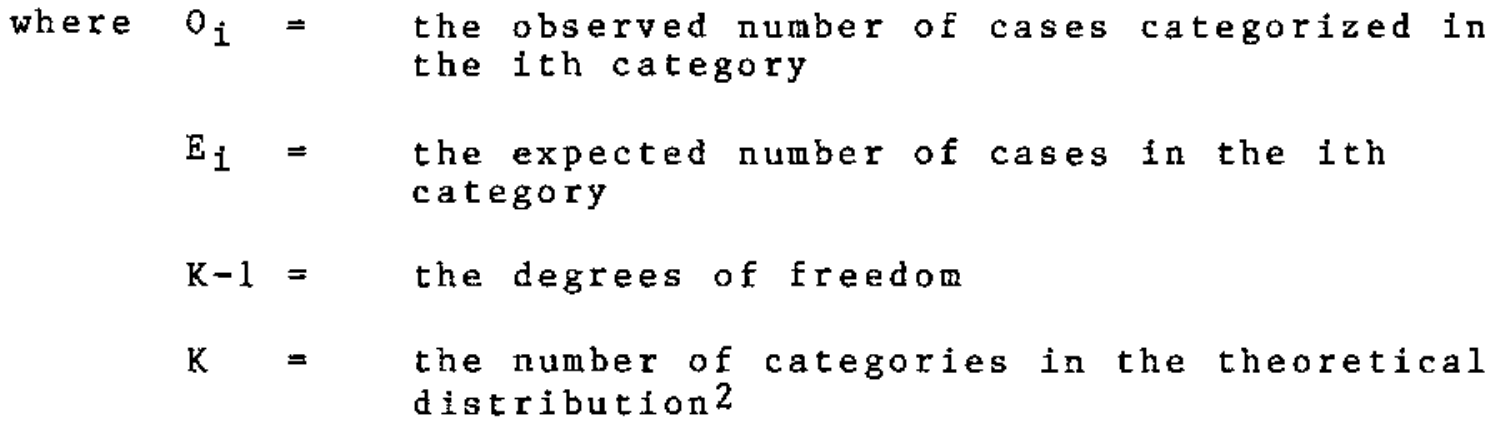

Since these variables were measured at three different points in time, changes in citizen attitudes and opinions that occurred concomitantly with the advertising campaign could be ascertained. The opinion and purported behavior changes were not only analyzed temporally, but also according to socio-econonic classifications.

Methodological Assumptions and Weaknesses.-- To employ the chi-square goodness of fit test, one must assume simple random 
sampling is employed, observations are independent, each

observation falls into one category, and the sample is large. 3

Survey samples must "represent the population from which they are

drawn if they are to provide useful estimates about the

characteristics of that population."4 According to Louis, Bowles

and Grove, an attempt was made to create representative samples.

However, the simple random technique was not employed.

Respondents were selected by means of a modified probability sample in which field interviewers had no control over the selection of households where interviews were to be attempted. The sample was based on 267 sample points, with a cluster of no more than three interviews completed in city blocks adjacent to each point. Interviewers fulfilled quotas for age and sex of respondents to insure proper representation of these characteristics, but no other controls were imposed on respondent selection. If no one was home at the time of the first call at a household, interviewers made callbacks at such households while still in the neighborhood on the same day, but no callbacks were attempted at different times on different days. 5

The use of the modified probability sampling procedure results in a sampling distribution different from that produced by simple random sampling. The error introduced into the

\section{Ramon E. Henkel, Tests of Significance, (Beverly Hills,} 1976), p. 48 .

4Ear1 R. Babbie, Survey Research Methods, (Belmont, 1973), p. 78 .

5Louis, Bowles and Grove, Inc., Tabulations of Replies to Crime Prevention Survey, Report of a Public opinion Survey Conducted for the Dallas Police Department, (Dallas, March, 1976), p. i. 
probability calculations by this procedure is unknown. Nevertheless, sampling error is reduced when the elements within each cluster are homogeneous and the clusters are representative of the population.

The socio-economic characteristics of the sample respondents are compared in Table I with Dallas census statistics. Only tenure and income display marked differences from sample to sample.

The interview or questionnaire is the most useful device available for determining people's perceptions of their own behavior, future intentions, feelings, and attitudes. The interview is superior to the self-administered questionnaire because it overcomes the problem of low response rates and can be administered more uniformly.

However, any measure is only reliable "to the extent that application of the measure to a given situation produces the same results repeatedly, given that the situation in question does not change in between the measurements.. The effect of unreliability in measures is to dilute and obscure real differences when they exist."6

6Peter H. Rossi, Howard E. Freeman, and Sonia R. Wright, Evaluation, a Systematic Approach, (Beverly Hills, 1979), p. 168 . 
TABLE I

SAMPLE AND POPULATION CHARACTERISTICS

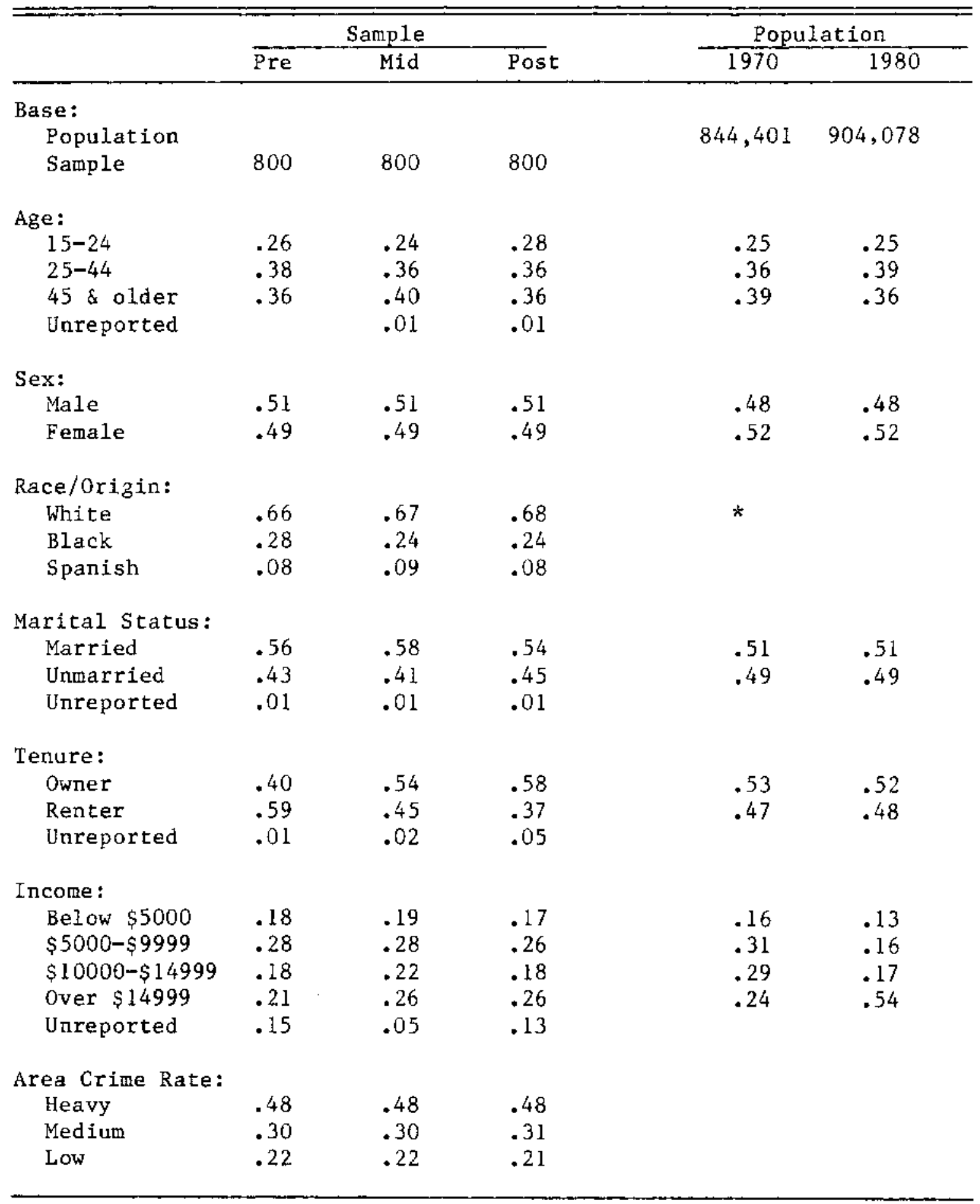

* In the census material, persons of Spanish origin may be of any race. 
Louis, Bowles and Grove attempted to improve the consistency of their results through the adequate training and supervision of their field interviewers.

Field interviewers were recruited, selected, trained and supervised by the opinion Meter Corporation, our subsidiary company that supplies data collection and data processing services. All. interviewers received personal training plus written specifications detailing how respondents were to be selected and interviewed. A minimum of 10 per cent of each interviewer's assignment was verified by means of re-interviewing to be certain that the interviews were completed according to our specifications. If discrepancies were found in any interviewer's work, 100 per cent of his or her interviews were verified and replaced with new interviews if necessary. 7

The validity of a measure is defined as the degree to which "a particular indicator measures what it is supposed to measure rather than reflecting some other phenomenon."8

The relationship established between the interviewer and the respondent creates the major problem in any survey research. This public opinion survey purported to measure the Dallas citizenry's attitudes concerning the importance of specific crime prevention techniques and their perceptions of their own recent behavior in this area. However, the interviewer, through his actions and questions, may have

7Louis, Bowles and Grove, Inc., Tabulations of Replies to Crime Prevention Survey, Report of a Public opinion Survey Conducted for the Dallas Police Department, (Dallas, March, 1976), p. i.

8Edward G. Carmines and Richard A. Zeller, Reliability and Validity Assessment, (Beverly Hills, 1979), p. 16 . 
provided cues to the respondent. The subject then may have replied to the questions in the manner that he perceived the interviewer desired rather than actually reporting his true attitudes and behavior. This creates a non-random bias in the survey results and reduces validity. The severity of this problem is unknown.

\section{Program Impact \\ Procedures.--Impact indicators are created to} ascertain the success or fallure of the theory underlying a particular program. Crimes are events that occur at specific locations in space and time. Each successfully completed violation requires three conditions: an offender with both criminal inclinations and the ability to carry out the act, a person or object supplying a suitable target for the offender, and the absence of a guardian capable of preventing violations.9

It was hypothesized that an increased awareness on the part of potential victims of crime prevention techniques and their subsequent implementation should reduce criminal activity. The police regularly tabulate statistics on reported crime in seven categories: murder, rape, assaul, burglary, robbery, larceny, and auto theft. An interrupted

9Laurence E. Cohen and Marcus Felson, "Social Change and Crime Rate Trends: A Routine Activity Approach", American Sociological Review, XLIV (August, 1979), p. b90. 
time series quasi-experimental design utilizing an autoregressive integrated moving average (ARIMA) model was employed to ascertain whether the advertising had an impact upon the incidence of major crime in the city. An ARIMA model, in an teerative fashion, removes any confounding nonstationaxity, seasonality, autoregressive, and moving average influences from a set of ordered observations.10 Once this has been accomplished, an impact assessment model can be built and analysis can be conducted to ascertain whether the intervention had a statistically significant impact upon the time series.ll

The complete interrupted time series model can be denoted as follows. 12 4.2) $\mathrm{Y}_{\mathrm{t}}=\mathrm{N}_{\mathrm{t}}+\mathrm{I}_{\mathrm{t}}$

Where:

$Y_{t}=$ the $t^{\text {th }}$ observation of a time series

$\mathrm{N}_{t}=$ the noise component

$I_{t}=$ the intervention component

Underlying any observed time series is a sequence of random shocks, at. To model this process, four assumptions

10Richard McCleary and Richard A. Hay, Jr., Applied Time

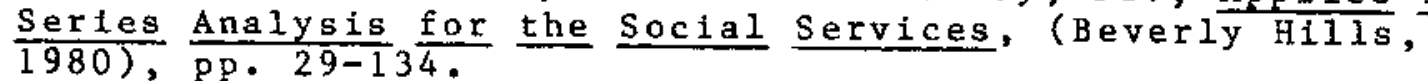

11Ibid., p. 141-203.

12David McDowal1, Richard Mccleary, Errol E. Meidinger, and Richard A. Hay, Jr., Interrupted Time Series Analysis, (Beverly Hills, 1980), p. 13. 
are made about the behavior of these shocks. There must be:

1) a zero mean for the shocks $\left(a_{t}\right)=0$,

2) constant variance for the shocks: variance $\left(a_{t}\right)=0^{2}$,

3) independent shocks: covariance $\left(a_{t} a_{t}+k\right)=0$,

4) and a normal distribution for the shocks: $a_{t} \sim$ N.13

An ARIMA model has three structural parameters which describe the relationship between random shocks and the observed time series. An observed time series is an integrated process. If a series drifts or displays a trend, it must be differenced or transformed into a stationary process before further modeling can commence. The parameter d indicates whether differencing was included in the modeling process.14 An ARIMA $(0,1,0)$ model is denoted as fol1ows.

4.3) $Y_{t}=Y_{t-1}+a t$

When autoregression is present, $Y_{t}$ is composed of a portion of the preceding observations $Y_{t-l}$. . . Yt-n and a random shock. The autoregressive parameter p denotes the number of past observations utilized in the model to predict the current observation.15 An $\operatorname{ARIMA}(1,0,0)$ model is written as follows. 4.4) $Y_{t}=\$ 1 Y_{t-1}+a t$

13 I bid., p. 15 .

14 Ibid., p. 20 .

15 tbid., p. 6 
Where:

$\phi_{1}=$ the correlation coefficient describing the magnitude of dependency between adjacent time-series observations.

The parameter of $q$ indicates the number of moving average structures in the mode1. Random shocks at persist from one observation to the next. When this confounding influence is present, the current time series observation $x_{t}$ is composed of a current random shock at and portions of the q-1 preceding random shocks at-1 ... at-n.16 An ARIMA $(0,0,1)$ model would be written in the following manner. 4.5) $Y_{t}=a_{t}-\theta 1 a t-1$

Where:

$\partial 1=$ the correlation coefficient describing the magnitude of dependency between the current observation $Y_{t}$ and the preceding random shock.

Autoregressive and moving average parameters are constrained by the bounds of stationarity and invertibility, respectively. Both parameters must be smaller than unity in an absolute sense. 17

once the time series has been adequately defined, the model residuals will be distributed as white noise $\mathrm{N}_{t}$. This model can then be used to assess whether the incluston of the exogenous intervention component increases the

16 Ibid., p. 16 .

17 I b1d., PP. $32-36$. 
explanatory power of the model by a statistically

slgnificant quantity.

Four types of impact can be observed. An impact can be either abrupt or gradual in onset and either permanent or temporary in duration. Three impact models can be readily developed. First, an abrupt shift of permanent duration may occur in the process level. This model is denoted as follows. 18

4.6) $\mathrm{Y}_{\mathrm{t}}=\omega \mathrm{It}_{t}+\mathrm{N}_{\mathrm{t}}$

Where:

$w=$ the magnitude of the abrupt, permanent change

$I_{t}=0$ prior to the event and 1 thereafter

Secondly, a gradual, but permanent, change may be observed. This impact model, which is determined by a first order transfer function, is denoted as follows.19

4.7) $Y_{t}=1 \frac{\omega_{Q}}{-f_{1} B} I_{t}+N_{t}$

Where: $\quad S_{1}=$ the rate of change in the impact

$I_{t}=0$ prior to the event and 1 thereafter

$\mathrm{B}=\mathrm{Y}_{\mathrm{t}-1}$

Finally, an abrupt impact may occur which is temporary in duration. This impact is calculated by applying the

18Richard McCleary and Richard A. Hay, Jr., Applied Time $\frac{\text { Series }}{1980)} \frac{\text { Analysis }}{\text { p. } 168 \text {. }}$ the Social services, (Beveriy Hi1ls,

19 Ibid., p. 169. 
first-order transfer function to a differenced $I_{t} .20$ The model is:

4.8) $Y_{t}=1 \frac{\omega_{0}}{-S_{1 B}}(1-B) I_{t}+N_{t}$

Each of these impact models were investigated to determine which fit the data best.

Methodological Assumptions and Weaknesses.--There are two major sources of potential unrellability in the use of reported crimes as the data base for the time series analysis: measurement changes and underreporting of comitted crimes. A change in the Dallas police reporting system could alter the observed trends in crimes. This could lead to the erroneous conclusion that a change occurred as a result of the program when the opposite was actually the case. According to police officials, their measurement system did not change during the period under the investigation. Thus, this threat is alleviated. Secondly, victimization studies have consistently indicated that many crimes are not reported to the police. Therefore, reported crimes are not a valid index of the actual incidence of crime. However, if the percentage of reported crimes to total ones committed has remained constant, these data will rellably reflect changes in the

20 Ibid., p. 169. 
volume of major crimes during the experimental period, even if the absolute magnitude remains unknown.

Two Dallas victimization surveys were conducted in the $1970^{\prime}$ s under the National Crime Survey program. These results contained in Table II indicate that, with the exception of burglary, victimizations reported to the police did not change significantly during the periods studied.

There is also a threat to the internal validity of this research design. Failure to control history presents a major internal weakness.21 since no control group was utilized, it can not be ruled out that some rival event produced any observed shift at the time of the experimental intrusion.

Annual crime statistics were obtained from the Uniform Crime Reports published by the F.B.I. for Dallas and Houston to ascertaln if trends observed in Dallas were replicated in another comparable locality. Houston is roughly twice the size of Dallas. However, both display many similar socio-economic characteristics.

2lDonald T. Campbell and Julian C. Stanley, Experimental $\frac{\text { and }}{1963), \text { puasi-Experimental } 1}$ Designs for Research, (Chicago, 


\section{TABLE II}

PERSONAL, HOUSEHOLD AND COMMERCIAL CRIMES: PERCENT OF VICTIMIZATIONS REPORTED TO THE POLICE 1971/72 AND 1974/75

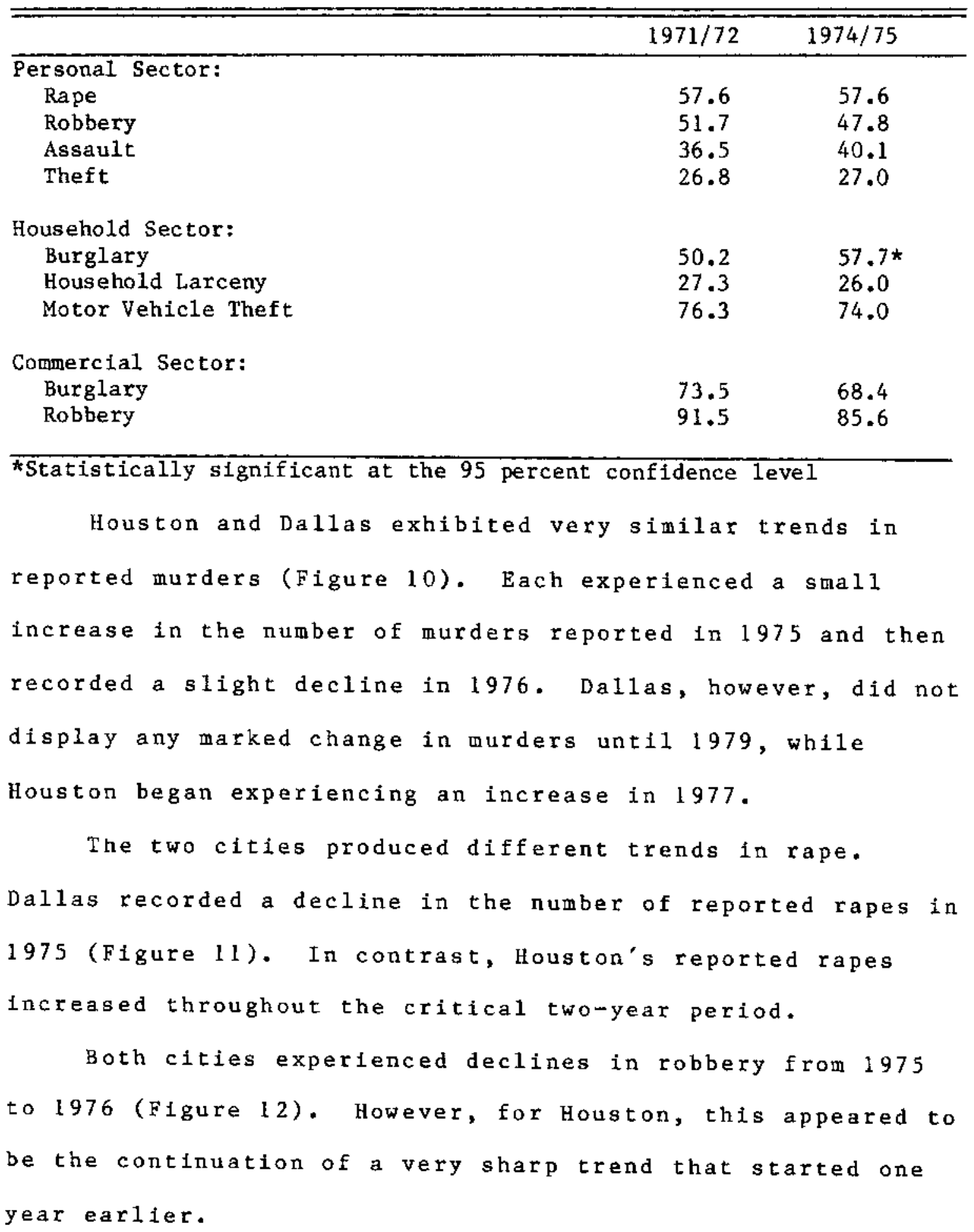




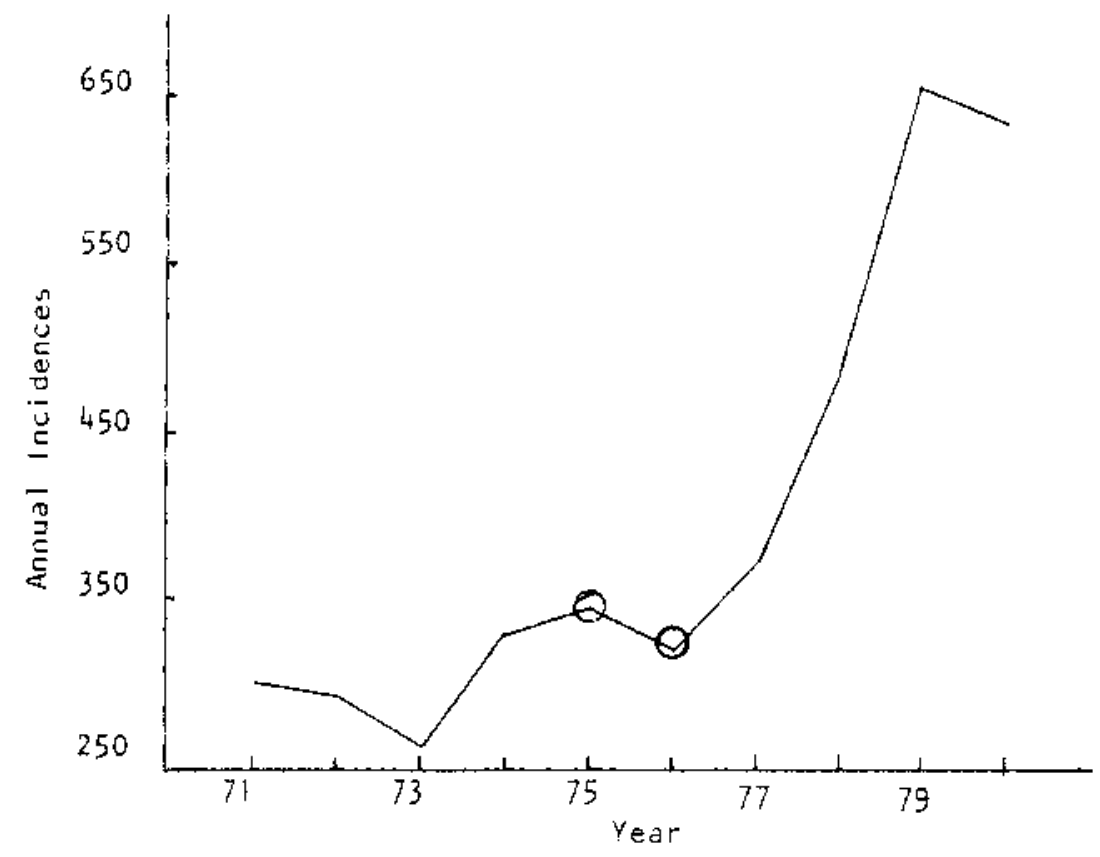

Houston

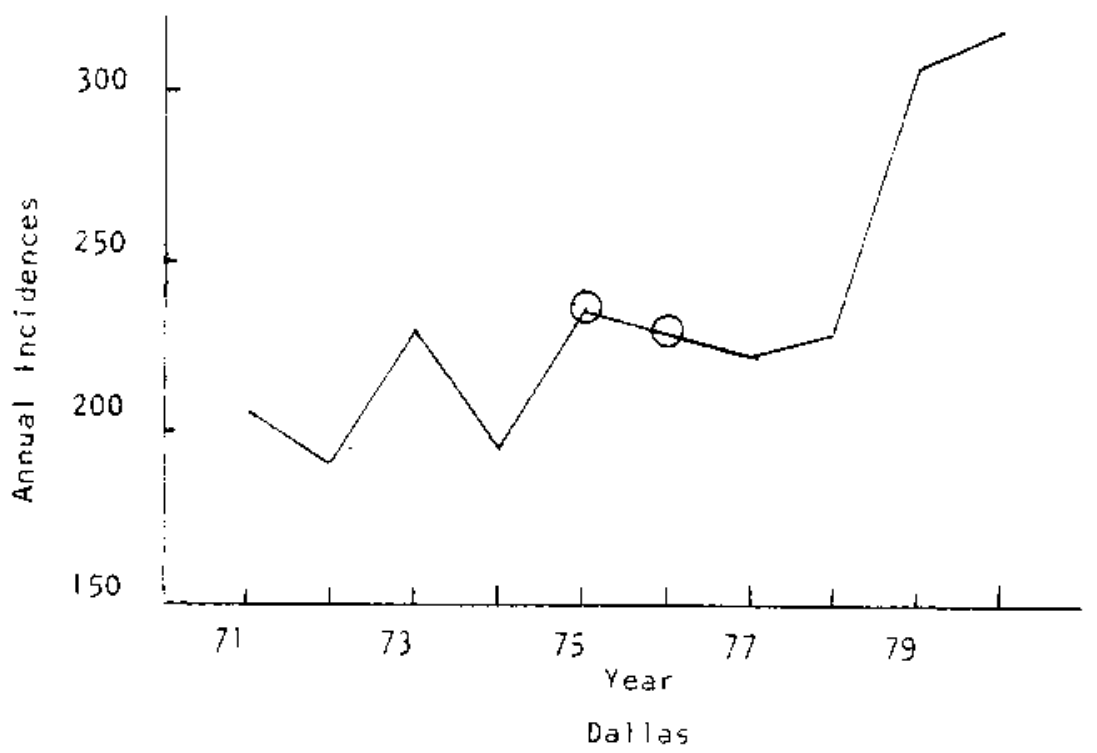

Fig. 10--Reported Murder Dallas and Houston 

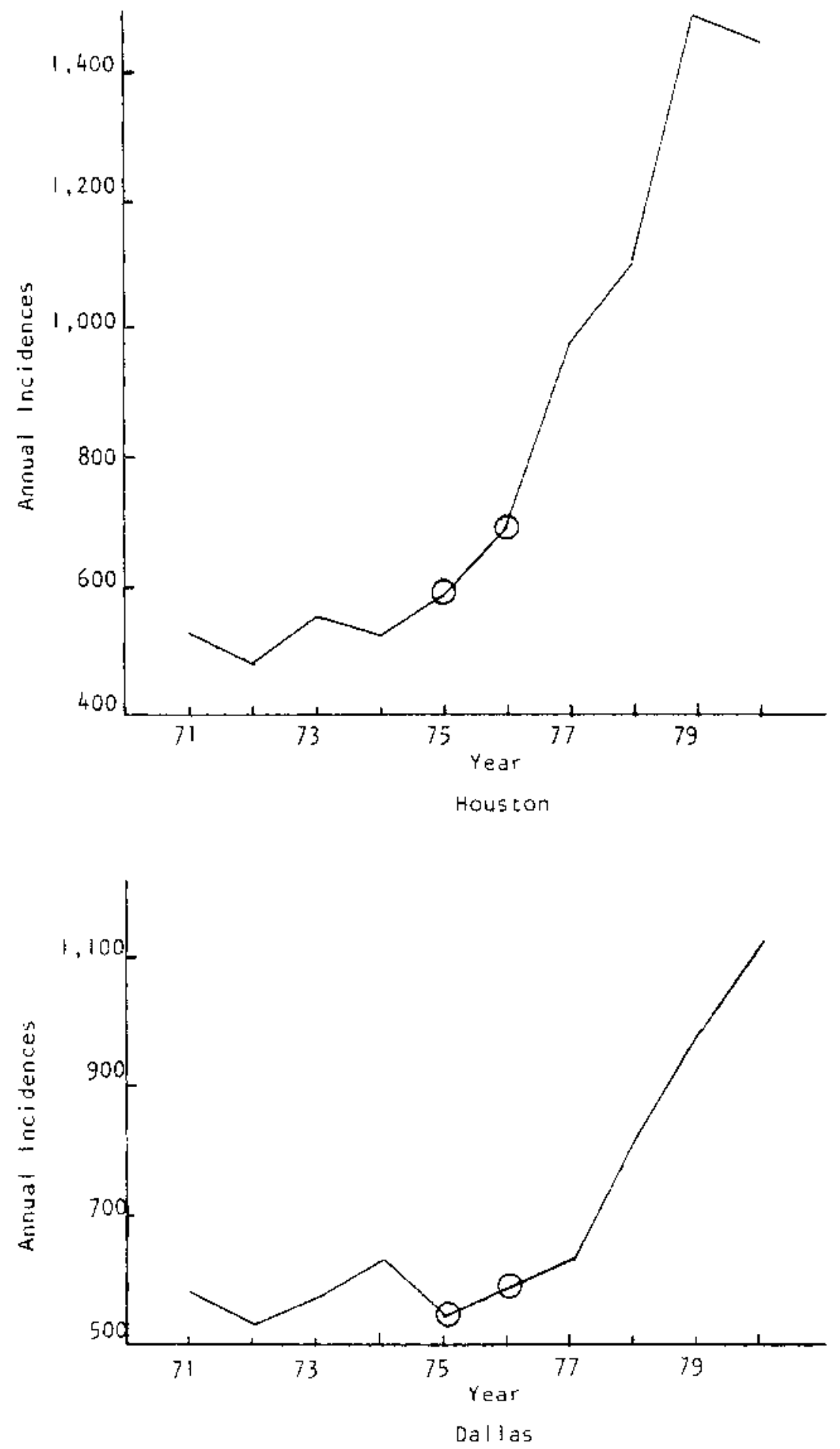

Fig. 11--Reported Rape Dallas and Houston 


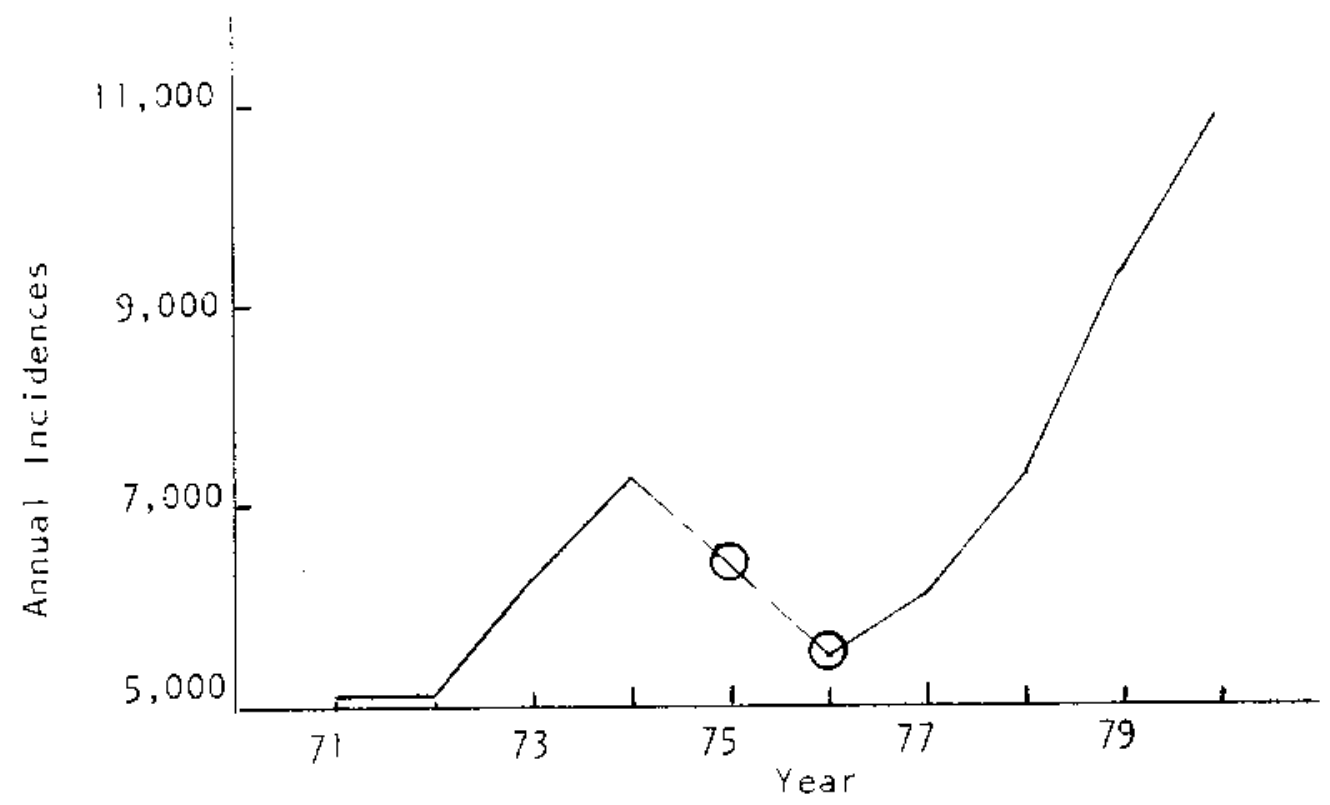

Houston

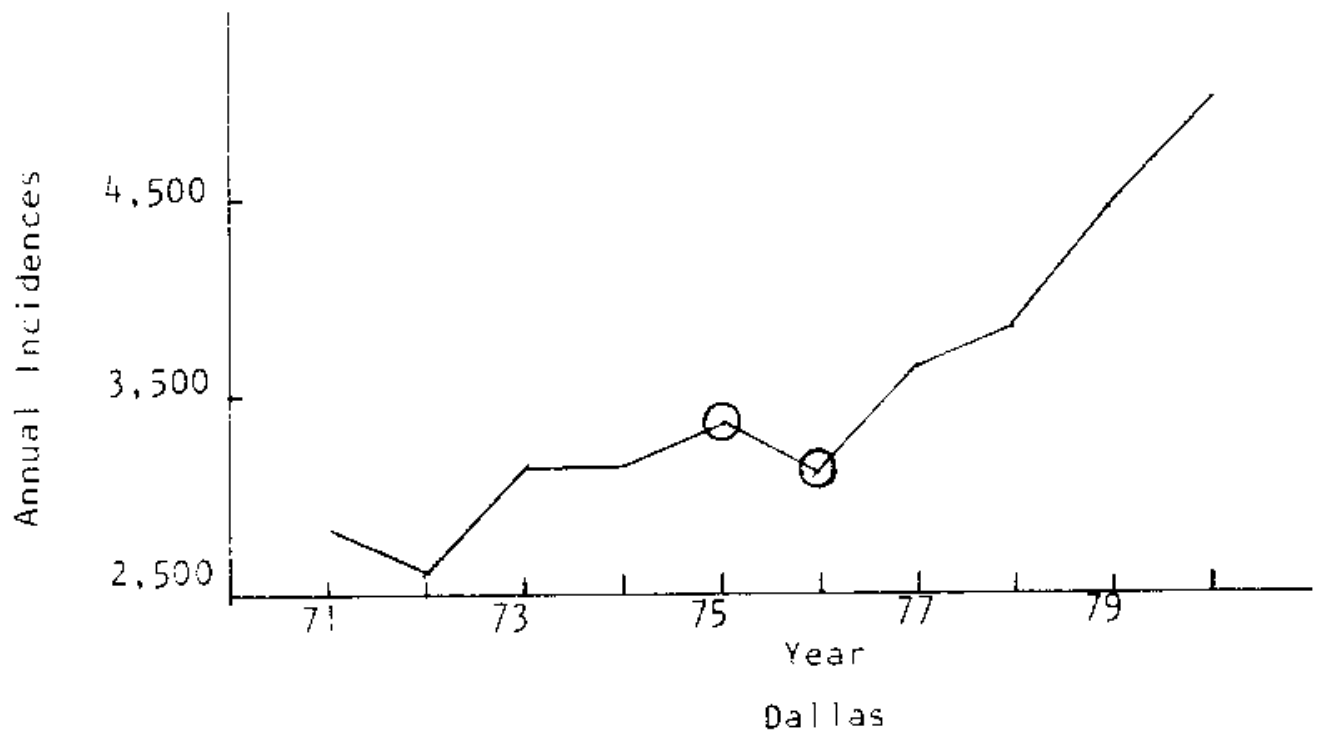

Fig. I2--Reported Robbery - Dallas and Houston 
Assault patterns were also similar for both cities (Figure 13). Both declined in the mid $1970^{\prime} \mathrm{s}$ and then began to rise significantly. Nevertheless, both in 1975 and 1976 , Dallas displayed a greater reduction than Houston.

A simflar trend was noted in reported burglaries (F1gure 14). Dallas exhiblted a sharper decline in 1976 and did not begin experiencing any significant increase until 1979, while Houston burglaries began rising substantially in 1977

Larceny trends, however, were quite different for the two Texas cities. As can be seen in Figure 15, both Houston and Dallas began experiencing a sharp increase in reported larcenies in 1973. Houston's upward spiral continued through 1978, while Dailas exhibited an earlier halt in this upward movement in 1976 .

Both cities produced comparable trends in auto theft (Figure 16). However, again Dallas displayed a greater drop in 1976 than did Houston.

Comparison of the reported annual crithe statistics for Dallas and Houston suggested that while in general both cities experienced some decline in major reported crimes in the mid $1970^{\prime} \mathrm{s}$, Houston did not display as persistent a crime reduction in 1975 and 1976 as did Dallas. As Table III indicates, with the exception of murder and robbery, Dallas recorded lower percentage increases or greater percentage decreases than did Houston in 1975 and 1976. 

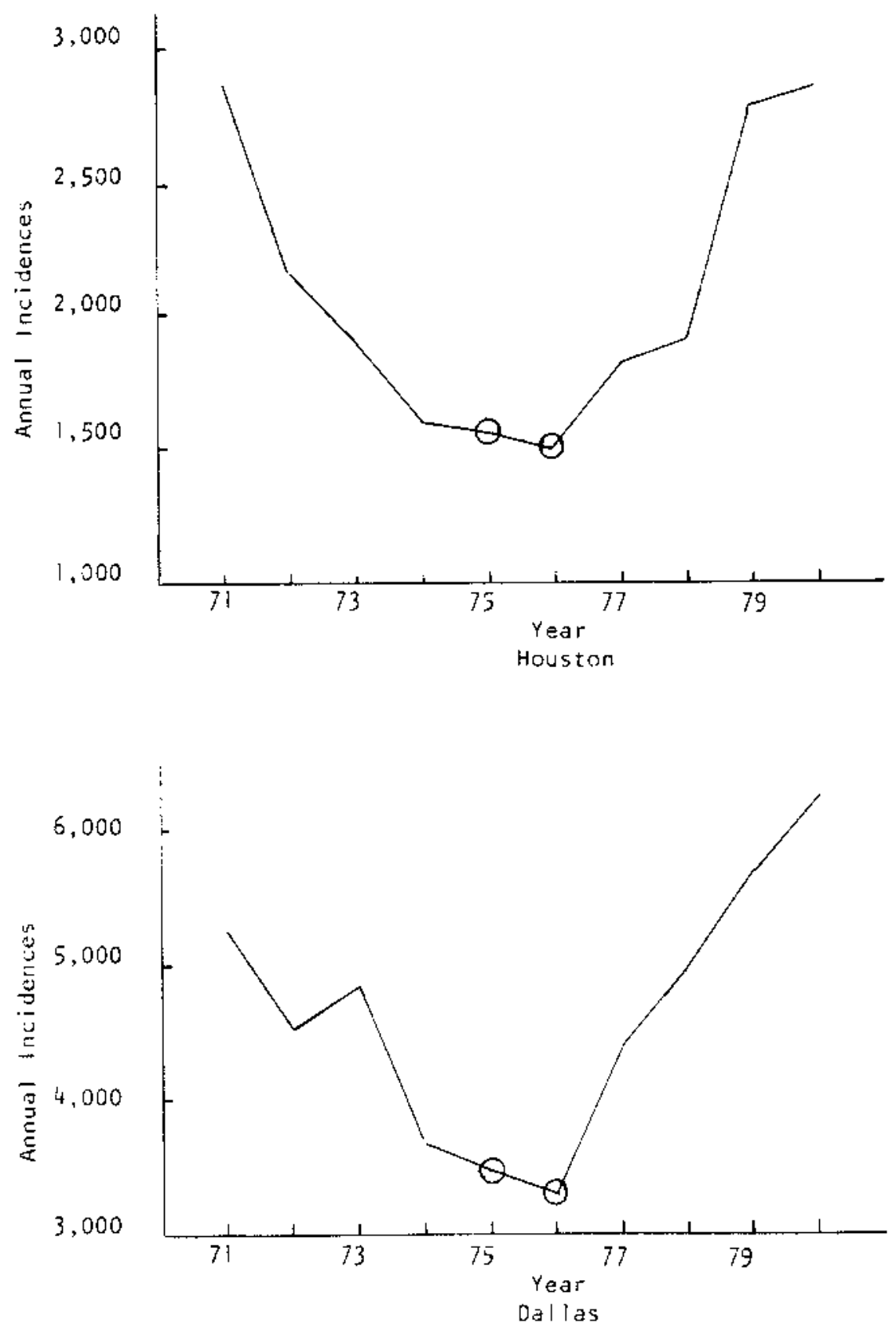

Fig. 13--Reported Assault Dallas and Houston 

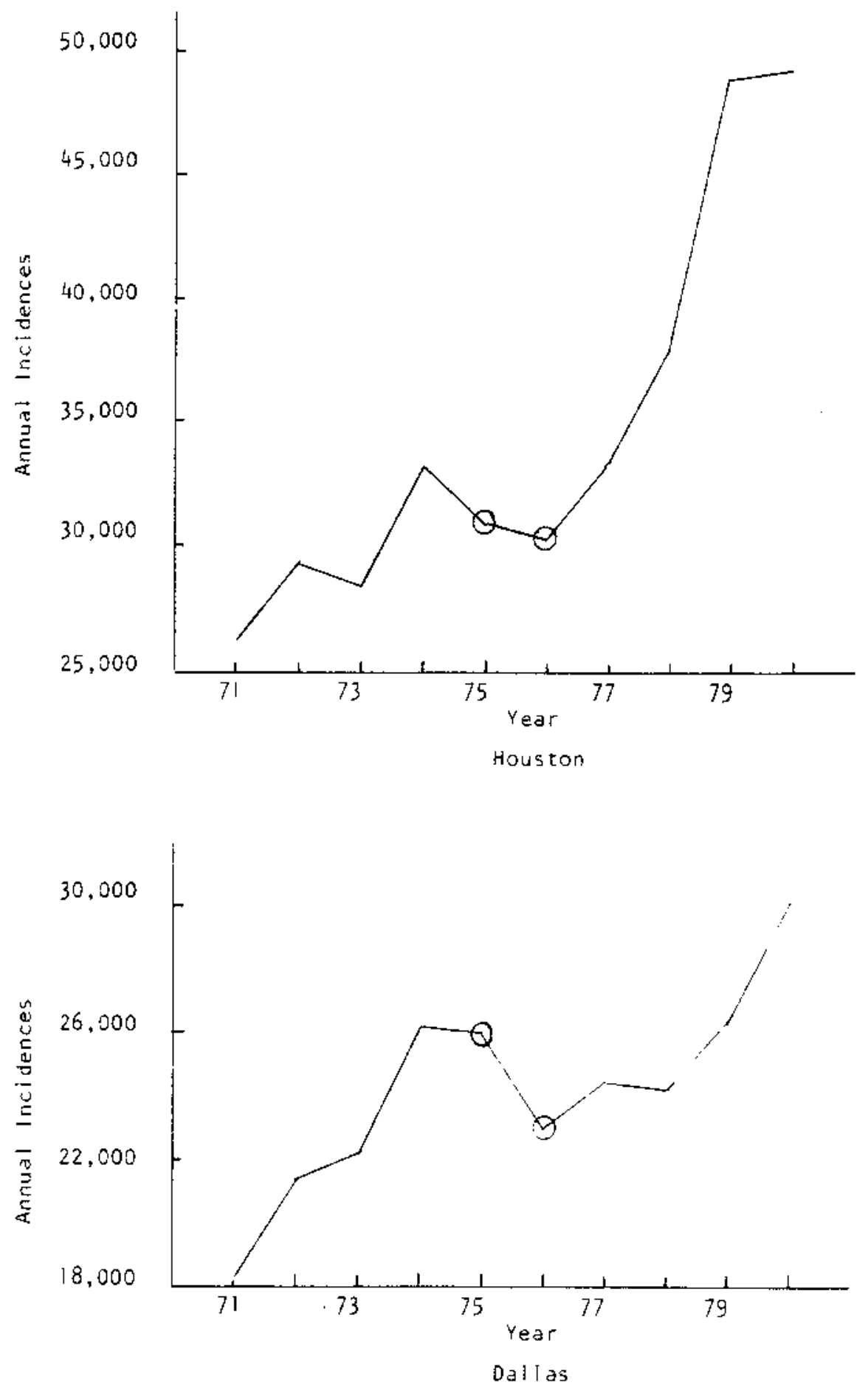

Fig. 14--Reported Burglary Dallas and Houston 


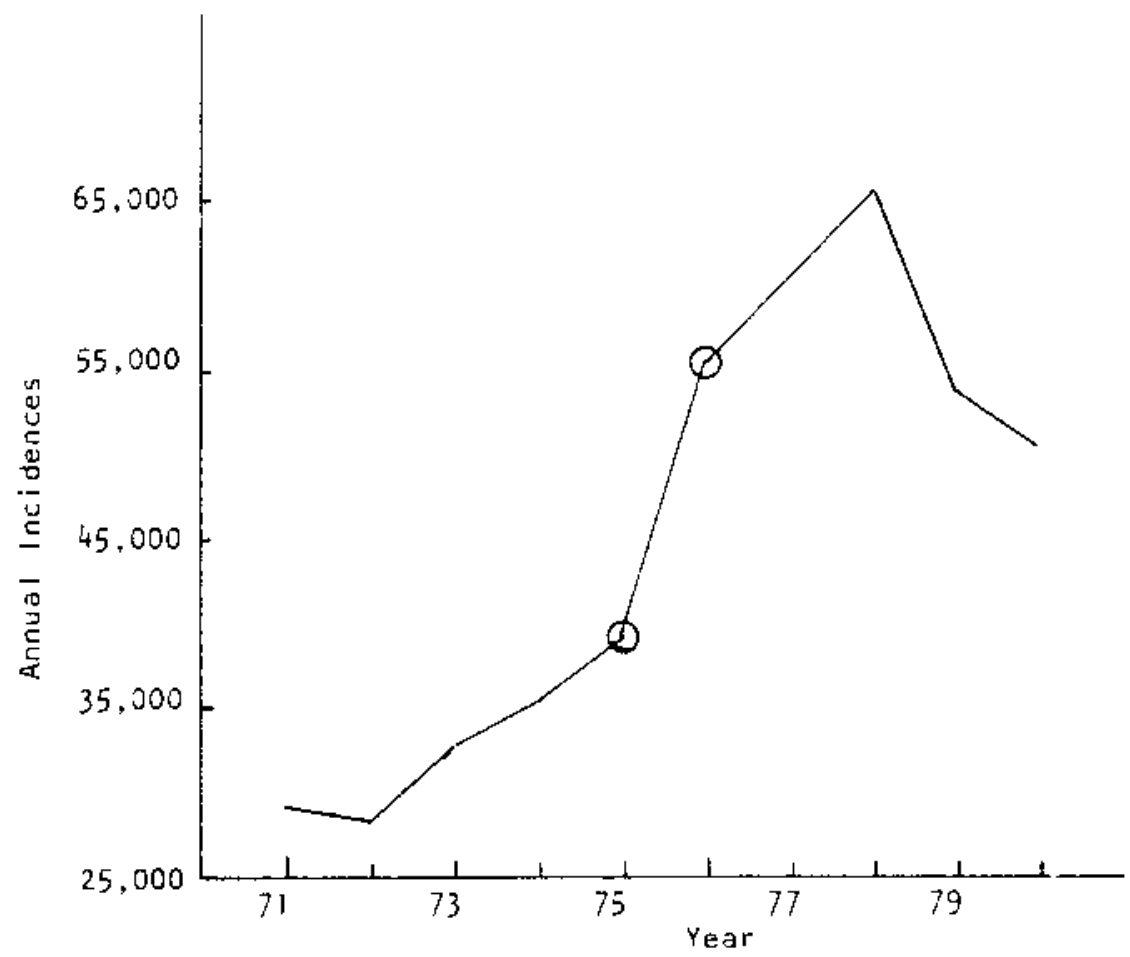

Houston

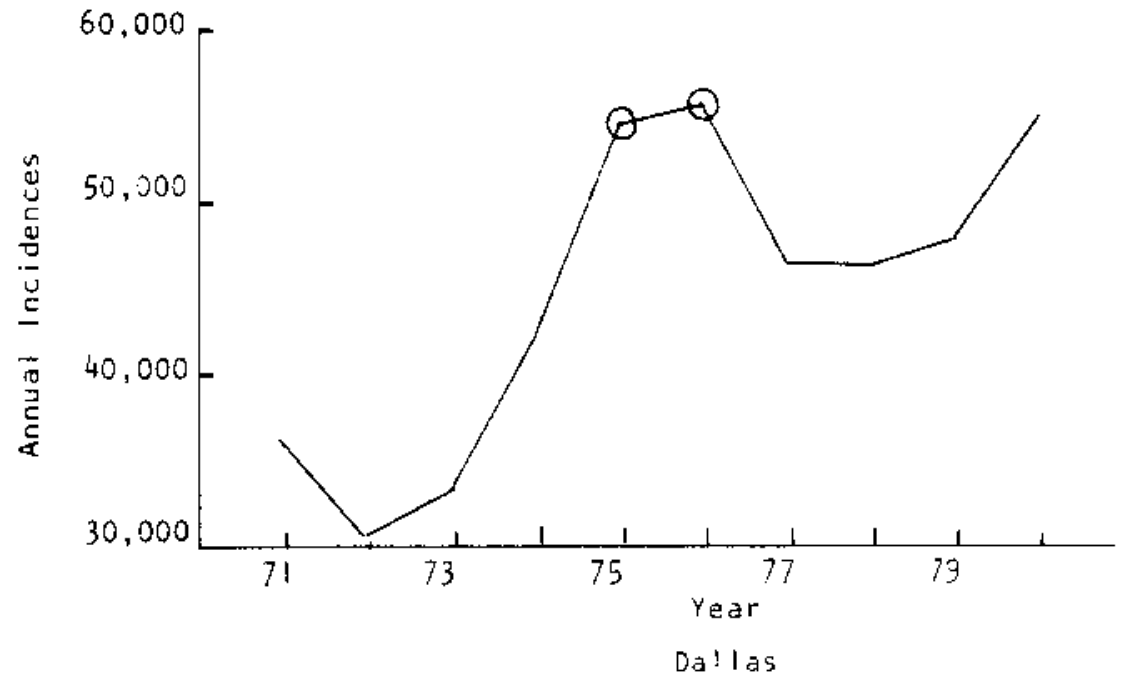

Fig. 15--Reported Larceny Dallas and Houston 

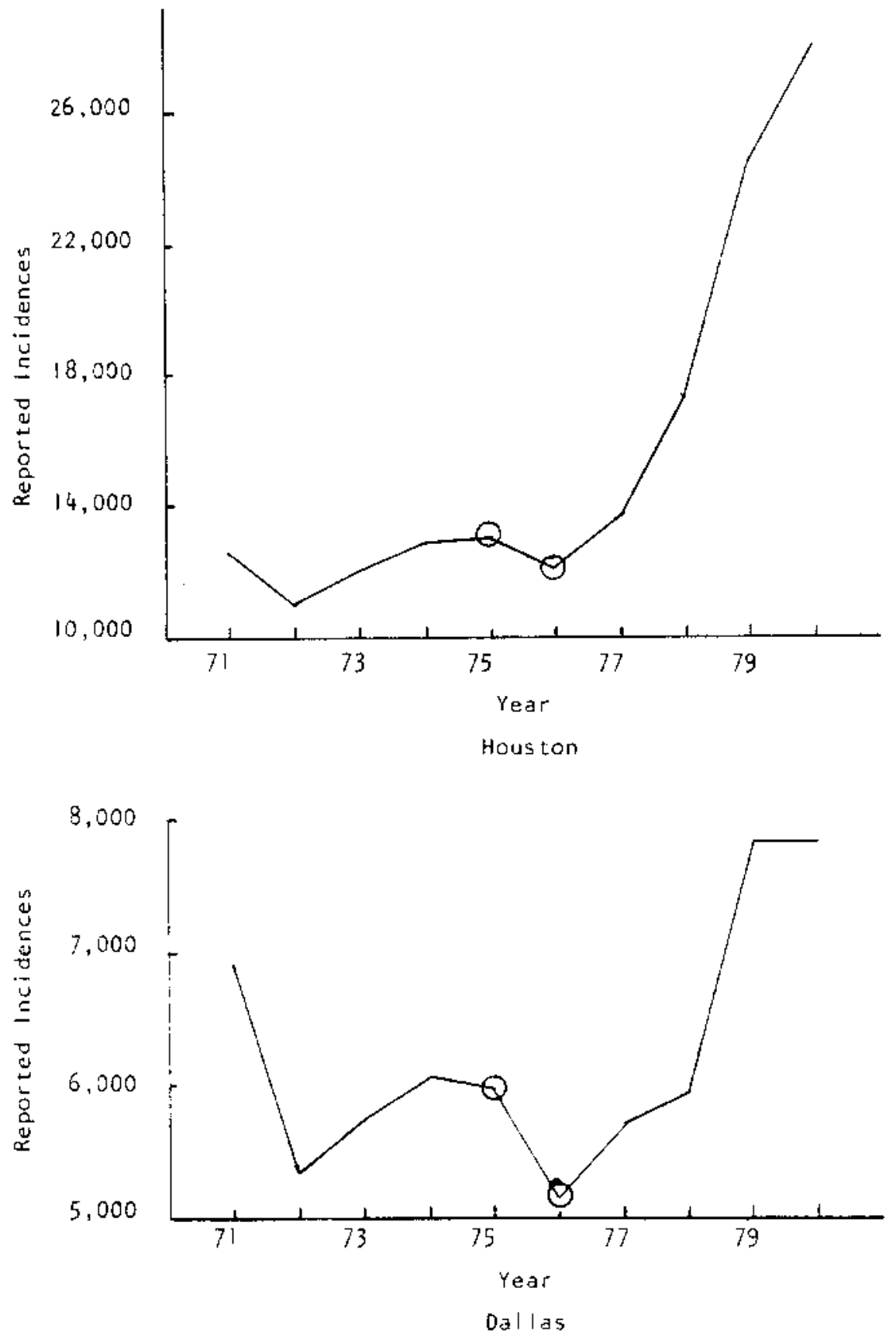

Fig. 16--Reported Auto Theft Dallas and Houston 
Therefore, it was concluded that any changes observed in Dallas in these critical years were not in fact occurring, at least in the same magnitude, in a comparable city.

TABLE III

PERCENTAGE CHANGE IN CRIME 1974 TO 1976

\begin{tabular}{lll}
\hline & Dallas & Houston \\
\hline Murder & $+14.8 \%$ & $-2.7 \%$ \\
Rape & -6.9 & +32.7 \\
Robbery & -1.0 & -23.7 \\
Assault & -10.0 & -6.2 \\
Burglary & -12.6 & -8.6 \\
Larceny & +32.4 & +57.8 \\
Auto Theft & -15.7 & -5.8 \\
\hline
\end{tabular}

Lab Experiment Research Design

A lab experiment was conducted to ascertain if the inclusion of non-monetary performance measures in a budget request proposal would reduce the decision maker's uncertainty pertaining to past progratn effectiveness and would alter the subsequent budgetary decision. Data obtained from the quasi-experiment was incorporated into the cases utilized in the study.

\section{Mode1 Specification}

According to the Lens Model, individual judgment accuracy, ( $r_{a}$ ) is affected by the extent to which the deciston maker detects the essential properties of the task through his cue weighting (G), the consistency with which he applies his judgment policy $\left(R_{S}\right)$, and the extent to which 
the environment is actually predicted with the available cues $\left(R_{e}\right)$. As stated before:

4.9) $\quad r_{a}=G R_{S} R_{e}$

Empirical research in the human information processing

field has focused upon the processing and application of cues in a judgnent situation. It has been demonstrated that while individuals in many situations apply idiosyncratic judgment processes that result in large "differences in cue weighting across dectsion makers in the same decision context", an individual's judgment over time is generally stable. 22

In this research, it is assumed that an individual's cue weighting and judgment policy remain constant and cue predictability $\left(R_{e}\right)$ is varied systematically to determine the effect this variable has upon judgment accuracy. It is hypothesized that as cue predictability increases, individual judgment accuracy will also increase. Thus:

4.10) $\mathrm{r}_{\mathrm{a}}=\mathrm{k} \mathrm{R}_{\mathrm{e}}$

Furthermore, as judgment accuracy across individuals increases, the resulting decision variability among individuals will decrease. 4.11) $\operatorname{var}_{D}=a-b r_{a}$

22 Robert Ashton, Human Information Processing in Accounting, (Washington, $198 \overline{2}$ ), p. 151 . 
Individuals employ probability theory when they utilize cues to form a judgment as to whether a particular outcome or event will occur. Assume that initially a particular hypothesis $\left(\mathrm{H}_{\mathfrak{i}}\right)$ is held about the state of the world. The receipt of additional data (D) should increase or decrease the decision maker's degree of belief in the truth of that hypothesis. 23 Therefore,

4.12) $P\left(\mathrm{H}_{i} / \mathrm{D}\right)=\frac{P\left(\mathrm{D} / \mathrm{H}_{i}\right) P\left(\mathrm{H}_{i}\right)}{P(D)}$

Where:

$$
\begin{aligned}
& P\left(H_{i}\right)=\text { probability that hypothesis } H_{1} \text { is true } \\
& P\left(H_{i} / D\right)=\text { probability that hypothesis } H_{i} \text { is true } \\
& \text { after receipt of datum } D \\
& \mathrm{P}\left(\mathrm{D} / \mathrm{H}_{\mathbf{i}}\right)=\text { conditional probablitity of observing } \\
& \text { datum } D \text { given that } \mathrm{H}_{i} \text { is true }
\end{aligned}
$$

In this equation, if $P\left(H_{i}\right)$ and $P\left(H_{i} / D\right)$ are known,

$P\left(D / H_{i}\right)$ represents the impact of $D$ on the hypothesis $H_{i}$ and measures the diagnosticity of datum D. 24 The extent to which the envixonment is perceived to be actually described by the available cues may be measured by the change in an individual's probability assessments concerning the environmental state in question given the receipt of all cues. Thus

4.13) $R_{e}=\frac{P\left(H_{i} / D\right)}{P\left(H_{i}\right)}$

23 Ibid., pp. $94-95$.

${ }^{24}$ Ibid., p. 95 . 
Probabilities for an event that has only two possible outcomes--occurrence (I) and non-occurrence (0)--can be depicted schematically as shown in Figure 17.

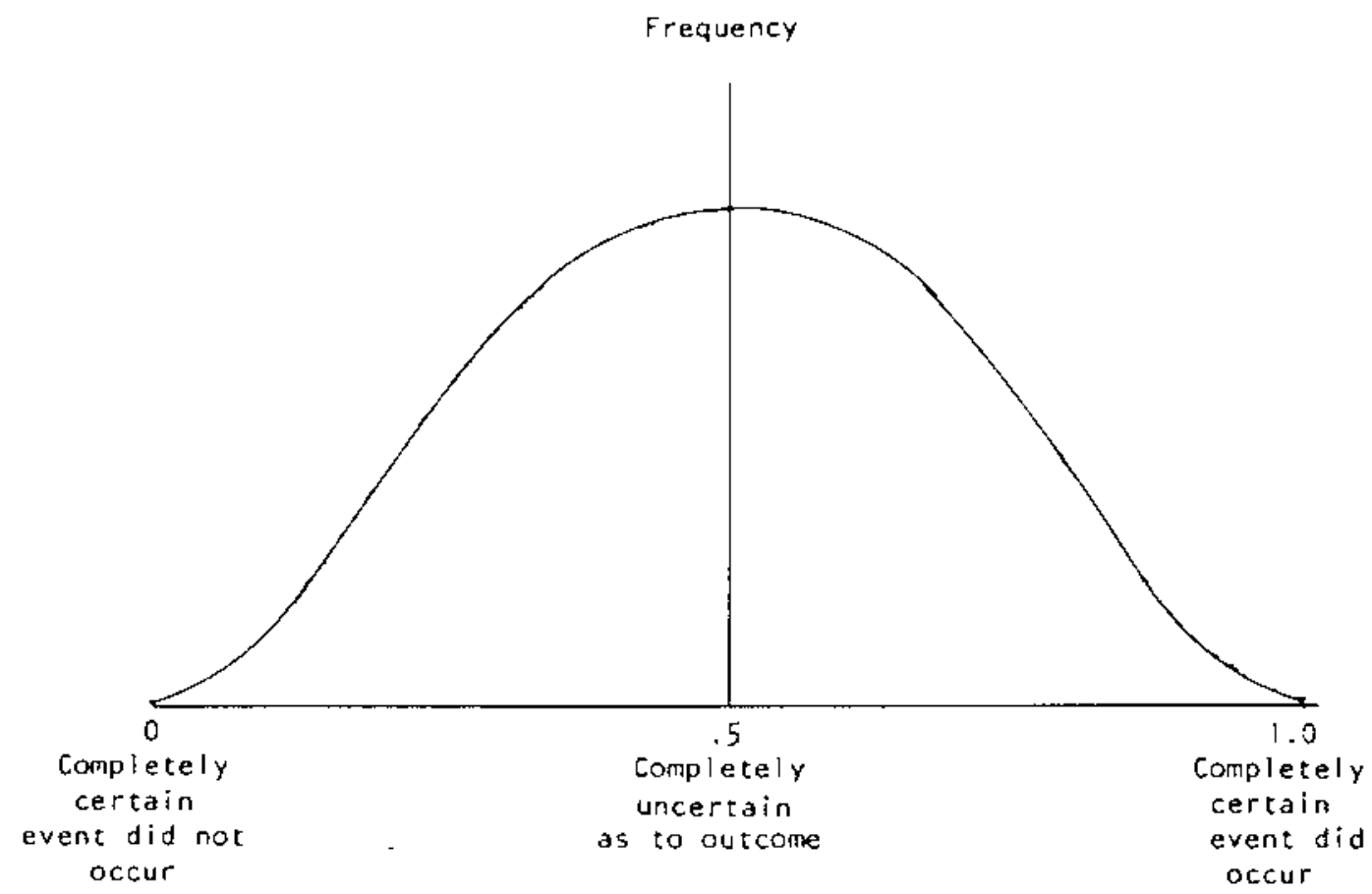

Fig. 17--Certainty of Event Outcomes

If posterior probabtlities move in either direction away from .5 (completely uncertain) when compared with prior probabilities, then it is hypothesized that the datum $D$ has information value because uncertainty has been reduced. Furthermore, it is hypothesized that as uncertainty ( $U_{e}$ ) is Lessened, the variability displayed among decision makers in their ultimate judgments (Vard) will decline.

4.14) $\operatorname{var}_{D}=a+b U_{e}$ 


\section{Research Hypotheses}

Budgetary decision makers must weigh the benefits to be derlved from a particular program against the costs of other opportunities that must be foregone if available funds are channeled into the activity under consideration. one piece of information needed to make this decision is data pertaining to past organizational performance.

In addition to the budget request for future funds, a decision maker ideally should receive three sets of cues.

Cue 1: (Output Cues) A report on how resources were utilized in the past period to accomplish the program's objectives. These workload measures provide an indication of how efficiently the avallable funds were converted into an output.

Cue 2: (Outcome Cues) A report on program outcomes indicating whether the past program activities resulted in a change in the perceived conditions of the direct. targets. These cues focus upon progran success or failure.

Cue 3: (Impact Cues) A report on the impact of the program activities on the broader conditions prevalant in society. These cues focus on theory success or failure.

The following five research hypotheses were tested.

$$
\begin{aligned}
& \mathrm{H}_{\mathrm{R} 1}: \quad \text { Experimental subjects' uncertainty } \\
& \text { concerning the impact of the Dallas crime } \\
& \text { Prevention Advertising Program upon the } \\
& \text { target population's awareness of crime } \\
& \text { prevention techniques and self-reported } \\
& \text { behavior will be significant } 1 y \text { reduced by } \\
& \text { the provision of outcome cues. } \\
& \text { Experimental subjects' uncertainty } \\
& \text { concerning the impact of the Dallas crime } \\
& \text { Prevention Advertistig Program }
\end{aligned}
$$




\author{
upon criminal activity in the target area \\ will be significantiy reduced by the \\ provision of impact cues. \\ $\mathrm{H}_{\mathrm{R} 3}: \quad$ As cue availability increases, variation \\ in the resulting monetary budget decisions \\ among experimental subjects will \\ significantly decline. \\ $\mathrm{H}_{\mathrm{R} 4}$ : As cue availability increases for a \\ program displaying positive past program \\ results, the mean of the monetary budget \\ allocations approved by experimental \\ subjects will significantly increase. \\ $H_{R 5}:$ As cue availability increases for a \\ program displaying negative past program \\ results, the mean of the monetary budget \\ allocations approved by experimental \\ subjects will significantly decline.
}

\title{
Research Design
}

A controlled laboratory experiment was conducted to ascertain the impact of performance feedback upon a decision maker's uncertainty and subsequent budgetary deciston. The following posttest-only control group experimental design was employed.

4.15) $\begin{array}{lllll}\mathrm{R} & & & 0_{1} \\ & \mathrm{R} & \mathrm{X}_{1} & \mathrm{X}_{\mathrm{a}} & 0_{2} \\ & \mathrm{R} & \mathrm{X}_{2} & \mathrm{X}_{\mathrm{a}} & 0_{3} \\ & \mathrm{R} & \mathrm{X}_{1} & \mathrm{X}_{\mathrm{b}} & 0_{4} \\ & \mathrm{R} & \mathrm{X}_{2} & \mathrm{X}_{\mathrm{b}} & 0_{5}\end{array}$

where:

$$
\begin{aligned}
& \mathrm{R}=\text { groups created by random processes } \\
& \mathrm{O}=\text { observations that are subject to measurement } \\
& \mathrm{X}=\text { intervention of the experimental variables }
\end{aligned}
$$

Briefly each subject was told that (s)he had recently been appointed head of a federal task force to fight crime. Fifty milion dollars was appropriated by Congress for this 
endeavor. These monies were to be utilized solely to fund local projects that had exhibited prior success. The subject's job as head of the task force was to decide which local crime projects requesting funds would be approved. Each subject was then provided with one such local budget request to review. All cases contained two identical bits of information: (1) a budget request for 1983 federal funds and (2) 1982 local program output cues. The control group's budget document (Case 1) contained only this data. Budget personnel typically receive data similar to that contained in the control case. The remaining four groups received experimental intrusion in the form of the number of additional cues provided about past program results $\left(X_{1}, X_{2}\right)$ and the successfulness of these 1982 local activities ( $x_{a}$, $\left.x_{b}\right)$. A brief description of the information provided to each group follows:

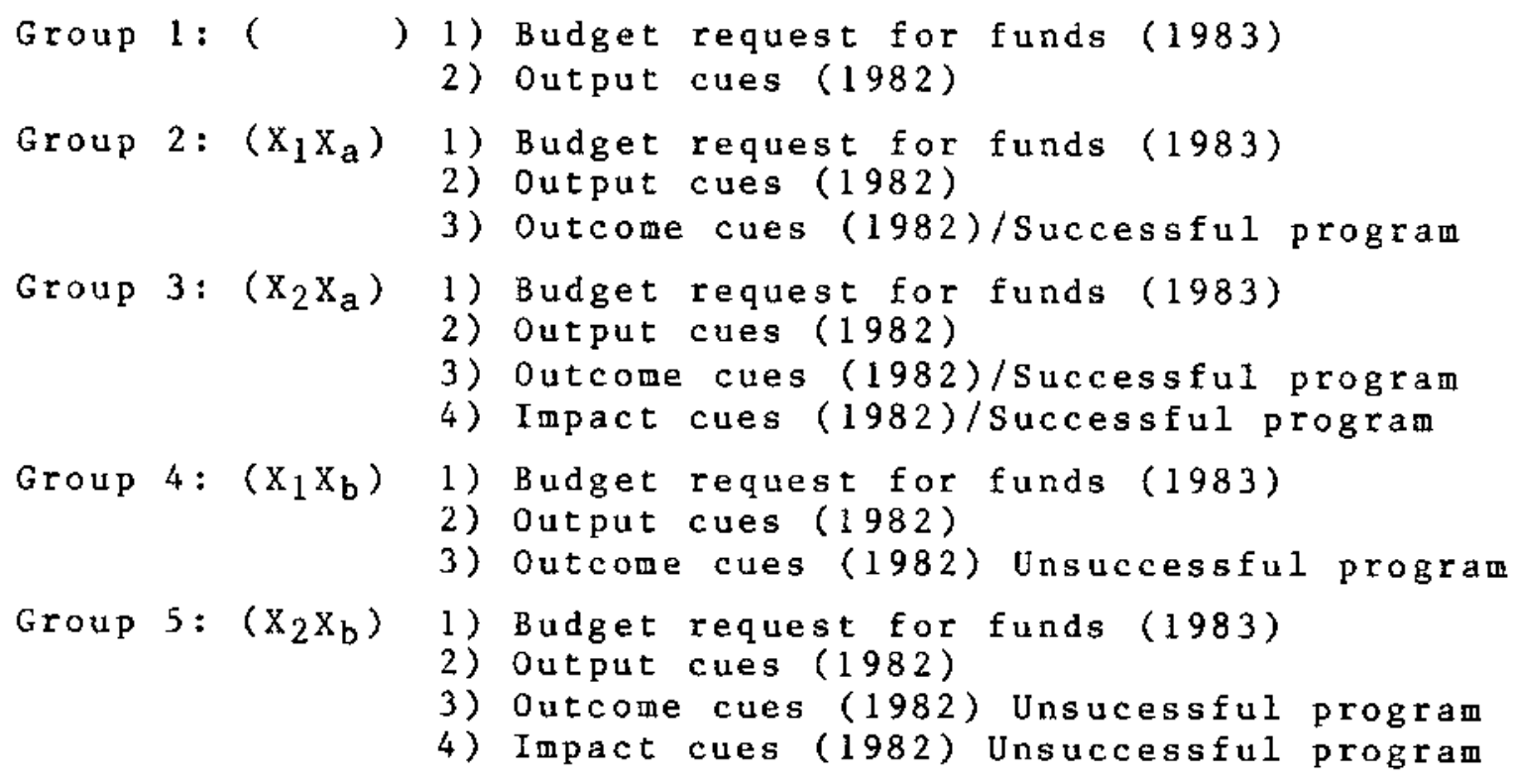


The results of the evaluation of the Dallas crime prevention advertising program were utilized to create the information contained in the Control Case and the outcome and impact cues for the successful program. The experimental cues were fabricated for the unsuccessful program. In all instances, benchmarks were provided within the budget document by which the subjects could judge the past successfulness of the local entity in achieving the desired outcome and impact. Copies of the cases and the research instrument utilized in the study are contained in Appendix B.

The subjects were asked to perform several duties. First, they established the dollar amount, if any, at which the crime prevention program would be funded in 1983. It was hypothesized that as cue availability increased, the mean of the approved funding for the successful program would rise and the mean for the unsuccessful case would fa11.

A $2 \times 3$ factorial research design was employed to test independently the main and interaction effects of the program results and cue availability upon the budget decisions. The design was structured so that each level of one independent variable was crossed or associated with each level of the second independent varlable. Cell size was equal. Therefore, the experimental variables were 
orthogonal and independent of one another. This design can be diagramad as follows.

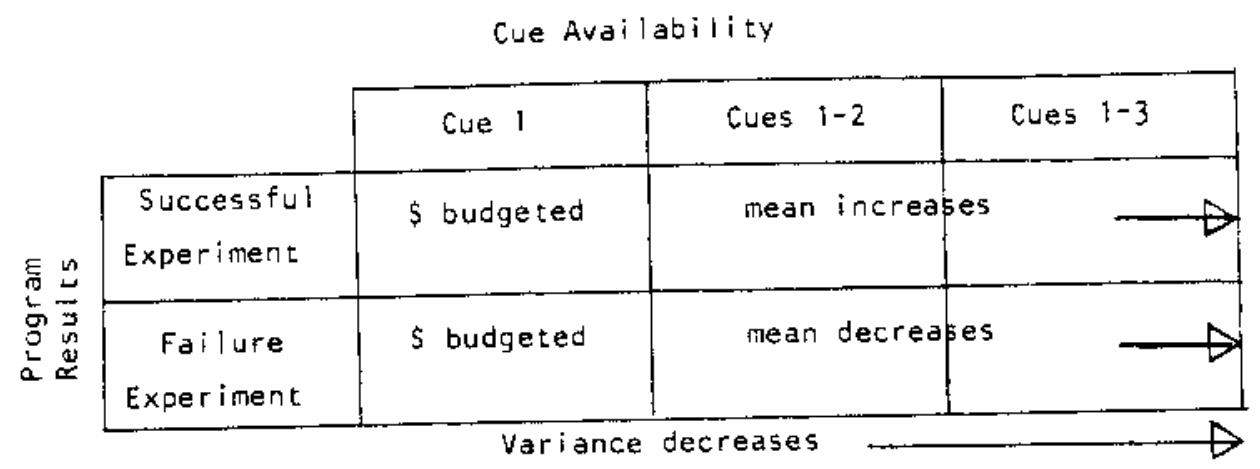

Fig. 18--Budgeted Mean: Factorial Research Design

Subjects were also asked to respond to a series of statements concerning the efficiency and effectiveness of the crime prevention program in 1982. Statements utilized included the following:

1) The Metro City Police Department Crime Prevention Advertising Program utilized the available resources in an efficient manner to obtain and distribute information concerning individual crine prevention techniques to the general public.

2) The Metro City Police Department Crime Prevention Advertising Program was successful in altering citizens' behavior concerning crime prevention techniques that they actually practice.

3) The Metro City Police Department Crime Prevention Advertising Program was successful in reducing crime by waking the local citizenry less susceptible to being victimized.

Subjects responded to each statement on a scale that encompassed simultaneously their degree of agreement with the statement posed and their confidence in their answer. It was hypothesized that as more cues were furnished to the 
subjects, they would respond with greater certainty to the statements. The observed change in certainty is a measure of the information content of the cues. The independent varlable (cue avallability) had three values. The dependent variable measured the subjects' agreement and certainty as to the effictency and effectiveness of the 1982 program. Ninety subjects from twenty-two state agencies were recruited to participate in the experiment. All were employed as budget preparers, budget examiners, or auditors for the state of Texas. This group formed the pool from which the experimental and control groups were randomly created. It was anticipated that the use of subjects with similar backgrounds and experiences would reduce the observed variability in individual cue weighting and judgment policy to a minimum. Table IV contains a brief blographical sketch of the subjects who participated in the experiment.

The experiment was conducted over a four-day period in Austin, Texas. The researcher met with the participants at their respective agencies. Initially, the background case materlal was refterated and the questionnaire was reviewed. Then the subjects were observed while they read the cases and completed the instrument to assure that no communication ensued. All subjects from any agency simultaneously participated in the experiment so that knowledge of either the cases or the variables being investigated could not be 
TABLE IV

EXPERIMENTAL SUBJECTS

\begin{tabular}{|c|c|c|c|c|c|}
\hline & \multicolumn{5}{|c|}{ Group } \\
\hline & 1 & 2 & 3 & 4 & 5 \\
\hline \multicolumn{6}{|l|}{ Job: } \\
\hline Preparer & 11 & 11 & 12 & 12 & 11 \\
\hline Examiner & 7 & 7 & 6 & 6 & 7 \\
\hline \multicolumn{6}{|l|}{ Gender: } \\
\hline Male & 13 & 14 & 13 & 13 & 14 \\
\hline Female & 5 & 4 & 5 & 5 & 4 \\
\hline \multicolumn{6}{|l|}{ Work Experience: } \\
\hline $0-4$ years & 8 & 7 & 5 & 8 & 5 \\
\hline 5-9 years & 8 & 3 & 4 & 5 & 7 \\
\hline 10-14 years & 1 & 4 & 6 & 5 & 4 \\
\hline Over 14 years & 1 & 4 & 3 & 0 & 2 \\
\hline \multicolumn{6}{|l|}{ Age: } \\
\hline $20-29$ years & 4 & 3 & 2 & 2 & 1 \\
\hline $30-39$ years & 10 & 7 & 9 & 12 & 11 \\
\hline $40-49$ years & 2 & 4 & 5 & 3 & 1 \\
\hline Over 49 years & 2 & 4 & 2 & 1 & 5 \\
\hline \multicolumn{6}{|l|}{ Education: } \\
\hline High School & 1 & 3 & 2 & 1 & 1 \\
\hline College & 10 & 11 & 10 & 12 & 12 \\
\hline Post Graduate & 7 & 4 & 6 & 5 & 5 \\
\hline
\end{tabular}


relayed among prospective subjects prior to involvement in the experiment.

\section{Methodologlcal Assumptions and Weaknesses}

This experimental design provided a trade-off between increased internal validity and decreased generalizability. While a pretest would be useful in determining if the experimental and control groups were equal before differential experimental treatment, it is not essential. The posttest-only control group design provided adequate assurance through randomization that initial biases were distributed equally anong all groups.25

Thus, subject randomization and careful control of the experimental intrusion eliminated the threats to internal validty. The use of a randomily produced control group removed the threats from historical forces, subject maturation, and selection, because such threats acted upon all groups in a random fashion. The absence of a pretest removed the threats from instrumentation decay, test reactivity, regression, and subject mortality.

However, since the experiment was conducted in a controlled setting, little generalizability resulted. Several threats reduced the generalizability of the results.

25Donald T. Campbell and Julian C. Stanley, Experimental and Quasi-Experimental Designs for Research, (ChIcago, 
First, cues were varled in a selective fashion. program results were depicted as a dichotomous variable and cue avallability was set at only three levels. Subjects were not allowed to ask for any additional information, but were required to make their budget decision on only the available information. While this device controlled the experimental intrusion, it limited generalizability to only those particular variables under investigation.

Secondly, benchmarks were included in each experimental cue presentation so that subjects had a consistent source by which they could judge success or failure of past program results. These indicators reduced the degree to which the two negative cases appeared realistic. An agency would not wish to voluntarily provide data that was detrimental to its cause. However, this eliminated one possible source of subject variation. Uniform prior knowledge of both acceptable advertising standards and crime statistics could not be assumed. Thus, the improvement in lnternal validity due to the inclusion of the benchmarks outweighed the decline in generalizability.

Thirdly, budgets are typically created in a competitive environment in which each project requesting funds is weighed against all other alternatives. In this instance the subjects were asked to make a budget deciston in isolation without any information concerning any other programs competing for funds. The artificiality of the 
experimental environment and the subject's knowledge of experimental participation created a powerful source of non-generalizability.26 To partially overcome thts difficulty, the subjects were informed that the proposed budget would only utilize approximately one percent of the total available funds. Furthermore, the case material implied that the subjects were operating within a relatively neutral budgetary environment and that the program being reviewed was a typical request for funds.

Finally, there may be an interaction between selection and treatment. Both the experimental and control groups were radiom produced from a volunteer agency sample. While many subjects were experts in the field of state budget preparation and deciston making, few had previously performed this activity at the federal level and few had been involved in decision making pertaining to crime prevention programs. Thus, one might argue that any results obtained concerning the usefulness of the cues in decision making would not be applicable in a more realistic environgent.

The experimental design utilized, however, did defeat one potential threat to external validity. There was no interaction between the testing and the experimental

26rhomas D. Cook and Donald T. Campbe11, QuasiExperimentation, (Chicago, 1979), p. 68 . 
variable. A pretest would have sensitized the subjects by focusing attention on the problem under investigation. This might possibly have increased the effect of the experimental variable, but would have contaminated the observed results. Experimental studies are "more powerful than non-experimental designs in uncovering causal relationships among variables. This is due to the fact that through control and randomization, potential confounding effects can be removed from a study."27 This endeavor is viewed as the initial empirical test of a new theory. Thus, the measurement of the actual effect of non-monetary performance indicators on decision making was the foremost concern in the development of the research design. only in a tightly controlled experiment can one state with reasonable assurance that a change in one variable caused a change in another variable. Since only causality can be considered as positive evidence of a theory, this experiment intentionally sacrificed external validity for internal validity. Generalizability must be subsequently gained through replication in other less artificial settings.

${ }^{27}$ Paul E. Spector, Research Designs, (Beverly Hills, 1981), p. 20. 
CHAPTER V

RESEARCH FINDINGS

Quasi-Experiment

The Dallas police department's crime prevention advertising program was evaluated initially to ascertain its affect upon citizens' attitudes pertaining to the importance of certain preventive techniques in reducing crime and their purported likelihood of implementing such measures. The following question was addressed. Did the crime prevention advertising program raise the target population's level of consciousness to the point where past behavioral patterns were modified? This portion of the evaluation dealt with whether the program had achieved its stated goals.

After the outcome measures were developed attention was then directed at a second question. Did a modification in the potential victim's behavior alter the existing rate of crime being experienced In Dallas? Impact measures were created to test the theory underlying the program.

Evaluation results are summarized below. Detailed discussions of the outcome analysis and impact assessment are contained in Appendices $C$ and $D$, respectively.

\section{Recall of Advertising}

Recall of crime prevention advertising increased significantly over time. Almost 80 per cent of the subjects 
remembered having seen or heard crime prevention advertising after the cessation of the program. This represented a 23 per cent 1ncrease over the pre-campaign level. Changes in recall ranging from 32 per cent to 110 per cent were noted in three communication mediums--television, radio, and news papers.

\section{Attitudinal and Behavioral Changes}

In general, the advertising campaign had a notable effect upon the citizenry of Dallas. As may be seen in Figure 19, alterations in both attitudes and behavior occurred across all socio-economic elements of society. In most cases, the likelthood of implementing the measures increased significantly from the nid to the post survey. A total increase of 16.7 per cent was observed. Furthermore, in any instances, perceived importance also rose.

The crime prevention techniques advanced in the advertising messages may be suminarized into three categories: home security, vehicular security, and personal security. Generally, home and vehicular security elements displayed more change over the program period than did personal security measures.

The target population at which the crime prevention advertising campaign was directed could be termed the entire citizenry of Dallas. However, certain groups incur more risk of being victimized than do others. Dallas 


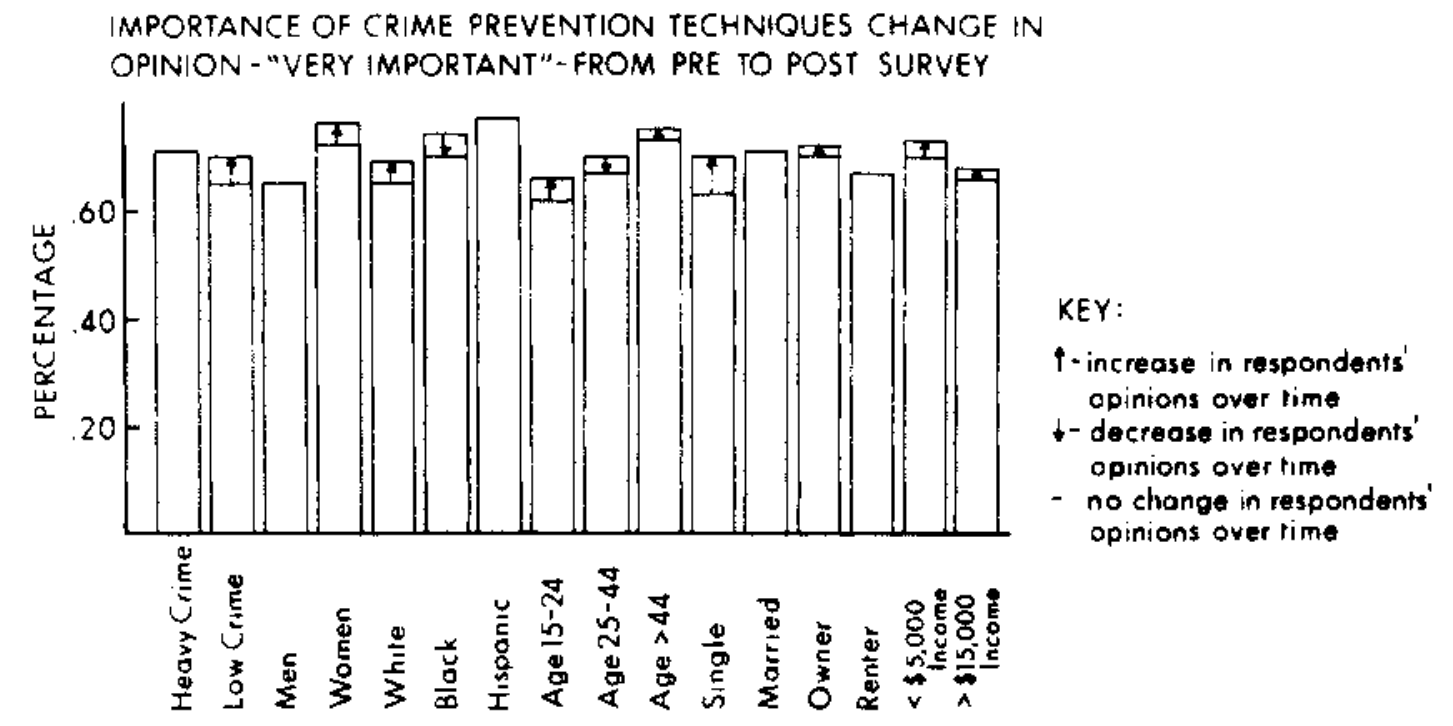

LIKELIHOOD OF IMPLEMENTING CRIME PREVENTION TECHNIQUES

CHANGE IN OPINION - "MORE LIKELY NOW THAN 6 MONTHS AGO"- FROM MID TO POST SURVEY

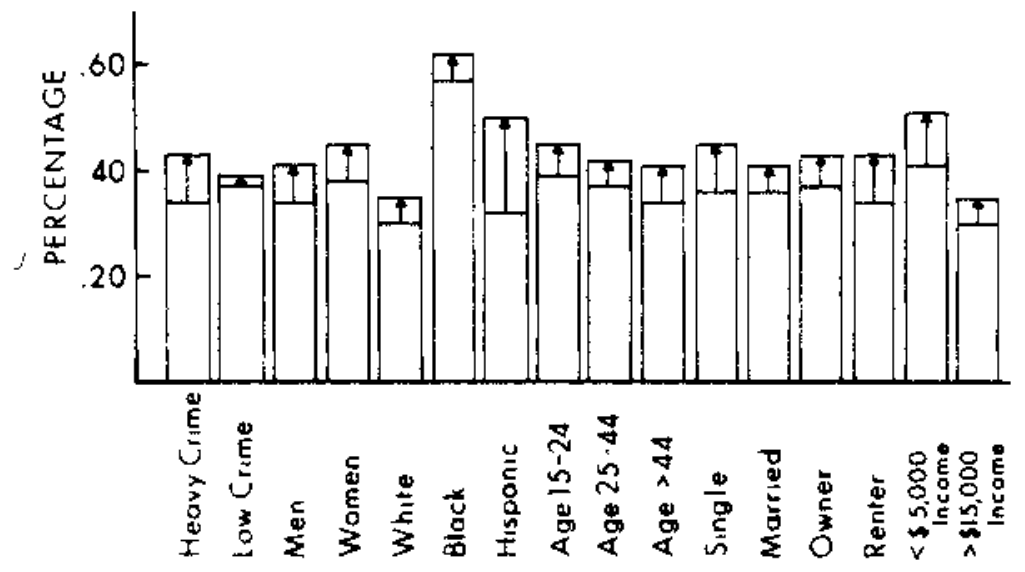

Fig. 19--Summary of Impact of Dallas Crime Prevention Advertising Program upon Citizens' Attitudes 
victimization data for 1974-1975 is contained in Table V.l Men as opposed to women, Blacks as opposed to Whites, the young in contrast to the old, single individuals instead of warried persons, renters as opposed to owners, and in many cases, the very poor and the very rich were more likely to report that they had been recently victimized. Thus, certain socio-economic groups might be expected to receive more potential benefit from the advertising ressages than others. Area Crime Rate.--The program had an impact upon individuals residing in areas experiencing heavy crime. While they reported negligible change in perceived technique importance, they did report significant alceration in thelr actual actions in all three categories. The opposite was true for low crime area residents. They recorded more change in perceived importance than they did in actual implenentation. Thus, where individuals existed in a potentially hostile environment, the progran created an impetus for action. Elsewhere, the ads caused a greater awareness of the severity of the problem and suggested one possible remedy.

Gender.- Women consistently considered preventive techniques more important than did men and reported some greater likelthood of implementation, particularly in the

$1_{U}$.S. Department of Justice, Criminal Victimization Surveys in Eight American Cities, Washington, D.C., 1976. 
TABLE $\mathrm{V}$

DALLAS VICTIMIZATION RATES EOR PERSONS

AGE 12 AND OLDER

1974-1975

\begin{tabular}{|c|c|c|c|c|c|c|}
\hline & Rat & per 100 & 0 Reside & nts & Rate per 1000 & Households \\
\hline & Rape & Robbery & Assault & Theft & Burglary & MV Theft \\
\hline Gender: & & & & & & \\
\hline Male & 0.1 & 19.4 & 48.7 & 129.3 & & \\
\hline Female & 3.0 & 6.3 & 22.1 & 105.5 & & \\
\hline Race: & & & & & & \\
\hline White & 1.3 & 11.3 & 34.6 & 116.7 & 132.5 & 20.8 \\
\hline Black & 2.7 & 15.7 & 33.2 & 116.2 & 250.1 & 31.4 \\
\hline Age: & & & & & & \\
\hline $16-19$ & 5.3 & 19.1 & 79.2 & 175.8 & 247.8 & 41.8 \\
\hline $\begin{array}{l}20-24 \\
25-34\end{array}$ & 3.1 & $\begin{array}{l}14.9 \\
14.3\end{array}$ & $\begin{array}{l}67.5 \\
34.4\end{array}$ & $\begin{array}{l}186.8 \\
149.8\end{array}$ & 189.9 & 32.6 \\
\hline $35-49$ & 0.2 & 8.5 & 22.5 & 103.5 & 195.2 & 25.7 \\
\hline $50-64$ & 0.0 & 6.2 & 8.8 & 61.2 & 127.5 & 18.8 \\
\hline 65 and over & 0.0 & 7.1 & 5.4 & 31.9 & 82.8 & 6.2 \\
\hline Marital Status & & & & & & \\
\hline Single & 3.5 & 20.9 & 64.4 & 162.7 & & \\
\hline Married & 0.6 & 8.2 & 20.1 & 94.5 & & \\
\hline Income: & & & & & & \\
\hline$<3000$ & 3.5 & 17.5 & 35.6 & 83.7 & 186.7 & 13.9 \\
\hline $3000-7499$ & 3.6 & 14.6 & 40.4 & 94.0 & 160.9 & 24.0 \\
\hline $7500-9999$ & 1.4 & 14.6 & 29.2 & 131.4 & 160.5 & 31.0 \\
\hline $10000-14999$ & 1.0 & 10.0 & 38.8 & 123.7 & 144.7 & 25.2 \\
\hline $15000-24999$ & 0.7 & 8.8 & 29.7 & 133.0 & 149.3 & 19.9 \\
\hline$>25000$ & 0.0 & 13.7 & 33.0 & 139.4 & 209.5 & 32.1 \\
\hline Tenure: & & & & & & \\
\hline Owner & & & & & 152.9 & 18.7 \\
\hline Renter & & & & & 169.0 & 28.7 \\
\hline
\end{tabular}


areas of home and personal security. They also experienced both altered perceptions and actions during the campaign. Even though men reported little change in perceived importance, they did indicate a conversion of behavior concerning home and vehicular security over time. This is 1mportant since the victimization study suggested that they were more susceptible to crime than were women. Ethnic Group.--In general, non-whites expressed the opinion that crime preventive techniques were much more important than did whites. However, Whites recorded significant changes in their perceptions of the importance of home and vehicular security techniques in preventing crime. Blacks actually experienced a decline in attitudes. A significantly larger number of Blacks indicated that they had recently changed their behavioral patterns and were more likely now to utilize crime prevention measures. However, rarely did their opinions alter over time. Hispanles consistenty in all three areas indicated behavioral changes over time and their recorded increases were quite dramatic. Age---older individuals were apt to consider all security measures to be very important. They also experienced more changes in their perceptions over time than did younger subjects, particularly in the home security area. The campaign had less impact upon individuals grouped according to age in the areas of vehicular or 
personal safety. Earlier attitudes and behavior persisted throughout the period under study.

The young are more apt to be victimized. However, the advertising campign failed to reach this segment of the population to any significant degree. In several instances, individuals aged $15-24$ reported some attitudinal changes during the first half of the program; however, decay occurred after that point.

Marical Status.--With one exception, little difference was displayed between married and single respondents concerning either their perceptions of the importance of security measures or their purported likelihood of implementing such techniques. Married individuals considered personal security measures more important than did single persons.

Nevertheless, singles reported numerous changes in attitudes and significant behavioral modification during the period of the advertising campaign. Thus, there is indication that the program impacted that segment of the target population at risk.

Tenure.--In the home and personal security areas, home owners were more likely to consider security measures very important. No differences were noted in vehicular security. Renters displayed some temporary increases in awareness of the importance of home security techniques. Then attitudes decayed to former levels. Nevertheless, non-homeowners 
reported numerous changes over time in the likelihood of implementing security measures to protect their home and car. These reported alterations were of sizeable magnitude. Thus the ad campaign is again associated with the conversion of attitudes into actions in a target population.

Income.--Major crimes impact people of varying economic means differently. The poor are more likely to be victims of robbery and rape and the rich are more susceptible to larceny, burglary, and motor vehicle theft. Generally, the poor perceived of security measures as being more important than did the rich. However, persons in the upper income bracket experienced attitudinal changes of a permanent nature in the home security area and indicated an increased likelihood of implementing vehicular security measures.

In contrast, individuals with incomes under $\$ 5,000$ reported some attitudinal changes over time in the vehicular and personal security areas, but little behavioral alteration. The opposite was true in home security. Significant behavioral changes were indicated here by the poor.

Conclusion.--The Dallas crime prevention advertising program had a slight impact upon citizens' attitudes concerning the importance of utilizing simple measures to prevent crime against their persons, their homes, and their 
property. This was particularly true for those segments of the population less likely to be victinized.

More importantly, however, with the possible exception of Blacks and the young, the survey results indicated that the advertising campaign spurred the target population at risk into action. Such measures were being utilized throughout the populace in greater numbers at the conclusion of the program than before.

\section{Impact Assessment}

To determine whether the modification of the target population's behavior altered the reported lincidences of major crime in Dallas, an interrupted time series analysis was conducted on seven categories of crime: murder, rape, assault, burglary, auto theft, larceny, and robbery. First, a model of the stochastic process evident in each time series was bult. These ARIMA models comprise the noise $\left(N_{t}\right)$ component of the equation:

$5.1 \quad Y_{t}=f\left(I_{t}\right)+N t$

Then, by adding an intervention component to these stochastic ARIMA models, the impact of the crime prevention advertising program upon reported incidences of major crime in Dallas was assessed. Table VI provides a sumary of the seven stochastic models and Table VII contains data pertaining to the program impact findings. 


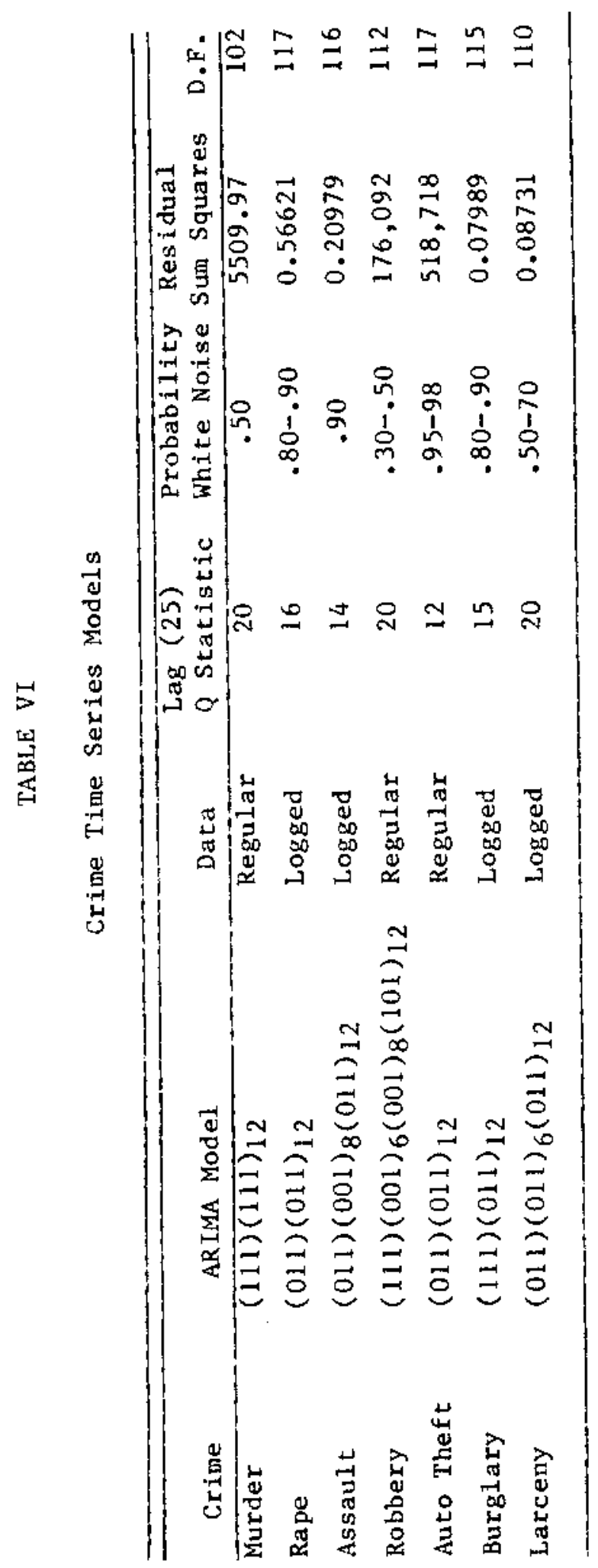


TABLE VII

Crime Prevention Advertising Program Impact

\begin{tabular}{lcccccc}
\hline Crime & $\begin{array}{c}\text { Impact } \\
\text { (Month) }\end{array}$ & T-Value & $\begin{array}{c}\text { Signi- } \\
\text { ficance }\end{array}$ & $\begin{array}{c}\text { Change } \\
\text { RSS }\end{array}$ & F-Ratio & $\begin{array}{c}\text { Signi- } \\
\text { ficance }\end{array}$ \\
\hline Murder* & & & & & & \\
Rape & -8 & -2.54 & $<.05$ & $-4.3 \%$ & 5.21 & $<.05$ \\
Assault & -22 & -1.34 & .10 & $-1.4 \%$ & 1.68 & .25 \\
Robbery & -50 & -1.76 & .05 & $-3.4 \%$ & 1.93 & .25 \\
Auto Theft & -78 & -1.31 & .10 & $-1.0 \%$ & 1.13 & .25 \\
Burglary & -85 & -1.64 & .10 & $-3.4 \%$ & 4.06 & .05 \\
Larceny & -175 & -1.97 & .05 & $-3.3 \%$ & 2.10 & .10 \\
\end{tabular}

${ }^{*}$ Not signfficant at .10 level of probability 
Murder.--The intervention estimate of -4.9 was not significant at the .10 level of probabiltty for a one-tail test. Therefore, the crime prevention program had no impact upon murder. This, however, was not surprising. Many murders are acts of violence cominited while the actors are under extreme emotional stress. Once this chain of events has started, little could probably be done by the victim to alter the ultimate outcome.

Rape--Survey results indicated that women were quite receptive to the advertising campaign. They repeatediy indicated that these measures were an important means of reducing crime and that they had recently altered their own behavior. This is confirmed in the one time series analysis which impacts solely women.

The introduction of the intervention estimate into the rape time series caused a significant decline in unexplained model variance. The intervention estimate was also statistically significant at the .0l level of probability for a one-tail test. The crime prevention advertising program was associated a 11.26 per cent abrupt and permanent decline in reported rapes. This represents a reduction of approximately eight rapes per month.

Assault.--In many instances, the victim of an assaut is acquainted with the perpetrator of the crime. The advertising campaign was directed at reducing stranger-to-stranger crimes. Thus, one would not anticipate 
a significant decline in the number of reported assauls during the period under investigation. The intervention parameter estimate of .049 was significant only at the .10 level for a one-tail test. This equates to approximately twenty-two fewer assaults per month. The .003023 decline in the residual sum of squares from .209794 to. 206771 was also not particularly large. It is only significant at the .25 level of probability. Perhaps, if stranger-to-stranger assaults could have been analyzed separately, more significant results could have been obtained.

Robbery.--The intervention parameter of -49.7 was statistically significant at a .05 level of probability for a one-tail test. The decline in the residual sum of squares with a loss of two degrees of freedom was 5955. This resulted in a calculated F Ratio that was only significant at the .25 level of probability.

The second degree of freedom lost in the intervention estimation was the parameter for the mean of the differenced series. It accounted for a 2929 reduction in the unexplained variance. The intervention variable was responsible for the remainder of the decline. Analyzed separately, the intrusion continued to not account for a statistically significant reduction in the residual sum of squares $(F=2.60)$. However, the model was accepted as written. The crime prevention advertising program was 
associated with an abrupt and permanent decline of fifty robberies per month.

Auto Theft.--The advertising campaign was associated with a slight change in the number of reported auto thefts. The intervention parameter of -78 was statistically significant at the .10 level of probability for a one-tail test. However, again there was only a minimal reduction in the unexplained variance.

While individuals residing in heavy crime areas Indicated that they had altered their vehicular security behavior, perhaps they were not necessarily the population at risk in this instance. According to victimization records, the very poor and the very rich were more likely to be the victim of an automobile theft than others. Study results indicated that the poor did not alter their behavior in this area and the rich showed only a slight conversion of attitudes 1 nto actions.

Burglary.--The intervention estimate, with a t-value of 1.64 , was significant at the .10 level of probability for a one-tail test. The tabulated $t$ at the .05 level of probability is 1.658 . The decline in unexplained variance of .002748 was significant at the .05 level of probability. These results suggest that a 3.9 per cent abrupt and permanent decline occurred in reported burglaries when the program was implemented. Outcome survey results had suggested that individuals in numerous socio-economic groups 
had altered their behavior to improve the security of their abodes. These data confirm that supposition. Larceny.-A second event, in addition to the advertising campaign impacted the larceny time series. Civilan band radios experienced an explosion in popularity in the thid 1970s. As they gained consumer approval, there was a concomitant increase in their theft. The fad created a 20.2 per cent gradual, but permanent increase in reported thefts. On the other hand, the advertising campaign was associated with a 4.5 per cent abrupt and permanent decline. This amounted to a reduction in reported larcencies of 175 per month.

Conclusion.--The crime prevention advertising program was associated with an abrupt and permanent reduction in major crime in Dallas. Rape, Robbery, Burglary and Larceny were particularly impacted. Thus, alteratton of a potential victim's pattern of behavior through repeated advertising resulted in less situations arising where a potential criminal located a suitable target and consunated the illegal act. Table VIII contains a sumary of the efforts and accomplishments of the Dallas crime prevention advertising program.

\section{Lab Experiment}

The results of the quasi-experiment were utilized in a laboratory experiment to determine whether the inclusion of 


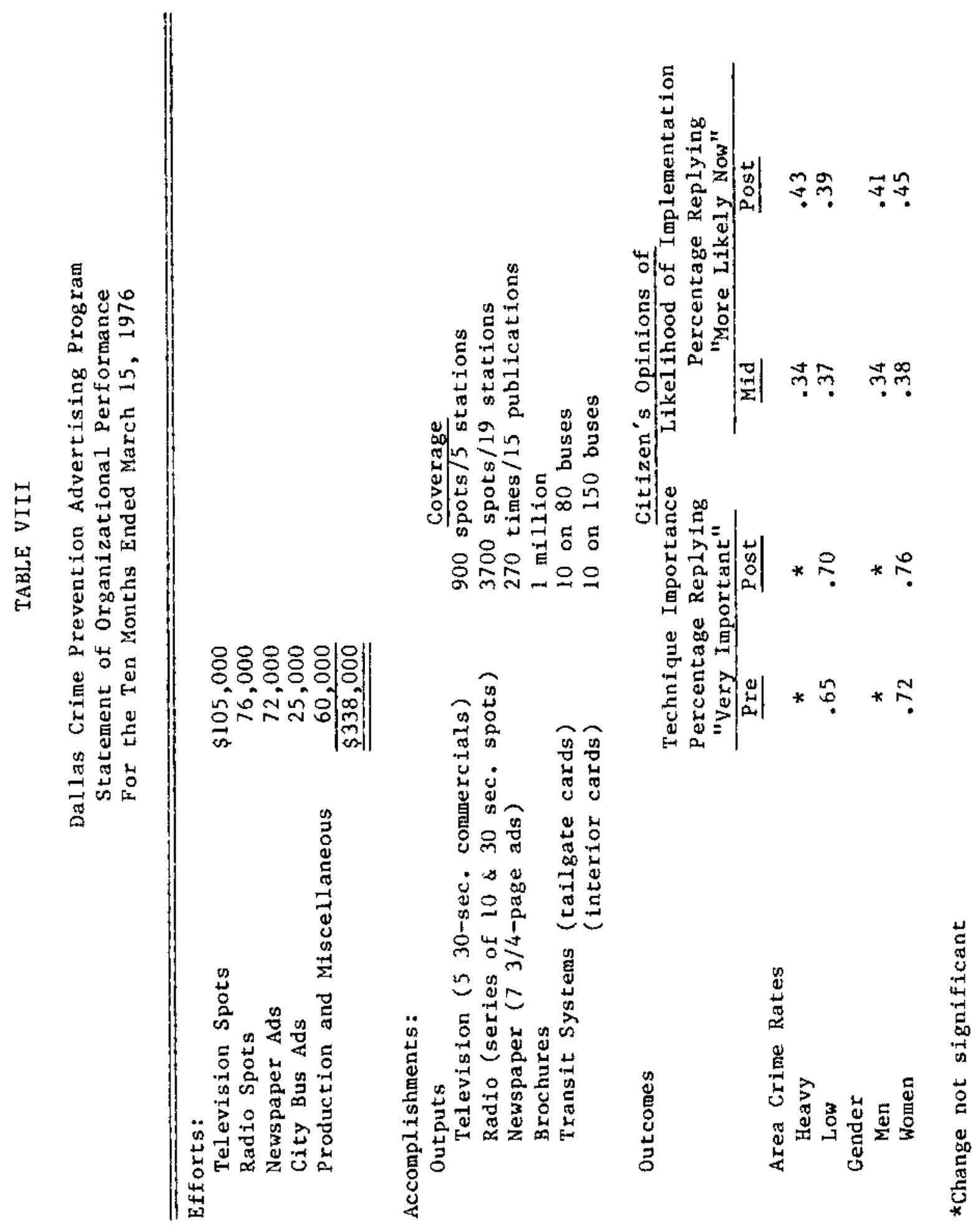




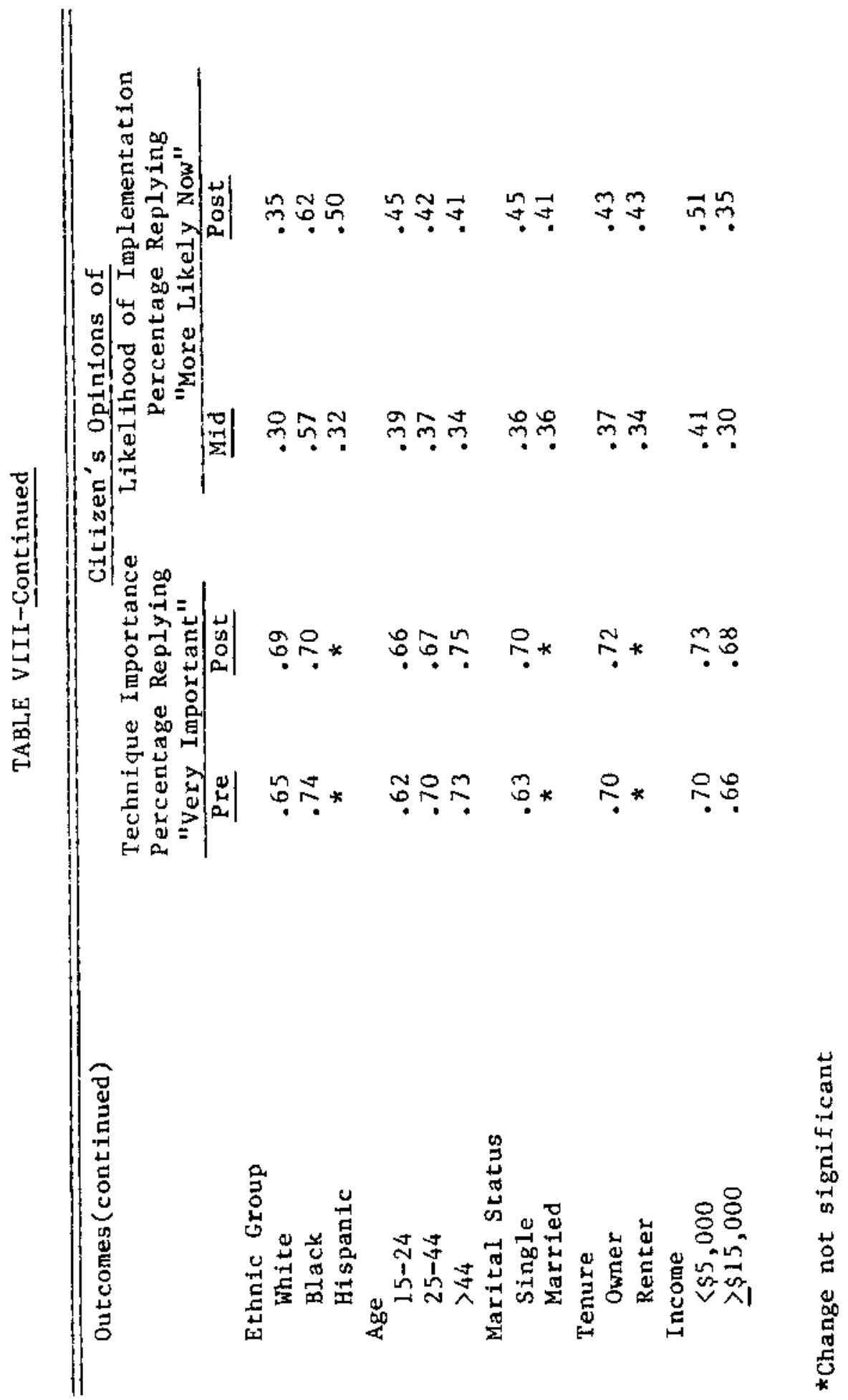




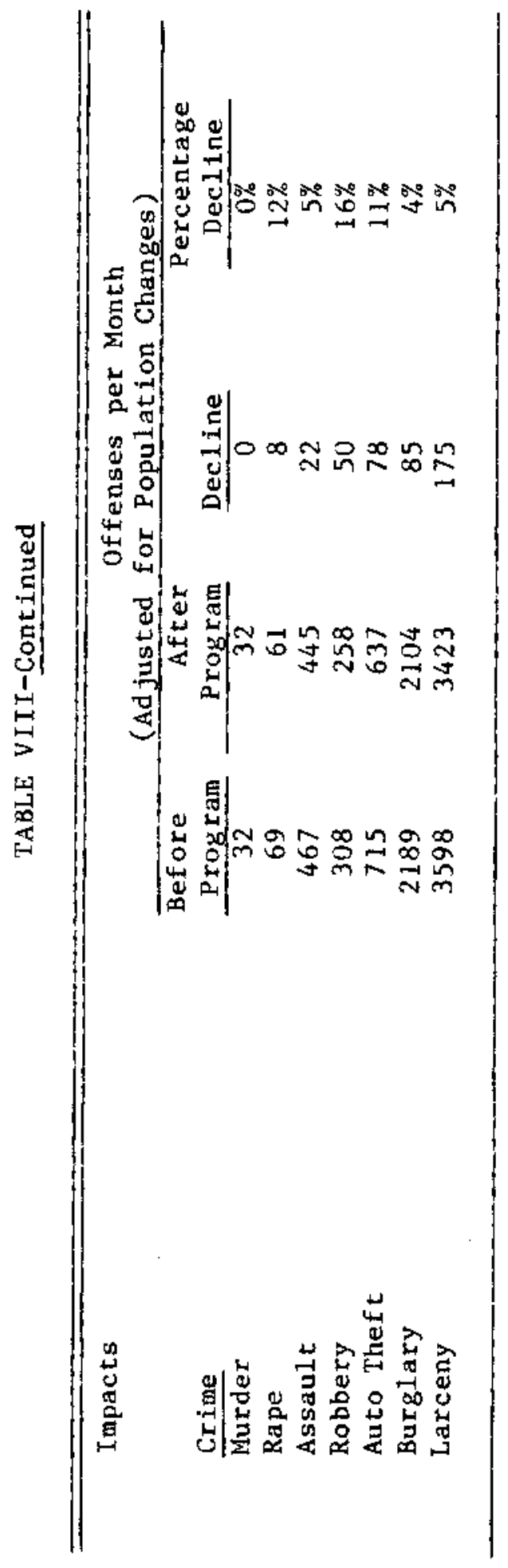


performance measures in a budget request document would reduce decision maker's uncertainty about past program effectiveness and alter their resultant budgeting decisions. Five research hypotheses were investigated. The first two dealt with the informational content of performance cues and the remaining three with the impact of these measures upon budgetary decisions. Each hypothesis is discussed below.

\section{Informational Content of Cues}

\section{Nu11 Hypotheses.--The experimental subjects were}

provided two statements pertaining to the past effectiveness of the crime prevention program in altering citizen behavior and reducing the growing trend of crime. They were asked to indicate simulataneousiy their level of agreement with each statement and their degree of certainty in their response. They utilized the following measurement scale.

1. certain statement incorrect

2. reasonably certain statement incorrect

3. somewhat certain statement incorrect

4. uncertain whether statement correct or incorrect

5. somewhat certain statement correct

6. reasonably certain statement correct

7. certain statement correct

Each subject thus provided an Indication of their perception of program outcome effectiveness (Eoutcome) and program 1mpact effectiveness ( $E_{\text {impact }}$ ). It was hypothesized 
that as additional cues were provided to subjects, uncertainty would be reduced. According to the model specified, information reduces uncertainty. Therefore, the extent of uncertafnty reduction determines the informational content or value of a particular cue.

To ascertain if a relationship existed between the presence of effectiveness cues and uncertainty reduction, the following hypotheses were tested.

$$
\begin{aligned}
& \mathrm{H}_{0}: \mathrm{E}_{\mathbf{i}} \leq 0 \\
& \mathrm{H}_{1}: \mathrm{E}_{\mathbf{i}}>0
\end{aligned}
$$

Statistical Tests.--Hierarchial regression analysis was employed to test the hypotheses. The general model that estimates the relationship between uncertainty reduction and the controlling and experimental variables is

$5.2 E_{i}=a_{i}+b_{l} x_{1 i}+b_{2} x_{2 i}+\ldots+b_{n} x_{n i}+e_{i}$ where:

$E_{i}=$ outcome or impact uncertainty reduction

$a_{1}=$ the regression constant

$b_{1} \ldots b_{n}=$ the regression coefficients that estimate the relationship between the individual independent variables and the dependent variable

$\mathrm{x}_{1 \mathrm{i}} \ldots \mathrm{x}_{\mathrm{n} i}=$ the controlling and experimental variables

$e_{i}=$ the portion of the uncertainty reduction variance not explained by the model

Since a reply of four in the research instrument indicated complete uncertainty pertaining to past effectiveness, a numerical response in either direction from 
the center suggested uncertainty reduction and the possible presence of information. The numerical values for the dependent variables $E_{1}$ and $E_{2}$ were created in the following fashion.

Successful Cases Failed Cases

$\mathrm{E}_{1}$

$$
\text { Eoutcome }-4
$$$$
4-E_{\text {out come }}
$$

$\mathrm{E}_{2}$

EImpact -4

$4-E_{\text {Impact }}$

In all cases, if the resultant computed value was positive, the uncertainty reduction was considered information. If the sign was negative, misinformation had been conveyed. significant independent variables were entered in a preordained order. Potential controlling variables lucluded the subject's gender (SEX), age (AGE), education (SCHOOL), job ( $I O B)$, and work experience (WORK); plus, their opinion concerning the severity of the crime problem in their own locality (CRIME). Experimental variables were only entered after the effect of all controlling variables had been partialled out.

Contrast coding was employed to ascertain the degree of association between the presence of effectiveness cues and the reduction of uncertainty. One experimental variable (CON1) contrasted the control case containing one cue with the cases that contained two cues. The second variable (CON2) contrasted the control case with the three-cue cases. The experimental variable CoNl was entered into the model 
first so that the incremental affect of adding the impact cue could be ascertained.

Several slgnificance tests were performed to test whether there was an association between uncertainty reduction and the cues. The F-test was utilized for the complete model and t-tests were used to determine the significance of each regression coefficient contained therein. Furthermore, analysis was conducted to ascertain the incremental impact of each independent variable as it entered the equation and to determine its direct or indirect Impact upon the dependent variable.

$$
\text { Analysis.--Table IX presents the correlation }
$$
coefficients between $E_{i}$ and $e a c h$ independent variable. Since occupation was not correlated with a subject's degree of uncertainty reduction, it was assumed that all experiment subjects formed a common pool. Gender was marginally correlated with both dependent variables and crime proved to be quite significant. Without controlling for any other variables, the subjects' perception of crime problems in their own environment explained 6.9 per cent of the variance in outcome uncertainty reduction and 6.7 per cent of the impact uncertainty reduction variance. The experimental variable con 2 which contrasted the control group subjects with those receiving three cues displayed the greatest potential explanatory power. It accounted for 24.4 per cent and 28.9 per cent of the variance in the outcome and impact 
TABLE IX

CORRELATION COEFFICIENTS BETWEEN UNCERTAINTY REDUCTION AND INDEPENDENT VARIABLES

\begin{tabular}{|c|c|c|c|c|}
\hline Variable & Correlat $\frac{E_{1}}{i o n}$ & $\frac{\text { with }}{\text { Significance }}$ & Correlat $\frac{E_{2}}{i o n}$ & $\frac{\text { with }}{\text { Significance }}$ \\
\hline Sex & .14426 & .08746 & .14415 & .08762 \\
\hline Age & .17238 & .05211 & .12834 & .11400 \\
\hline School & -.07326 & .24630 & -.07423 & .24344 \\
\hline Job & -.03130 & .38482 & -.07059 & .25427 \\
\hline Work & .09946 & .17549 & .20298 & .02751 \\
\hline Crime & -.26246 & .00623 & -.25882 & .00689 \\
\hline CONl & .22040 & .01843 & -.04132 & .34949 \\
\hline CON2 & .49346 & .00000 & .53719 & .00000 \\
\hline
\end{tabular}


dependent variables, respectively. The other experimental variable CONi was only significant for the outcome model. This was not unexpected, since no data pertaining to past program impacts was provided to the subjects in the two-cue cases.

The complete regression models employed in the analysis were as follows:

$5.3 \mathrm{E}_{1}=a+\mathrm{b}_{1} \mathrm{SEX}+\mathrm{b}_{2} \mathrm{CRIME}+\mathrm{b}_{3} \mathrm{CON} 1+\mathrm{b}_{4} \mathrm{CON} 2+\mathrm{e}$ $5.4 E_{2}=a+b_{1} S E X+b_{2}$ WORK $+b_{3} \operatorname{CRIME}+b_{4} \operatorname{CON} 2+e$ Summary data on these models is contained in Table $X$. Each model expla1ned over 30 per cent of the total vartance in uncertainty reduction, and both were statistically significant. With the exception of CONl in the first model and WORK in the second, all regression coefficients in the final equations were at least marginally statistically significant. In both instances, these coefficients dropped noticeably when $\operatorname{CON} 2$ entered the equation.

The direct and indirect effects of each variable on uncertainty reduction, plus all spurious relationships are sumarized in Table XI. Most of the gender and crime attitudes effect was direct and not mediated by any of the measured varlables. In both models, after partialling out the effect of other variables, men's uncertainty was reducedby .60 on a scale of $0-3$, or 20 per cent, more than women's. Eurthermore, those subjects who perceived crime in their own city as greatly increasing, showed greater certainty in 


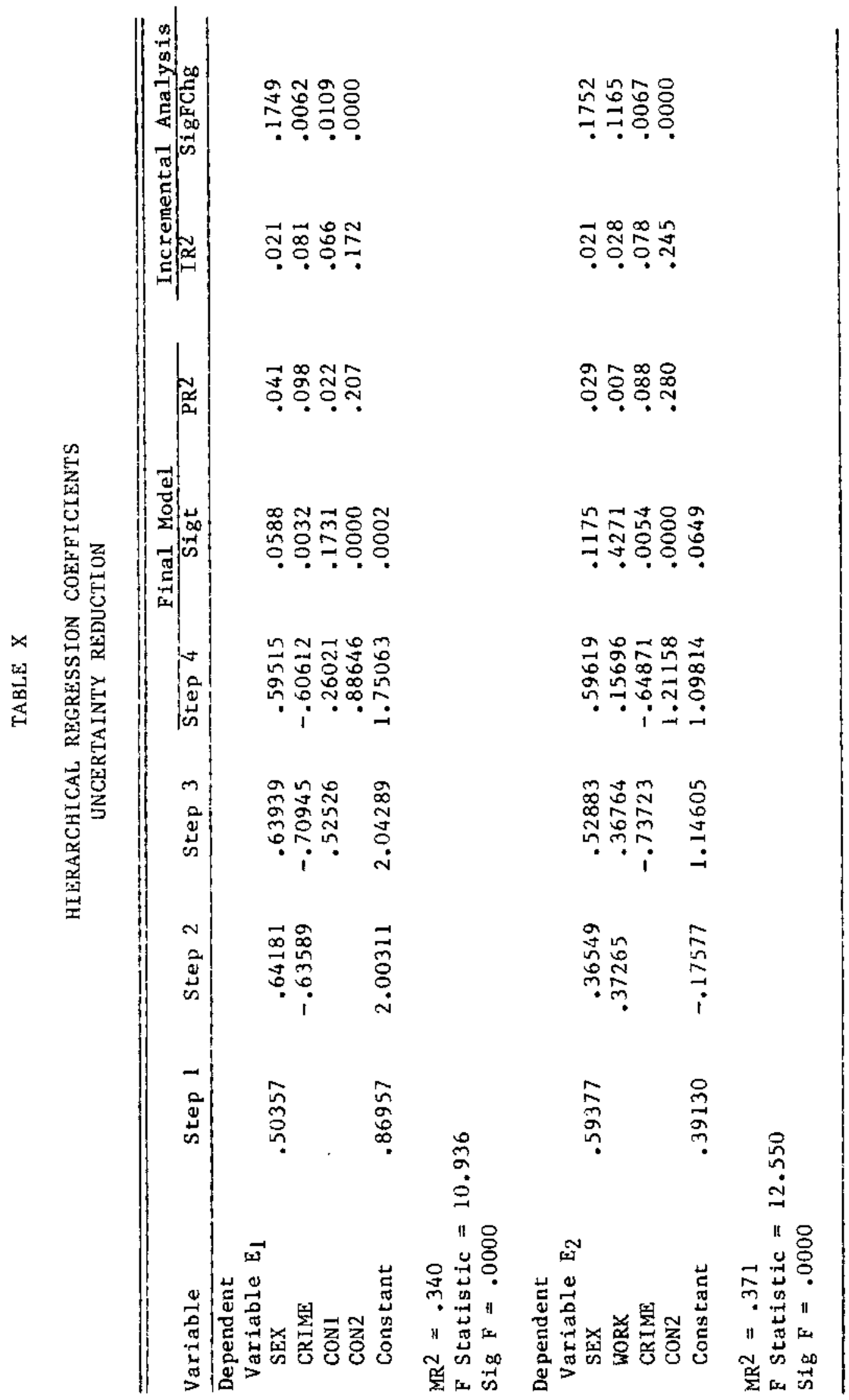


TABLE XI

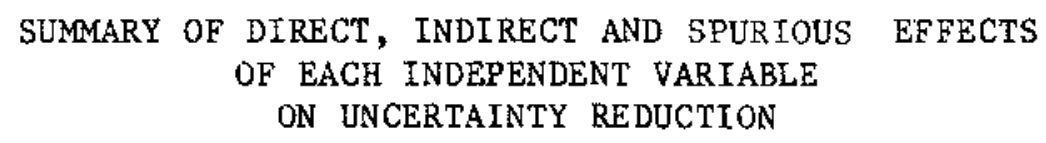

\begin{tabular}{|c|c|c|c|c|c|}
\hline Variable & $\begin{array}{l}\text { Zero-order } \\
B\end{array}$ & Spurious & Direct & Indirect & Tota 1 \\
\hline \multicolumn{6}{|c|}{ Outcome Effectiveness: } \\
\hline \multicolumn{6}{|c|}{ Sex } \\
\hline $\begin{array}{l}\text { via Crime } \\
\text { via CoN } 1\end{array}$ & & & & $\begin{array}{r}-.13824 \\
.00242\end{array}$ & \\
\hline via CON2 & .50357 & - & .59515 & $=.04424$ & .50357 \\
\hline \multicolumn{6}{|l|}{ Crime } \\
\hline via CON 1 & & & & .07356 & \\
\hline via CON2 & -.57997 & .05592 & -.60612 & $=. .10333$ & -.63589 \\
\hline \multicolumn{6}{|l|}{ CON1 } \\
\hline via CON2 & .44841 & -.07685 & .26021 & .26505 & .52526 \\
\hline CON2 & 1.00397 & .11751 & .88646 & & .88646 \\
\hline \multicolumn{6}{|c|}{$\begin{array}{l}\text { Impact Effectiveness: } \\
\text { Sex }\end{array}$} \\
\hline $\begin{array}{ll}\text { via } & \text { Work } \\
\text { via } & \text { Crime } \\
\text { via } & \text { CON2 }\end{array}$ & & & & $\begin{array}{r}.22828 \\
-.16334 \\
-.06736\end{array}$ & \\
\hline & .59377 & - & .59619 & $=.0024 \overline{2}$ & .59377 \\
\hline $\begin{array}{l}\text { Work } \\
\text { via Crime } \\
\text { via CON2 }\end{array}$ & & & & $\begin{array}{r}.00501 \\
.21068 \\
\end{array}$ & \\
\hline & .43259 & .05994 & .15696 & .21569 & .37265 \\
\hline Crime & & & & & \\
\hline $\begin{array}{l}\text { via } \operatorname{CON} 2 \\
\text { CON2 }\end{array}$ & $\begin{array}{l}-.67490 \\
1.28968\end{array}$ & $\begin{array}{l}.06233 \\
.07810\end{array}$ & $\begin{array}{l}-.64871 \\
1.21158\end{array}$ & -.08852 & $\begin{array}{r}-.73723 \\
1.21158\end{array}$ \\
\hline
\end{tabular}


progam outcomes of .61 (20 per cent) and program impacts of . 65 (22 per cent) than did individuals who thought crime was only moderately increasing.

Work produced a total effect of .37 ( 13 per cent) in increased impact certainty. Less than one-half of this was direct, the remainder was due mainly to the affect of this variable upon the experimental intrusion. People with more work experience displayed greater certainty regarding the measures of past effectiveness than did others.

The experimental cue intrusion had a significant direct effect upon uncertainty reduction in both instances. In the outcome model, subjects who reviewed the experimental cases containing two cues recorded 1.05 (or 30 per cent) greater certainty pertaining to outcome effectiveness than did those individuals who received the control case. Approximately one-half of this effect was direct and the remainder was mediated by the subsequent inclusion of the third cue. It contained impact information and evidently served as confirmatory evidence.

The cue that provided program impact data had the greatest effect upon both mode1s. Individuals who received all three cues displayed 1.77 greater assurance $(55.4$ per cent) in past program outcomes and 2.42 increased certainty (60.7 per cent) of program impacts than did those 
who reviewed the control case. This variable accounted for 20.7 and 28.0 per cent of the variance in $E_{l}$ and $E_{2}$, respectively, after the effect of all other variables had been removed.

Table XII contains estinations of the experimental results obtained from the final models. Misinformation was present in the control case, particularly pertaining to past program impacts. Control subjects drew erroneous conclusions from the incomplete data that was provided them. on the average, however, subjects who received outcome measures indicated that they were somewhat certain as to the effectiveness of the program in achieving its stated goals, and those who reviewed cases containing all cues indicated that they were reasonably certain as to both the outcome and impact of their program.

TABLE XII

ESTIMATION OF EXPERIMENTAL RESULTS UNCERTAINTY REDUCTION

\begin{tabular}{lcc}
\hline & Outcome Model & Inpact Model \\
\hline Control Case & -.13155 & -.62049 \\
Two Cues & 1.27533 & - \\
Three Cues & 1.90158 & 1.80267 \\
& & \\
\hline
\end{tabular}


Conclusion.--The nuli hypotheses were rejected. The provision of outcome and impact cues reduced uncertainty in decision makers about the effectiveness of past program outcomes and impacts. Outcome cues altered perceptions to a much lesser extent than did impact cues. Thus data pertaining particularly to the impact of a program upon soctety does produce information that aids ju the rational assessment of past program effectiveness. However, subjective perceptions, not under the control of the budget preparer, also affected the decision making process. While cues can increase rational decision making, these irrational factors cause decision makers to view similar data differently and this alters their ultimate conclusion.

\section{Budget Variance}

Nuli Hypotheses.--Each subject was given one budget request proposal to review and to decide at what level the package would be funded. It was hypothesized that as cue availability increased, budget variance among the decision makers would decline. Table XIII summarized the amounts budgeted by each experimental group.

Two null hypotheses were posited. One dealt with the cases containing successful past performance and the other pertained to the failed programs. To ascertain if a relationship existed between the presence of cues and the reduction of variance in the cases containing indications of 
TABLE XIII

\section{DESCRIPTIVE STATISTICS - EXPERIMENT}

\begin{tabular}{lccccc}
\hline Case & $\begin{array}{l}\text { Number of } \\
\text { Subjects }\end{array}$ & Mean & Medium & Mode & $\begin{array}{l}\text { Variance } \\
\text { (billion) }\end{array}$ \\
\hline Control & 18 & 218,772 & 275,000 & 0 & 3.228 \\
Success-2 Cues & 18 & 250,556 & 329,950 & 0 & 3.065 \\
Success-3 Cues & 18 & 329,139 & 350,000 & 350,000 & .604 \\
Failure-2 Cues & 18 & 120,222 & 75,000 & 0 & 2.205 \\
Failure-3 Cues & 18 & 89,478 & 0 & 0 & 2.475 \\
& & & & & \\
\hline
\end{tabular}

past successful performance, the following hypothesis based

upon the F-statistic was tested.

$$
\begin{aligned}
& \mathrm{H}_{\mathrm{o}}: \frac{\sigma_{\mathrm{C}}^{2} \leq 1}{\sigma_{\mathrm{S} i}^{2}} \leq 1 \\
& \mathrm{H}_{\mathrm{i}}: \frac{\sigma_{\mathrm{C}}^{2}}{\sigma_{\mathrm{S} i}^{2}}>1
\end{aligned}
$$

The null hypothesis would be rejected if the calculated $F \rightarrow$ statistic was greater than the tabulated $F$ where $n_{1}-1=$ $17, \mathrm{n}_{2}-1=17$ and $\mathrm{a}=.05$.

Variance in the Failure-Three Cue case increased while the mean declined. This was due to the fact that those subjects who chose to fund this program did so at relatively high levels. The mean of the five funded cases was 322,120 . Therefore, large variance resulted.

It has been theorized that cues would create greater predictability in the resultant budgetary dectsions. Reduction in variance was deemed an appropriate surrogate for increased predictability. In this instance, however, a 
significant increase in the number of no-fund decisions would signify greater predictability. Thus, the binomial distribution with only two posstble variable outcomes--fund or not fund--was utilized. The hypothesis was

$$
\begin{aligned}
& \mathrm{H}_{0}: \mathrm{p}_{1}=\mathrm{p}_{2}=.5 \\
& \mathrm{H}_{1}: \mathrm{p} 1<\mathrm{p}_{2}
\end{aligned}
$$

where $p_{1}=$ fund

$$
\mathrm{p}_{2}=\text { not fund }
$$

The null hypothesis states that there is no difference between the probability of funding or not funding. The alternate hypothesis asserts that there will be fewer funding decisions than not funding. Analysis.--The calculated $F$ for the Three Cue-Successful case was 5.3417 . It falls within the rejection region and thus the null hypothesis was rejected. The calculated $F$ for the Two Cue-Successful case was only 1.05. Therefore, in this instance the null hypothesis could not be rejected. There was no statistically significant difference between the variance obtalned from budgeting decisions derived from data containfng output and outcome measures and those produced from the control cases.

In the binomial test of the Three Cuem-Failure case, the probability of obtaining five or fewer fundings in eighteen cases was .048 . Since this was less than a $=.05$, the null hypothesis was rejected. The statistical test for the failed-two cue sample failed to reject the null hypothesis. 
Conclusion.--Greater predictability in budgetary decisions was achieved by providing three cues pertaining to past program outputs, outcomes and impacts. Significantly less variance was noted anong decision makers reviewing successful cases and more norfunding decisions were made by subjects examining failed programs. The inclusion of only output and outcome cues did not achieve similar results. The critical cue, therefore, was the measure of the impact of a particular program upon society.

\section{Budget Change}

Nu11 Hypothesis.--As additional cues are provided to deciston makers concerning past program effectiveness, the resultant approved budget should move toward the maximum requested for a successful program and toward zero for a program that failed. To ascertain whether significant differences existed in the budgeted means for the various cases, the following two hypotheses were formulated.

Successful Experiment:

$$
\begin{aligned}
& \mathrm{H}_{0}: \overline{\mathrm{X}}_{\mathrm{esi}}-\overline{\mathrm{X}}_{\mathrm{c}} \leq 0 \\
& \mathrm{H}_{\mathrm{i}}: \overline{\mathrm{X}}_{\mathrm{esi}}-\overline{\mathrm{X}}_{\mathrm{c}}>0 \\
& \text { Failure Experiment: } \\
& \mathrm{H}_{\mathrm{o}}: \overline{\mathrm{X}}_{\mathrm{c}}-\overline{\mathrm{X}}_{\mathrm{f} i \mathrm{i}} \leq 0 \\
& \mathrm{H}_{\mathrm{i}}: \overline{\mathrm{X}}_{\mathrm{c}}-\overline{\mathrm{X}}_{\mathrm{f} i}>0
\end{aligned}
$$


Statistical Tests.--Several statistical tests were performed. First, the parametric z-test was utilized. If the null hypothesis is true, then the calculated $z$ statistic will be less than the tabulated $z$ of 1.69 , where $a=.05$ and $\mathrm{n}=36$. The non-parametric Mann-Whitney $\mathrm{U}$ Test for means was also employed to provide additional evidence about the mean differences. It considers only the rank value of each observation, not the actual budgeted amount. Finally, hierarchial regression analysis was performed to test the hypotheses.

Two regression models were created for each experiment. The first postulated that an individual's perceptions of past program effectiveness were a function of the number of cues contained in the budget package under review. The second model stated that budget decislons were a function of the decision maker's perception of past program effectiveness. Thus

5.5 AVGEFF $=f($ control variables + Cues $)$

5.6 BUDGET $=f($ control variables + AVGEFF $)$

The numerical values for effectivenss perceptions (AVGEFF) were generated by averaging each subject's responses to the three effectiveness statements contained in the research instrument. The independent control and experimental variables were identical to those utilized in testing the uncertainty reduction hypotheses. The 


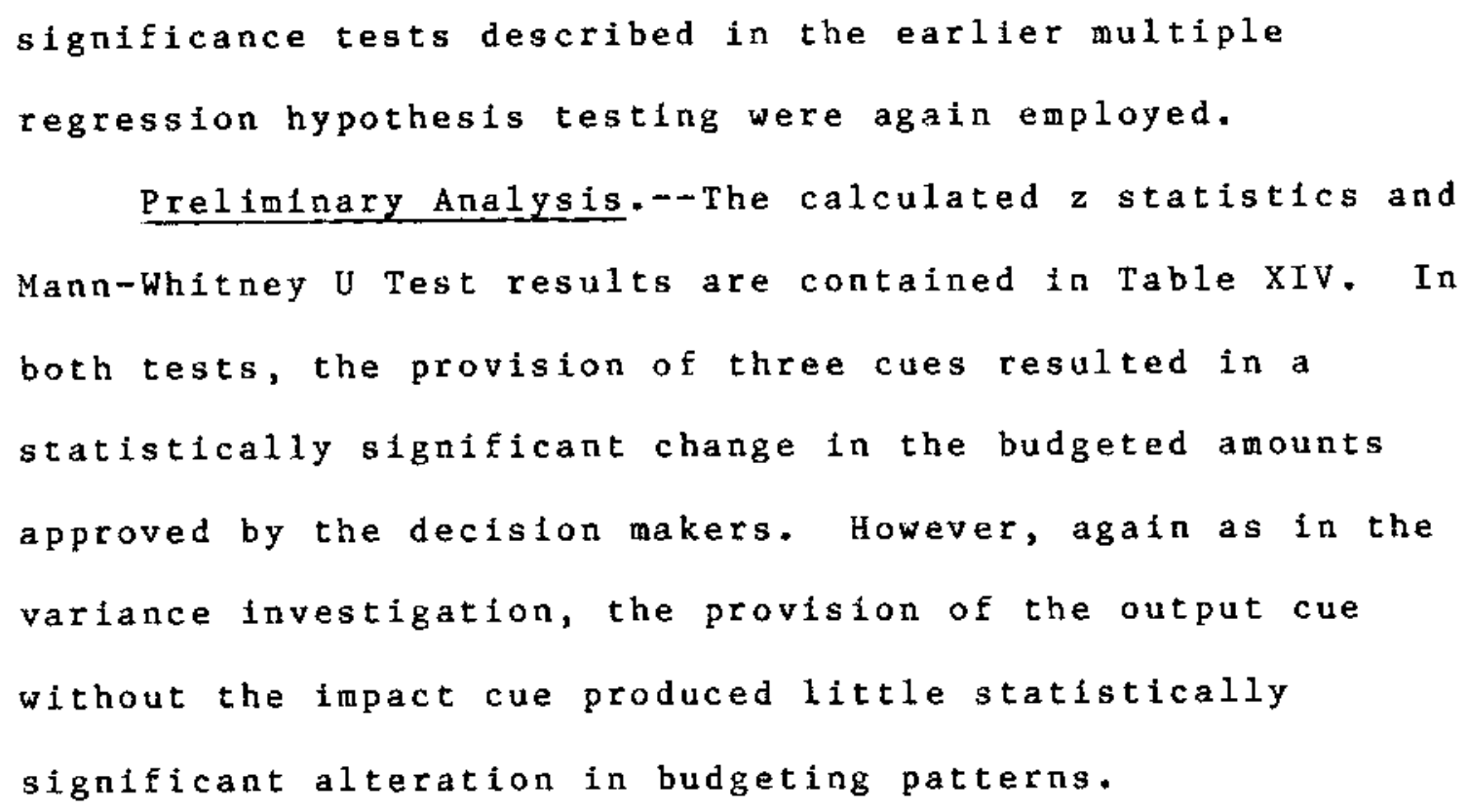

\begin{tabular}{lcc}
\hline & $\begin{array}{c}\text { Calculated } \\
\text { Comparison of Control with: }\end{array}$ & $\begin{array}{c}\text { Mann-Whitney } \\
\text { Calculated Z }\end{array}$ \\
Two Cue - Successful & .54 & .67 \\
Three Cue - Successful & $2.39^{*}$ & $1.65^{*}$ \\
Two Cue - Failure & $1.79^{*}$ & 1.36 \\
Three Cue - Failure & $2.30^{*}$ & $2.29^{*}$ \\
\hline
\end{tabular}

Re ject null hypothes is

Some interesting associations were observed in the zero-order correlations contained in Table XV. The two controlling variables SEX and CRIME that produced a significant impact upon uncertainty reduction did not display uniform associations in both experiments. Gender exhibited no correlation with either the perceived 
TABLE XV

CORRELATION COEFFICIENTS BETWEEN THE DEPENDENT AND INDEPENDENT VARIABLES

\begin{tabular}{lcccc}
\hline & \multicolumn{2}{c}{ Success } & & Failure \\
& Correlation Significance & Correlation Significance \\
\hline $\begin{array}{l}\text { Avgeff with: } \\
\text { Sex }\end{array}$ & .00861 & .47536 & -.20280 & .07068 \\
Age & .11558 & .20262 & -.28741 & .01755 \\
Schoo1 & -.14566 & .14665 & -.07225 & .30183 \\
Job & -.12167 & .19040 & -.08638 & .26726 \\
Work & .10710 & .22041 & -.29560 & .01500 \\
Crime & -.42683 & .00064 & .02702 & .42312 \\
CoN1 & .17825 & .09860 & -.23324 & .04482 \\
Con2 & .58822 & .00000 & -.42650 & .00065 \\
& & & & \\
Budget with: & .00921 & .47364 & -.28494 & .01383 \\
Sex & .20437 & .06912 & -.05870 & .33666 \\
Age & -.12588 & .18220 & -.26887 & .02466 \\
School & -.12436 & .18513 & -.09925 & .23761 \\
Job & .02400 & .43162 & -.33719 & .00633 \\
Work & -.33954 & .00600 & -.11027 & .21365 \\
Crime & .53159 & .00002 & .41271 & .00096 \\
Avgeff & & & & \\
\hline
\end{tabular}


effectiveness or the ultimate budgeting of the successful cases, but was noticeably correlated with the dependent variables in the failure experiment. The reverse was true for CRIME. People who perceived crime as being a problem in their own locality indicated greater certainty that the successful crime prevention program had been effective in the past than did those who did not view local crime as greatly increasing. Work experience proved to be significantly correlated with both dependent variables in the failure experiment, but was uncorrelated in the other model.

As before, the experimental variable CON2, which contrasted control group subjects with those receiving all three cues, displayed the greatest potential explanatory power. Effectiveness perceptions also displayed high zero-order correlations in both experiments. The experimental variable CONl was only signiflcant in the failure experiment.

The following regression models were utilized in the analysis of budget decision changes.

Successful Experiment:

5.7 AVGEFF $=a+b_{1}$ CRIME $+b_{2} \operatorname{CON} 1+b_{3} \operatorname{CON} 2+e$

5.8 BUDGET $=a+b_{1} A G E+b_{2} C R I M E+b_{3 A V G E F P+e}$

Failure Experiment:

5.9 AVGEFF $=a+b_{1} \operatorname{SEX}+b_{2} W_{0 R K}+b_{3} I_{1}+b_{4} \operatorname{CON} 1+b_{5} \operatorname{CON} 2+b_{6} I_{2}+e$

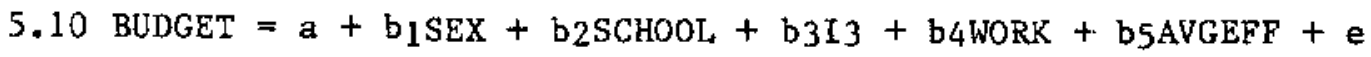


where: $I_{1}=\operatorname{SEX}$ * WORK

$I_{2}=S E X * \operatorname{CON} 2$

$\mathrm{I}_{3}=\mathrm{SEX} * \mathrm{SCHOOL}$

A summary of the hierarchial regression coefficients and the direct, fndirect and spurious effect of each independent variable is contained in Table XVI through Table XIX. Each experiment is discussed separately below.

Successful Experiment.--The decision makers' perceptions of the severity of crime in their own environment had a positive impact upon their opinions as to the effectiveness of the program under consideration and their resultant budgeting decision. Subjects who viewed local crime as greatly increasing evaluated past program effectiveness with .85666 greater certainty than did those who believed crime was only moderately increasing. Furthermore, controlling for the effect of age, high crime perception subjects funded their case on an average almost $\$ 75,000$ higher than did others. One-third of the budget effect was direct. The remainder impacted the budgetary decision through the subject's effectiveness rating. However, most of the relationship of crime perceptions to effectiveness was direct and not mediated by other variables in the equation. If a subject perceived of crime as being an immediate problem that needed corrective action, (s)he was more apt to be receptive to indications of past effectiveness. Thus, past successes in an area of 


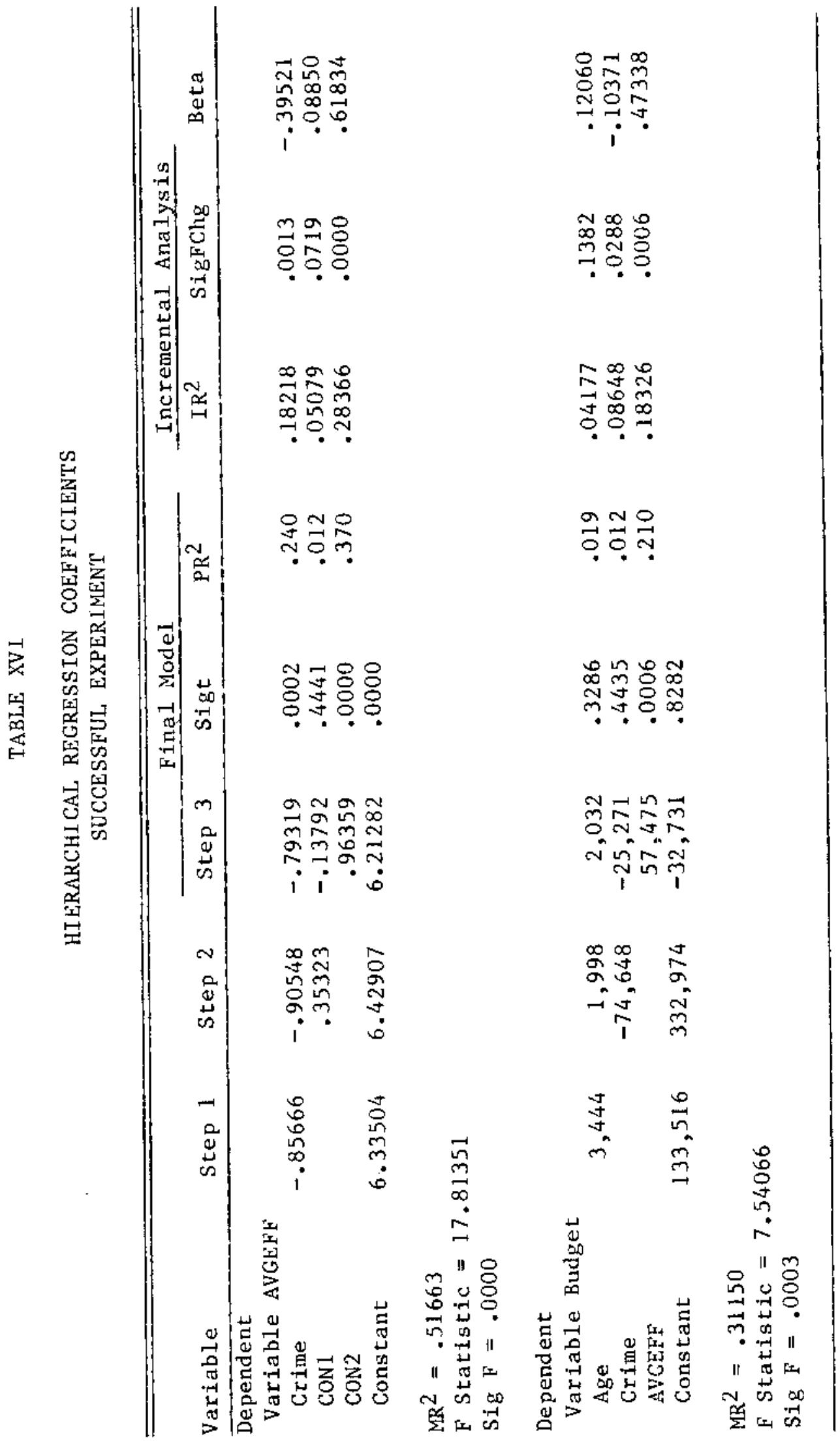


TABLE XVII

SUMMARY OF DIRECT, INDIRECT AND SPURIOUS EFFECTS

OF EACH INDEPENDENT VARIABLE SUCCESSFUL EXPERIMENT

\begin{tabular}{|c|c|c|c|c|c|}
\hline & $\begin{array}{c}\text { Zero-Order } \\
B\end{array}$ & Spurious & Direct & Indirect & Total \\
\hline \multicolumn{6}{|l|}{$\begin{array}{l}\text { Avgeff Mode1: } \\
\text { Crime }\end{array}$} \\
\hline \multirow{3}{*}{$\begin{array}{ll}\text { via } & \text { CON1 } \\
\text { via } & \text { CON2 }\end{array}$} & & & & .04882 & \\
\hline & & & & -.11229 & \\
\hline & -.85666 & - & -.79319 & -.06347 & -.85666 \\
\hline \multicolumn{6}{|l|}{ CON1 } \\
\hline $\begin{array}{l}\text { via CON2 } \\
\text { CON2 }\end{array}$ & $\begin{array}{l}.27778 \\
.91667\end{array}$ & $\begin{array}{l}-.07545 \\
-.04692\end{array}$ & $\begin{array}{r}-.13792 \\
.96359\end{array}$ & .49115 & $\begin{array}{l}.35323 \\
.96359\end{array}$ \\
\hline \multicolumn{6}{|l|}{$\begin{array}{l}\text { Budget Model: } \\
\text { Age }\end{array}$} \\
\hline \multicolumn{6}{|l|}{ Age } \\
\hline \multirow{2}{*}{$\begin{array}{l}\text { via Crime } \\
\text { via Avgeff }\end{array}$} & & & & $\begin{array}{r}1,446 \\
-34\end{array}$ & \\
\hline & 3,444 & - & 2032 & 1,412 & 3,444 \\
\hline \multicolumn{6}{|l|}{ Crime } \\
\hline via Avgeff & $-82,741$ & $-8,093$ & $-25,271$ & $-49,377$ & $-74,648$ \\
\hline Avgeff & 64,542 & 7,067 & 57,475 & - & 57,475 \\
\hline
\end{tabular}




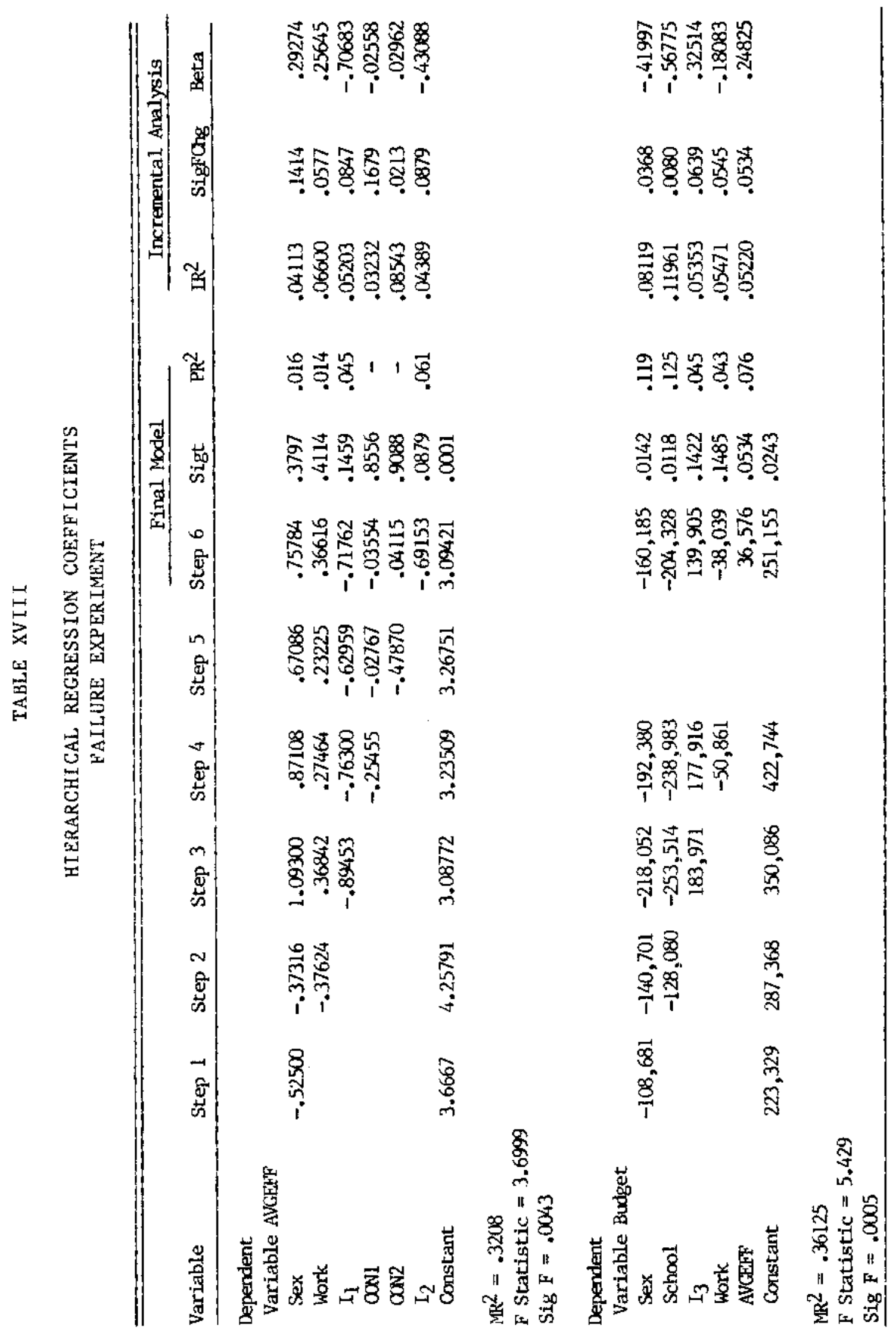


TABLE XIX

\begin{abstract}
SUMMARY OF DIRECT, INDIRECT AND SPURIOUS EFFECTS OF EACH INDEPENDENT VARIABLE

FAILURE EXPERIMENT
\end{abstract}

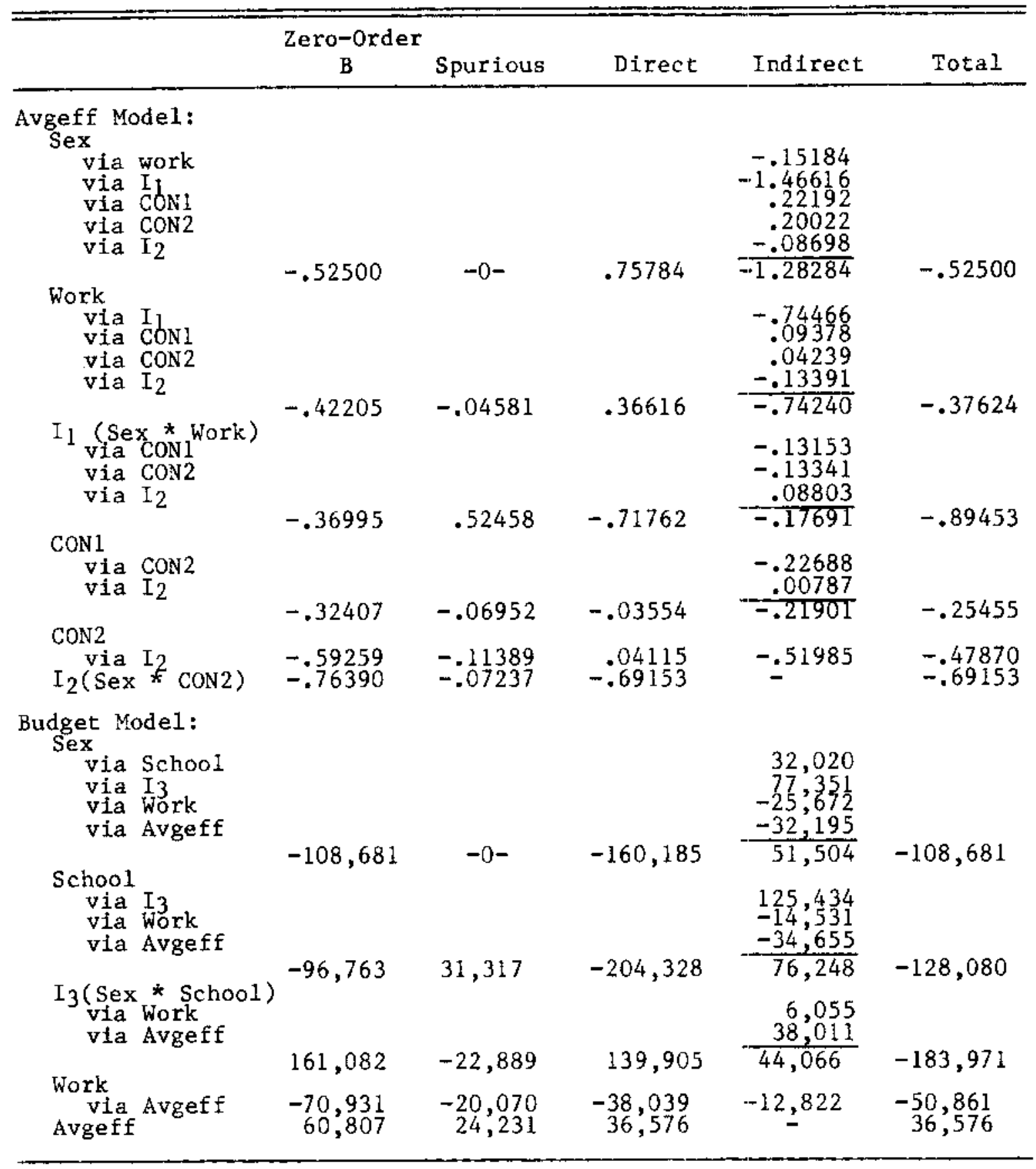


particular interest to the decision maker were rewarded accordingly with higher funding.

The subject's age was also positively correlated to the recorded budget decision. Without controlling for any other variables, individuals aged fifty funded the program for $\$ 68,880$ more than did subjects aged thirty. This variable impacted the model both directly and indirectly through the decision maker's perception of the local crime problem.

Studies have indicated that older individuals view crime with greater concern than do younger people. Therefore, they may have been more apt to perceive of this program in a positive sense and to be more receptive to additional funding.

The inclusion of performance cues accounted for 33.4 per cent of the total variance in the effectiveness perceptions model. Those subjects who reviewed the case containing program outcomes judged past effectiveness with .70718 greater certainty than did individuals who based their opinions upon data contained in the control case. The outcome cue impacted the model in a positive manner through the impact cue. Apparently positive opinions concerning past performance were only created when confirmatory evidence in the form of output, outcome and impact measures were provided.

The Impact cue had a large incremental effect upon the subject's perceptions of past program performance. Review 
of the three-cue case resulted in subjects displaying 1.90 greater certalnty in past effectiveness than did the control case information. This cue accounted for 28.4 per cent of the total variance of the model. After all other variables had been partialled out, the impact cue explained 37 per cent of the remaining variance in effectiveness decisions. Effectiveness estimations obtained from the complete model indicated that the output cue produced no information. Control subjects on the average displayed relative uncertainty as to past performance (AVGEFF=3.85947, where $4=$ complete uncertainty). Individuals who reviewed the two-cue case indicated a marginal change in uncertainty (4.54722). Decision makers who received the impact cue reported reasonable certainty $(5.64873)$.

In the buggeting model, a subject's opinion of past program effectiveness displayed the greatest explanatory power. This variable explained 18.3 per cent of the total variance in budgetary decisions. After the effects of all intervening variables had been renoved from the equation, effectiveness certainty accounted for 21 per cent of the remaining variance. An alteration in the decision makers' perceptions of past program effectiveness from complece uncertainty to siight certainty caused a direct increase of $\$ 57,475$ in the dollars funded.

Failure Experiment.--The subject's gender and budgeting work experience proved to be significant intervening 
variables in both effectiveness certainty and ultimately budgeting for the crime prevention program that had falled to produce satisfactory results in the past. Without controlling for any other variables in the two equations, males indicated .525 greater certainty that the program had failed and funded the program for $\$ 108,681$ less than did females. On the average, females were relatively uncertain about past program results, while males indicated that they were somewhat certain the campaign had falled.

Work experience was positively associated with ineffectiveness certainly and negatively correlated with budgeting. Controlling for other intervening variables, people with ten or more years of work experience depicted .7494 greater certainty that the program had not been effective in the past and funded the package for $\$ 101,722$ less than did people with less than five years experience. In the effectiveness model, gender and work experience effected the equation variance indirectly through an 1nteraction term. On the whole, females with greater work experience displayed greater uncertainty about past program results (AVGEFF = 4.193) than did females with less work experience (AVGEFF $=3.456)$. The opposite was true for males. While men with less than five years work experience indicated average effectiveness certainty of 3.6 .55 , males with ten or more years experience concluded that they were somewhat certain the program had failed (AVGEF = 2.602). 
Figure 20 depicts this interaction graphlcally. Most of this relationship was either direct or spurious. The spurious effect was due to comon causes. The interaction variable was highly correlated to SEX (.775) and WORK $(.735)$

Forma 1 education had an effect upon the budgeting decision. Controlling for gender, subjects with a post-college graduate degree funded the program $\$ 128,080$ less than did individuals with less formal education. Approximately two-thirds of this effect was direct and the remainder was indirect via an interaction of SEX and SCHOOL. While both males and females displayed a negative correlation between education and program budgeting, females with less than a master's degree funded the program for $\$ 218,052$ more than did males with similar formal training. This difference narrowed with additional education to only $\$ 34,081$. Thus, even though work experience did not alter females' uncertainty pertaining to past program effectiveness, additional education eliminated the impact of gender upon the budget decision. Education at the graduate level frequently includes some training in objective decision making. This training neutralized the unique gender biases. Most of this relationship was direct and was not mediated by the other variables in the equation. Figure 21 illustrates the impact of the interaction upon the budgeting decision. 


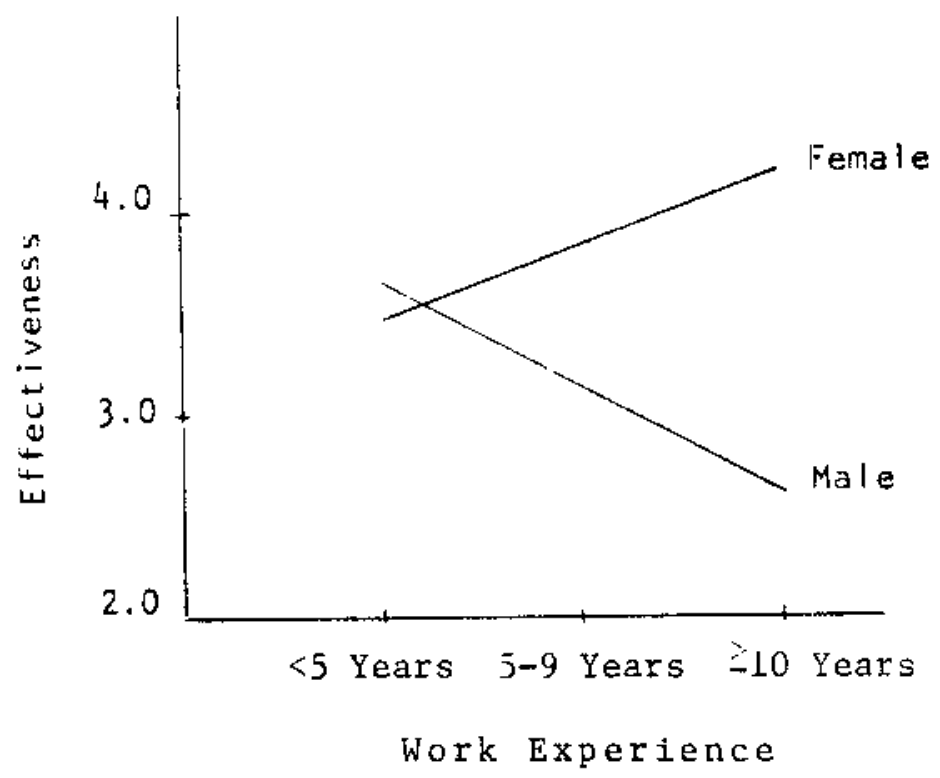

Fig, 20--Interaction of Gender and work Experience with Effectiveness certaintyFailure Experiment 


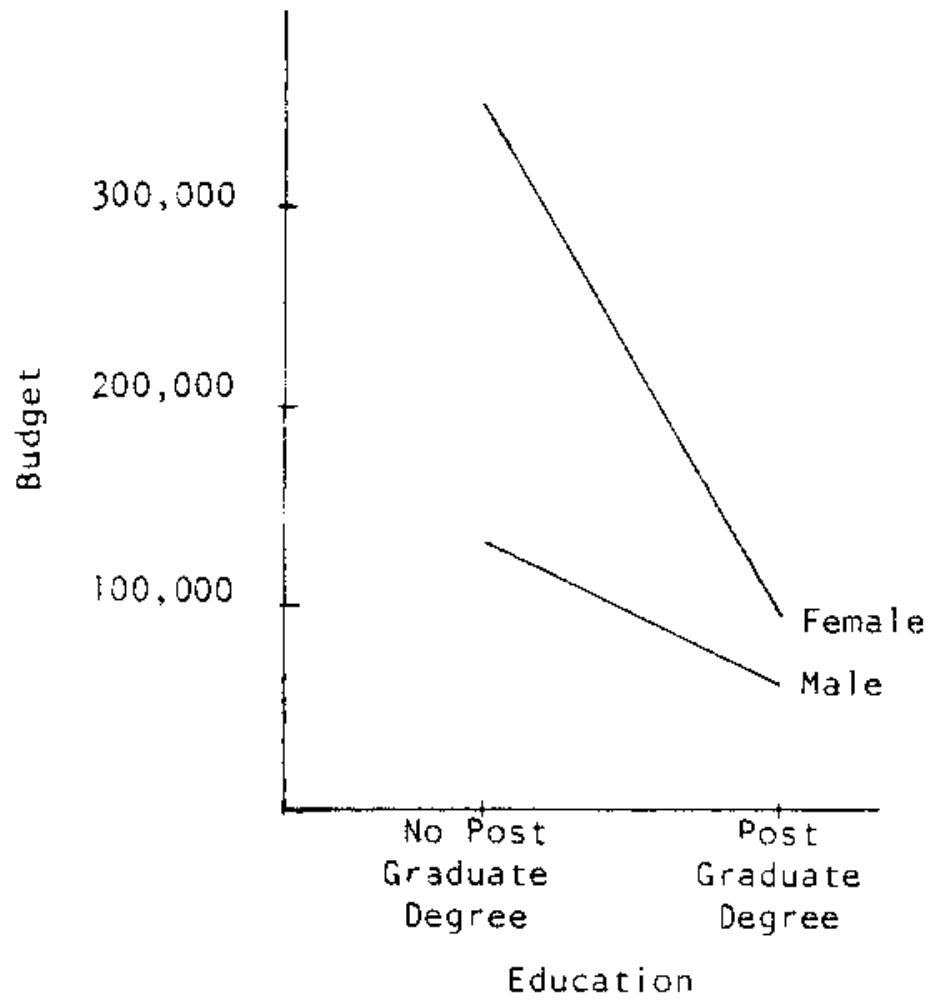

Fig. 21--Interaction of Gender and Education with Budget--Failure Experiment 
Intrusion of the experimental cues into the first model impacted the decision makers' certainty of past performance. over 16 per cent of the total variance in effectiveness certainty was explained by these variables. Controlling for intervening variables, the presence of the outcome cue increased the subjects' certainty that the program had been ineffective by .5091. The addition of the impact cue altered perceptions even more. This variable recorded an incremental effect of .957 .

Both variables fmpacted the model indirectly. The outcome cue affected the equation through the impact cue, and the results of this cue, in turn, entered the model via an interaction with gender. Regardless of the number of cues provided, females on the average indicated greater uncertainty than did males. Furthermore, the addition of performance measures impacted only males' perceptions of past program effectiveness. A female subject's uncertainty was not altered by additional cues. Figure 22 contains a graph of the interaction. Controlling for other variables, the control subjects' estimates of effectiveness indicated almost complete uncertainty (3.97942). The addition of the outcome cue increased certainty to 3.25507 and the impact measure increased certainty even further to 2.81934 . Perception of past program effectiveness only had a sight impact upon the budget wodel. The incremental coefflcient of determination was .05220. However, as 


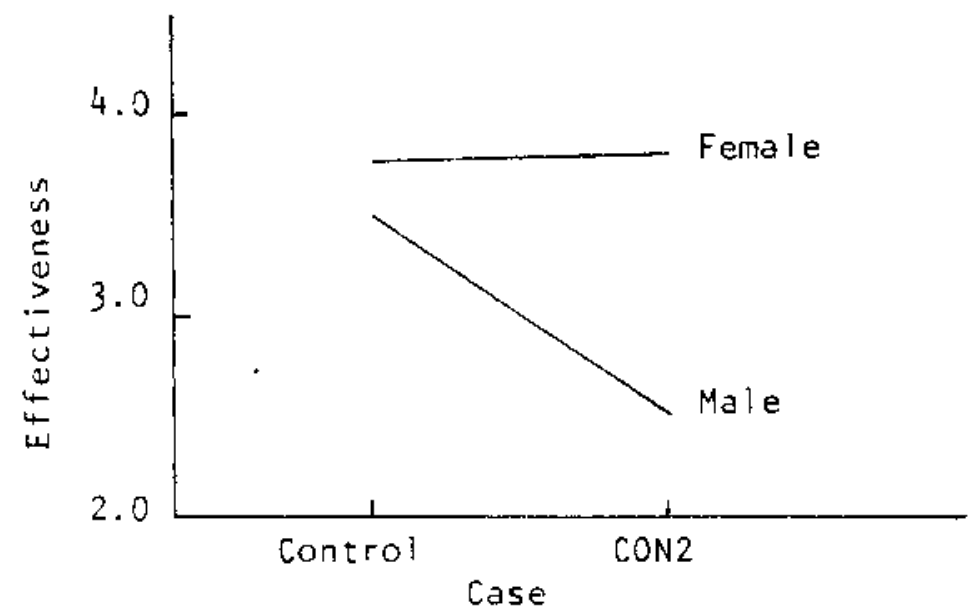

Fig. 22--Interaction of Gender and Impact Cue with Effectiveness Certainty-Failure Experiment 
subjects altered their beliefs of past programs ineffectiveness from complete uncertainty to slight certainty, they reduced their budget appropriations by $\$ 36,576$. A spurious relationship of $\$ 24,231$ due to common causes also existed. This was attributed to slight correlation of effectiveness perceptions with gender and work experience.

Conclusions.--Table XX depicts the incremental effect of additional performance measurement cues upon the subjects' certainty pertaining to past effectiveness and the impact of past performance certainty upon budgeting. In both experiments, the addition of new cues pertaining to past performance reduced program effectiveness uncertainty significantly. Furthermore, the observed increase in certainty altered the resultant budgetary decision. A change from complete uncertainty to slight certainty caused the successful program to be funded for 25.3 per cent more or $\$ 57,475$, and reduced the falled program's budget 21.6 per cent. Performance cues accounted for 33.4 per cent and 16.2 per cent of the total variance in the effectiveness perceptions of the successful and failure programs respectively. Table XXI contains a summary of the analysis of variance. In both experiments the reduction in variance due to the experimental intrusion was statistically significant. Therefore, the null hypothesis are rejected. Information pertaining to past performance not only removed decision 
TABLE XX

MODEL ESTIMATES

\begin{tabular}{|c|c|c|c|c|c|c|}
\hline \multirow[b]{3}{*}{ Case } & \multicolumn{3}{|c|}{ Successful Experiment } & \multicolumn{3}{|c|}{ Failure Experiment } \\
\hline & \multirow[b]{2}{*}{ Estimate } & \multicolumn{2}{|c|}{ Percentag } & \multirow{2}{*}{ Estimate } & & \multirow{2}{*}{$\begin{array}{l}\text { Percentage } \\
\text { Change }\end{array}$} \\
\hline & & Change & Change & & Change & \\
\hline \multicolumn{7}{|l|}{ Effectiveness: } \\
\hline Control & 3.85947 & & & 3.79742 & & \\
\hline Cue 2 & 4.54722 & .68775 & 17.8 & 3.25507 & .54235 & 14.3 \\
\hline Cue 3 & 5.64873 & 1.10151 & 24.2 & 2.81934 & .43573 & 13.3 \\
\hline \multicolumn{7}{|l|}{ Budget: } \\
\hline Uncertainty & 226,771 & & & 169,148 & & \\
\hline Somewhat Certain & 284,246 & 57,475 & 25.3 & 132,572 & 36,576 & 21.6 \\
\hline Reasonably Certain & 341,721 & & & 95,996 & & \\
\hline
\end{tabular}

makers' uncertainty about past performance, but also altered the amount budgeted for a subsequent period. While performance cues did increase budgeting rationality, irrational elements also played a significant role in the Individual decision making process. Factors, such as gender, age and preconceived notions as to the importance of the particular program under review, circumvented the presence of cues and altered the manner in which various individuals approached the budgeting task and their resultant decisions. 
TABLE XXI

\section{ANALYSIS OF VARIANCE \\ EXPERIMENTAL VARIABLES}

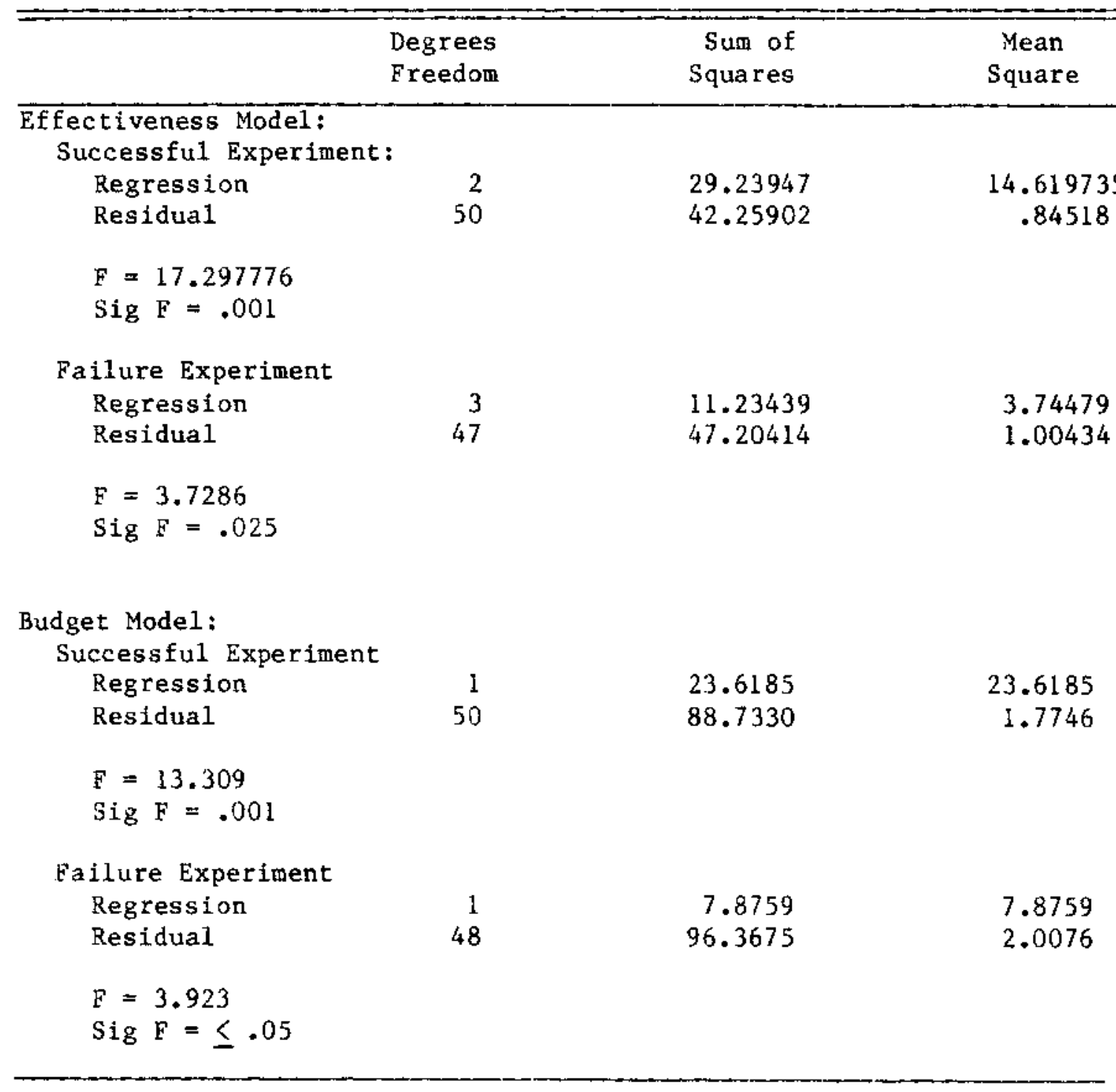


Chapter VI

CONCLUSIONS AND RECOMMENDATIONS

FOR FUTURE RESEARCH

Conc1usions

A new Statement of organizational Performance was

introduced in this dissertation. The underlying theory was

developed, the feastbility of implementation was examined,

and the impact of information contained therein upon

budgetary decision making was investigated. The following

conclusions were drawn from the results of this research:

1. Existing not-for-profit entity financial

statements do not adequately convey information

pertaining to both past efforts and

accomplishments. Thus a new statement of

organizational performance which compares the

dollar resources utilized in a particular

project with non-monetary measures of

performance should be prepared.

2. The evaluation of a particular program in terms of goods or services produced, program outcomes and societal impact encompased to a satisfactory degree all levels of accomplishment.

3. In a bugeting setting, the provision of cues pertaining to program outcomes and societal impacts significantly modified the decision makers' certainty of past performance, reduced budget variance, and altered the resultant budgetary decision. However, subjective biases, created by gender, work experience, age, education and perceptions of the severity of local crime, were not completely removed from the process. 
This study had two major limitations. First, in the measurement feasibility investigation, practicality was not considered. Knowledge of the research techniques needed to properly evaluate a program are not commonly provided to an undergraduate either in the social sciences or to accountants. Furthermore, even if this problem could be overcome through additional education, it may well be that the increase in rational budget decision making is more than offset by the costs of measuring, analyzing and interpreting past performance. An alternate suggestion might be to utilize these measures to evaluate only new projects or programs undergoing great change. Secondly, the investigation of the effect of performance measures upon budgetary decision making was conducted in an artificial setting. Therefore, no generalizability can be placed upon the conclusions drawn from this experiment. However, a controlled environment was required since the research intent was to investigate causality. Generalizability must be obtained through future replication.

$$
\text { Recommendations for Future Research }
$$

The following recommendations for further work are made :

1. Conduct a cost-benefit analysis of performance measurement. 
2. Investigate the impact of performance cues upon different types of decision makers. One comparison would be to contrast the change in uncertainty and resultant budgetary decisions of people employed in the private sector with those who work in the public sector. Another possibility is to compare the five groups who interact in the budget process: the agency, the legislature, the administration, the resource providers and the actual recipients of a particular program.

3. Conduct a study of the impact of different budgetary climates upon the budgeting process. Decision makers existing in a tight budgetary climate may react differently to the presence of cues of past performance than do individuals making decisions in an environment where funds are readily available.

4. Systematically study, in a controlled setting, the impact of subjective biases upon the budgetary decision making process. The decision makers' use of judgmental heuristics can influence human inference and the resultant decision.

5. Examine the problem of information overload as it relates to the provision of performance meas ures.

6. Ascertain the effect that each type of cue has upon budgetary decision making when the cues provide mixed results. 
APPENDIX A. URBAN CRIME-DESCRIPTION AND PREVENTION

Introduction

Determinants of Crime

Crime Prevention Policies

Crime Prevention Mode1 
Appendix A

URBAN CRIME - DESCRIPTION AND PREVENTION

Introduction

Crime is considered one of the major problems confronting our society today. Seldom can one read a newspaper or watch the local news without obtaining the impression that cities are in a virtual state of seige because of rampaging crime. In 1979, it was estimated that over $\$ 22$ billion was spent on crime control and criminal justice.l Criminal justice system expenditures per capita have more than doubled in the last two decades. This, however, has had little apparent deterrent effect upon crime rates. Between 1960 and 1975 reported rates of robbery increased by 263 per cent, burglary 200 per cent, aggravated assault 164 per cent, forcible rape 174 per cent, and homicide by 188 per cent. 2

The incidence of crime is high, but according to the National Crime Victimization Survey conducted from 1973 through 1978, most major index crimes are only keeping pace

lJohn Conyers, "Criminology, Economics, and Public Policy", Crime and Delinquency, XXV (April, 1979), p. 141 .

2Lawrence $E$. Cohen and Marcus Felson, "Social Change and Crime Rate Trends: A Routine Activity Approach", American Sociological Review, XLIV (August, 1979) p.588. 
with population growth. Table XXII sumarizes crime rates for this period by category. 3

Determinants of Crime

Crimes are events that occur at specific locations in

space and time. Each successfully completed violation

requires three conditions: an offender with both criminal

Inclinations and the ability to carry out the act, a person or object supplying a suitable target for the offender, and the absence of a guardian capable of preventing violations.4

\section{The offender}

The existence of crime is "societally normal". It "is inevitable because individuals differ in character, which is manifested in behavior and because groups erect limits upon the differences they are willing to allow."5

Much crime is economically motivated. The benefits to the individual criminal are the expected payoffs from comitting the act. The costs include the opportunity cost of foregone legal wages and occupational costs of a life of crime such as the risk of being arrested, convicted, and punished. If the costs of a criminal act are increased, there will be less illegal acts, because in some cases, the

3U.S. Department of Justice, Criminal Victimization in the U.S.: $1973-78$ Trends, Bureau of Justice statistics (December, 1980).

4Lawrence E. Cohen and Marcus Felson, "Social Change and Crime Rate Trends: A Routine Activity Approach", American Sociological Review, XLIV (August, 1979) p. 590.

5Robert A. Dentler, Urban Problems: Perspectives and

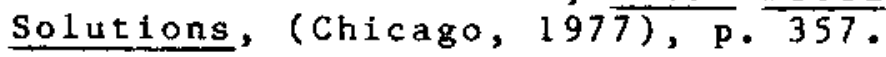


TABLE XXII

CRIMTNAL VICTIMIZATION RATES

(Rate per 1000 Population, Age 12 and 01der)

\begin{tabular}{|c|c|c|c|c|c|}
\hline & 1973 & 1974 & 1975 & 1976 & 1978 \\
\hline \multicolumn{6}{|l|}{ Personal Sector: } \\
\hline \multicolumn{6}{|l|}{ Crimes of Violence- } \\
\hline Rape & 1.0 & 1.0 & 0.9 & 0.8 & 1.0 \\
\hline Robbery & 6.7 & 7.2 & 6.8 & 6.5 & 5.9 \\
\hline Assault & 24.9 & 24.8 & 25.2 & 25.3 & 26.9 \\
\hline \multicolumn{6}{|l|}{ Crimes of theft- } \\
\hline Larceny with Contact & 3.1 & 3.1 & 3.1 & 2.9 & 3.1 \\
\hline Without Contact & 88.0 & 92.0 & 92.9 & 93.2 & 93.6 \\
\hline \multicolumn{6}{|l|}{ Household Sector: } \\
\hline Burglary & 91.7 & 93.1 & 91.7 & 88.9 & 86.0 \\
\hline Household Larceny & 107.0 & 123.8 & 125.4 & $124 \cdot 1$ & 119.9 \\
\hline Motor Vehicle Theft & 19.1 & 18.8 & 19.5 & 16.5 & 17.5 \\
\hline \multicolumn{6}{|l|}{ Commercial Sector: } \\
\hline Burg1ary & 203.7 & 226.1 & 228.6 & 217.3 & \\
\hline Robbery & 38.8 & 38.8 & 39.4 & 38.5 & \\
\hline
\end{tabular}


benefits will no longer outweigh the costs. Furthermore, as the value of legitimate opportunities increases, the relative benefits of crime will drop. Again, less illegal acts will be comitted.6

Crime is the product of "malevolent interdependence". The offender is concerned not only with the absolute value of his legal income, but also with his relative economic position within his reference group and to the society as a whole.7 Interpersonal welfare comparisons affect an individual's perceptions of the benefits to be gained from illegal activity and the likelihood that a crime will be comitted.

Class-culture and personality factors also enter into the individual's cost-benefit analysis. Five elements determine his propensity towards criminal activity. First, the way in which a person conceptualizes right and wrong and the weight that he places upon legal and moral rules in naking choices will determine the extent to which his actions can be influenced by authority. Second, an individual's ability to control hioself, especially his ability to adhere to his intentions will affect his ability to implement a plan of action. Third, the time perspective

${ }^{6}$ Arthur F. Schreiber, Paul Gatons and Richard Clemmer, Economics of Urban Probiems, (Boston, 1976), pp. 303-305.

${ }^{7}$ Sheldon Danziger and David wheler, "The Economics of Crime: Punishment or Income Redistribution", Review of Social Econony, XXXIII (October, 1975), pp. 1 $\overline{13-131}$. 
an individual utilizes in estimating costs and benefits of alternative courses of action, can affect the likelihood that consequences that occur in the future will be taken into consideration. Fourth, commission of most crimes involves a certain amount of risk. Individuals who are risk takers will be biased to comit crtmes. Finally, most crimes involve a possibility of injury to others. Therefore, a certain willingness on the part of the actor to inflict injury may cause criminal behavior. 8

The decision to engage in illegal or legal activity is not mutually exclusive. Offenders attempt to allocate their time and resources optimally according to thelr preference for risk and the incentives present at any point in time. Soide workers move freely back and forth between irregular and regular activities depending upon the opportunities of the day.

\section{The Victim}

Incidences of victimization vary across socio-denographic groups. Selected rates for 1978 are contained in Table XXIII and Table XXIV.9

Men, as opposed to women; the young, as opposed to the aged; the city dweller, as opposed to the rural inhabitant,

${ }^{8}$ Edward C. Banfield, The Unheavenly City Revisited, (Boston, 1974), pP. 182-183.

9u.S. Department of Justice, Criminal victimization in

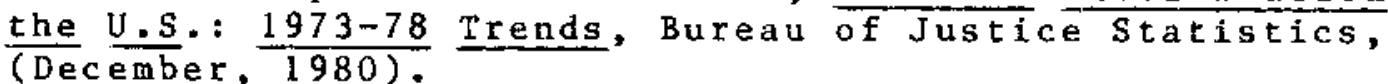


TABLE XXIII

PERSONAL CRIMINAL VICTIMIZATION RATES

(Rate per 1000 Population, Age 12 and Older)

\begin{tabular}{lrrrrrr}
\hline & \multicolumn{2}{c}{ Sex } & \multicolumn{2}{c}{ Age } & \multicolumn{2}{c}{ Location } \\
\cline { 2 - 5 } & \multicolumn{1}{c}{ Men } & Women & & \multicolumn{1}{c}{ Cen. City Rura 1} \\
\hline Rape & 0.2 & 1.7 & 2.5 & 0.1 & 1.6 & 0.5 \\
Robbery & 8.3 & 3.7 & 9.8 & 3.0 & 9.9 & 2.2 \\
Assault & 37.2 & 17.4 & 56.6 & 4.7 & 34.5 & 18.9 \\
Larceny & 105.6 & 88.7 & 152.6 & 23.0 & 118.9 & 64.6 \\
\hline
\end{tabular}

TABLE XXIV

HOUSEHOLD CRIMINAL VICTIMIZATION RATES

(Rate per 1000 Households)

\begin{tabular}{|c|c|c|c|c|c|c|}
\hline \multirow[b]{3}{*}{ Ruralary } & \multirow{2}{*}{\multicolumn{2}{|c|}{$\frac{\text { Form of Tenure }}{\text { Owned Rented }}$}} & \multicolumn{2}{|c|}{ Age } & \multicolumn{2}{|c|}{ Location } \\
\hline & & & $\overline{19}$ & 65 & Cen. & Rura 1 \\
\hline & 71.0 & $\overline{114.1}$ & 246.6 & 45.2 & 110.0 & 63.9 \\
\hline Larceny & 107.8 & 142.7 & 239.4 & 53.6 & 140.2 & 86.9 \\
\hline Motor Vehicle & 24.5 & 24.5 & 52.6 & 5.2 & 23.6 & 9.0 \\
\hline
\end{tabular}


are all more likely to be victimlzed. Whites are more likely to be victims of a theft, while blacks are more likely to be victims of a violent offense. However, for both groups, the more urbanized the area, the higher the crime rate. 10

The spatial and temporal structure of routine legal acts are important determinants of the location, type, and quantity of illegal activities. The dispersion of activities away frow the home increases the opportunity for predatory crime, because the offender and the victim are more likely to converge in a suitable location.l

Predatory property crimes are not random events. Individuals most likely to be victimized in robberies are those "whose lifestyles 1ncrease the Ir exposure to risk not only by placing them in proximity to likely offenders, but also by increasing their attractiveness as targets to potential offenders."12 In general, the risk of being robbed is greater for the young than for the old, the poor than for

10 John Gibbs, Crime Against Persons - In Urban, Suburban and Rural Areas: A Comparative Añlysis of Victimization Rates, (Washington, D.C., 1979), p. 26.

1Llawrence E. Cohen and Marcus Felson, "Social Change and Crime Rate Trends: A Routine Activity Approach", American Soc10logical Review, XLIV (August, 1979) p. 605.

12Lawrence $E$. Cohen, David Cantor and James R. Kluegel, "Robbery Victimization in the U.S.: An Analysis of a Nonrandom Event", Social Science Quarterly, LXII (December, $1981)$, p. 655 . 
the rich, the black than for the white, and for males than for females.13

Victimization studies of persons, businesses and households that have been repeatedly victimized confirm this hypothesis. Adherence to a lifestyle that brings potential victins in closer proximity with potential offenders is more likely to cause multiple crimes.14

Specific crime incidences, however, depend upon the degree of criminality in a particular environment and the adjustments made by an individual to avoid such places. Fear of crime is a positive function of the perceived real victimization rate. Factors that affect it are the proportion of a population termed criminal, the quantity and effectiveness of law enforcement, the physical ability of the victims to ward off offenders, and the presence of other capable guardians.

Fear for personal safety on the streets varies among the populace. Women, older adults, and urban residents in several polls have stated that they are uncomfortable at night in some places within a mile of their home.15

$13 \mathrm{James} Q$. Wilson and Barbara Boland, "Orime", in The Urban Predfcament, edited by William Gorham and Nathan Glazer (Washington, D.C., 1976), p. 185.

$14 \mathrm{James}$ F. Nelson, "Multiple Victimization in American Cities: A Statistical Analysis of Rare Events", American Journal of Sociology, LXXXV (1980), pp.870-89i.

15 Hazel Erskine, "The Polls: Fear of Violence and Crime", The Public opinton Quarterly, XXXVIII (1974), pp. 137-140. 
on the other hand, exposure to crime is a negative function of an individual's fear and his propensity to act upon his fears. An individual's personal lifestyle and his ability to subsititute non-exposing activities for other more dangerous ones will affect specific exposure to crime r1sk. Thus, the measured victimization rate for any social group is the product of the real victimization rate and the number of exposures to potential crime situations.16 The fears expressed by the elderly and females for their personal safety may lead them to less exposure. This will result in less crime and could explain their lowered measured victimization rates.

\section{Environgent}

A survey conducted in the nid-1970's indicated that 27.5 per cent of central city respondents as opposed to only 17.1 per cent of suburban dwellers identified crime as a major neighborhood problem. This was true even when race and tenure were considered.17

The fear for one's safety is not only affected by the incldence of crime in a particular locality, but also by the

16 Steven Balkin, "Victimization Rates, Safety and Fear of Crime", Social Problems, XXVI (february, 1979), pp. 343-358.

17 Barrett A. Lee, "The Urban Unease Revisited: Perceptions of Local Safety and Neighborhood Satisfaction Among Metropolitan Residents", Social Science Quarterly, LXII (December, 1981), p. 620 . 
TABLE XXV

RESPONDENTS INDICATING FEAR FOR PERSONAI. SAFETY

\begin{tabular}{lccccccc}
\hline \hline Year & $\begin{array}{c}\text { Total } \\
\text { Afraid }\end{array}$ & Men & Women & 20 & 50 & & \multicolumn{2}{c}{ Aocation } \\
\hline 1967 & $31 \%$ & $16 \%$ & $44 \%$ & & $33 \%$ & $38 \%$ & $21 \%$ \\
1968 & 35 & 19 & 50 & & 39 & 42 & 24 \\
1972 & 41 & 22 & 60 & $24 \%$ & 48 & 51 & 24 \\
\hline
\end{tabular}

TABLE XXVI

PERCEIVED NEIGHBORHOOD CRIME PROBLEM

\begin{tabular}{llll}
\hline & Total & Owner & Renter \\
\hline White & $17.0 \%$ & $16.6 \%$ & $17.9 \%$ \\
Suburban & 26.3 & 23.1 & 30.0 \\
Central City & 19.8 & 19.5 & 20.1 \\
Black & 32.2 & 29.2 & 33.9 \\
$\quad$ Suburban & & \\
\hline
\end{tabular}


level of "incivility" in the environment. 18 As a neighborhood physically deteriorates, the sense of danger and decay rises and an individual's perceived risk of victimization increases.

Perceptions of a crime problem have been found to be negatively related to neighborhood satisfaction, particularly for the poor and single adults. Urban dwellers "lacking essential resources, those possessjug weakened social ties, and those with a minimal stake in the residential setting tend to translate their concern over safety into lower levels of neighborhood satisfaction."19 However, dissatisfaction does not necessartly mean that people will relocate. Progress on through the family life cycle dominates decisions to move out of a neighborhood. Particularly, changes in job circumstances will result in nobility. Families compare the available housing when making a location decision. Considered services include "the characteristics of the structure (space and comfort), physical aspects of the neighborhood (its location, site amenties), neighborhood social character, and Inunicipal

18 Dan A. Lew 1 s and Michael G. Manfield, "Fear in the Neighborhoods: An Investigation of the Impact of Crime", Journal of Research in Crime and Delinquency, XVII (July, 1980), p. 161 .

19 Barrett A. Lee, "The Urban Unease Revisited: Perceptions of Local Safety and Neighborhood Satisfaction Among Metropolitan Residents", Social Sclence Quarterly, LXII (December, 1981 ), p. 624 . 
services (quality of schools, tax rates)."20 Increased crime impacts the social character of a neighborhood and thus decreases the desirability of a dwelling.

Katzman concludes:

Risk of property crime is indeed an important influence in determining the attractiveness of a particular destination. The attractiveness of safe neighborhoods is greater for higher-income families and for all families with children. As high-income households rove away from high crime areas, the crime rates in the declining area may even increase, as the crime-prone population increases proportionally. This increase in crime may then further repel families thus hastening neighborhood decline. 21

Crime may be viewed as an externality of economic

growth. As production increases, social forces create deviant behavior in excess of the feasible deterrence capabilities of the society. Advanced civilizations require concentrations of people in urban areas for production purposes and to provide markets. Thls density increases the opportunities for crime and reduces the likelihood of apprehension. 22

Investigation of 1974 central city victimiation data indicates that property crimes with contact are positively correlated with population density. However, household

20 Martin T. Katzman, "The Contribution of Crime to Urban Decline", Urban Studies, XVII (1980), p. 280 .

$21_{\text {Ibid., p. } 286 .}$

22David D. Hemley and Lee R. MePheters, "Crime as an Externality of Economic Growth", American Economist, XIX (Spring, 1975), pp. 45-47. 
property crimes are negatively correlated.23 Since higher density is associated with greater visibility, offenders wishing to avoid contact would naturally prefer less dense areas in which to perpetrate their crimes.

Varlous central cities display differing crime rates. The number of criminal incidences occurring in a central city is a function not only of the socio-demographic variables comonly related to crime, but also vary directly with the central city population and its functional dominance within the surrounding area. 24 Non-residents are attracted to the central ctty and thus are more likely to stumble into a potentially criminal situation. As the relative population and dominance of the central city in the surrounding community increases, the number of potential participants in a crime also rises.

Different neighborhoods are also explotted for different types of crime. Homicides and assaults have high occurrence rates 1 n offender neighborhoods. In 45 per cent of the assaults and 61.8 per cent of the murders, the offender and victim were etther related or acqualnted. These crimes arise generally from the interactions of people

$23^{2}$ avid Shichor, David Decker and Robert O'Brien, "Population Density and Criminal Victimization", Criminology, XVII (August, 1979), pp. 187-188.

${ }^{24}$ Mark C. Stafford and Jack Gibbs, "Crime Rates in an Ecological Context: Extension of a Proposition", Social Science Quarterly, LXI (December, 1980), p. 655 . 
with similar backgrounds.25 In these instances, the offender is apt to be familiar with his potential victim and may act on the spur of the moment.

Non-residential burglary, business robbery, auto theft, and grand theft are more often located in high social rank neighborhoods. Profitableness may be the motive here. Targets are likely to possess a greater value than those in the offender's lower rank area. 26

Residential burglaries are Increasingly being imported to "wealthy, developed, and commercially enriched communties" that are easily accessible to the offender's residence.27 Furthermore, other things being equal, non-contact property crime offenders prefer targets containing fewer rather than more, potential guardians. Thus, an increase in the number of persons per household in transit to activities away from their residence produces an increase in criminal opportunity and a corresponding rise in property crime violations.28 In 1975 , over $\$ 400$ million in

${ }^{25}$ Christopher Dunn, The Patterns andDistribution of Assault Incident Characteristics Among social Areas, (Washington, D.C., 1976), p. 11.

26sarah L. Boggs, "Urban Crime Patterns", American Soclological Review, XXX (1965), pp. 899-908.

27simon Hakin, "The Attraction of Property Crimes to Suburban Localities: A Revised Economic Model", Urban Studies, XVII (1980), p. 275 .

28Lawrence E. Cohen, Marcus Felson and Kenneth C. Land, "Property Crime Rates in the United States: A Macro-dynamic Analysis, 1947-1977: With Ex Ance Forecasts for the Mid-1980"s", American Journal of Sociology, LXXXVI (1980), pp. $90-118$. 
cash and property were lost in burglaries. Four-fifths of the goods were never recovered.29

Suburbs are not only importing property crimes from the central cities, other problems are being introduced as well. Suburbs are taking on more of the socio-economic and physical characteristics of an urban center. As the characteristics such as size, density, and the employment/residence ratio increase and the percentage of the population that is low income or black rises, crime rates climb. 30

\section{The Guardian}

The criminal justice system, is a complex, multi-faceted system that includes the police, the courts, the prisons, and the probationary/parole system. However, the brunt of the deterrence effort falls upon the police department's shoulders. The police mission is the raintenance of social order within certain ethical and constitutional restrictions. It involves:

(1) The Prevention of criminality- This activity views the police role in constuctive terms and concerns involving the police in sectors of the community where criminal tendencies are brea and motivated and includes seeking to reduce the causes of crime.

${ }^{29}$ U.S. Department of Justice, The Cost of Negligence: $\frac{\text { Losses }}{\text { D.C. }} \frac{\text { from }}{1979)}$ Preventable Household Burglaries, Twashington, 30John M. Stahura, Ronald Huff and Brent Smith, "Crime in the Suburbs", Urban Affairs Quarterly, XV (March, 1980), pp. 29l-316. 
(2) The Repression of crime-This focuses on adequate patrol and a continuous role toward eliminating or reducing hazards as the principal means of reducing the opportunities for criminal behavior.

(3) Apprehension of offenders- This activity views quick apprehension as a means to discourage the would-be offender and, at the same time, enable society to punish wrong-doers.

(4) Recovery of property- Efforts to reduce the monetary costs of crime as well as to restratn those who wight benefit from the gains of a criminal act.

(5) Regulation of non-criminal conduct- This involves numerous activities not always directly concerned with criminal behavior, such as the enforcement of traffic and sanitary code provisions.

(6) Performance of miscellaneous services-This involves the performance of a variety of activities related to police duties including the operation of detention facilities, search and rescue operations, and licensing. 31

The overall level of police expenditures is dependent upon the demand for police services generated by the populace. Given a particular police budget, the department must decide how to distribute its services within the communty. Two alternatives are available.

(1) Equality of service level- Under this method, assuming each neighborhood has an equal proportion of the total population, each precinct receives an equal proportion of the total budget. Thus, all residents are provided with an identical bundie of services.

${ }^{31}$ Texas Crime Prevention Institute, Principles and Practices of Crime Prevention, p. 9 . 
(2) Efficiency in terms of the minimization of the incidence of total crime- Since victimization probabilities are different in each neighborhood, resources are allocated so that the marginal rates of crime prevention are equal for all precincts. This results in a redistribution of wealth from the predominately low crime middle-class residential districts to denser, poorer, and older neighborhoods of the central city. It is the most efficient and effective method of reducing crime with public resources. 32

\section{Crime Prevention Policies}

Crime prevention can be defined as the "anticipation, the recognition, and the appraisal of a crime risk, and the initiation of action to remove or reduce it."33 Actions taken to reduce crime may be labeled punitive, corrective, or mechanical. They may be performed by specialists in the criminal justice system or by the general citizenry. Numerous crime reduction activities have been developed to alter either the offender's or the victin's behavior or to change the environment in which they interact.

32 David Kennett, "The Distribution of Unpriced Public Goods, a Frame with Some Empirical Results for Police Services", American Economist, XXIII (Spring, 1979), pp. $22-27$.

${ }^{33}$ Texas Crime Prevention Institute, Principles and Practices of Crime Prevention, p. 14 . 


\section{Offender Policles}

Policles directed at the actual or prospective criminal include rehabilitation, incapacitation, and detercence. Ideally, potential or actual criminal's preferences should be altered by increasing their attachment to socially acceptable norms and reducing their taste for risk. However, reducing poverty, improving housing, or equalizing educational opportunities can not in the short run counteract the effects of a disorganized environment. 34

A slight rehabilitative effect has been found for youthful offenders immediately after their entry into prison. It appears to be attributable to deflated expectations about the wisdom of criminal behavior. Extended imprisonment, however, reverses this effect and the relative expected value of criminal choice increases significantly. 35

Incapacitation refers to the physical restraint of offenders by confining them in jails. This results in a reduction in crime because, during the period of his incarceration, a criminal is unable to comit more crimes. The United States during the $1960^{\prime} \mathrm{s}$ viewed imprisonment with

$34 \mathrm{James} Q$. Wilson and Barbara Boland, "Crine", in The Urban Predicament, edited by William Gorham and Nathan Glazer, (Washington, D.C., 1976), Pp. 193-196.

${ }^{35}$ Anthony R. Harris, "Imprisonment and the Expected value of Criminal Choice: A Specification and Test of Aspects of the Labeling Perspective", Amerlcan Sociological Review, XL (February, 1975), pp. $71-87$. 
declining favor. Despite an enormous increase in crime, the prisoner population declined. 36

The third method of alleviating crime d.s termed

deterrence. It is based upon the assumption that an

offender acts rationally and will perform iliegal activities

if the expected utility to hin from the act exceeds the

utility he could gain by utilizing hts time and resources in legal endeavors.37 Thus, deterrence can be viewed as the attempt to lower the private benefits of the criminal or to raise his private costs.

\section{Potential Victims Policies}

Two dimensions of citizens' crime prevention behavior have been defined: avoidance and access control. Citizens restrict their actions so that they will not enter into a situation that might lead to a criminal confrontation. They drive rather than walk, avoid certain local areas that they perceive as being dangerous, and limit the amount of cash that they carry.

Access control refers to the safeguarding of the residential target. Locks, alarms, and guard dogs are purchased. Deliveries are stopped and neighbors are asked

${ }^{36}$ David M. Gordon, Problems in Political Economy: An Urban Perspective, $(197 \overline{6), p, 2} 1 \overline{1}$.

37Gary S. Becker, "Crime and Punishment: An Economic Approach", Journal of Pol1cical Economy, LXXVI (March/Apri1, 1968), pp. $\overline{169-217}$. 
to watch homes when they are to be unoccupied for long

periods of time.38

Numerous crime prevention initiatives by potential

victims may take place at the individual level. Individual activities include residential security surveys, property marking programs, Installation of residential security systems, and personal avoidance techniques.

Residential security survey programs involve the law enforcement public sector and the private individual. An in-depth on-site examination of the physical factlity and its surrounding property is conducted by the police to determine the facility's security status. Deftciencles and related security risks are identified and actions are recomended to minimize criminal opportunity.39 The implementation of the suggested alterations is left to the private individual. Compliance is hampered by cost. Property marking programs, commonly known as operation Identification, seek to deter burglars by encouraging citizens to mark valuable property with a unique, traceable number or name that can be used to identify the item and

${ }^{38}$ Paul J. Lavrakas and Dan A. Lewis, "The Conceptualization and Measurement of Citizens' Crime Prevention Behaviors", Journal of Research ln Crime and Delinquency, XVII (Ju1y, 1980) pp. $\frac{254-272}{\text {. }}$

39v.S. Department of Justice, Crine Prevention Security Surveys, Phase I Report, (Washington, D. C., 1977), $\overline{\text { p. }} 2$. 
establish 1 ts ownership if it is stolen.40 The existing programs have experienced difficulties. Participation has been minimal. Furthermore, no standard marking procedure has been developed. Therefore, marking has not facilitated the return of property or reduced the opportunity to fence it. 41

The function of residential security systems is to control access by strangers to the semimprivate and private areas of residences, to hamper forced entry, to increase the likelihood that an offender will be detected in the act through surveillance, to decrease the likelihood that an offender if discovered can escape, and to decrease the likelihood that a potential criminal will decide to commit a particular crime once he has observed the setting. 42

The probability that a structure will be a target of a crime during a specified period is a function of the crime pressure in the neighborhood and the vulnarability of the individual unit. While reduction in the vulnerability of one residence will reduce its $r i s k$, it increases the vulnerability of other residences in the area, because the criminal simply moves on to another nearby suitable target.

$40 \mathrm{Nelson} B$. Heller and others, Operation Identification Projects: Assessnent of Effectiveness, (Washington, D.C., 1975), p. 2.

4lJ.T. Duncan, Citizen Crime Prevention Tactics, (Washington, D.C., 1980), p.9.

42Arnold Sagalyn, Residential Security, (Washington, D.C., 1973 ), p. 9 . 
In principle, collective programs emphasize group action to make whole neighborhoods safer and less vulnerable to crime. Existing citizen patrols operate in neighborhoods with varied income and racial composition. There is also wide variation in operating activities. Some protect residents of a specific building, some perform surveillance on the streets of a poorly defined neighborhood, and others also engage in commity service functions in addition to crime prevention. There is wide variation in costs; however, most operate on a small budget and on a voluntary bas1s. Building patrols have been the most effective in reducing crime and increasing the residents' sense of security. 43

\section{Environmental Policies}

Proper design and effective use of the bullt environment can also lead to a reduction in crime and to an improvement in the quality of urban life. The physical environment affects the opportunities for crime. It provides places where the criminal act can occur unnoticed or where the criminal can watt inconspiciously. The offender will be deterred by the physical proximity of the pollce or citizen guardians. 44

43 Robert Yin and others, Citizen Patrol Projects, (Washington, D.C., 1979), pp. 1-31.

$44 \mathrm{U}$. S. Department of Justice, Reducing Residential Crime and Fear: The Hartford Neighborhood Crime Prevention Program, (Washington, D.C.), Pp.1-7. 
Differentiation of space and the assumption of

territoriality through design can have a crucial impact upon the development of proprietary attitudes and increased citizen surveillance activities. 45 Defensible space is a design concept consisting of four features.

The defintion of space which demarcates areas of influence of the inhabitants and creates territorial attitudes, the positioning of windows to allow natura 1 surveillance of public areas, the adoption of building forms and idioms which avoid the stigma of peculiarity and the suggestion of vulnerabtlity, and the location of developments away from areas that provide continued threat. 46

Architectural design can create spaces which can be defended. Actual intervention in a crime in such an area, however, will depend upon the individual's sense of responsibility and his effective modes of intervention. Thus, defensible space design may lead to disappointing results if the social fabric necessary for defensive behavior and the institutional supports for effective intervention are absent. 47

45 Arnold Sagalyn, Residential Security, (Washington, D.C., 1973), pp. 34-36.

46Sally E. Merry, "Defens1ble Space Undefended", Urban Affairs Quarterly, XVI (June, 1981), p. 398 .

47 I bid., PP. $397-422$. 


\section{Crime Prevention Model}

A model has been developed to describe the demand for and supply of crime prevention services. 48

\section{Supply of Criminal offenses Function}

(a.1) $0=f$ (Soc, Pay, Pol, Priv)

$0=$ Supply of criminal offenses

Soc = Socioeconomic indices

Pay = Expected payoff from criminal activity

Pol = Deterrence factor of police intervention

Priv = Deterrence factor of citizen crime prevention meas ures

The supply of crimes is a function of four basic elements. First, the environment surrounding an individual will have an effect upon his propensity towards criminal behavior. Socioeconomic indices such as percentage poverty, percentage youth, education, median income from legitimate sources, percentage nonwhite, and unemployment rates will affect an individual's time horizons and thus his perceptions of the costs if apprehended.

The second element in the equation pertains to the expected wage or payoff from going into crime. The aggregate property value and median income of the community can measure the potential income that could be gained from criminal activities-the greater the income level, the

${ }^{48}$ These functions are based in part upon the work of Daryl A. Hellman and Joel Naroff, The Urban Public sector and Urban Crime: A Simultaneous Systems Approach, (Washington, D.C., 1980). 
greater the opportunities. Housing stock characteristics and the lumpiness of density that indicate the quantity, quality, and mix of structures within an area provide some notion of the availability of suitable sites for crime. The third element pertains to the deterrence factor of police intervention. The individual contemplating crime compares the benefits to be derived from such activity with the wages that could be gained in legitimate endeavors. However, an adjustment must be made for the probability that the criminal will not be able to enjoy the fllegal benefits. Thus, measures of arrest rates, conviction rates, and laprisonment terms are appropriate indicators of deterrence. An estimation of the police crime prevention effort should also be included. As police expenditures increase, the department is in a better position to exercise tts guardianship duties. 49

Finaliy, citizen preventive techniques can impact the supply of criminal offenses. As individuals and connunities harden the target by taking preventive measures, less victimization is apt to occur. Measures of purchases of preventive devices and private security services provide some indication of this factor. 


\section{Demand for Pollce Services Function}

(a.2) $\mathrm{Pol}=\mathrm{E}\left(0,0_{t-1}, \mathrm{CRev}\right)$

where:

$\mathrm{Pol}=$ Deterrence factor of police intervention 0 - Supply of criminal offenses

CRev = City revenue

The demand for police crime prevention services depends upon two factors. First, the existing crime and the past supply of offenses impacts the demand for police in two ways. One comes from the actual need for protection by businesses and residents in the community. The other is more psychological, and grows as the fear of being victimized 1 ncreases. 50

The second element that affects demand for police services concerns the wealth and class status of the commity. In determining the level of police services that a community will demand, inhabitants consider not only the cost of providing for safety, but they weigh the marginal benefit that they will recelve from reducing the crime rate.51 Wealthier areas demand more preventive services. Not only do they have more to lose, but they also are better

50, Jeffrey I. Chapman, "An Economic Model of Crime and Pollce: Some Empirical Results", Journal of Research in Crime and Delinquency, XIII (January, 1976), p. 57 .

$5 l E m a n u e l$ Haas, "The Supply and Demand for Municipal Crime Prevention", American Economist, XXIV (Spring, 1980), p. 11 . 
able to afford the expense. The property of demand is measured by city revenue. 52

\section{Demand for Private Preventive Services Function}

(a.3) Priv $=f\left(0,0_{t-1}\right.$, PRev, CRev $)$

The demand for personal crime prevention activities is a function of three factors. The existing crime occurring in the community and the wealth and social class of the citizens will impact the amount of private services that are obtained. Furthermore, a trade off will occur between public and private preventive activities.

Private protection can be substituted for public protection. The extent of this substitution depends in part on the relative costs of publically and privately provided inputs. These costs are affected by the available technology and the relative efficiency and effectiveness of public and private production. 53

Changes in one location can impact the production of public services in adjacent locations. Increases in suburban population create a large demand for central city services; even when central city size and age, per capita

52Daryl A. Hellman and Joel Naroff, The Urban Public Sector and Urban Crime: A Simultaneous System Approach, (washington, D.C. $\frac{\text { C. }}{1980), \text { pp. }} \frac{112-115}{1}$

53Charles T. Clotfelter, "Public Services, Private Substitutes, and the Demand for Protection Against Crime", The American Economic Review, LXVII (December, 1977), pp. $\overline{867}-\overline{877}$. 
Income of central city residents, and the percentage non-white in the central city population are held constant.54 The suburban population, through its daily use of central city factlitles substantially raises the costs of all municipal services without providing the necessary revenues in the form of sales taxes, employment taxes, or user fees with which to finance the added services. Interjurisdictional spillovers within a metropolitan area can also occur between suburbs. When the level of police expenditures is ralsed in one communtty, property crime--particularly burglary and auto theft--flows to an adjacent area. It is estimated that a dollar increase in police expenditures per capita in a community will generate a five cent increase in police expenditures per capita in neighboring areas. 55

In conclusion, crlme is a problem that pervades every corner of our society. No group and no area are Immune. Numerous avenues--public and private--are being investigated to ascertain their effect upon crime rates. No sure answer has been discovered, and none probably ever will be. It would be impossible to eradicate all crime. Some level will persist. It is the cost that society must pay for the benefits of freedom and affluence. However, concerted

$54 \mathrm{~J}$ ohn D. Kasarda, "The Impact of Suburban Population Growth on Central City Service Functions", American Journal of Sociology, LXXVII (1972), p. 1120 .

55 Simon Hakin, "The Attraction of Property Crimes to Suburban Localities: A Revised Economic Model", Urban Studies, XVIL $(1980)$, p. 211 . 


\begin{abstract}
effort will still provide useful results. Cooperative activities between the public and private sectors should be directed toward prevention before the fact rather than apprehension after the deed. If crime is perceived as being too costly by the perpetrator, then fewer ill deeds will be committed. Not only should this reduce criminal incldences, but it should also improve the communty spirit.
\end{abstract}


APPENDIX B

LAB EXPERIMENT CASES AND RESEARCH INSTRUMENT

Background Case Material

Past Program outputs

Post Program Outcomes-Failure Case

Past Program Outcomes--Successful Case

Past Program Impacts--Eailure Case

Past Prograr Impacts--Successful Case

Research Instrument 
After considerable public outcry over rising urban crime and increasing constituent pressure, the United States Congress, in November 1982, created an emergency fund to be used to halt this upward trend. It will be actninistered by the Crime Attack Task Eorcema select group of experts in the field. Fund monies may be used to finance any local project aimed at preventing or reducing crime. Acceptable specific programs may focus upon the potential victim, the criminal, or any portion of the public sector that serves in a guardianship capacity, such as the poice, the judiciary, the prison system, or the parole/probationary apparatus. The only restriction placed upon the usage of funds is that acceptable projects must have been operational at the local level for at least one year prior to the grant request.

The general philosophy of the Crime Attack Task Force is to assist local entities that have operated successful programs. If the funding for these local crime prevention campaigns is assumed by the federal C.A.T. Fund, then local dollars originally needed to finance these programs will be released and new, more experimental preventive efforts can then be funded locally. It is hoped that old successes will breed new successes.

Your job, as head of the Crime Attack Task Force and administrator of the C.A.T. Fund is (1) to review all fund request proposals as they come in, (2) to decide whether a particular project is acceptable, and (3) to determine the level of funding that will be granted. It is anticipated that approximately 300 requests for federal funds will be received in 1983 . They will range from $\$ 100,000$ to $\$ 800,000$ and will total about $\$ 100$ million. Congress approved $\$ 50$ milition to be spent in 1983 from the C.A.T. Fund. Therefore, all proposals received can not be approved and those that 
are will not necessarily be funded at the requested levels. Any proposal can be funded at any dollar amount up to the total requested in the budget proposal. Unfortunately, however, you can not wait until all proposals are received to make your final allocation decisions. Since local entities may request funds throughout 1983, you must decide each case on its own merits when the request is received.

You are asked to make a funding decision on one request for 1983 funds. Metro City Police Department prepared and submitted this proposal to you on January 18, 1983. All information contained in the document has been audited by Metro's independent certified public accountantsasmith and Jones, C.P.A.'s. Remember, you may decide not to fund the request, to grant the full request, or you may allocate any dollar amount between the two extremes. There are no right of wrong answers. 
1983 BUDGET PROPOSAL

AGENCY REQUESTING FUNDS: Metro City Police Departnent FUNDS REQUESTED: $\$ 440,000$ 
AGEs:CY: Metro City Police Department

I. PROGRAM DESCRIPTION DESCRIPTION OF THE ACTIVITIES TO BE CONDUCTED IN THE PROPOSED PROGRAM.

A ten-month general media advertising campaign will be conducted to encourage citizens to undertake their own crime prevention measures. Commercials will be developed to be aired on orime viewing-time television and prime drive-time radio. In addition, advertisements will be placed in area newspapers and on city buses. The campaign slogan will be "Don't Ask For It". Basically, we want Metro City residents to help us by helping themselves. We want them to start doing a few simple things to make their homes, their persons, and their property safer from criminals.

II. BUDGET RECAPITULATION = SUMMARIZATION OE THE PROPOSED 1983 EXPENSES BY MAJOR EUNCTIONAL CATEGORIES AND COMPARISON WITH 1982 BUDGETED AND ACTUAL EXPENDITURES.

\section{CATEGORY}

1. Television Spots

2. Radio Spots

3. Newspaper Ads

4. City Bus Ads

5. Production/Misc. Total
1983

PROPOSED

BUDGET

130,000

95,000

87,000

28,000

100,000

440,000

The 1983 proposed budget was increased $30 \%$ over the 1982 estimates to double the number of commercials produced and to increase media coverage by $15 \%$.

III. PROJECTED PROGRAM OUTCOME DESCRIPTION OF THE EEEECT ON THE TARGET POPUEAT ION THE AGGENCY EXPECTS AS A RESULT OF 1983 ACTIVITIES.

Motivate $10 \%$ of the population to take positive action in crime prevention.

IV. PROJECTED PROGRAM IMPACT = PROJECTION OF THE ANTICIPATED BENEEIT THE COMMUNITY WILL RECEIVE IN 1983 IN TERMS OE POPULATIONS SERVED OR PROBLEMS ADDRESSED.

Reduce major stranger-to-stranger crime by 5\% from 1982 Metro levels. 
V. TARGET POPULATION - DESCRIPTION OF THE CHARACTERISTICS OF THE POPULATION TO BE SERVED.

Total Population (1980 Census)

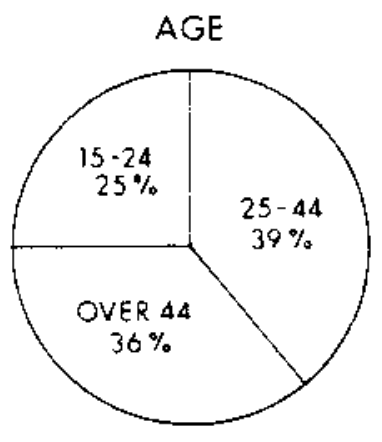

MARITAL STATUS

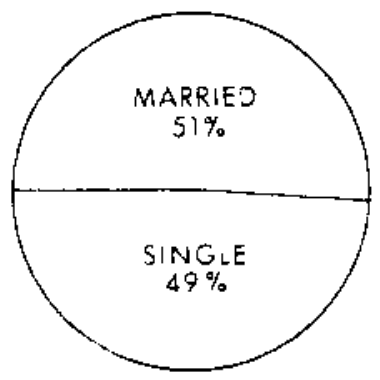

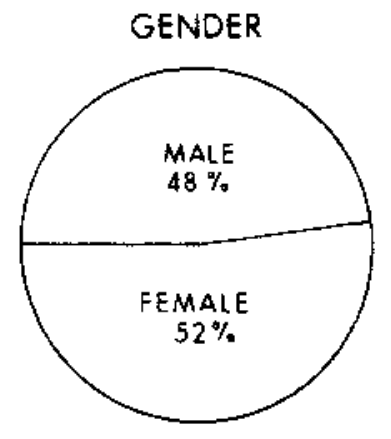

TENURE

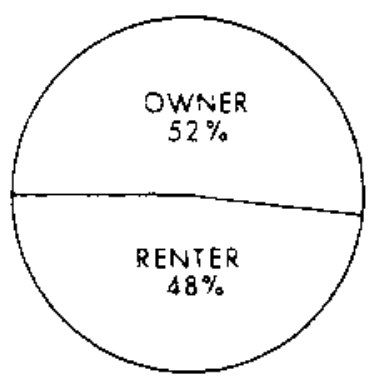

900,000
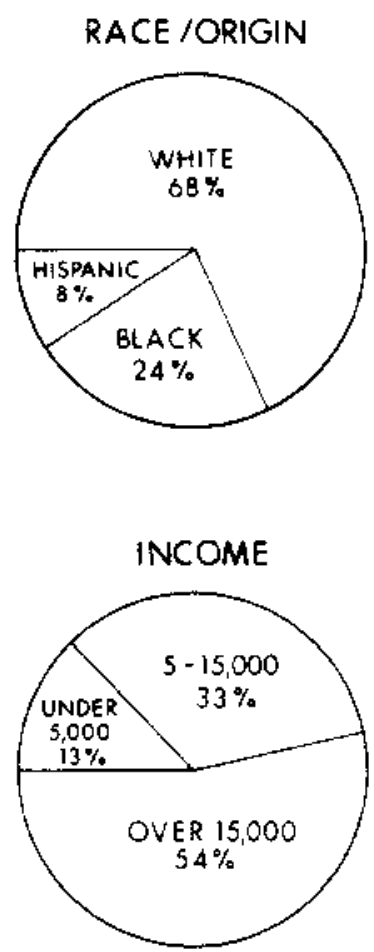

VI. CRIMINAC VICTIMIZATION - DESCRIPTION OF THE CURRENT LEVEL OE CRIME IN THE COMMUNITY.

Reported Victimization - Per National Crime Surveys conducted in Metro City in 1978 and 1981. (Adjusted for population changes)

$$
1981
$$

Victimization

Before

Introduction

of Prograrn

Inc rease

since

1978

Personal Sector:

Rape

Robbery

Assault

Personal Larceny

Household Sector:

Burglary

Household Larceny

Motor Venicle Theft

Commercial Sector:

Burglary

1,100

7,800

21,700

73,700

$22 \%$

$10 \%$

$20 \%$

47,300

$15 \%$

52,500

$28 \%$

6,900

-

19,700

$19 \%$

Robbery

2,600 
VII. PAST PROGRAM OUTPUTS - DESCRIPTION OF THE GOOOS OR SERVICES PRODUCED BY THE RROGRAM IN 1982.

Television Advertising:

- 5 30-second commercials were created

- 900 spots were aired during prime viewing-time on 5 stations

Radio Cormerciais:

- a series of 10 and 30-second radio spots were developed

- 3700 spots were broadcast during prime drive-time on 19 stations

Newspaper Ads:

- 7 ads were created

- $3 / 4$ page ads appeared 270 times in 15 local publications

Brochures:

- 1 million handout brochures were created

Transit System:

- a series of 10 cards with different messages were developed

- 80 buses displayed tailgate cards

- 150 buses had interior cards 
VIII. PAST PROGRAM OUTCOMES - DESCRIPTION OF THE CHANGES IN THE PERCEIVED CONDITIONS OF THE TARGET POPULATION AS A RESULT OE THE 1982 PROGRAM ACTIVITIES. ALTERATIONS MAY OCCUR IN THE TARGET'S PHYSICAL, MENTAL, OR EMOTIONAL STATE.

Three surveys were conducted of Metro citizens before, at the mid point, and within two weeks after the completion of the 1982 advertising program. Subjects were asked whether they could recall having seen or heard any advertising recently about what they could do to help prevent crime. Typically, for a public service campaign, anything over a $20 \%$ increase in recall during the period of the advertising program would be viewed as highly successful. In this instance, no more respondents recalled such advertising in the post-program survey than did prior to the commencement of the campa ign.

\section{GENERAL RECALL OF CRIME PREVENTION ADVERTISING}

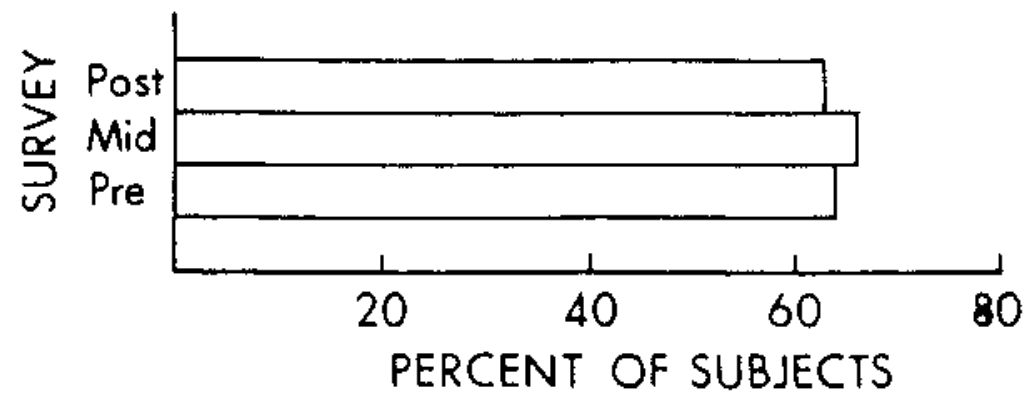

Litizens were also asked about their perceptions of the importance of numerous crime prevention techniques and whether they had recently implemented any of the measures. Survey results indicated that citizens' attitudes concerning the importance of personal crime prevention increased slightly during the 1982 program period. 1\% more people also indicated in the post-program survey than had in the mid-survey that they were more likely to employ crime prevention measures now than six months earlier. Typically, positive behaviorial changes resulting from public service campaigns of $4-7 \%$ are considered to be good. 
VIII. PAST PROGRAM OUTCOMES - DESCRIPTION OF THE CHANGES IN THE PERCEIVED CONDITIONS OF THE TARGET POPULATION AS A RESULT OF THE 1982 PROGRAM ACTIVITIES. ALTERATIONS MAY OCCUR IN THE TARGET'S PHYSICAL, MENTAL, OR EMOTIONAL STATE.

Three surveys were conducted of Metro citizens before, at the mid point, and after the completion of the 1982 advertising program. Subjects were asked whether they could recall having seen or heard any advertising recently about things they could do to help prevent crime. Typically, for a public service campaign, anything over a $20 \%$ increase in recall during the period of the advertising program would be viewed as highly successful. In this instance, 23\% more respondents recalled such advertising in the post-program survey than did prior to the commencement of the campaign.

\section{GENERAL RECALL OF CRIME PREVENTION ADVERTISING}

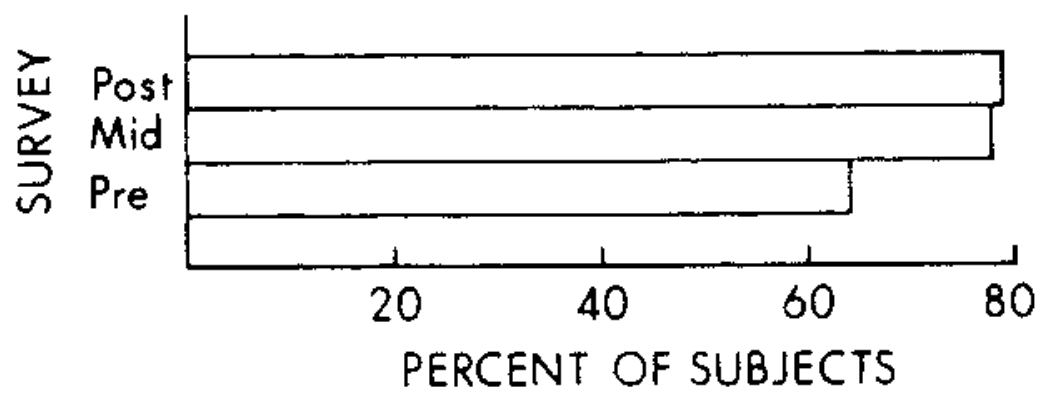

Citizens were also asked about their perceptions of the importance of numerous crime prevention techniques and whether they had recently implemented any of the measures. Survey results indicated that citizens' attitudes concerning the importance of personal crime prevention increased slightly during the 1982 program period. 16.7\% more people also indicated in the post-program survey than had in the mid-survey that they were more likely to employ crime prevention measures now than six months ago. Typically, positive behaviorial changes resulting from public service campaigns of $4-7 \%$ are considered to be good. 
IX. PAST PROGRAM IMPACTS - DESCRIPTION OE THE EFEECTS OF THE PROGRAM UPON THE BROADER SOCIAL CONDITIONS IN THE COMMUNITY IN 1982.

\begin{tabular}{|c|c|c|c|c|c|}
\hline \multirow[b]{2}{*}{ Crime } & \multicolumn{4}{|c|}{$\begin{array}{l}\text { Offenses per Month } \\
\text { ed for Population Changes) }\end{array}$} & \multirow[b]{2}{*}{$\begin{array}{c}1982 \\
\text { National } \\
\text { Percentage } \\
\text { Inc rease } \\
\end{array}$} \\
\hline & $\begin{array}{l}\text { Before } \\
\text { Program }\end{array}$ & $\begin{array}{l}\text { After } \\
\text { Program }\end{array}$ & $\begin{array}{c}\text { Increase } \\
\text { (Per Month) }\end{array}$ & $\begin{array}{l}1982 \\
\text { Metro City } \\
\text { Percentage } \\
\text { Increase } \\
\end{array}$ & \\
\hline Murder & 32 & 32 & -- & -- & -- \\
\hline Rape & 69 & 77 & 8 & $12 \%$ & $3 \%$ \\
\hline Assault & 467 & 489 & 22 & $5 \%$ & $4 \%$ \\
\hline Robbery & 308 & 358 & 50 & $16 \%$ & $5 \%$ \\
\hline Auto The ft & 715 & 793 & 78 & $11 \%$ & -- \\
\hline Burglary & 2189 & 2274 & 85 & $4 \%$ & $1 \%$ \\
\hline Larceny & 3598 & 3773 & 175 & $5 \%$ & $4 \%$ \\
\hline \multicolumn{6}{|c|}{$\begin{array}{l}\text { There was an increase in all types of crime except murder during the } \\
\text { period while the crime prevention advertising program was } \\
\text { operational. Assault, burglary, and larceny displayed lower } \\
\text { increases than did rape, robbery, and auto theft. National crime } \\
\text { offenses increased during the same period at similar rates. }\end{array}$} \\
\hline
\end{tabular}

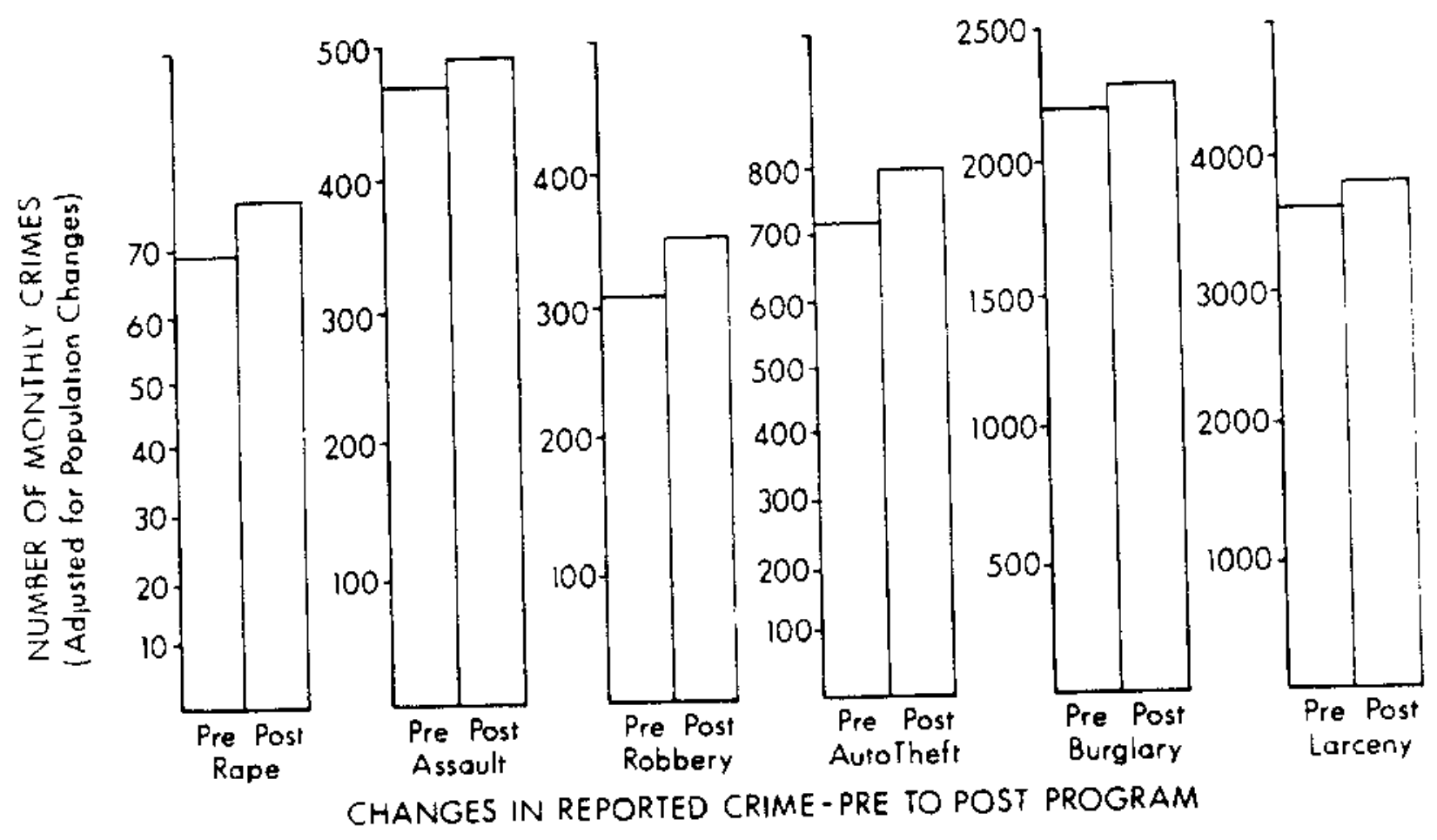


IX. PAST PROGRAM IMPACTS - DESCRIPTION OF THE EFEECTS OF THE PROGRAM UPON THE BROADER SOCIAL CONDITIONS IN THE COMMUNITY IN 1982 .

\begin{tabular}{|c|c|c|c|c|c|}
\hline \multirow[b]{2}{*}{ Crime } & \multicolumn{4}{|c|}{$\begin{array}{l}\text { Offenses per Month } \\
\text { ed for Population Changes) }\end{array}$} & \multirow[b]{2}{*}{$\begin{array}{c}1982 \\
\text { Nationa } 1 \\
\text { Percentage } \\
\text { Inc rease } \\
\end{array}$} \\
\hline & $\begin{array}{l}\text { Before } \\
\text { Program }\end{array}$ & $\begin{array}{l}\text { After } \\
\text { Program }\end{array}$ & $\begin{array}{c}\text { Dec line } \\
\text { (Per Month) }\end{array}$ & $\begin{array}{l}1982 \\
\text { Metro City } \\
\text { Percentage } \\
\text { Decline } \\
\end{array}$ & \\
\hline Murder & 32 & 32 & $\therefore$ & - & -- \\
\hline Rape & $6 y$ & 61 & 8 & $(12 \%)$ & $3 \%$ \\
\hline Assault & 467 & 445 & 22 & $(5 \%)$ & $4 \%$ \\
\hline Robbery & 308 & 258 & 50 & $(16 \%)$ & $5 \%$ \\
\hline Auto Theft & 715 & 637 & 78 & $(11 \%)$ & -- \\
\hline Burglary & 2189 & 2104 & 85 & $(4 \%)$ & $1 \%$ \\
\hline Larceny & 3598 & 3423 & 175 & $(5 \%)$ & $4 \%$ \\
\hline
\end{tabular}

An abrupt and permanent reduction in all types of major crime except murder occurred when the crime prevention advertising program was launched. The drop was quite spectacular in rape, robbery, and auto theft, but assault, burglary, and larceny also recorded significant declines. National crime rates increased during the same period.

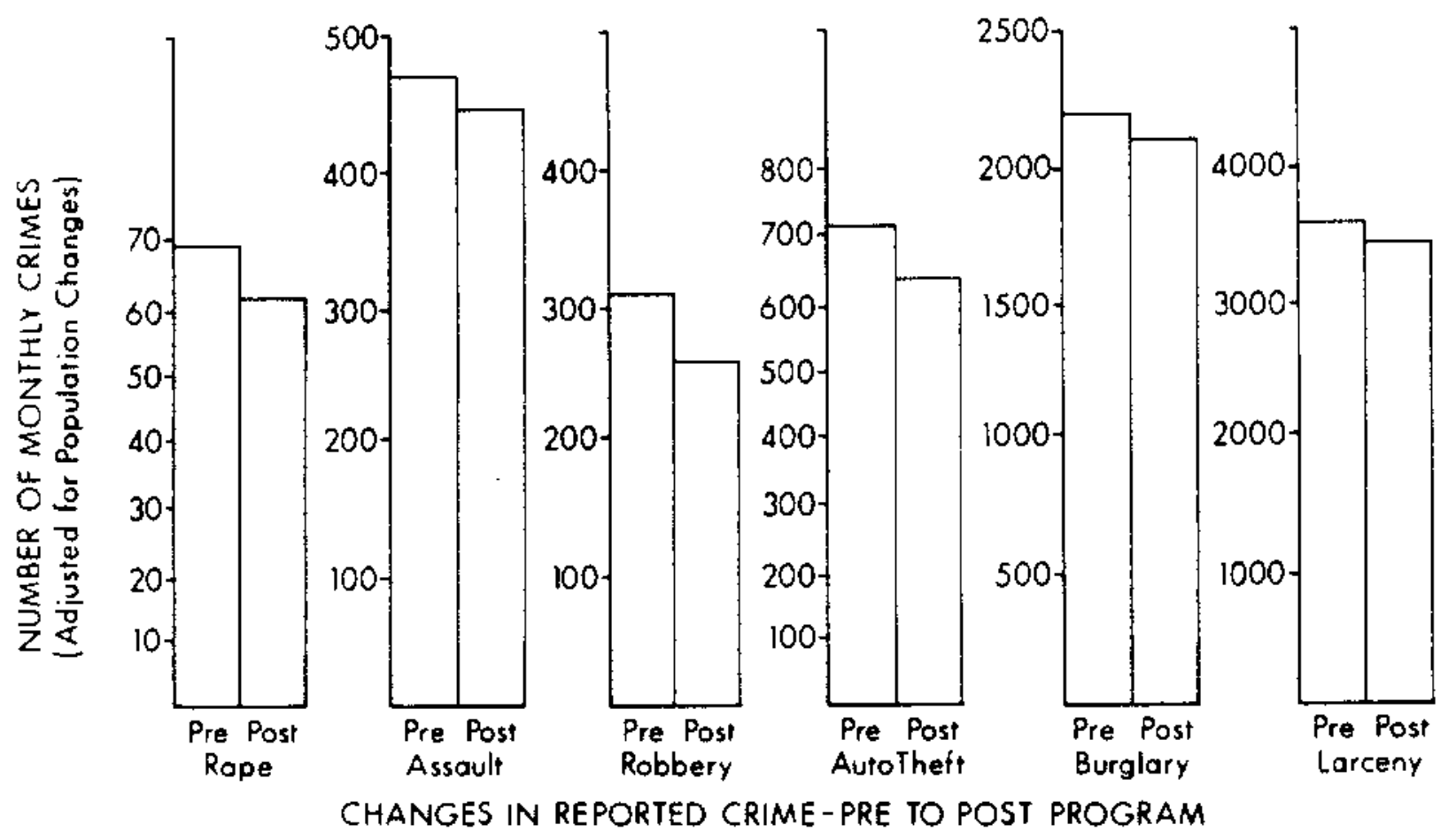




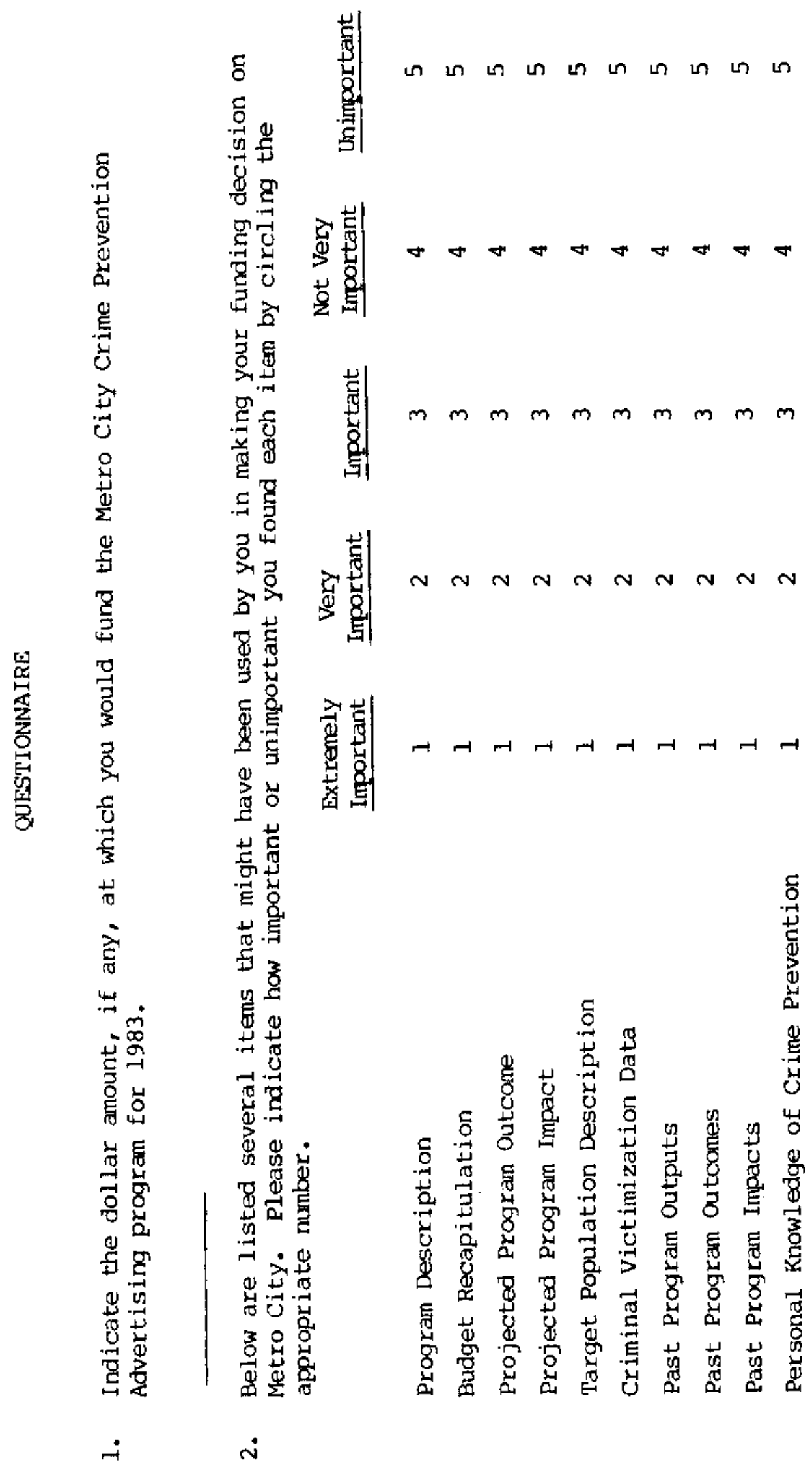




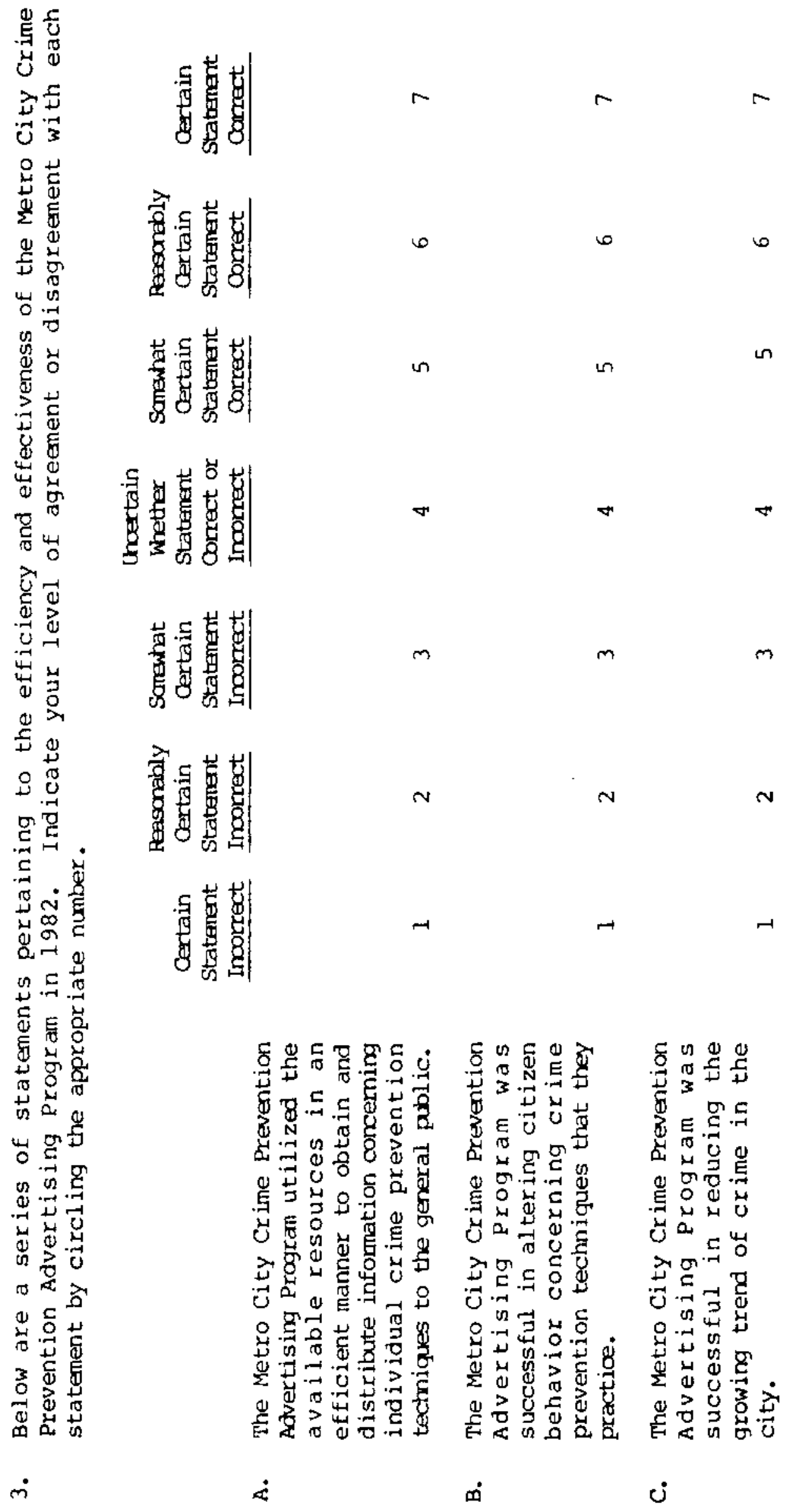




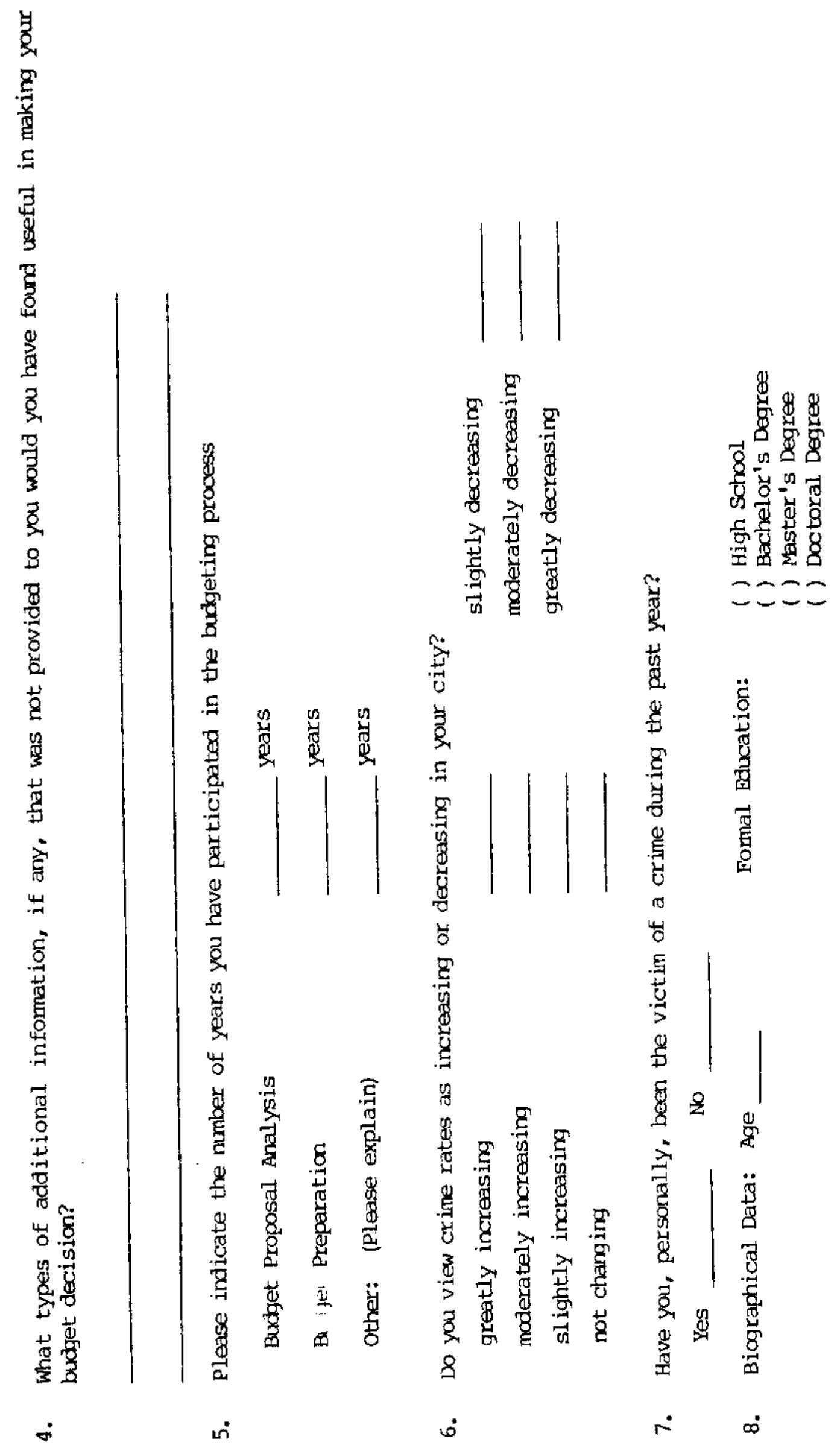


APPENDIX C. PROGRAM OUTCOMES

Recall of Advertising

Crime Prevention Techniques

Conclusion 


\section{APPENDIX C}

\section{PROGRAM OUTCOMES}

Tabular results of three surveys conducted by Louis, Bowles and Grove were analyzed utilizing the chi-square method to ascertain if people's attitudes concerning critue prevention and their reported implementation of such techniques varied across time and/or across socio-economic groups. In general, the preventive measures were concerned with home, vehicular, and personal security. A list of the specific techniques addressed in the survey is presented below.

Home Security:

1. Keep your home locked when away.

2. Keep your home locked even when home during the day.

3. Keep your home locked during the night when asleep.

4. Install stronger locks on your doors.

5. Install extra locks on windows of your house.

6. Install steel grills or bars on windows of home.

7. Install burglar alarm.

8. Ask friends or neighbors to pick up your mail and newspapers while on vacation.

9. Close and lock garage doors when away from home. 10. Close and lock garage when at home. 11. Mark personal property with identification numbers.

Vehicle Security:

1. Lock packages and valuables in car trunk.

2. Lock your car when you leave it with valuables inside.

3. Lock your car when you leave it to keep it from being stolen.

4. Lock your car when not in use, even at home.

5. Chain and lock bicycles when not in use. 


\section{Personal Security:}

1. Leave porch and yard lights on at night to discourage prowlers.

2. Be suspicious of strangers, at home and away.

3. Install peephole in door.

4. Never open door to strangers, unless they identify themselves.

5. Require identification of door-to-door salesmen.

6. Keep your car doors locked even when driving.

7. Never hitchilke or accept rides from strangers.

8. Never pick up hitchhikers or give rides to strangers.

9. Avoid being alone at night and avoid dark places.

10. Never carry or show a large amount of money.

Respondents were asked how important each measure was in preventing crime and whether the subject was more likely to do each item at the date of the survey compared with six months earlier. Additional questions dealt with the extent of crime prevention advertising recall and the perceived source of such communication.

Identical instruments were utilized for each survey with one important exception. In the preprogram questionnaire, subjects were not asked if they had recently altered their crime preventive behavior. Thus, any significant change in actions over the entire program could not be ascertained. Reported items in this instance only reflect changes over the second half of the program. A discussion of all survey results that were statistically significant at the .05 level of probability follows.

Recall of Advertising

Recall of crime prevention advertising increased over time. All socio-economic groups displayed significant 
changes. Seventy-eight per cent of the post-program subjects remembered having seen or heard crime prevention advertising in the past, while only 64 per cent indicated such recall in the survey conducted prior to the implementation of the ad campaign. As may be seen in Table XXVII, the major change in recall occurred at the onset of the ad campaign. Only Blacks and respondents with incomes of less than $\$ 5000$ reported a significant increase during the final five months. Recall of crime prevention advertising varied across socio-economic groups. Respondents living in high crime areas, Whites, persons aged 25-44, married individuals, home owners, and participants with incomes greater than $\$ 10,000$ displayed significant $1 y$ greater recall than did other survey respondents (Table XXVIII). However, there was no appreciable difference between men and women in their recollection of crime prevention advertising .

The effectiveness with which the Dallas Police Department was able to convey its message is also indicated by the fact that respondents increasingly over time remembered seeing or hearing the advertising in three different communication mediums (Table XXIX). Television advertisements were by far the most effective in inducing reca11. Nevertheless, knowledge of newspaper messages and radio spots also significantly increased over time. Only Hispanics, persons residing in medium crime areas, young 
Table XXVII

RECALL, OF CRIME PREVENTION ADVERTISING BY PERIOD

\begin{tabular}{lccc}
\hline & & Program & \\
\cline { 2 - 4 } Socio-Economic Group & & Pre & Post \\
\hline Total & .64 & .77 & .79 \\
High Crime Area & .69 & .80 & .78 \\
Medium Crime Area & .61 & .74 & .76 \\
Low Crime Area & .57 & .77 & .84 \\
Men & .64 & .78 & .79 \\
Women & .64 & .77 & .78 \\
White & .69 & .86 & .86 \\
Black & .54 & .56 & .66 \\
Mexican & .53 & .73 & .58 \\
15-24 Age & .61 & .77 & .76 \\
25-44 Age & .66 & .82 & .82 \\
Over 44 Age & .64 & .73 & .78 \\
Single & .59 & .72 & .74 \\
Married & .68 & .82 & .83 \\
Owner & .68 & .83 & .82 \\
Renter & .62 & .72 & .74 \\
Less than \$5000 Income & .51 & .58 & .68 \\
\$5000 \$999 Income & .61 & .73 & .77 \\
Over \$15,000 Income & .71 & .91 & .89 \\
\hline
\end{tabular}


Table XXVIII

RECALL OF CRIME PREVENTION ADVERTISING

BY SOCIO-ECONOMIC GROUP

\begin{tabular}{|c|c|}
\hline & Recall \\
\hline \multicolumn{2}{|l|}{ Area Crime Rate: } \\
\hline High Crime & .76 \\
\hline Medlum Crime & .70 \\
\hline Low Crime & .73 \\
\hline \multicolumn{2}{|l|}{ Ethinic Group: } \\
\hline White & .80 \\
\hline Black & .58 \\
\hline Hispanic & .62 \\
\hline \multicolumn{2}{|l|}{ Age: } \\
\hline $15-24$ & .71 \\
\hline $25-44$ & .76 \\
\hline Over 44 & .72 \\
\hline \multicolumn{2}{|l|}{ Marital Status: } \\
\hline Single & .68 \\
\hline Married & .78 \\
\hline \multicolumn{2}{|l|}{ Tenure: } \\
\hline Owner & .79 \\
\hline Renter & .68 \\
\hline \multicolumn{2}{|l|}{ Income: } \\
\hline Less than $\$ 5,000$ & .59 \\
\hline$\$ 5,000-\$ 9,999$ & .70 \\
\hline$\$ 10,000-\$ 14,999$ & .83 \\
\hline Over $\$ 15,000$ & .85 \\
\hline
\end{tabular}


Table XXIX

RECALL OF LOCATION OF ADVERTISING BY PERIOD

\begin{tabular}{|c|c|c|c|c|c|c|c|c|c|}
\hline & \multicolumn{3}{|c|}{ Newspaper } & \multicolumn{3}{|c|}{ Radio } & \multicolumn{3}{|c|}{ Television } \\
\hline & Pre & $\mathrm{Mid}$ & Post & Pre & Mid & Post & $\overline{\text { Pre }}$ & Mid & Post \\
\hline Total & .10 & .14 & .21 & .12 & .12 & .20 & .50 & .65 & .66 \\
\hline High Crime Area & .12 & .14 & .23 & .13 & .12 & .18 & .52 & .68 & .63 \\
\hline Low Crime Area & .08 & .13 & .26 & .11 & .08 & .28 & .46 & .61 & .71 \\
\hline Men & .10 & .13 & .17 & .15 & .12 & .22 & .50 & .66 & .66 \\
\hline Women & .10 & .16 & .24 & .09 & .11 & .17 & .50 & .63 & .66 \\
\hline White & .12 & .17 & .24 & .12 & .14 & .19 & .54 & .72 & .72 \\
\hline Black & .08 & .08 & .15 & .12 & .05 & .24 & .43 & .47 & .55 \\
\hline $25-44$ Age & .09 & .17 & .21 & .15 & .14 & .21 & .53 & .70 & .68 \\
\hline Over 44 Age & .13 & .15 & .29 & .11 & .08 & .19 & .47 & .60 & .64 \\
\hline Married & .11 & .17 & .23 & .12 & .12 & .19 & .54 & .72 & .69 \\
\hline Owner & .10 & .17 & .25 & .12 & .12 & .19 & .54 & .72 & .70 \\
\hline$\$ 5,000-\$ 9,999$ & & & & & & & & & \\
\hline Income & .08 & .10 & .19 & .10 & .07 & .21 & .49 & .63 & .66 \\
\hline
\end{tabular}


adults, single individuals, renters, the very poor, and persons with incomes greater than $\$ 10,000$ did not significantly alter their recollections of where crime prevention advertising had originated.

Recall of pamphlets dealing with crime prevention also increased over time (Table XXX). Only 23 per cent of the respondents initially remembered ever having seen such a publication. This increased to 34 per cent at the mid point of the campaign and then dropped to 28 per cent in the third survey. As may be observed in Table XXXI, persons in medium crime areas, Blacks, young adults, single individuals, renters, and the poor were less likely to recall such advertising than were other respondents.

\section{Crime Prevention Techniques}

Even though advertising recall significantly improved, it remained to be seen whether the campaign had any impact upon citizens' perceptions of the importance of various techniques in preventing crime and whether they had altered their own behavior in recent months. As stated before, the crime prevention techniques studied were grouped into three categories: 1) home security, 2) vehicular security, and 3) personal security. Each category will be discussed in turn.

\section{Home Security}

Eleven crime prevention techniques dealt with home security. Table XXXI presents data concerning the 
Table XXX

RECALL OF CRIME PREVENTION PAMPHLETS BY PERIODS

\begin{tabular}{|c|c|c|c|c|c|c|c|c|c|}
\hline & \multicolumn{3}{|c|}{ No Recal1 } & \multicolumn{3}{|c|}{ Recall-Have } & \multicolumn{3}{|c|}{ Recal1-Not } \\
\hline & Pre & Mid & Post & Pre & Mid & Post & Pre & Mid & $\overline{\text { Post }}$ \\
\hline Total & .77 & .66 & .72 & .11 & .17 & .15 & .12 & .17 & .13 \\
\hline Heavy Crime Area & .74 & .60 & .76 & .13 & .21 & .12 & .13 & .19 & .12 \\
\hline Low Crime Area & .77 & .64 & .62 & .11 & .17 & .22 & .12 & .20 & .16 \\
\hline Men & .75 & .66 & .71 & .12 & .15 & .16 & .13 & .19 & .13 \\
\hline Women & .78 & .66 & .73 & .11 & .19 & .14 & .11 & .15 & .13 \\
\hline White & .74 & .62 & .74 & .14 & .20 & .13 & .12 & .18 & .13 \\
\hline Biack & .81 & .80 & .68 & .07 & .10 & .18 & .12 & .10 & .14 \\
\hline Hispanic & .80 & .61 & .72 & .05 & .13 & .17 & .15 & .27 & .11 \\
\hline $25-44$ Age & .74 & .61 & .73 & .13 & .20 & .14 & .13 & .19 & .14 \\
\hline Over 44 Age & .77 & .66 & .68 & .12 & .17 & .20 & .11 & .17 & .13 \\
\hline Single & .81 & .73 & .75 & .07 & .11 & .12 & .12 & .16 & .12 \\
\hline Married & .73 & .61 & .70 & .15 & .21 & .17 & .12 & .18 & .14 \\
\hline Owner & .75 & .62 & .68 & .13 & .21 & .18 & .12 & .17 & .13 \\
\hline$\$ 5,000-\$ 9,999$ & & & & & & & & & \\
\hline Income & .83 & .69 & .72 & .07 & .16 & .17 & .10 & .15 & .11 \\
\hline Over $\$ 10,000$ & & & & & & & & & \\
\hline Income & .71 & .56 & .70 & .16 & .21 & .14 & .13 & .23 & .16 \\
\hline
\end{tabular}


Table XXXI

RECAIL OF CRIME PREVENITON PAMPHLETS

BY SOCIO-ECONOMIC GROUP

\begin{tabular}{|c|c|c|c|}
\hline & $\begin{array}{c}\text { No } \\
\text { Recail }\end{array}$ & $\begin{array}{c}\text { Recall } \\
\text { Have }\end{array}$ & $\begin{array}{c}\text { Recall } \\
\text { Not }\end{array}$ \\
\hline \multicolumn{4}{|l|}{ Area Crime Rate: } \\
\hline High Crime & .70 & .15 & .15 \\
\hline Medium Crime & .77 & .11 & .12 \\
\hline Low Crime & .68 & .17 & .16 \\
\hline \multicolumn{4}{|l|}{ Ethnic Group: } \\
\hline White & .70 & .16 & .14 \\
\hline Black & .77 & .11 & .12 \\
\hline Hispanic & .70 & .12 & .18 \\
\hline \multicolumn{4}{|l|}{ Age: } \\
\hline $15-24$ & .77 & .10 & .13 \\
\hline $25-44$ & .69 & .16 & .15 \\
\hline Over 44 & .70 & .16 & .14 \\
\hline \multicolumn{4}{|l|}{ Marital Status: } \\
\hline Single & .77 & .10 & .13 \\
\hline Married & .68 & .18 & .14 \\
\hline \multicolumn{4}{|l|}{ Tenure: } \\
\hline Owner & .68 & .18 & .14 \\
\hline Renter & .75 & .11 & .14 \\
\hline \multicolumn{4}{|l|}{ Income: } \\
\hline Less than $\$ 5,000$ & .77 & .09 & .14 \\
\hline$\$ 5,000-\$ 9,999$ & .75 & .13 & .12 \\
\hline$\$ 10,000-\$ 14,999$ & .68 & .19 & .13 \\
\hline Over $\$ 15,000$ & .65 & .17 & .18 \\
\hline
\end{tabular}


Table XXXII

HOME SECURITY MEASURES

TOTAI OPINION BY PERIOD

\begin{tabular}{|c|c|c|c|}
\hline & \multicolumn{3}{|c|}{ Very Important } \\
\hline & Pre & Mid & Post \\
\hline \multicolumn{4}{|l|}{ Importance of Techniques: } \\
\hline Keep home locked when away & .90 & .95 & $.92^{*}$ \\
\hline Keep home locked when home & .72 & .73 & .71 \\
\hline Keep home locked when asleep & .91 & .94 & $.94 *$ \\
\hline Install stronger locks on doors & .67 & .74 & $.70 *$ \\
\hline Install extra locks on windows & .42 & .51 & $.44 *$ \\
\hline Install grills/bars on windows & .31 & .28 & .29 \\
\hline Insta1l burglar alarm & .34 & .29 & .33 \\
\hline Have mail picked up while on vacation & .71 & .79 & $.77^{\star}$ \\
\hline Lock garage doors when away & .77 & .83 & $.83 *$ \\
\hline Lock garage doors when home & .51 & .60 & $.62 *$ \\
\hline \multirow[t]{3}{*}{ Mark property with ID } & .59 & .65 & $.68 *$ \\
\hline & \multicolumn{2}{|c|}{ More Likely } & to Do \\
\hline & & Mid & Post \\
\hline \multicolumn{4}{|l|}{ Likelihood of Using Techniques: } \\
\hline Keep home locked when away & & .39 & $.48 *$ \\
\hline Keep home locked when home & & .40 & $.44 *$ \\
\hline Keep home locked when asleep & & .38 & $.47 *$ \\
\hline Install stronger locks on doors & & .39 & $.44 *$ \\
\hline Install extra locks on windows & & .33 & $.38 *$ \\
\hline Install grills/bars on windows & & .22 & $.30^{\star}$ \\
\hline Install burglar alarm & & .22 & $.32 *$ \\
\hline Have mail picked up while on vacation & & .38 & .43 \\
\hline Lock garage doors when away & & .38 & $.45 *$ \\
\hline Lock garage doors when home & & .32 & $.41 *$ \\
\hline Mark property with ID & & .39 & $.47 *$ \\
\hline
\end{tabular}

*Significant at.05 level of probability 
percentage of respondents who constdered each measure very important and who indicated that they were currentiy moxe likely to use the technique than earlier.

opinions differed widely concerning the vartous measures. Much greater importance was placed upon techniques that required 1 ittle personal effort and expense than on those demanding a greater cost in time and money. However, respondents' opinions concerning the fmportance of home securtty consistently increased over time.

Furthermore, more respondents in the post-program survey indicated that they were more likely to make use of the preventive measures than did individuals at the mid point of the campaign. Again, however, many less subjects declared that they were more likely to install steel bars on their windows or burglar alarms in thefr homes after the completion of the campaign than to secure their houses in other ways. There was no change over time in the likelihood of having neighbors pick up mail and newspapers while on vacation.

Area Crime Rate.--In general, where there were significant dfferences among areas, individuals residing in locations experiencing high rates of crlme were more likely to consider home security measures very important than were persons elsewhere. They also reported that they were more likely to take the extreme measures of installing a burglar alarn or steel grills on the windows to prevent 
break-ins (Table XXXIII). Low crime area residents reported a higher incidence of recent behavioral change only in the case of keeping the home locked during the day even when at home.

Comparison of respondents in the heavy and low crime areas over time suggests that while the Dallas crime prevention program apparently had little effect upon high crime area residents' attitudes concerning the importance of home security measures, they were much more likely to implement many of these techniques after the program ended than they had been six months earlier (Table XXXIV). The opposite was true for low crime respondents. In this case the program was associated with attitude changes rather than actual behavioral changes (Table XXXV). These results suggest that when individuals existed in an environment where they were more likely to be victimized, the program created an impetus for action. At the other extreme, the ads caused a simple attitudinal change. Gender.--Significant1y more women considered home security measures to be very important than did men (Table XXXVI). The greatest differences were observed in securing the home when the respondent was home and in installing addtional locks on doors and windows.

Furthermore, female respondents' attitudes concerning the importance of such preventive devices increased significantly during the duration of the program. 
Table XXXIII

HOME SECURITY MEASURES

OPINION BY AREA CRIME RATE

\begin{tabular}{|c|c|c|c|}
\hline & \multicolumn{3}{|c|}{ Very Important } \\
\hline & Heavy & Medium & Low \\
\hline \multicolumn{4}{|l|}{ Importance of Techniques: } \\
\hline Keep home locked when away & .94 & .91 & .90 \\
\hline Keep home locked when home during day & .75 & .70 & .70 \\
\hline Have mail picked up while on vacation & .81 & .72 & .69 \\
\hline \multirow[t]{3}{*}{ Close/lock garage when away from home } & .83 & .80 & .78 \\
\hline & \multicolumn{3}{|c|}{ More Like1y to Do } \\
\hline & Heavy & Med Lum & Low \\
\hline \multicolumn{4}{|l|}{ Likelihood of Using Techniques: } \\
\hline Keep home locked when home during day & .38 & .46 & .45 \\
\hline Insta11 steel grills/bars on windows & .28 & .28 & .18 \\
\hline Install burglar alarm & .31 & .28 & .19 \\
\hline
\end{tabular}


Table XXXIV

HOME SECURITY MEASURES

HEAVY CRIME AREA OPINION BY PERIOD

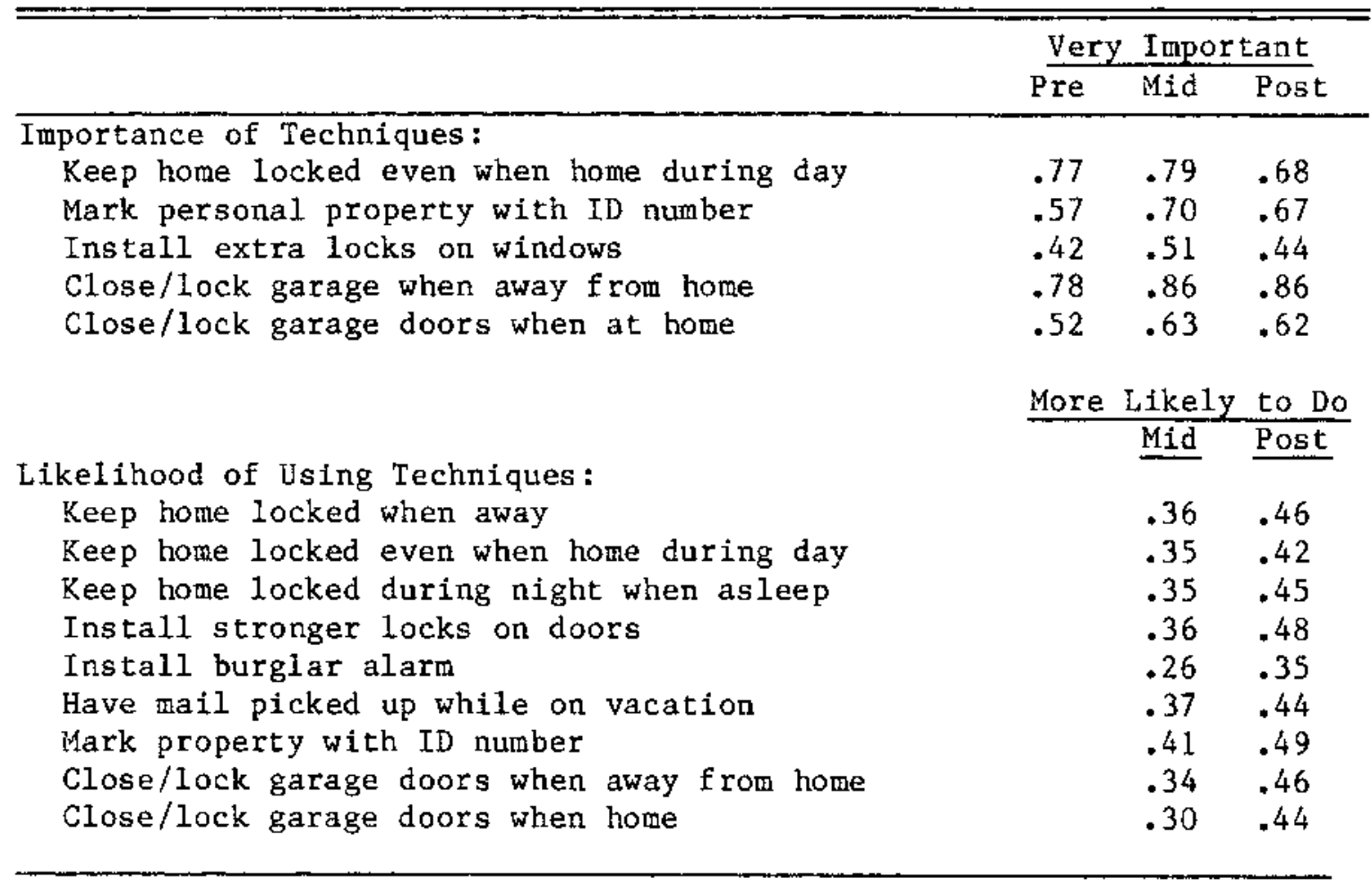


Table XXXV

HOME SECURITY MEASURES

LOW CRIME AREA OPINION BY PERIOD

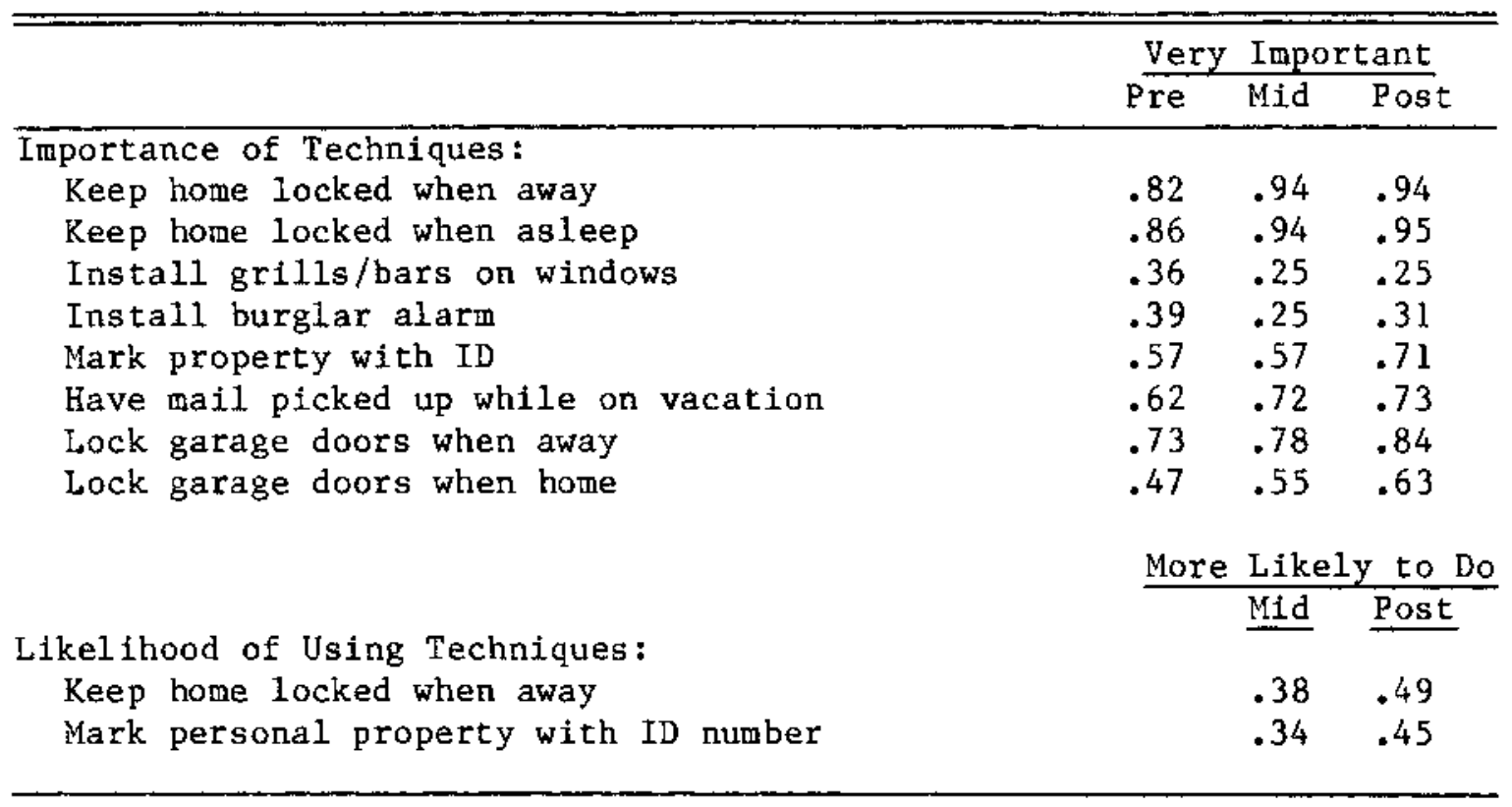

Table XXXVI

HOME SECURITY MEASURES

IMPORTANCE OF TECHNIQUES

OPINION BY GENDER

\begin{tabular}{lcc}
\hline & \multicolumn{2}{c}{ Very Important } \\
\cline { 2 - 3 } & Men & Women \\
\hline Keep home locked when away & .91 & .94 \\
Keep home locked when asleep & .91 & .94 \\
Install stronger locks on doors & .65 & .80 \\
Install extra locks on windows & .65 & .76 \\
Install steel grills /bars on windows & .42 & .53 \\
Install burglar alarm & .26 & .33 \\
Have mail picked up while on vacation & .29 & .35 \\
Lock garage doors when at home & .74 & .78 \\
\end{tabular}


Table XXXVII indicates that the major change was reported at the mid-program survey. Thus, the campaign apparently produced an abrupt alteration in females' attitudes of significant proportions. Men, on the other hand, displayed little such perceptual change.

Greater numbers of females also indicated that they were more likely to alter their behavior after the program was completed than they had been earlier (Table XXXVIII). However, in general there appeared to be little difference between the sexes in reported behavior.

Each group, nevertheless, individually reported several significant increases in the likelihood of implementing such techniques (Table $X X I X)$. Both sexes reported significant increases in the probability of locking their homes both when at home and away, locking their garages when at home, marking personal property and instaling burglar alarms. Different sexual patterns were apparent. The crime prevention program had little impact upon men's attitudes concerning home security measures, while it significanty affected women's perceptions of their importance. Nevertheless, both groups reported changes in their behavioral patterns during the critical period under study. Ethn1c Group.--With the exception of asking friends and neighbors to pick up mail and newspapers while on vacation, Whites were less likely to consider home security measures very important than were either Blacks or Hispanics 
Table XXXVII

HOME SECURITY MEASURES

IMPORTANCE OF TECHNIQUES

GENDER OPINION BY PERIOD

\begin{tabular}{|c|c|c|c|}
\hline & \multicolumn{3}{|c|}{ Very Important } \\
\hline & Pre & Mid & Post \\
\hline \multicolumn{4}{|l|}{ Women: } \\
\hline Keep home locked when away & .91 & .96 & .94 \\
\hline Keep home locked when asleep & .91 & .96 & .96 \\
\hline Have mail picked up while on vacation & .71 & .82 & .80 \\
\hline Install stronger locks on doors & .71 & .78 & .78 \\
\hline Mark property with ID & .57 & .68 & .72 \\
\hline Lock garage doors when away & .75 & .85 & .84 \\
\hline Lock garage doors when home & .56 & .64 & .68 \\
\hline \multicolumn{4}{|l|}{ Men: } \\
\hline Lock garage when at home & .45 & .55 & .55 \\
\hline
\end{tabular}

Table XXXVIII

HOME SECURITY MEASURES

LIKELIHOOD OF USING TECHNIQUES

OPINION BY GENDER

\begin{tabular}{lcc}
\hline & \multicolumn{2}{c}{ More Likely to Do } \\
\cline { 2 - 3 } & Men & Women \\
\hline Keep home locked when away & .39 & .47 \\
Keep home locked when home & .36 & .48 \\
Keep home locked when asleep & .39 & .46 \\
Lock garage doors when home & .34 & .40 \\
\hline
\end{tabular}


Table XXXIX

HOME SECURITY MEASURES

LIKELIHOOD OF USING TECHNIQUES

GENDER OPINION BY PERIOD

\begin{tabular}{lcc}
\hline & \multicolumn{2}{c}{ More Like1y to Do } \\
\cline { 2 - 4 } & Mid & Post \\
\hline Women: & .42 & .52 \\
Keep home locked when away & .41 & .51 \\
Keep home locked when asleep & .23 & .34 \\
Install burglar alarm & .22 & .31 \\
Install steel grills /bars on windows & .38 & .45 \\
Have mail picked up while on vacation & .39 & .49 \\
Mark property with ID & .36 & .44 \\
Lock garage doors while home & & \\
& & \\
Men: & .36 & .43 \\
Keep home locked when away & .35 & .43 \\
Keep home locked when asleep & .22 & .30 \\
Instal1 burglar alarm & .36 & .44 \\
Install stronger locks on doors & .39 & .46 \\
Mark property with ID & .29 & .39 \\
Lock garage doors when home & .36 & .45 \\
Lock garage doors while away & & \\
\hline
\end{tabular}


(Table XL). However, as can be seen in Table XLI, Whites reported numerous significant increases in their perceived importance of these preventive devices, while Blacks displayed such a pattern only once. In fact, the responding Blacks' oplnion of the importance of home security measures in preventing crime actually declined in four cases over the life of the program. The campaign also appeared to have little impact upon Hispanics' attitudes concerning the importance of home security devices. Only the installation of burglar alarms was perceived to be significantly more important at the end of the program than it had been at its onset.

Across the three ethnic groups, Blacks were much more likely to indicate that they had changed their behavioral patterns in the past six months (Table XLII). However, during the period of program lmplementation, they displayed the least significant increase in the use of such measures. Blacks reported only four significant increases, while Whites indicated six and Hispanics seven (Table XLIII). The program appeared to have the greatest impact upon this latter group where dramatic behavioral changes were reported. The only commonality reported among the three groups was an increased likelihood of installing steel grills or bars on windows and of locking the garage door when at home. 
Table XL

HOME SECURITY MEASURES

IMPORTANCE OF TECHNI QUES

OPINION BY ETHNIC GROUP

\begin{tabular}{lcccc}
\hline & \multicolumn{3}{c}{ Very Important } \\
\cline { 2 - 5 } & White Black Hispanic \\
\hline Keep home locked when home & .69 & .78 & .77 \\
Install stronger locks on doors & .69 & .76 & .68 \\
Install extra locks on windows & .42 & .59 & .60 \\
Install grilis/bars on windows & .22 & .45 & .40 \\
Install burglar alarm & .26 & .42 & .46 \\
Have mail picked up while on vacation & .78 & .68 & .72 \\
Mark property with ID & .59 & .74 & .73 \\
Lock garage doors when home & .53 & .68 & .58 \\
\hline
\end{tabular}

Table XLI

HOME SECURITY MEASURES

IMPORTANCE OF TECHNIQUES

ETHNIC GROUP OPINION BY PERIOD

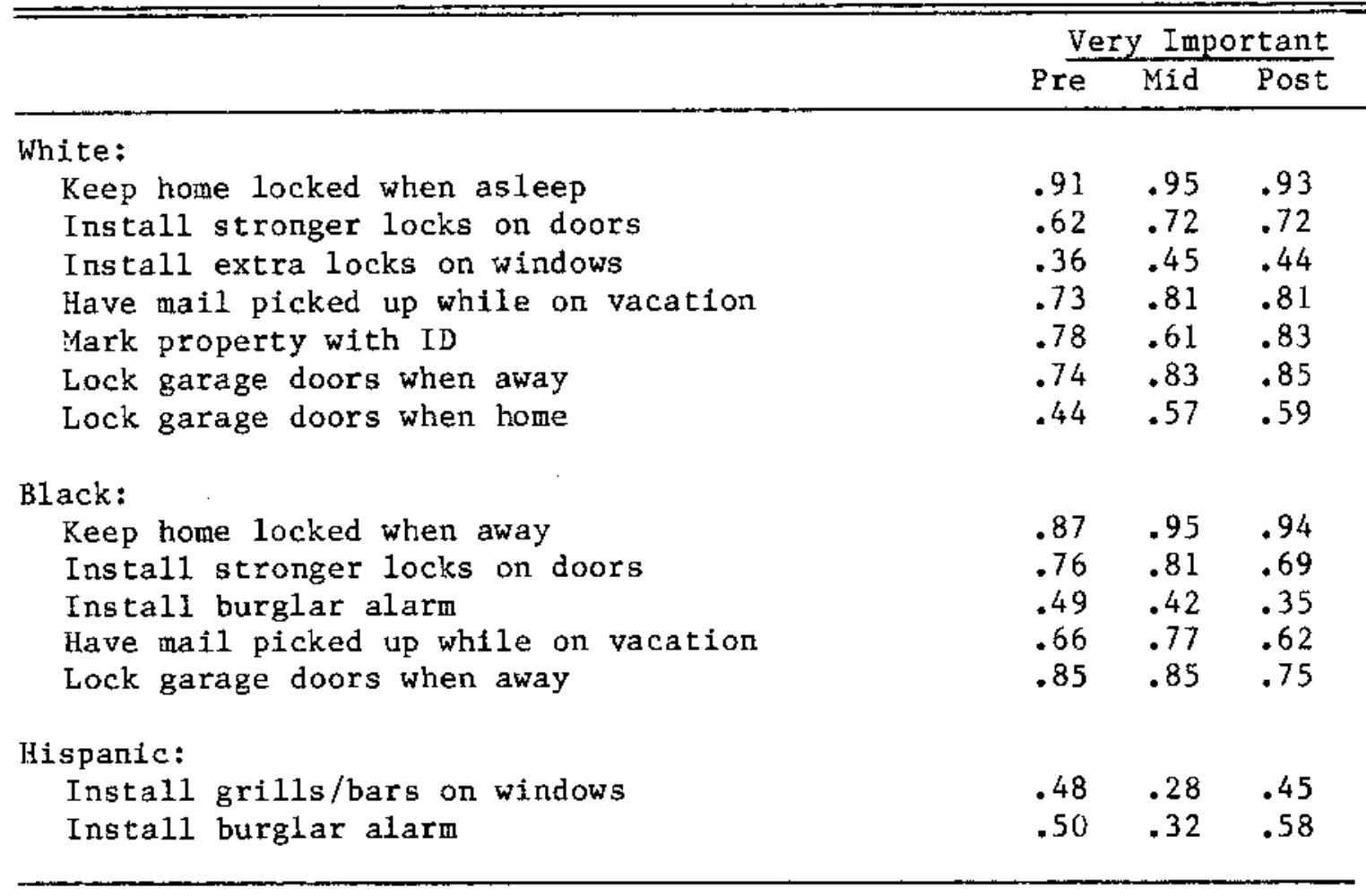


Table XLII

HOME SECURITY MEASURES

LIKELIHOOD OF USING TECHNIQUES

OPINION BY ETHNIC GROUP

\begin{tabular}{lccc} 
& \multicolumn{3}{c}{ More Likely to Do } \\
\cline { 2 - 4 } & \multicolumn{3}{c}{ White Black His panic } \\
\hline Keep home locked when home & .35 & .61 & .45 \\
Keep home locked when asleep & .34 & .66 & .46 \\
Keep home locked when away & .35 & .65 & .45 \\
Install extra locks on windows & .28 & .54 & .34 \\
Install burglar alarm & .24 & .35 & .29 \\
Install grills/bars on windows & .21 & .39 & .26 \\
Install stronger locks on doors & .37 & .57 & .40 \\
Have mail picked up while on vacation & .33 & .62 & .41 \\
Mark property with ID & .37 & .60 & .45 \\
Lock garage doors when away & .33 & .64 & .45 \\
Lock garage doors when home & .30 & .59 & .37 \\
\end{tabular}


Table XLIII

HOME SECURITY MEASURES

LIKELIHOOD OF USING TECHNIQUES

ETHNIC GROUP OPINION BY PERIOD

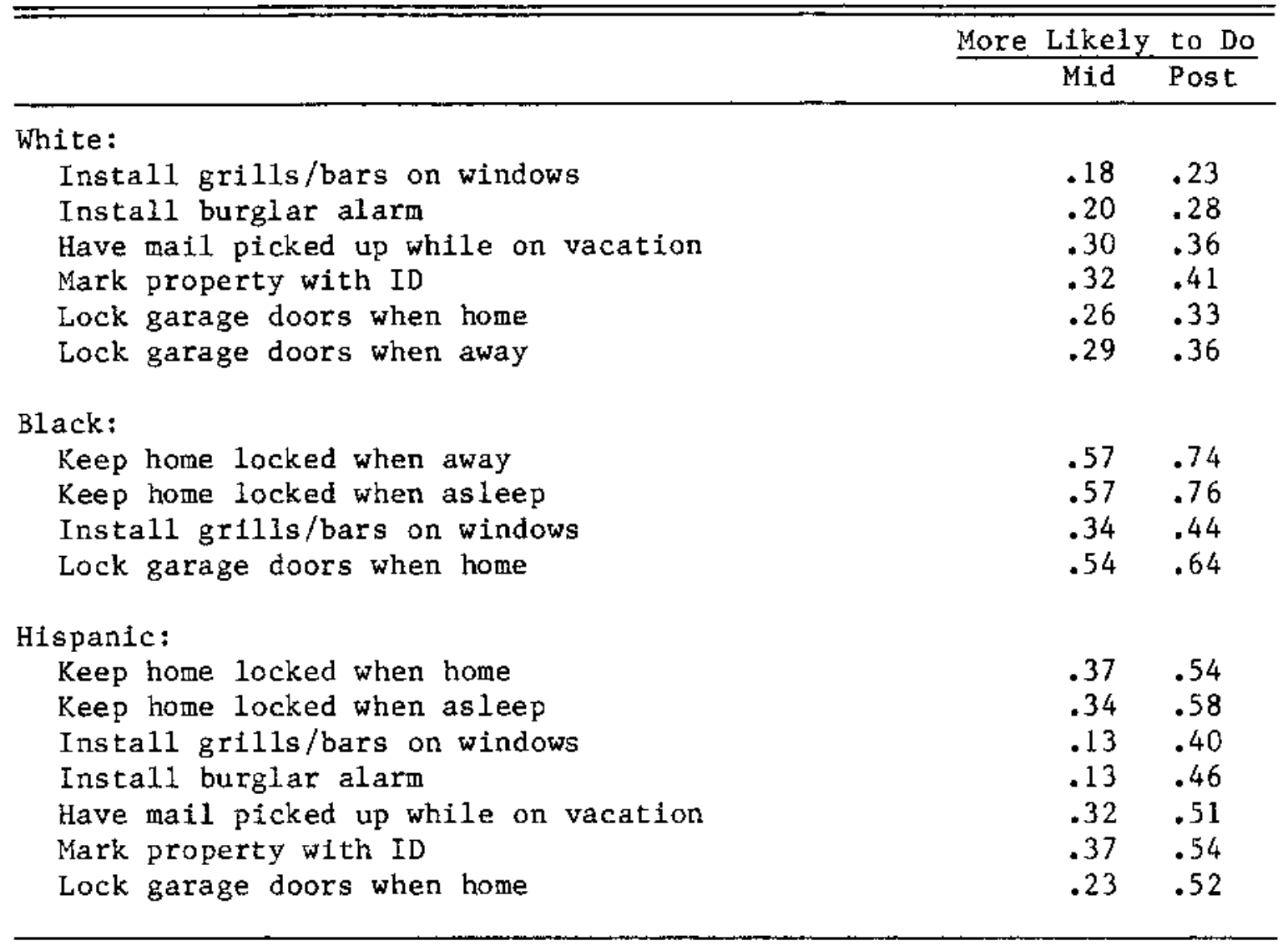


Age.--Table XlIV suggests that as individuals become older, they are more apt to consider home securtty measures to be very important. Significant differences across ages were particularly noted in techniques that dealt with securing the home while the respondent was there. Thus, the factor of personal safety appeared to enter into these differences in opinion among individuals of different ages. During the time of the program, however, both the old and the young reported significant changes in their perceptions of the importance of home security precautions (Table XLV). In most cases the major change occurred during the first half of the ad campaign. The young then displayed some decay in attitude after that point, while older adults experienced a more permanent change.

Negligible difference was noted across ages in respondents' reports of any increased likelihood of implementing home security devices. Significantly more young respondents ( 47 per cent) indicated a conversion of behavior pertaining to keeping their homes locked at night while asleep and marking personal property with an identification number then did older individuals ( 39 per cent). Nevertheless, the program appeared to have quite an impact upon the crime preventive behavior of adults aged 45 and older. Significant increases were noted in eight categories for this age group, and only five similar instances were reported elsewhere (Table XLVI). All three 
Table XLIV

HOME SECURITY MEASURES

IMPORTANCE OF TECHNIQUES

OPINION BY AGE

\begin{tabular}{lccc}
\hline & \multicolumn{3}{c}{ Very Important } \\
\hline Keep home locked when home & $15-24$ & $25-44>44$ \\
Keep home locked when asleep & .64 & .70 & .80 \\
Install grills /bars on windows & .91 & .93 & .94 \\
Have mail picked up while on vacation & .24 & .29 & .33 \\
Lock garage doors when home & .69 & .75 & .81 \\
\hline
\end{tabular}

Table XLV

HOME SECURITY MEASURES

IMPORTANCE OF TECHNIQUES

AGE OPINION BY PERIOD

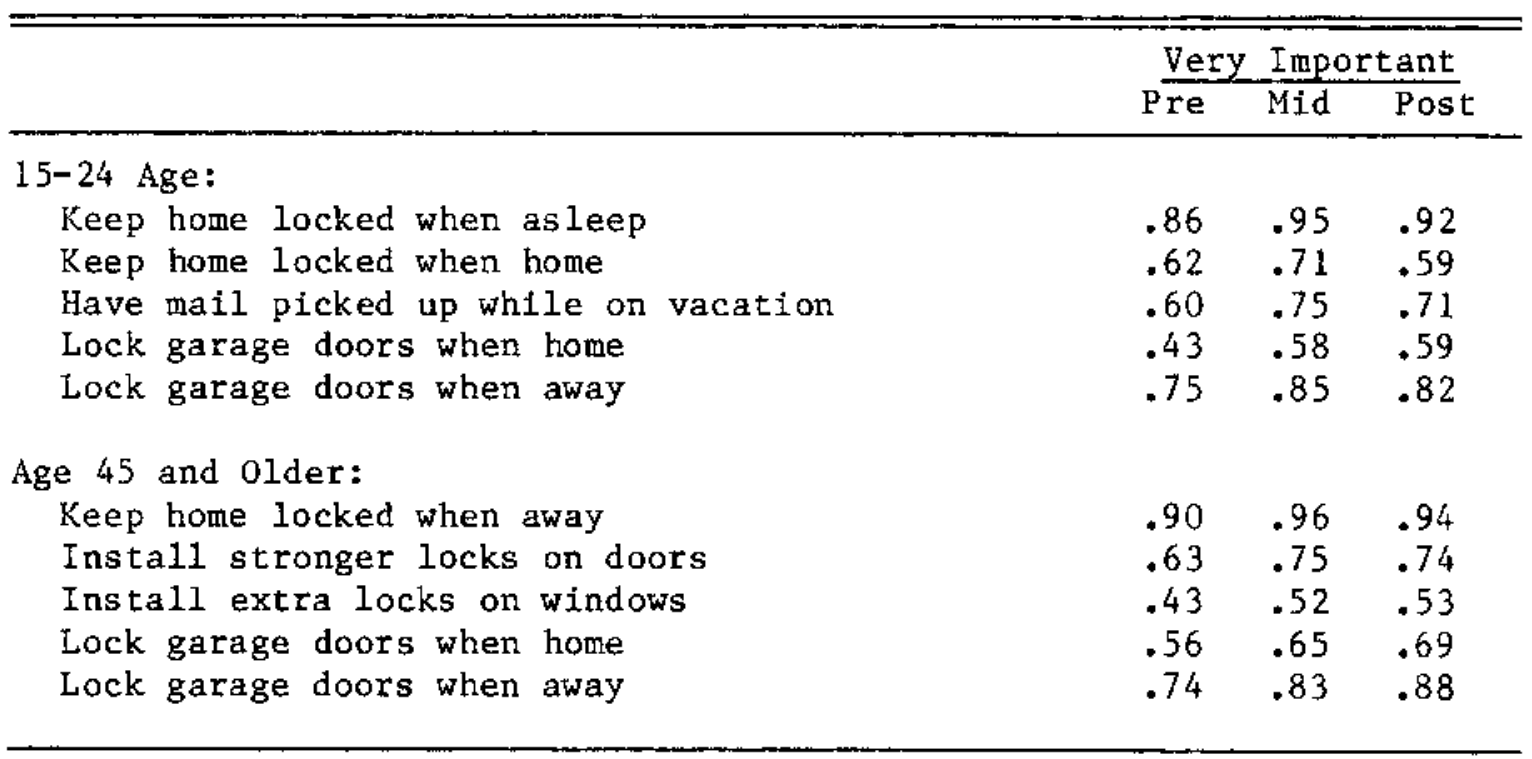


Table XLVI

HOME SECURITY MEASURES

LIKELIHOOD OF USING TECHNIQUES

AGE OPINION BY PERIOD

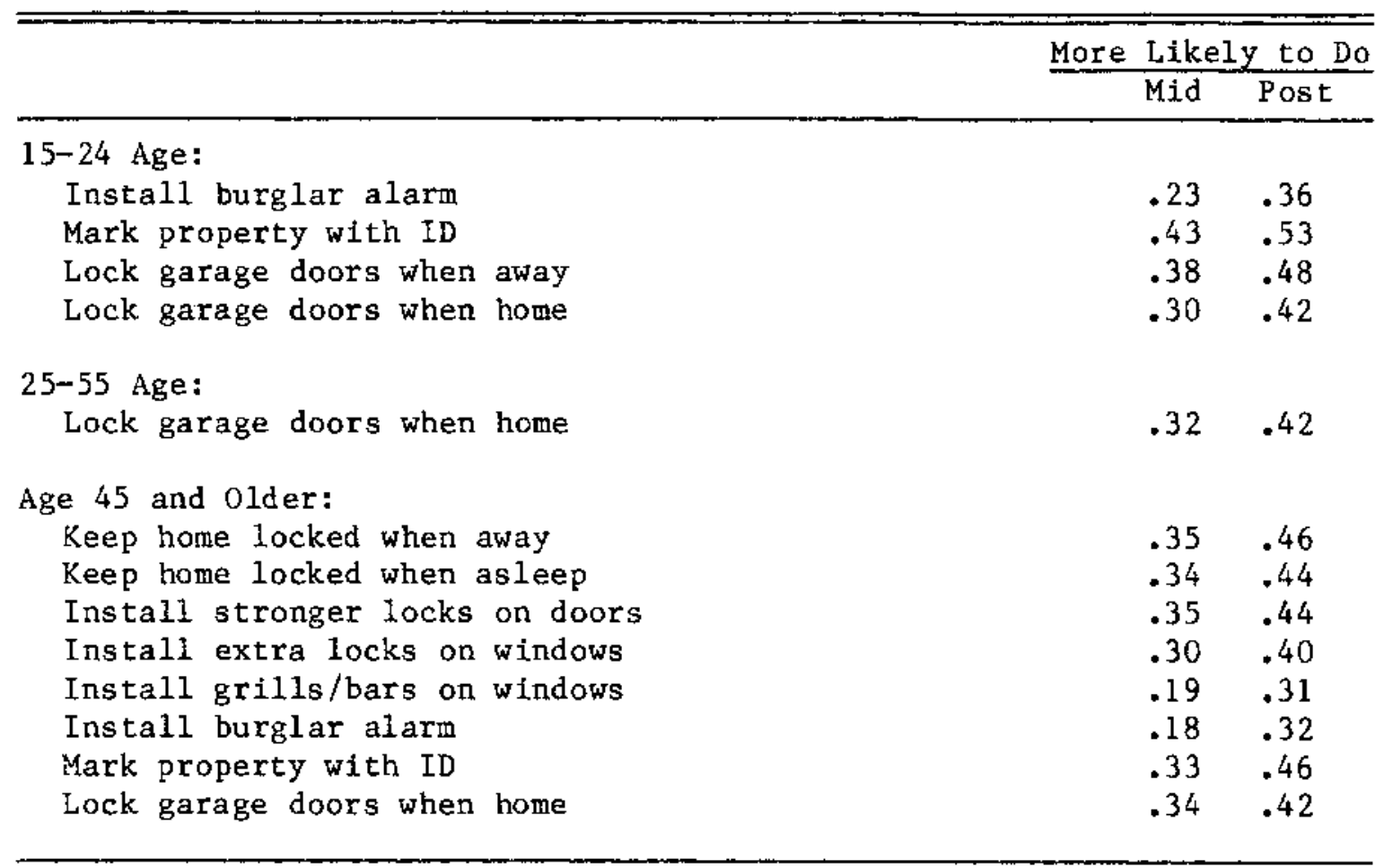


groups reported significant increases only in the likelihood of closing and locking the garage door when at home. These results indicate that the ad campaign altered perceptions for people of many ages, but generally only created an impetus for action among older adults.

Marital Status.--There were few significant differences noted between single and marrled individuals concerning either their opinions of the importance of crime preventive techniques or their reported behavioral changes. In four cases more married persons considered certain techniques to be very important and in two instances more single

respondents indicated that there was an increased likelihood that they would implement simple hone security measures than six months earlier (Table XLVII).

The crime prevention ad campaign appeared, however, to have a greater impact upon single persons than on married individuals. Singles increased their opinion of the importance of locking their abodes when home and away, installing stronger locks on doors, and properly marking personal valuables with identification number. They also indicated that they were more likely to implement such measures, as well as install additional security devices, after the program ended than they had been at the mid-point of the campaign (Table XLVIII). 
Table XLVII

HOME SECURITY MEASURES

OPINION BY MARITAI STATUS

\begin{tabular}{lcc}
\hline & \multicolumn{2}{c}{$\begin{array}{c}\text { Very Important } \\
\text { Single Married }\end{array}$} \\
\hline $\begin{array}{l}\text { Importance of Techniques: } \\
\text { Keep home locked when away }\end{array}$ & .91 & .94 \\
Keep home locked when home & .67 & .76 \\
Keep home locked when asleep & .91 & .94 \\
Have mail picked up while on vacation & .71 & .79 \\
& & More Likely to Do \\
Likelihood of Using Techniques: & Single Married \\
Keep home locked when away & .46 & .41 \\
Keep home locked when asleep & .45 & .40 \\
\hline
\end{tabular}

Table XLVIII

HOME SECURITY MEASURES

SINGLE OPINION BY PERIOD

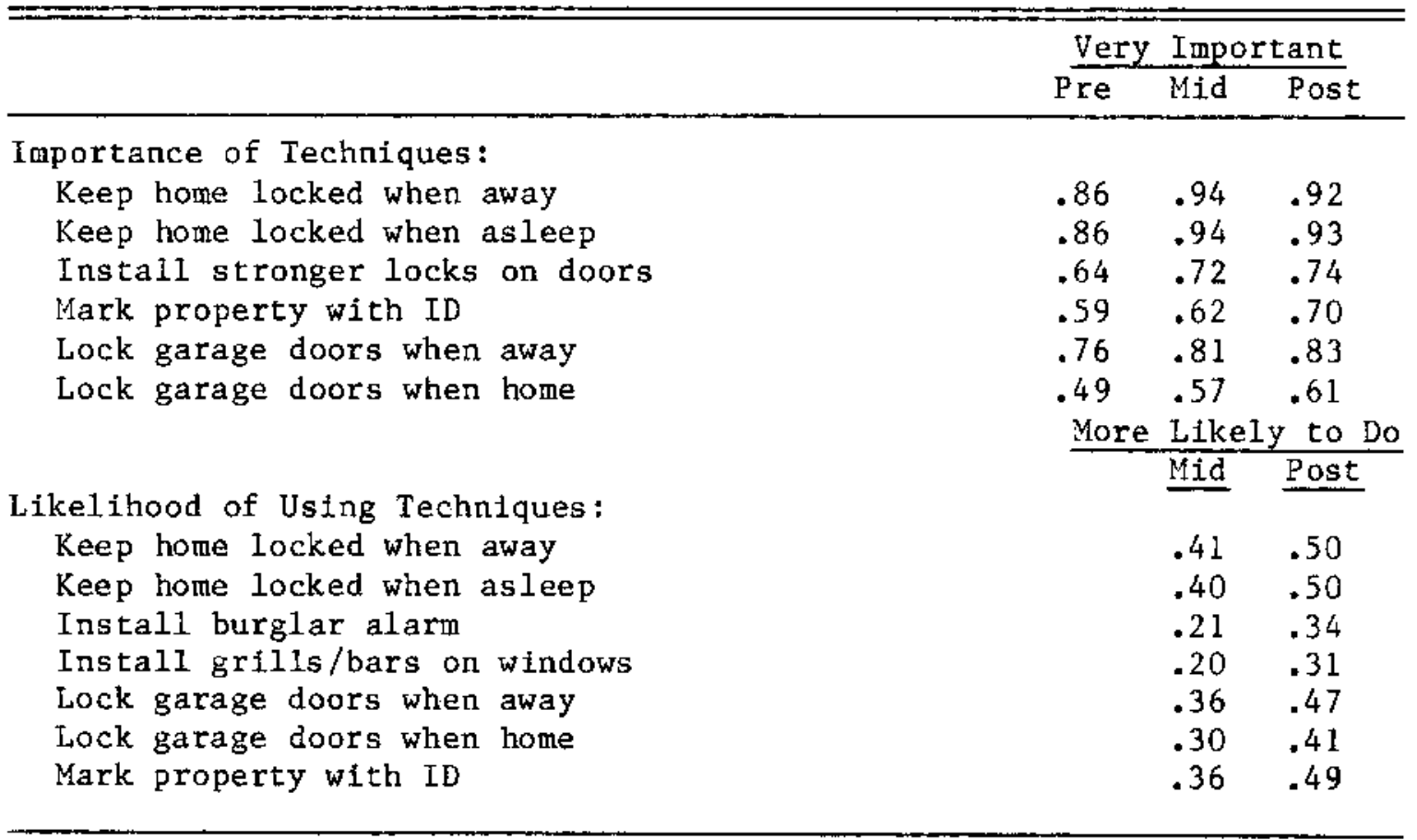


A lesser impact was noted among married respondents. In only four instances did their perception of the importance of home security measures increase over time, and in four cases individuals reported a greater likelihood of implementation (Table XLIX). Only two of these techniques, however, entalled major personal expenses. Tenure.--Home owners were more likely to consider certain home security measures very important than were renters. (Table L). However, only their opinions concerning the installation of stronger door locks and the marking of personal property with identification numbers changed over time. On the other hand, renters expressed greater concern with many different preventive techniques, particularly at mid-program (Table LI). These measures generally involved making additional efforts to keep the house and garage locked at all times. In those cases where significant differences were noted, however, changes in attitude appeared to be temporary and in many cases declined in the post-program survey to former levels.

Home owners also reported a greater likelihood that selective preventive measures would be implemented than did non-owners (Table LII). Nevertheless, renters reported more changes in behavior than did owners and their reported alterations were of a greater magnitude (Table LIII). Interestingly enough, the increased likelihood of installing expensive burglar alarm systems was only reported by non 
Table XLIX

HOME SECURITY MEASURES

MARRIED OPINION BY PERIOD

\begin{tabular}{|c|c|c|c|}
\hline & Vers & Import & $\operatorname{tant}$ \\
\hline & Pre & MId & Post \\
\hline Importance of Techniques: & & & \\
\hline Install stronger locks on doors & .69 & .75 & .67 \\
\hline Mark property with ID & .59 & .66 & .66 \\
\hline Have mail picked up while on vacation & .74 & .82 & .80 \\
\hline Lock garage doors when home & .51 & .61 & .63 \\
\hline Lock garage doors when away & .79 & .85 & .83 \\
\hline & Mor & Likely & $y$ to Do \\
\hline & & Mid & Post \\
\hline Likelihood of Using Techniques: & & & \\
\hline Keep home locked when away & & .37 & .45 \\
\hline Keep home locked when asleep & & .36 & .44 \\
\hline Install burglar alarm & & .23 & .30 \\
\hline Lock garage doors when home & & .34 & .42 \\
\hline
\end{tabular}

Table L

HOME SECURITY MEASURES

IMPORTANCE OF TECHNIQUES

OPINION BY TENURE

\begin{tabular}{lcc}
\hline & \multicolumn{2}{c}{ Very Important } \\
\cline { 2 - 3 } & Owner & Renter \\
\hline Keep home locked when home & .75 & .69 \\
Mark property with ID & .82 & .69 \\
Lock garage doors when away & .66 & .61 \\
Lock garage doors when home & .86 & .75 \\
\end{tabular}


Table LI

HOME SECURITY MEASURES

IMPORTANCE OF TECHNIQUES

TENURE OPINION BY PERIOD

\begin{tabular}{llll}
\hline & & \multicolumn{3}{c}{ Very Important } \\
\hline Owner: & Pre & Mid & Post \\
Install stronger locks on doors & & & \\
Mark property with ID & .64 & .74 & .71 \\
& .59 & .66 & .71 \\
Renters: & & & \\
Keep home locked when away & .89 & .95 & .91 \\
Keep home locked when asleep & .90 & .95 & .91 \\
Keep home locked when home & .70 & .73 & .62 \\
Install burglar alarm & .35 & .27 & .32 \\
Install extra locks on windows & .45 & .53 & .45 \\
Have mail picked up while on vacation & .64 & .72 & .72 \\
Lock garage doors when home & .44 & .54 & .59 \\
\end{tabular}

Table LII

HOME SECURITY MEASURES

LIKELIHOOD OF USING TECHNIQUES

OPINION BY TENURE

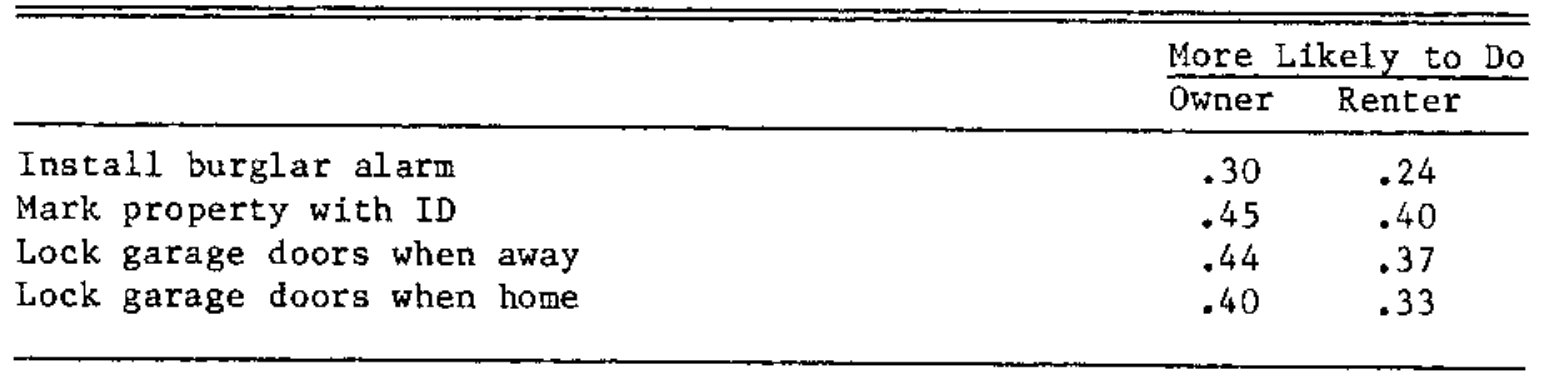


Table LIII

HOME SECURITY MEASURES

LIKELIHOOD OF USING TECHNIQUES

TENURE OPINION BY PERIOD

\begin{tabular}{lcc}
\hline & \multicolumn{3}{c}{ More Likely to Do } \\
\cline { 2 - 4 } & \multicolumn{3}{c}{ Mid } & Post \\
\hline Renters: & & \\
Keep home locked when away & .38 & .49 \\
Keep home locked when asleep & .38 & .49 \\
Install grills/bars on windows & .18 & .29 \\
Install burglar alarm & .17 & .32 \\
Mark property with ID & .36 & .45 \\
Lock garage doors when home & .27 & .40 \\
Lock garage doors when away & .32 & .44 \\
& & \\
Owners: & .39 & .47 \\
Keep home locked when away & .37 & .45 \\
Keep home locked when asleep & .24 & .30 \\
Install grills/bars on windows & .39 & .46 \\
Install stronger locks on doors & .40 & .50 \\
Mark property with ID & .36 & .44 \\
Lock garage doors when home & & \\
\hline
\end{tabular}


home owners. The most universal changes occurred where implementation involved little time or money.

Income.-As may be seen in Table LIV, two patterns emerged concerning the importance of home security measures according to respondents' income. Generally, the poor perceived these techniques as being more important than did the rich. However, persons in the upper income bracket placed much greater importance upon securing the hothe when away for extended periods of time. Perhaps these individuals were more likely to take vacations and to perceive burglary as a real threat during such absences. Nevertheless, both the rich and the poor experienced changes in their attitudes about home security measures during the implementation of the campaign (Table LV). In most cases, there was a jump in the perceived importance of the various techniques at the mid-progran survey and a slight decay thereafter. However, the poor drastically reduced their ideas of the importance of steel bars or burglar alarms in preventing crime over the life of the program.

The poor were the most likely to indicate that their home security behavior had been altered recently (Table LVI). They reported significant increases in the likelihood of utilizing such techniques in eight instances while upper income bracket individuals only altered their behavior twice (Table LVII). Both groups reported a greater 
Table LIV

HOME SECURITY MEASURES

IMPORTANCE OF TECHNIQUES

OPINION BY INCOME

\begin{tabular}{lccccc}
\hline & \multicolumn{4}{c}{ Very Important } \\
\cline { 2 - 6 } & & $<5$ & $5-9$ & $10-14$ & $>14$ \\
\hline Install stronger locks on doors & .76 & .68 & .69 & .70 \\
Instal1 extra locks on windows & .57 & .51 & .44 & .39 \\
Install grills /bars on windows & .37 & .30 & .32 & .21 \\
Install burglar alarm & .37 & .33 & .33. & .26 \\
Have mail picked up while on vacation & .67 & .73 & .77 & .85 \\
Mark property with ID & .68 & .65 & .64 & .59 \\
Lock garage doors when away & .80 & .78 & .80 & .86 \\
Lock garage doors when home & .65 & .54 & .55 & .55 \\
\hline
\end{tabular}

Table LV

HOME SECURITY YEASURES

IMPORTANCE OF TECHNIQUES

INCOME OPINION BY PERIOD

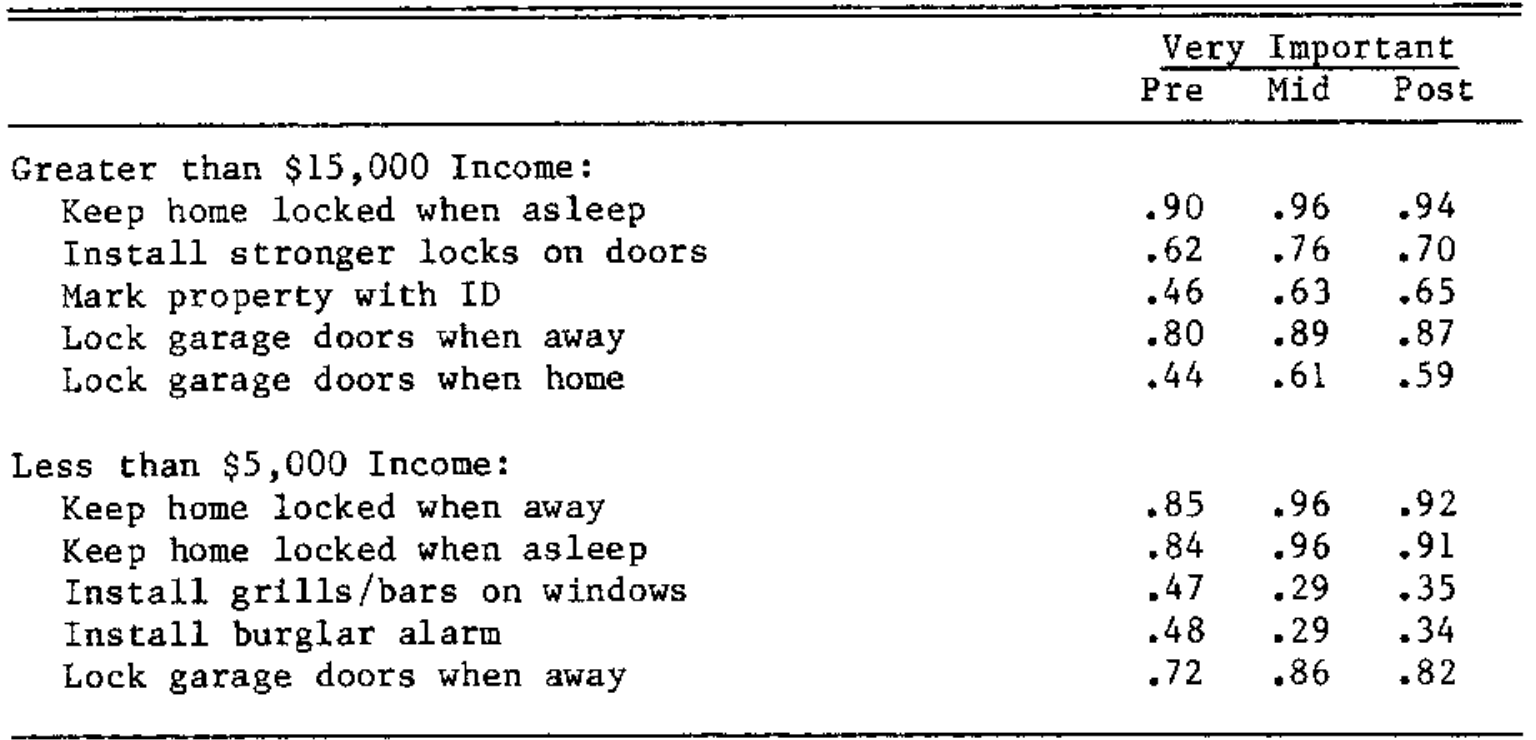


Table LVI

HOME SECURITY MEASURES

LIKELIHOOD OF USING TECHNIQUES

OPINION BY INCOME

\begin{tabular}{lccccc}
\hline & \multicolumn{4}{c}{ More Likely to Do } \\
\cline { 5 - 6 } & $<5$ & $5-9$ & $10-14$ & $>14$ \\
\hline Keep home locked when asleep & .51 & .47 & .42 & .33 \\
Keep home locked when home & .51 & .44 & .40 & .34 \\
Keep home locked when away & .49 & .48 & .43 & .33 \\
Install extra locks on windows & .42 & .34 & .37 & .31 \\
Have mail picked up while on vacation & .47 & .43 & .41 & .33 \\
Mark property with ID & .46 & .45 & .45 & .38 \\
Lock garage doors when home & .46 & .37 & .38 & .31 \\
Lock garage doors when away & .49 & .42 & .44 & .33 \\
\hline
\end{tabular}

Table LVII

HOME SECURITY MEASURES

LIKELIHOOD OF USING TECHNIQUES

INCOME OPINION BY PERIOD

\begin{tabular}{|c|c|c|}
\hline & \multicolumn{2}{|c|}{ More Likely to Do } \\
\hline & Mid & Post \\
\hline \multicolumn{3}{|l|}{ Greater than $\$ 15,000$ Income: } \\
\hline Mark property with ID & .32 & .43 \\
\hline Lock garage doors when home & .26 & .36 \\
\hline \multicolumn{3}{|l|}{ Less than $\$ 5,000$ Income: } \\
\hline Keep home locked when as leep & .44 & .58 \\
\hline Keep home locked when away & .42 & .56 \\
\hline Install burglar alarm & .20 & .39 \\
\hline Install stronger locks on doors & .39 & .51 \\
\hline Install extra locks on windows & .35 & .50 \\
\hline Install grills/bars on windows & .18 & .38 \\
\hline Mark property with ID & .40 & .53 \\
\hline Lock garage doors when home & .40 & .53 \\
\hline
\end{tabular}


likelihood of marking personal property with an identification number. However, the poor indicated that they were much more apt to make other physical changes to secure their home than were the rich.

\section{Vehicular Security}

Five crime prevention measures were concerned with vehicular security. Table LVIII contains a sumary of the survey respondents' attitudes concerning the importance of these particular techniques and the likelihood of personal implementation.

Individuals differed in their perceptions of the importance of the various measures. Locking a car to prevent theft of valuable articles or of the car itself was considered on the whole more important than locking bicycles and cars simply when they were not in use. Attitudes pertaining to some procedures also changed over time. Three techniques were deemed significantly more important at the close of the ad campign than at its onset. Furthermore, all vehicular security techniques were more likely to be utilized after the cessation of program activities than earlier. Thus, the advertisements may be tentatively deemed to have had an effect upon citizen attitudes and behavior. Area Crime Rate.--As was the case with home security, individuals residing in areas experiencing heavy crime were more likely to express the opinion that vehicular security measures were very important (Table LIX). Respondents in 
Table LVIII

VEHICULAR SECURITY MEASURES

TOTAL OPINION BY PERIOD

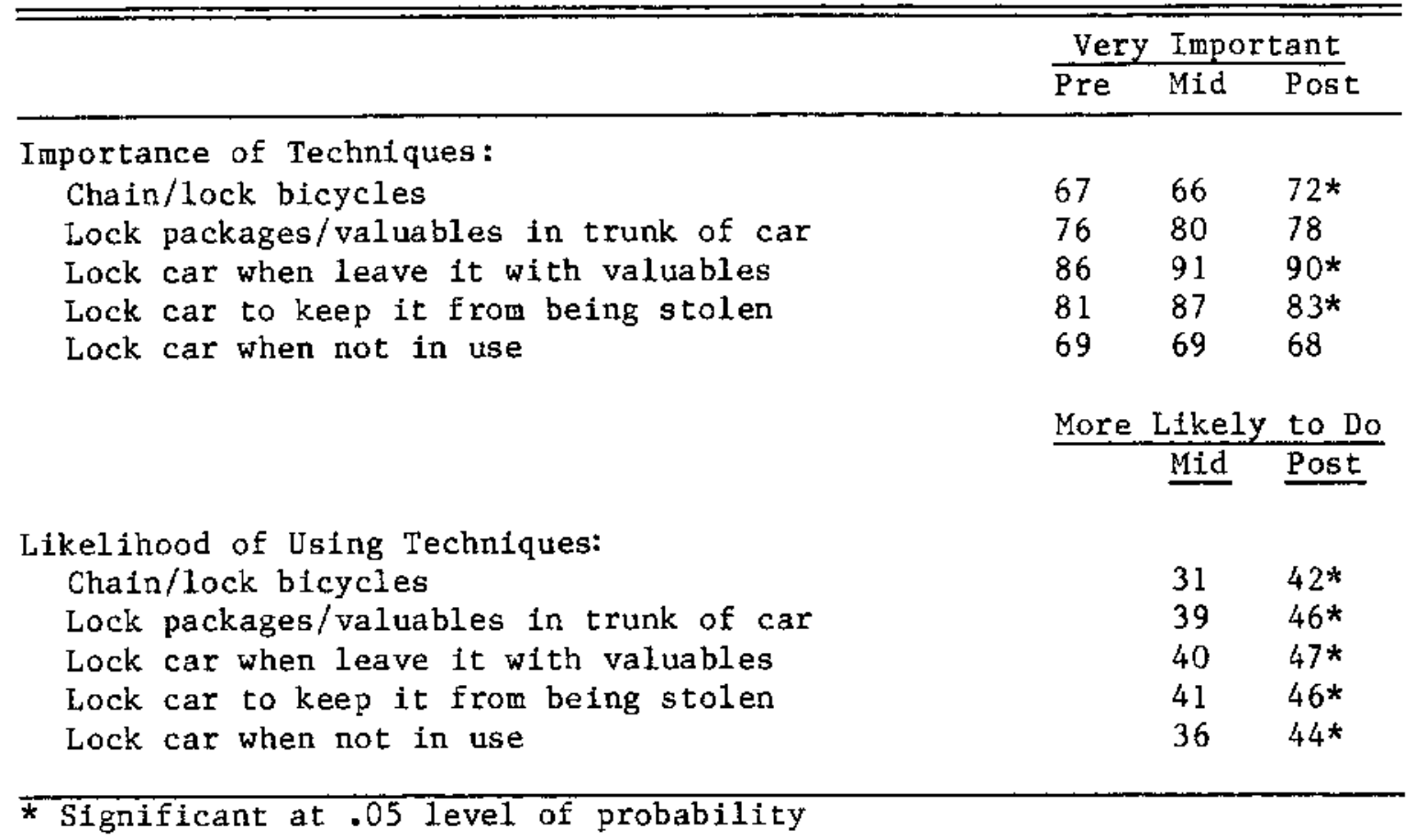

Table LIX

VEHICULAR SECURITY MEASURES

IMPORTANCE OF TECHNI QUES

OPINION BY AREA CRIME RATE

\begin{tabular}{|c|c|c|c|}
\hline & \multicolumn{3}{|c|}{ Very Important } \\
\hline & Heavy & Med & Low \\
\hline $\begin{array}{l}\text { Lock car to keep it from being stolen } \\
\text { Lock car when leave it with valuables } \\
\text { Lock packages/valuables in trunk of car }\end{array}$ & $\begin{array}{l}.86 \\
.92 \\
.81\end{array}$ & $\begin{array}{l}.83 \\
.88 \\
.76\end{array}$ & $\begin{array}{l}.80 \\
.84 \\
.75\end{array}$ \\
\hline
\end{tabular}


al1 three areas displayed little variation in attitudes over time (Table LX). Furthermore, when differences did occur, the advertising impact was usually felt at the mid-point of the campaign with decay thereafter.

There was little difference among crime area respondents as to whether they were more likely to implement preventive techniques than six months earlier. High crime area residents indicated significant increases in their purported likelihood of implementing all vehicular security techniques (Table LXI). However individuals residing elsewhere only reported behavioral changes concerning the safeguarding of bicycles from theft. This inconsistency may reflect a personal reaction to the relative environments in which the various respondents find themselves. Motor vehicle theft may be perceived as being more prevalent in high crime areas and bicycle theft more severe elsewhere. Gender.--There was little difference in attitudes between males and females concerning the importance of vehicular safety techniques or their increased likelihood of implementation. In only one instance was a significant difference uncovered. Women considered locking packages and valuables in the car trunk to be of slightly greater importance than did men.

However, women in many cases recorded an increase over time in their views concerning the importance of these measures and expressed the opinion that they were more 
Table LX

VEHICULAR SECURITY MEASURES

IMPORTANCE OF TECHNIQUES

AREA CRIME RATE OPINION BY PERIOD

\begin{tabular}{|c|c|c|c|}
\hline \multirow{3}{*}{ Heavy Crime: } & \multirow{2}{*}{$\frac{\text { Ver }}{\text { Pre }}$} & \multicolumn{2}{|c|}{ Important } \\
\hline & & Mid & Post \\
\hline & & & \\
\hline Chain/lock bicycles & .65 & .67 & .75 \\
\hline \multirow{2}{*}{$\begin{array}{l}\text { Medium Crime: } \\
\text { Lock car to keep it from being stolen }\end{array}$} & & & \\
\hline & .79 & .88 & .82 \\
\hline \multirow{3}{*}{$\begin{array}{l}\text { Low Crime: } \\
\text { Lock car to keep it from being stolen } \\
\text { Lock car when leave it with valuables }\end{array}$} & & & \\
\hline & .72 & .85 & .82 \\
\hline & .74 & .90 & .87 \\
\hline
\end{tabular}

Table LXI

VEHICULAR SECURITY MEASURES

LIKELIHOOD OF USING TECHNIQUES

AREA CRIME RATE OPINION BY PERIOD

\begin{tabular}{lll}
\hline & \multicolumn{2}{l}{ More Likely to Do } \\
\hline Heavy Crime Area: & \multicolumn{1}{l}{ Mid } \\
$\quad$ Chain/lock bicycles & .30 & .41 \\
Lock car when not in use & .30 & .44 \\
Lock car to keep it from being stolen & .36 & .47 \\
Lock car when leave it with valuables & .36 & .48 \\
Lock packages/valuables in trunk of car & .36 & .46 \\
Medium Crime Area: & & .45 \\
Chain/lock bicycles & .35 & \\
Low Crime Area: & & .41 \\
Chain/lock bicycles & .27 & \\
\hline
\end{tabular}


likely to implement such techniques after the program than earlier (Table LXII). Men, on the other hand, exhibited little attitudinal change. Significant differences only occurred once concerning locking unattended cars to keep them fram being stolen. In this instance, after conveying an initial rise in importance, attitudes returned to their former level. Nevertheless, consistently more men did express the opinion in the post program survey that they were more likely to implement all vehicular security measures than earlier (Table LXIII). Thus, while the ad campaign appeared to only alter women's attitudes pertaining to vehicular safety, it universally impacted actual behavior.

Ethnic Group.--No consistent pattern was evident across ethnic groups as to their perceptions of the importance of various measures for preventing vehicular theft, Less Whites perceived the importance of locking a car when it was not in use and less Blacks thought it very important that a car should be locked when valuables were left inside (Table LXIV). In the remaining three cases there was no signiflcant difference among the groups at a11.

The ad campaign impacted Whites' attitudes more than it did the other two ethnic groups surveyed. Whites indicated an increased perception of the importance of three measures over time, while Hispanics and Blacks altered their opinions only once each (Table LXV). Blacks, after a surge at 
Table LXII

VEHICULAR SECURITY MEASURES

FEMALE OPINION BY PERIOD

\begin{tabular}{|c|c|c|c|}
\hline & \multicolumn{3}{|c|}{ Very Important } \\
\hline & Pre & Mid & Post \\
\hline \multicolumn{4}{|l|}{ Importance of Techniques: } \\
\hline Chain/lock bicycles & .65 & .67 & .75 \\
\hline Lock car to keep it from being stolen & .80 & .87 & .84 \\
\hline Lock car when leave it with valuables & .85 & .91 & .92 \\
\hline \multirow[t]{3}{*}{ Lock packages/valuables in trunk of car } & .76 & .82 & .83 \\
\hline & More & Like1y & to Do \\
\hline & & Mid & Post \\
\hline \multicolumn{4}{|l|}{ Likelihood of Using Techniques: } \\
\hline Chain/lock bicycles & & .30 & .42 \\
\hline Lock car when leave it with valuables & & .39 & .46 \\
\hline Lock packages/valuables in trunk of car & & .40 & .47 \\
\hline
\end{tabular}

Table LXIII

VEHICULAR SECURITY MEASURES

MALE OPINION BY PERIOD

\begin{tabular}{lccc}
\hline & \multicolumn{3}{c}{ Very Important } \\
\hline Pre & \multicolumn{2}{c}{ Mid } & Post \\
\hline Lock car to keep it from being stolen & .82 & .87 & .81 \\
& & More Likely to Do \\
Likelihood of Using Techniques: & $\frac{\text { Mid }}{\text { Post }}$ \\
Chain/lock bicycles & .32 & .42 \\
Lock car when leave it with valuables & .40 & .49 \\
Lock car when not in use & .36 & .44 \\
Lock car to keep it from being stolen & .40 & .47 \\
Lock packages/valuables in trunk of car & .37 & .45 \\
\hline
\end{tabular}


Table LXIV

VEHICULAR SECURITY MEASURES

IMPORTANCE OF TECHNIQUES

OPINION BY ETHNIC GROUP

\begin{tabular}{lccc}
\hline & \multicolumn{3}{c}{ Very Important } \\
\cline { 2 - 4 } & White & Black Hispanic \\
\hline Lock car when not in use & .64 & .77 & .82 \\
& .90 & .86 & .90 \\
\hline
\end{tabular}

Table LXV

VEHICULAR SECURITY MEASURES

IMPORTANCE OF TECHNIQUES

ETHNIC GROUP OPINION BY PERIOD

\begin{tabular}{|c|c|c|c|}
\hline & Very & \multicolumn{2}{|c|}{ Important } \\
\hline & Pre & Mid & Post \\
\hline \multicolumn{4}{|l|}{ White Opinion: } \\
\hline Chain/1ock bicycles & .64 & .68 & .75 \\
\hline Lock car to keep it from being stolen & .80 & .86 & .84 \\
\hline Lock car when leave it with valuables & .86 & .92 & .92 \\
\hline \multicolumn{4}{|l|}{ Black Opinion: } \\
\hline Lock car to keep it from being stolen & .81 & .91 & .75 \\
\hline \multicolumn{4}{|l|}{ Hispanic Op Inion: } \\
\hline Chain/lock bicycles & .72 & .56 & .77 \\
\hline
\end{tabular}


mid-program, actually conveyed a lower opinion subsequent to the program than they had prior to its inception.

As was the case with home security measures, a significantly larger number of Black subjects indicated that they had changed their behavioral patterns recently and were more likely now to utilize crime prevention measures than before ( $T a b l e$ LXVI). However, in only two instances, locking bikes and locking cars with valuables inside did their opinions actually alter over time (Table LXVII). In contrast, Whites reported changed behavior in one additional case and Hispanics in a 11 instances. Not only did this final group consistently indicate altered preventtve action, but their recorded increases were quite dramatic. Thus, it appears that the ad campaign had a greater impact upon non-Black ethnic groups, particularly Whites' attitudes and Hispanics' actions.

Age.--With the exception of chaining and locking bicycles, more older adults considered vehicular security techniques very important than did younger individuals (Table LXVIII). The exception to the general pattern is readily explained. Younger people are much more likely to own a bike and be aware of the dangers of leaving it unsecured.

More younger respondents also stated that they were more likely to secure their bicycles at the date surveyed than six months earlier. However, both groups recorded a 
Table LXVI

VEHICULAR SECURITY MEASURES

LIKELIHOOD OF USING TECHNIQUES

OPINION BY ETHNIC GROUP

\begin{tabular}{lccc}
\hline & \multicolumn{3}{c}{ More Likely to Do } \\
\cline { 2 - 5 } & White & Black Hispanic \\
\hline Chain/lock bicycles & .30 & .56 & .35 \\
Lock car when not in use & .32 & .63 & .43 \\
Lock car to keep it from being stolen & .35 & .64 & .49 \\
Lock car when leave 1t with valuables & .35 & .66 & .50 \\
Lock packages/valuables in trunk of car & .34 & .66 & .43 \\
\hline
\end{tabular}

Table LXVII

VEHICULAR SECURITY MEASURES

LIKELIHOOD OF USING TECHNIQUES

ETHNIC GROUP OPINION BY PERIOD

\begin{tabular}{lll}
\hline \hline & More Likely to Do \\
\hline White 0pinion: & Mid & Post \\
Chain/lock bicycles & .26 & .34 \\
Lock car when leave it with valuables & .32 & .38 \\
Lock packages/valuables in trunk of car & .31 & .37 \\
Black Opinion: & & \\
Chain/lock bicycles & .49 & .63 \\
Lock car when leave it with valuables & .61 & .71 \\
Hispanic Opinion: & & .51 \\
Chain/lock bicycles & .21 & .60 \\
Lock car when leave it with valuables & .41 & .54 \\
Lock packages/valuables in trunk of car & .34 & .54 \\
Lock car when not in use & .32 & .58 \\
Lock car to keep it from being stolen & .39 & \\
\hline
\end{tabular}


Table LXVIII

VEHICULAR SECURITY MEASURES

OPINION BY AGE

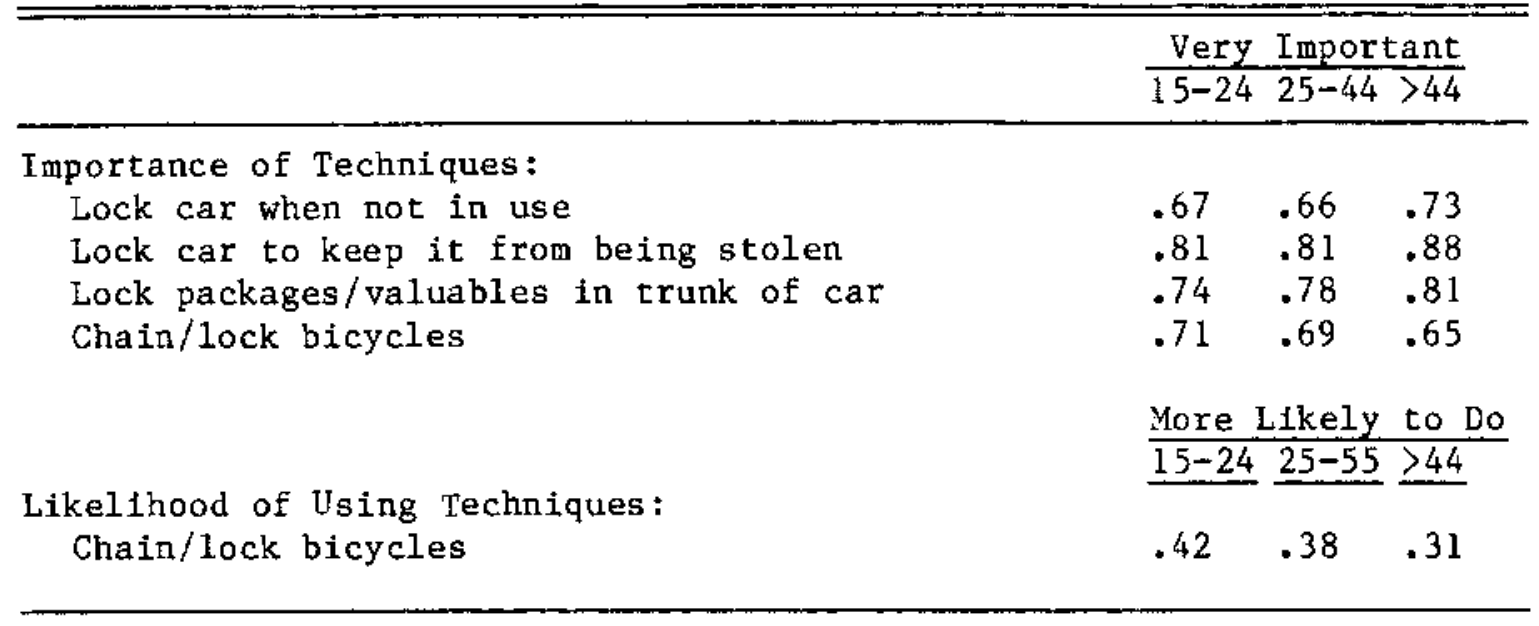


significant change in their reported likelihood of locking bicycles over time (Table LXIX). Little additional

significant behavioral conversion was noted. Only the young indicated that they were more likely at the end of the program to lock their car when not in use than before. Furthermore, only two increases over time in the perceived importance of locking vehicles were found in older adults and one in younger individuals aged 15-24. In each case the major change occurred between the pre and wid-program surveys. Some decay was observed thereafter in two instances.

The Dallas crime prevention advertising campaign thus appeared to have little impact upon 1ndividuals grouped according to age. Their preconceived notions persisted throughout the period under study.

Marital Status.--There was little difference displayed between married and single respondents concerning either their perceptions of the importance of vehicular security measures or their purported likelihood of implementing such techniques. Table LXX contains the only two significant variations uncovered.

Married individuals' opinions and behavior were basically unaffected by the advertising campign. They only reported an increased likelihood in securing bicycies. Furthermore, their perceptions of the importance of 
Table LXIX

VEHICULAR SECURITY MEASURES

AGE OPINION BY PERIOD

\begin{tabular}{|c|c|c|c|}
\hline & More & Likel & $\frac{\text { to Do }}{\text { Post }}$ \\
\hline \multicolumn{4}{|l|}{ Likelihood of Using Techniques: } \\
\hline Chain/lock bicycles & & .34 & .49 \\
\hline Lock car when not in use even at home & & .37 & .48 \\
\hline \multirow[t]{3}{*}{ Chain/lock bicycles } & & .25 & .37 \\
\hline & Very & Impo & $\tan t$ \\
\hline & Pre & Mid & Post \\
\hline \multicolumn{4}{|l|}{$\begin{array}{l}\text { Importance of Techniques: } \\
15-24 \text { Age - }\end{array}$} \\
\hline $\begin{array}{l}\text { Lock packages/valuables in trunk of car } \\
\text { over Age } 44-\end{array}$ & .67 & .79 & .77 \\
\hline $\begin{array}{l}\text { Lock car when leave it with valuables } \\
\text { Lock car to keep it from being stolen }\end{array}$ & .85 & .91 & $\begin{array}{l}.92 \\
.89\end{array}$ \\
\hline
\end{tabular}

Table LXX

VEHICULAR SECURITY MEASURES

OPINION BY MARITAL STATUS

\begin{tabular}{lcc}
\hline $\begin{array}{l}\text { Importance of Techniques: } \\
\text { Lock packages/valuables in trunk of car }\end{array}$ & $\frac{\text { Very Important }}{\text { Single Married }}$ \\
$\begin{array}{l}\text { Likelihood of Using Techniques: } \\
\text { Chain/Lock bicycles }\end{array}$ & More Likely to Do \\
\hline
\end{tabular}


vehicular security measures was altered in only one case and this proved to be temporary ( $T a b l e$ LXXI).

The Dallas crime prevention program, however, had a greater impact upon the single population. They altered their opinions concerning the importance of chaining bicycles when not in use and providing extra precautions when valuables were to be left in a car (Table LXXII). They also recorded a significant increase over time in the likelihood of implementing these measures, plus that of locking the car when it was not in use.

Tenure.--Owners and renters were generally in agreement on the importance of vehicular security measures. However, they displayed different perspectives concerning the two questions pertaining to locking an unoccupied car. More howe owners perceived the importance of locking cars to prevent their theft, while significantly more renters responded that it was important to lock a car even when at home (Table LXXII). This reflects the differing environmental impacts upon the two groups. Renters generally would be more apt to park their cars in public space when at home, and thus, would perceive a greater susceptibility to theft in this instance.

Home owners' opinions of the importance of these vehicular security techniques were completely unaffected by the advertising campaign. No differences were noted over time. Furthermore, renters displayed only nominal 
Table LXXI

VEHICULAR SECURITY MEASURES

MARRIED OPINION BY PERIOD

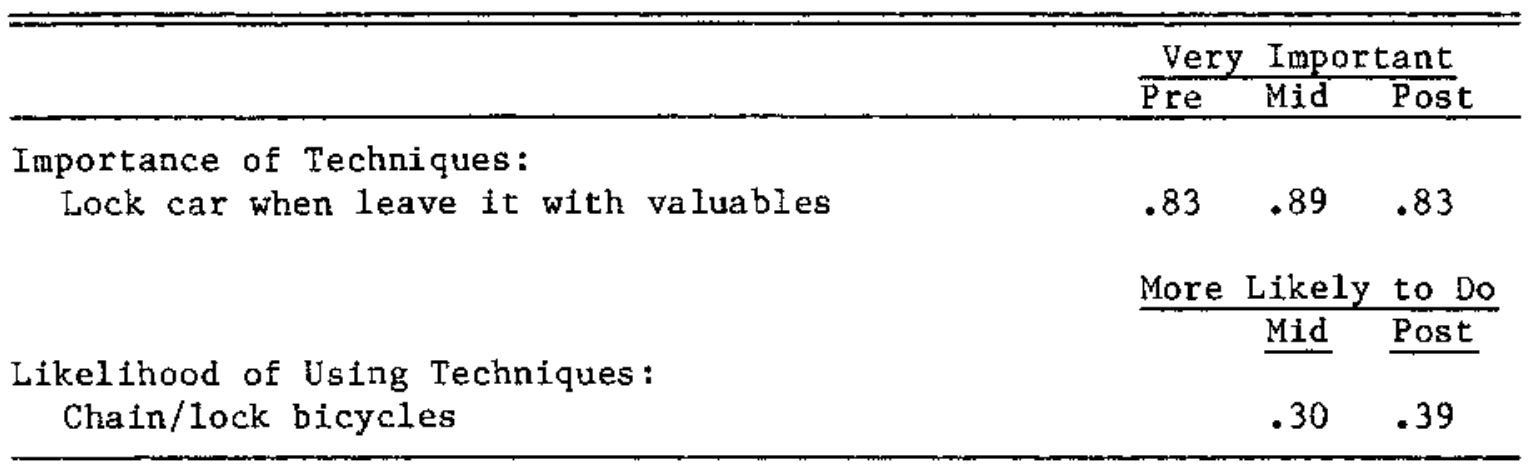

Table LXXII

VEHICULAR SECURITY MEASURES

SINGLE OPINION BY PERIOD

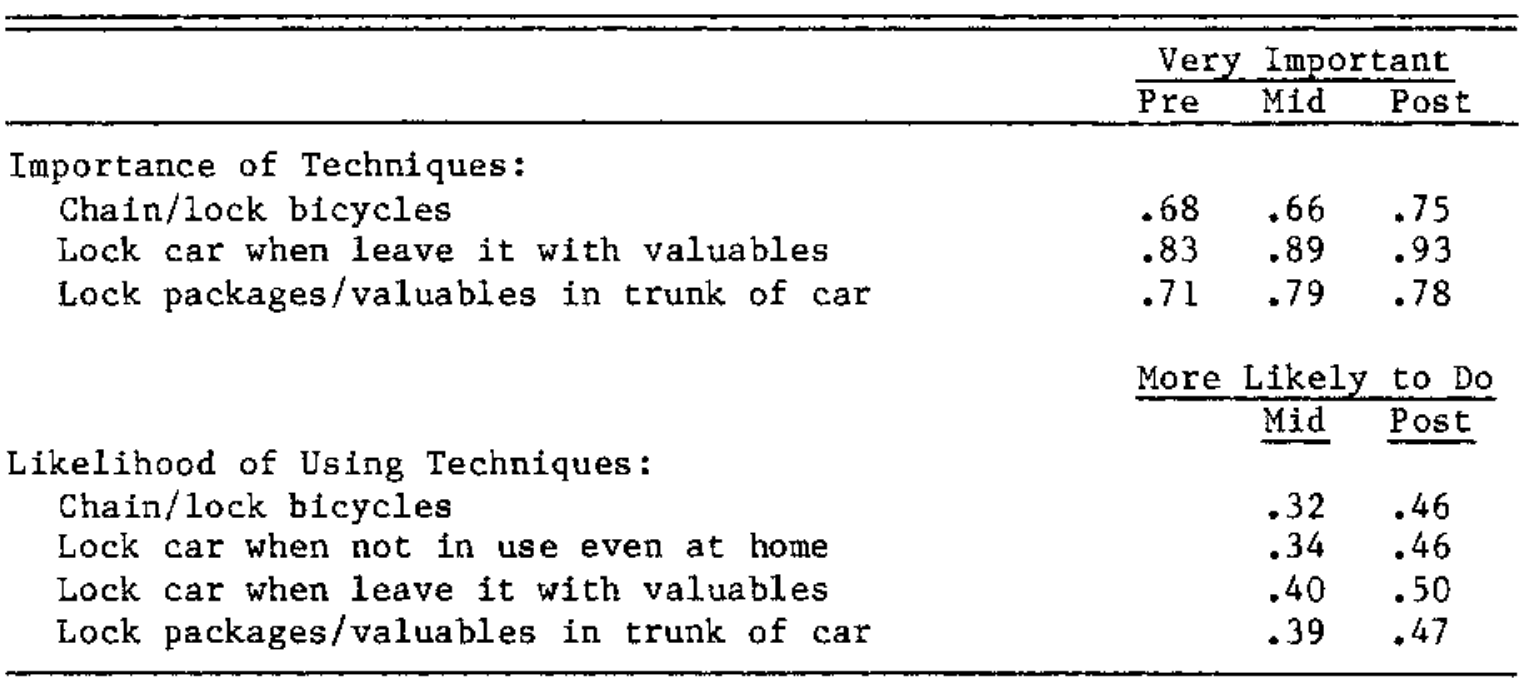

Table LXXIII

VEHICULAR SECURITY MEASURES

IMPORTANCE OF TECHNIQUES

OPINION BY TENURE

\begin{tabular}{lcc}
\hline \hline$\ldots$ & Very Important \\
\hline Lock car when not in use even at home & Owner & .64 \\
Lock car to keep it from being stolen & .65 & .73 \\
\hline
\end{tabular}


alterations in their perceptions. In only one instance was there a marked increase reported. This concerned locking packages and valuables in a car trunk. However, the Increase that occurred in the early months of the program subsequently decayed slightly.

Both groups, however, in increased numbers indicated that they were more apt to utilize certain vehicular security measures than before. Both displayed an increased likelihood of securing valuables in the trunk of a car, always locking an unattended car, and chaining bicycles to prevent their theft (Table LXXIV). Thus, the Dallas advertising campaign did appear to have an impact upon citizens' preventive behavior.

Income.--With one exception, citizens at various income levels were in virtual agreement on the importance of securing automobiles and bicycles. The poor were significantly more aware of the importance of locking a car when it was parked at home than were the rich. Environmental conditions probably necessitate these automobiles being left unoccupied on the street or in a public lot, while people with greater incomes would be more apt to utilize a private garage.

More poor also consistently stated that they were more likely at the time surveyed to lock their automobiles than they had been in the past (Table LXXV). Only in the case of 
Table LXXIV

VEHICULAR SECURITY MEASURES

LIKELIHOOD OF USING TECHNIQUES

TENURE OPINION BY PERIOD

\begin{tabular}{|c|c|c|}
\hline & \multicolumn{2}{|c|}{ More Likely } \\
\hline & Mid & Post \\
\hline \multicolumn{3}{|l|}{ Owner: } \\
\hline Lock packages/valuables in trunk of car & .40 & .47 \\
\hline Lock car when not in use even at home & .37 & .44 \\
\hline Chain/lock bicycles & .32 & .43 \\
\hline \multicolumn{3}{|l|}{ Renter: } \\
\hline Lock packages/valuables in trunk of car & .37 & .45 \\
\hline Lock car when not in use even at home & .36 & .44 \\
\hline Lock car when leave it with valuables & .38 & .48 \\
\hline Chain/lock bicycles & .29 & .42 \\
\hline
\end{tabular}

Table LXXV

VEHICULAR SECURITY MEASURES

OPINION BY INCOME

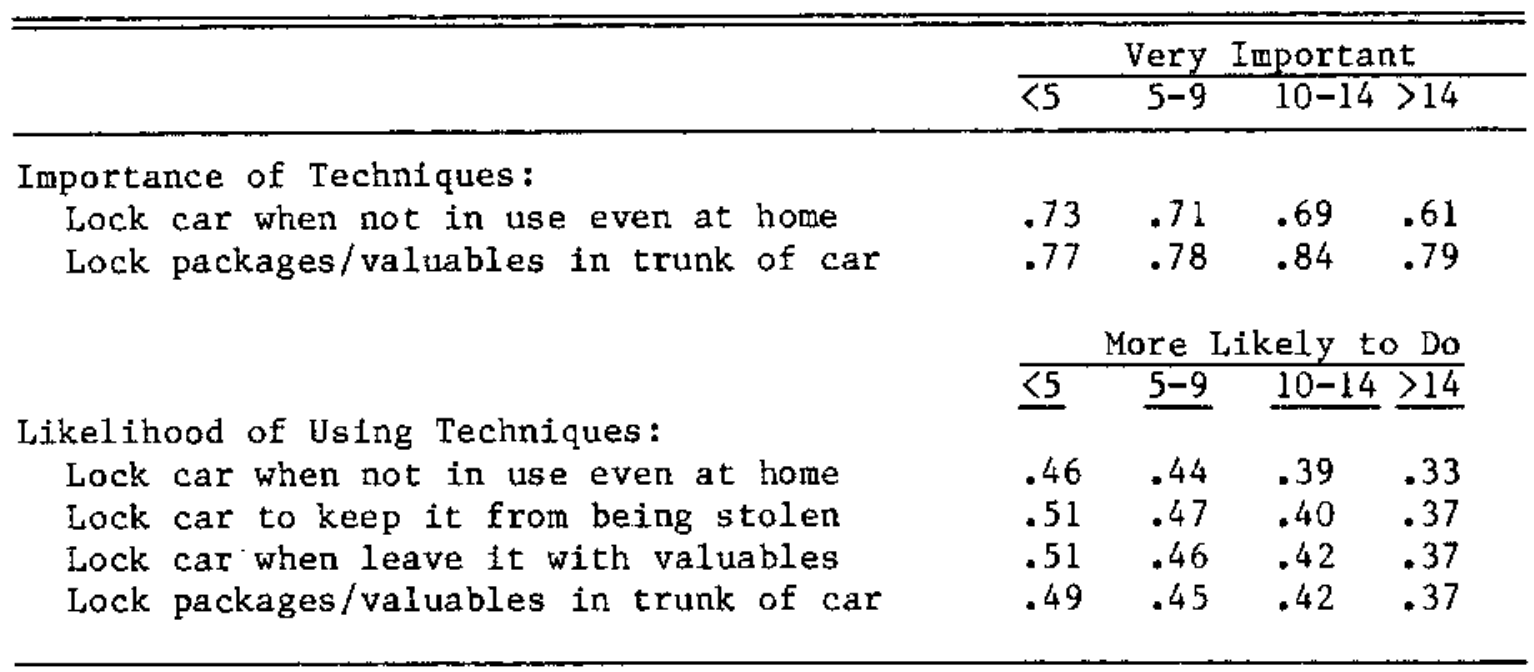


securing bicycles was no significant difference noted among income categories.

The Dallas program had differing impacts upon the citizens located at the two income extremes. Individuals with incomes under $\$ 5000$ reported attitudinal changes over time, but little behavioral alteration. The opposite was true for people with incomes greater than $\$ 15,000$. They indicated they were more likely to implement several vehicular techniques after the program, but reported little change in perceptions of their importance (Table LXXVI).

\section{Personal Safety}

Ten crime prevention techniques dealt with personal safety, five with safety within the home and five with security while away. Table LXXVII presents a sumary of the survey respondents' opinions pertaining to these measures.

The crime prevention advertising program had a noticeably smaller impact upon citizens' personal safety perceptions and their behavior. A common trend can be ascertained. In all cases where a significant change occurred in people's feelings concerning the importance of techniques in preventing crimes agatnst their person, the change was only temporary in duration. Furthermore, in only four instances did respondents indicate any greater likelihood of utilizing such measures after the duration of the program. 
Table LXXVI

VEHICULAR SECURITY MEASURES

INCOME OPINION BY PERIOD

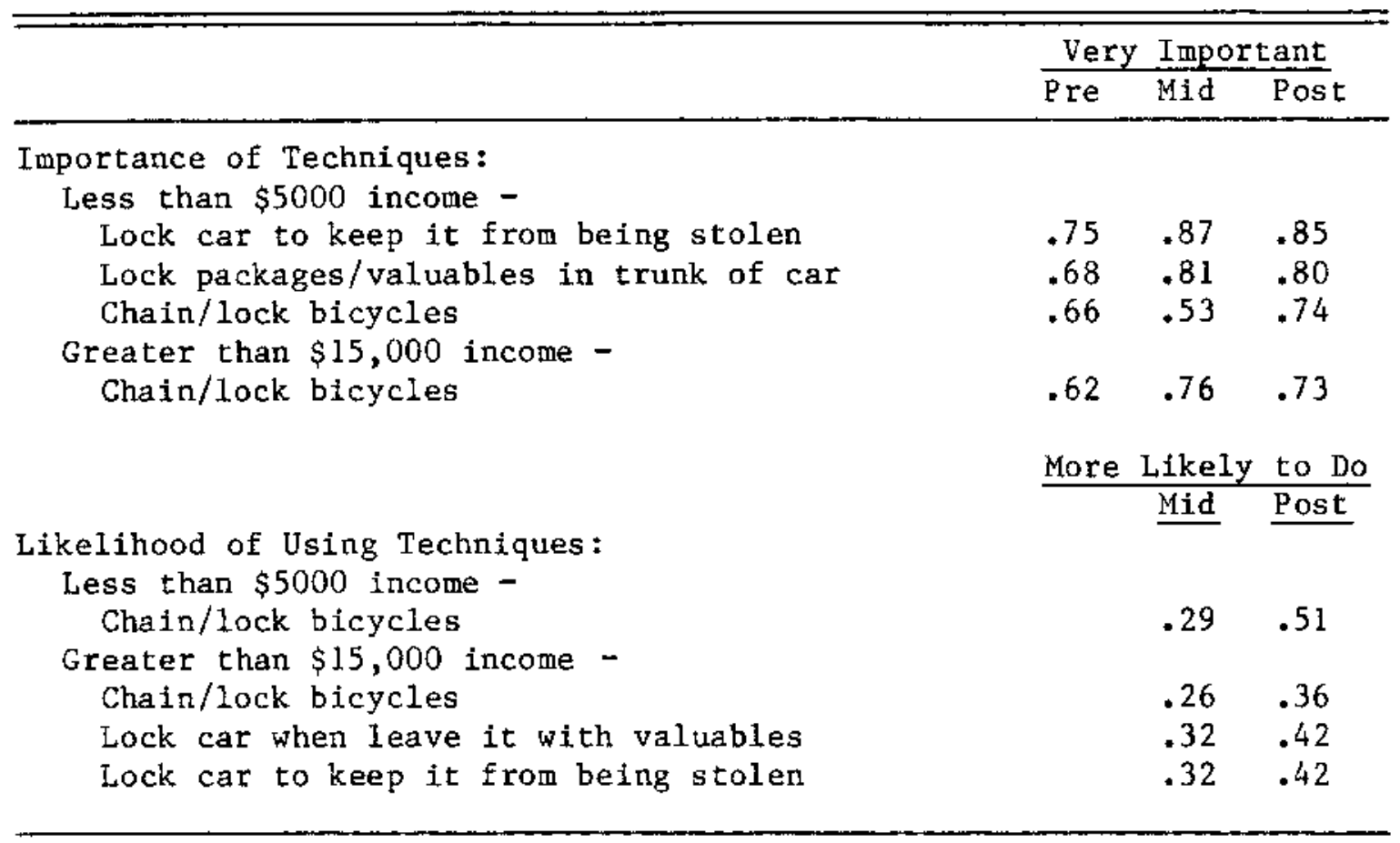


Table LXXVII

PERSONAL SECURITY MEASURES

TOTAL OPINION BY PERIOD

\begin{tabular}{|c|c|c|c|}
\hline \multirow{3}{*}{ Importance of Techniques: } & \multicolumn{3}{|c|}{ Very Important } \\
\hline & Pre & Mid & Post \\
\hline & & & \\
\hline Leave porch/yard lights on at night & 56 & 57 & $51 *$ \\
\hline Be suspicious of strangers & 66 & 70 & $64 *$ \\
\hline Install peephole in door & 67 & 64 & 64 \\
\hline Never open door to strangers & 76 & 75 & 76 \\
\hline Require ID of salesmen & 66 & 73 & $68 *$ \\
\hline Keep car doors locked when driving & 64 & 66 & 64 \\
\hline Never hitchhike & 79 & 84 & $79 *$ \\
\hline Never pick up hitchhikers & 78 & 84 & $77 *$ \\
\hline Avoid being alone at night & 73 & 77 & 75 \\
\hline \multirow[t]{3}{*}{ Never show/carry large dollars } & 89 & 89 & 88 \\
\hline & \multirow[t]{2}{*}{ More } & Likely & to Do \\
\hline & & Mid & Post \\
\hline \multicolumn{4}{|l|}{ Likelihood of Using Techniques: } \\
\hline Leave porch/yard lights on at night & & 36 & 39 \\
\hline $\begin{array}{l}\text { Be suspicious of strangers } \\
\text { Install peephole in door }\end{array}$ & & 41 & 44 \\
\hline & & 32 & $40 *$ \\
\hline $\begin{array}{l}\text { Never open door to strangers } \\
\text { Require ID of salesmen }\end{array}$ & & 39 & $46 *$ \\
\hline $\begin{array}{l}\text { Require ID of salesten } \\
\text { Keep car doors locked when driving }\end{array}$ & & 40 & 44 \\
\hline Keep car doors locked when driving & & 36 & $42 *$ \\
\hline Never hitchhike & & 38 & 40 \\
\hline Never pick up hitchhikers & & 38 & 40 \\
\hline Avoid being alone at night & & 41 & 45 \\
\hline Never show/carry large dollars & & 39 & $45 *$ \\
\hline
\end{tabular}


Area Crime Rate--As was true with the other crime prevention techniques mentioned above, respondents from heavy crime areas tended to consider measures aimed at safeguarding one's person to be more important than did others (Table LXXVIII). Only in avoiding being alone at night, never carrying large amounts of cash, and leaving exterior 1 ights on at night was there no difference noted among groups.

High crime area respondents also experienced more alteration in thelr beliefs on this subject over the period of the program than did low crime area subjects. However, in all cases where a signiflcant increase occurred, it was only temporary in duration (Table LXXIX).

There was no significant difference among individuals according to area of residence concerning their reported personal crime preventive behavior. However, high crime area respondents indicated in seven cases that their actions had changed over the period of the program (Table LXXX). A similar response was not observed elsewhere. Low crime area subjects reported unaltered behavior in each survey. Thus, while the advertising campaign had only a slight, but temporary impact upon attitudes, it induced an alteration in high crime area residents' behavior.

Gender.--Women consistently considered measures aimed at improving personal safety more important than did men 
Table LXXVIII

PERSONAL SECURITY MEASURES

IMPORTANCE OF TECHNIQUES

OPINION BY AREA CRIME RATE

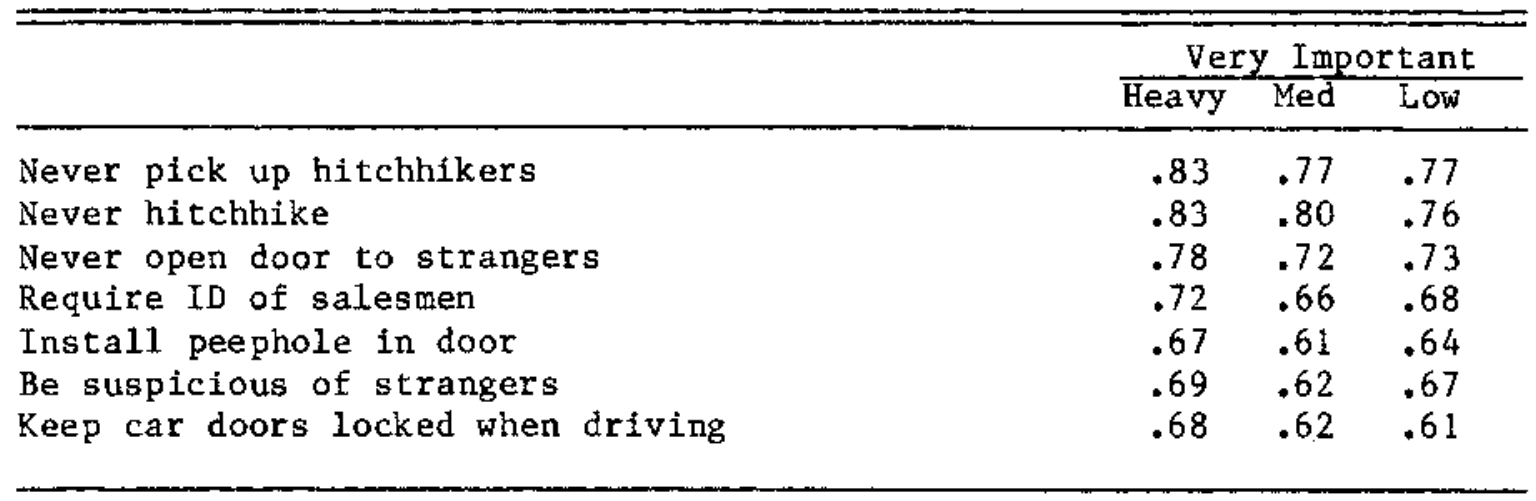

Table LXXIX

PERSONAL SECURITY MEASURES

IMPORTANCE OF TECHNIQUES

AREA CRIME RATE OPINION BY PERIOD

\begin{tabular}{|c|c|c|c|}
\hline \multirow{3}{*}{ Heavy Crime Area: } & \multicolumn{3}{|c|}{ Very Important } \\
\hline & Pre & Mid & Post \\
\hline & & & \\
\hline \multirow{4}{*}{$\begin{array}{l}\text { Never pick up hitchhikers } \\
\text { Require ID of salesmen } \\
\text { Never hitchhike } \\
\text { Leave porch/yard lights on at night }\end{array}$} & .83 & .87 & .78 \\
\hline & .71 & .76 & .68 \\
\hline & .83 & .86 & .79 \\
\hline & .59 & .57 & .49 \\
\hline \multicolumn{4}{|l|}{ Low Crime Area: } \\
\hline Never pick up hitchhikers & .71 & .83 & .76 \\
\hline
\end{tabular}


Table LXXX

PERSONAL SECURITY MEASURES

LIKELIHOOD OF USING TECHNIQUES

HIGH CRIME AREA OPINION BY PERIOD

\begin{tabular}{llc}
\hline & \multicolumn{2}{c}{ More Likely to Do } \\
\hline Install peephole in door & Mid & Post \\
Never show/carry large dollars & .32 & .43 \\
Keep car doors locked when driving & .35 & .44 \\
Require ID of salesmen & .34 & .44 \\
Never open door to strangers & .35 & .45 \\
Be suspicious of strangers & .35 & .46 \\
Leave porch/yard lights on at night & .36 & .45 \\
& & .32 \\
\hline
\end{tabular}


(Table LXXXI). This is understandable when one considers the fact that females have reported in other studies that they fear for their personal safety more than do males. Thus, they are more apt to perceive of any measures that might improve personal security as being very important.

However, the advertising campaign had little impact upon either group's attitudes. With one exception, significant variations in opinion over time were either temporary in duration or actually negative in results (Table LXXXI).

Women also stated that they were more likely to implement personal safety measures than were men (Table LXXXIII). However, again, little program impact upon behavior was observed. Women only reported one significant increase, while men indicated two (Table LXXXIV).

Ethnic Group.--Greater numbers of Blacks and Hispanics stated that they believed personal safety measures to be very important than did Whites (Table LXXXV). Only in the installation of peepholes, accepting or giving rides to strangers, and carrying large sums of cash was such a pattern not noted.

Again, no permanent program impact upon people's attitudes was observed. Where significant differences did occur, they were temporary and in many cases even negative. As may be seen in Table LXXXVI, all of these impacts occurred only among Blacks. 
Table LXXXI

PERSONAL SECURITY MEASURES

IMPORTANCE OF TECHNIQUES

OPINION BY GENDER

\begin{tabular}{lcc}
\hline & \multicolumn{2}{c}{ Very Important } \\
\hline Be suspicious of strangers & Men & Women \\
Leave porch/yard lights on at night & .59 & .74 \\
Install peephole in door & .50 & .60 \\
Avoid being alone at night & .59 & .71 \\
Never carry/show large dollars & .65 & .85 \\
Never pick up hitchhikers & .86 & .92 \\
Never hitchhike toon strangers & .69 & .90 \\
Never open door to stiving & .70 & .92 \\
Keep car doors locked when driving & .67 & .84 \\
Require ID of salesmen & .55 & .75 \\
& .63 & .76 \\
\hline
\end{tabular}

Table LXXXI I

PERSONAI SECURITY MEASURES

IMPORTANCE OF TECHNIQUES

GENDER OPINION BY PERIOD

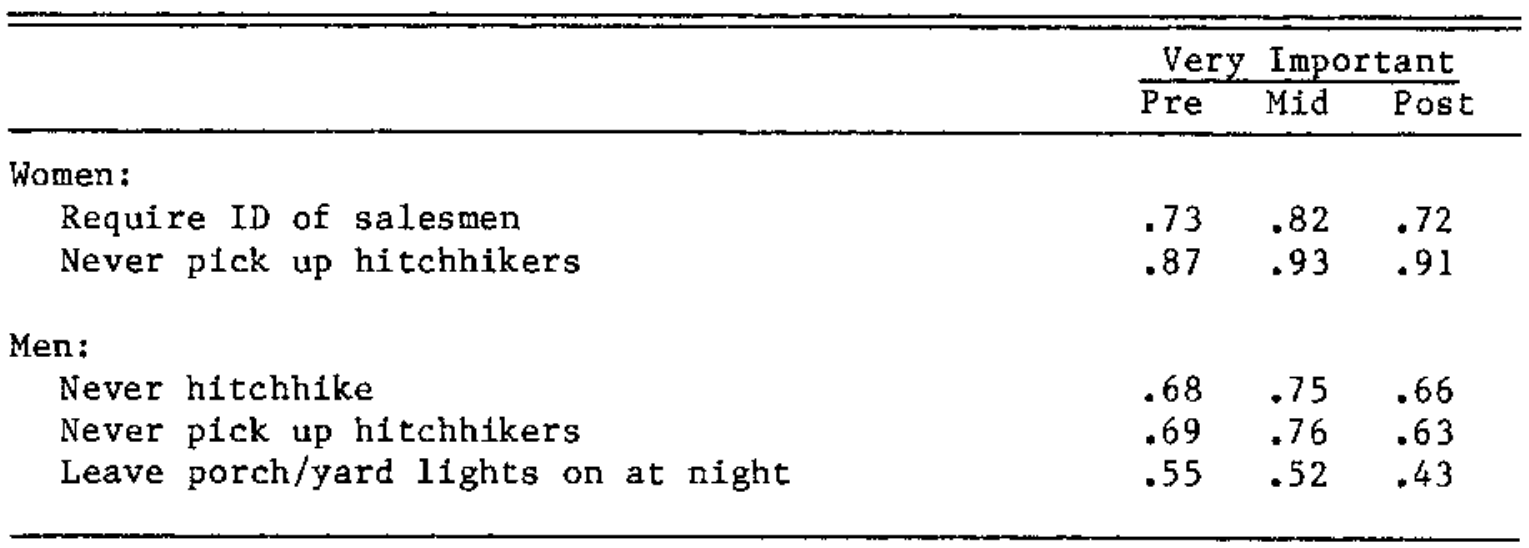


Table LXXXIII

\section{PERSONAL SECURITY MEASURES \\ LIKELIHOOD OF USING TECHNIQUES \\ OPINION BY GENDER}

\begin{tabular}{lcc}
\hline & \multicolumn{2}{c}{ More Likely to Do } \\
\cline { 2 - 3 } Never show/carry large dollars & Men & Women \\
Avoid being alone at night & .39 & .45 \\
Require ID of salesmen & .39 & .46 \\
Never open door to strangers & .39 & .44 \\
Be suspiclous of strangers & .39 & .46 \\
Never hitchhike & .39 & .45 \\
Keep car doors locked when driving & .36 & .42 \\
\end{tabular}

Table LXXXIV

PERSONAL SECURITY MEASURES

LIKELIHOOD OF USING TECHNIQUES

GENDER OPINION BY PERIOD

\begin{tabular}{llc}
\hline & More Likely to Do \\
\hline Men: & Pre & .38 \\
$\quad$ Keep car doors locked when driving & .31 & .39 \\
Install peephole 1n door & .29 & .50 \\
Women: & & .42 \\
$\quad$ Never open door to strangers & \\
\hline
\end{tabular}


Table LXXV

PERSONAL SECURITY MEASURES

IMPORTANCE OF TECHNIQUES

OPINION BY ETHNIC GROUP

\begin{tabular}{lccc}
\hline & \multicolumn{4}{c}{ Very Important } \\
\hline Avoid being alone at night & White & Black & Hispanic \\
Never open door to strangers & .72 & .81 & .82 \\
Be suspicious of strangers & .72 & .83 & .79 \\
Keep car doors locked when driving & .63 & .74 & .67 \\
Require ID of salesmen & .62 & .71 & .71 \\
Leave porch/yard lights on at night & .67 & .73 & .72 \\
\end{tabular}

Table LXXXVI

PERSONAL SECURITY MEASURES

IMPORTANCE OF TECHNIQUES

BLACK OPINION BY PERIOD

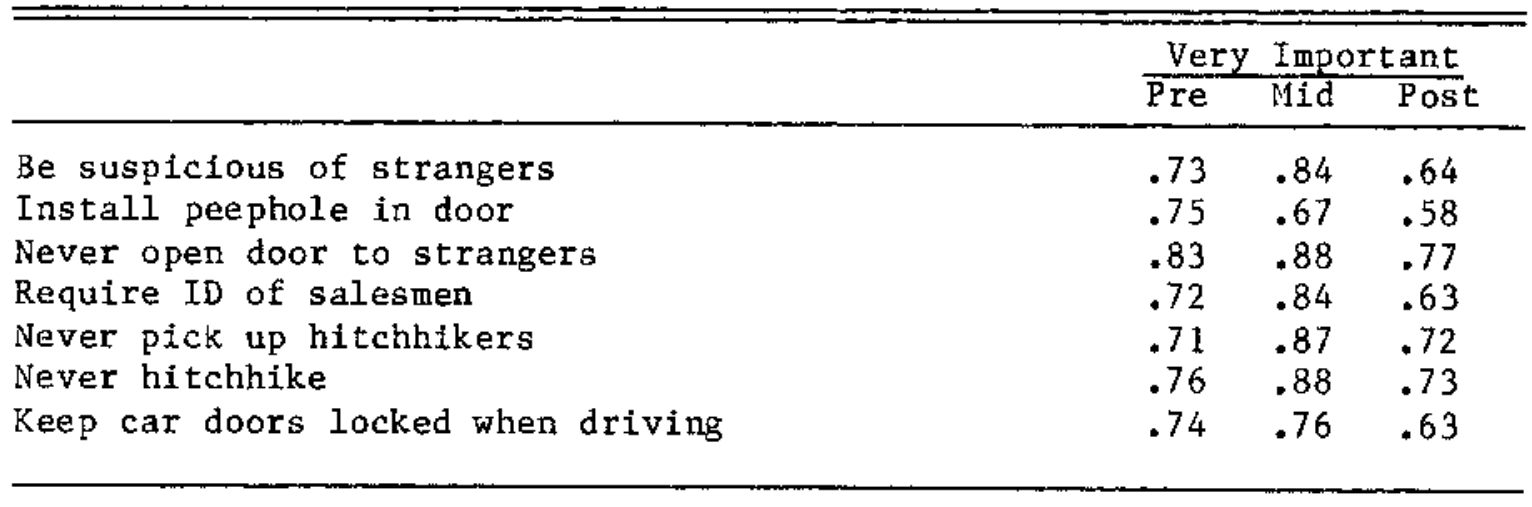


More Blacks also consistentiy stated that they had recently changed their personal crime preventive behavioral patterns (Table LXXXVII). However, the program appeared to have little impact upon any ethnic group's behavior over time. Only the Installation of peepholes marked a significant increase between the mid and post-surveys for all three groups (Table LXXXVIII). Besides this measure, Blacks posted only one other change, Whites two and Hispanics three.

$$
\text { Age.--0lder adults placed greater importance upon all }
$$

measures pertaining to personal safety than did younger individuals (Table LXXXIX). They also were the only group to change any opinion over time in a positive permanent fashion (Table XC). This only happened once concerning never carrying a large amount of money. While young adults recorded several initial increases, they were only temporary in duration. Persons aged 25-44 displayed only negative patterns.

There was no statistically significant difference among the various age groups as to their propensity to utilize crime prevention measures. Furthermore, the ad campaign had only a negligible effect in altering citizen behavior. In only two instances was there any increase reported between the mid and post-program surveys. Individuals aged 25-44 were more likely to keep car doors locked even when driving 
Table LXXXVII

PERSONAL SECURITY MEASURES

LIKELIHOOD OF USING TECHNIQUES

OPINION BY ETHNIC GROUP

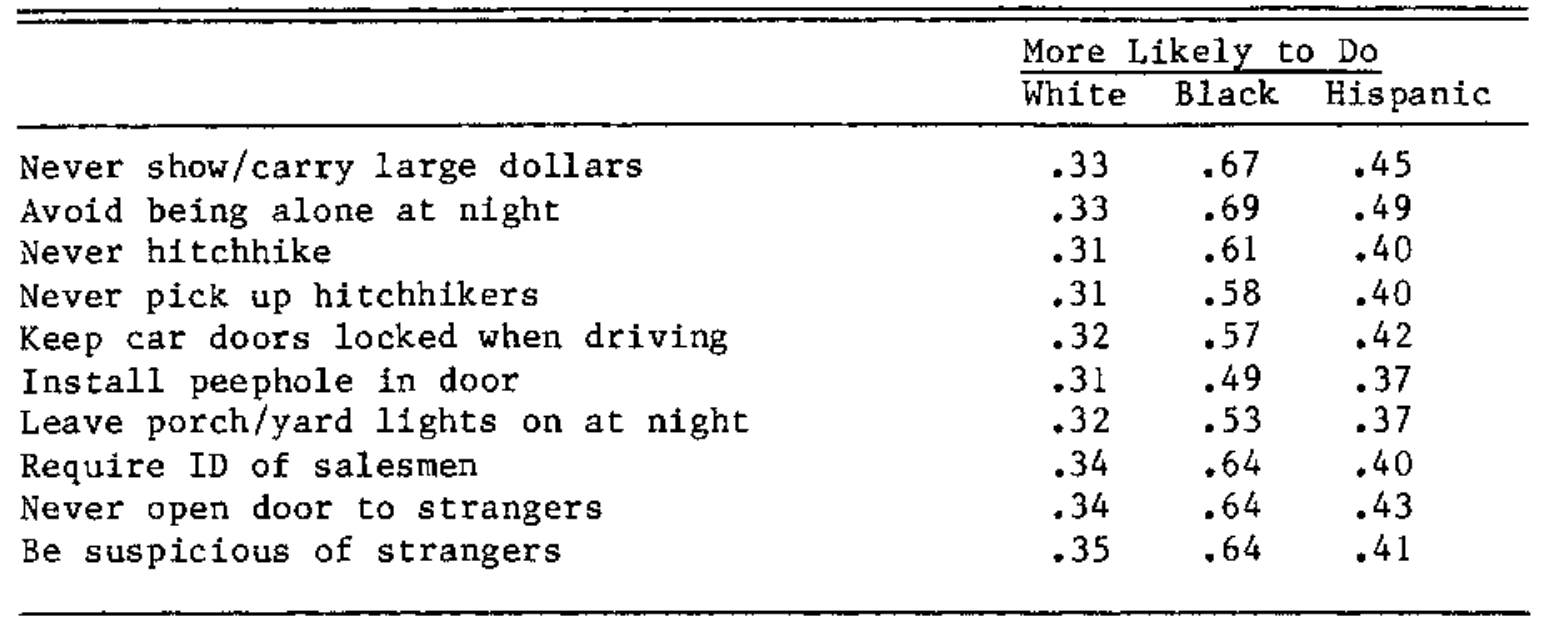

Table LXXXVIII

PERSONAL SECURITY MEASURES

LIKELIHOOD OF USING TECHNIQUES

ETHNIC GROUP OPINION BY PERIOD

\begin{tabular}{lll}
\hline & More Likely to Do \\
\hline White: & & Post \\
Insta11 peephole in door & .28 & .34 \\
Never open door to strangers & .31 & .38 \\
Keep car doors locked when driving & .29 & .35 \\
Black: & & \\
Insta1l peephole in door & .43 & .54 \\
Never show/carry large dollars & .61 & .73 \\
& & \\
Hispanic: & .28 & .46 \\
Install peephole in door & .35 & .55 \\
Never show/carry large dollars & .31 & .57 \\
Never open door to strangers & .31 & .49 \\
Require ID of salesmen & & \\
\hline
\end{tabular}


Table LXXXIX

PERSONAL SECURITY MEASURES

IMPORTANCE OF TECHNIQUES

OPINION BY AGE

\begin{tabular}{|c|c|c|c|}
\hline & $\frac{\text { Very }}{15-24}$ & $\frac{\text { Importa }}{25-44}$ & $\frac{\operatorname{ant}}{>44}$ \\
\hline $\begin{array}{l}\text { Never hitchhike } \\
\text { Never pick up hitchhikers }\end{array}$ & $\begin{array}{l}.71 \\
.68\end{array}$ & $\begin{array}{l}.78 \\
.78\end{array}$ & .88 \\
\hline $\begin{array}{l}\text { Never show/carry large dollars } \\
\text { Avoid being alone at night }\end{array}$ & .83 & $\begin{array}{r}.88 \\
.71\end{array}$ & .93 \\
\hline Require ID of salesmen & .64 & .68 & .74 \\
\hline Never open door to strangers & .71 & .73 & .81 \\
\hline $\begin{array}{l}\text { Be suspicious of strangers } \\
\text { Leave porch/yard lights on at night }\end{array}$ & $\begin{array}{l}.59 \\
.53\end{array}$ & .63 & $\begin{array}{l}.75 \\
.58\end{array}$ \\
\hline Keep car doors locked when driving & .57 & .61 & .74 \\
\hline Install peephole in door & .61 & .63 & .69 \\
\hline
\end{tabular}

Table XC

PERSONAL SECURITY MEASURES

IMPORTANCE OF TECHNIQUES

AGE OPINION BY PERIOD

\begin{tabular}{|c|c|c|c|}
\hline & Very & $\operatorname{Imp}$ & $\tan$ \\
\hline & Pre & Mid & $\overrightarrow{\text { Post }}$ \\
\hline \multicolumn{4}{|l|}{ 15-24 Age: } \\
\hline Avoid being alone at night & .62 & .79 & .66 \\
\hline Never pick up hitchhikers & .62 & .78 & .65 \\
\hline Never hitchhike & .67 & .79 & .68 \\
\hline Require ID of salesmen & .58 & .72 & .62 \\
\hline Keep car doors locked when driving & .52 & .65 & .54 \\
\hline \multicolumn{4}{|l|}{$25-44$ Age: } \\
\hline Never open door to strangers & .78 & .66 & .74 \\
\hline Install peephole in door & .70 & .62 & .58 \\
\hline Keep car doors locked when driving & .68 & .55 & .59 \\
\hline Leave porch/yard lights on at night & .57 & .53 & .46 \\
\hline \multicolumn{4}{|l|}{ Over 44 Age: } \\
\hline Never show/carry large dollars & .90 & .95 & .95 \\
\hline
\end{tabular}


and older adults were more apt to install peepholes in doors.

Marital Status.--There was a considerable difference between married and single respondents' opinions of the importance of personal safety measures (Table XCI). Married persons cansistently considered these devices to be more important than did single individuals. However, the two groups moved closer to agreement over time. Single subjects increased their perceptions of importance in three cases, while married respondents recorded a decline (Table XCII).

There was little difference between the two groups concerning their reported behavior. In only one case was there a significant difference between married and single people. More single respondents replied that they were less likely to hitchilke than six months earlier.

Single respondents recorded some increase over time in their likelihood of actually utilizing personal safety measures. In four instances-ttwo dealing with protective behavior while at home and two concerning security measures when away--a signiflcant $x$ ise was reported (Table XCIII). Married individuals' behavior was unaffected by the advertising campaign.

Tenure.--Owners and renters displayed differing perceptions on the importance of personal safety measures. Generally, owners deemed these security devices more important than did renters. The only exception concerned 
Table XCI

PERSONAL SECURITY MEASURES

IMPORTANCE OF TECHNIQUES

OPINION BY MARITAL STATUS

\begin{tabular}{lcc}
\hline & \multicolumn{2}{c}{ Very Important } \\
\hline Require id of salesmen & Single & Married \\
Never open door to strangers & .66 & .71 \\
Be suspicious of strangers & .71 & .78 \\
Keep car doors locked when driving & .63 & .69 \\
Avoid being alone at night & .61 & .67 \\
Never show/carry large dollars & .70 & .79 \\
Never pick up hitchhikers & .85 & .91 \\
Never hitchhike & .73 & .85 \\
\hline
\end{tabular}

Table XCII

PERSONAL SECURITY MEASURES

IMPORTANCE OF TECHNIQUES

MARITAL STATUS OPINION BY PERIOD

\begin{tabular}{lcccc}
\hline & \multicolumn{3}{c}{ Very Important } \\
\hline Single: & \multicolumn{1}{c}{ Pre } & Mid & Post \\
Require ID of salesmen & & & \\
Never pick up hitchhikers & .60 & .69 & .70 \\
Avoid being alone at night & .68 & .76 & .75 \\
& .63 & .72 & .75 \\
Married: & & & \\
Require ID of salesmen & & & \\
Never pick up hitchhikers & .71 & .76 & .66 \\
Never hitchhike & .86 & .91 & .78 \\
Be suspicious of strangers & .84 & .89 & .80 \\
Leave porch/yard lights on at night & .70 & .74 & .63 \\
\end{tabular}


Table XCIII

PERSONAL SECURITY MEASURES

LIKELIHOOD OF USING TECHNIQUES

SINGLE OPINION BY PERIOD

\begin{tabular}{lcc}
\hline & \multicolumn{2}{c}{ More Likely } \\
\hline Install peephole in door & Mid & Post \\
Never open door to strangers & .29 & .40 \\
Never show/carry large dollars & .39 & .49 \\
Keep car doors locked when driving & .40 & .48 \\
\hline
\end{tabular}


leaving exterior 11 ghts on to discourage prowlers ( Table XCIV).

Individuals" attitudes remained basically unchanged throughout the program period. In only two instances did a significant attitudinal alteration occur. Renters initially reported an increase in their perceived importance of giving rides to strangers. However, this proved to be temporary and opinions dropped to prior levels. In the other case renters actually recorded a decline in attitudes over the program period concerning the importance of leaving lights on at night to discourage prowlers.

There was no difference indicated between the two groups on reported crime preventive behavior and little alteration observed over time. Owners reported only one increase in the likelihood of implementing personal security measures and renters four changes (Table XCV). Both agreed that they were more likely to install peepholes in their doors.

Income.-Family income had an impact upon peoples" perceptions of the importance of personal safety measures. As may be observed in Table XCVI, the rich considered hitchhiking precautions more important than did the poor. In the other instances where a significant difference was present, the opposite was true. 
Table XCIV

\section{PERSONAL SECURITY MEASURES \\ IMPORTANCE OF TECHNIQJES \\ OPINION BY TENURE}

\begin{tabular}{lcc}
\hline \hline & \multicolumn{2}{c}{ Very Inportant } \\
\hline Require ID of salesmen & Owner & Renter \\
Never open door to strangers & .72 & .67 \\
Be suspicious of strangers & .78 & .73 \\
Leave porch/yard lights on at night & .70 & .62 \\
Avoid being alone at night & .49 & .60 \\
Keep car doors locked when driving & .79 & .71 \\
Never show/carry large dollars & .69 & .60 \\
Never pick up hitchhikers & .90 & .87 \\
Never hitchhike & .85 & .74 \\
\end{tabular}

Table XCV

PERSONAL SECURITY MEASURES

LIKELIHOOD OF USING TECHNIQUES

TENURE OPINION BY PERIOD

\begin{tabular}{lll}
\hline & \multicolumn{2}{c}{ More Likely } \\
\hline Renter: & Mid & Post \\
Install peephole in door & .31 & .40 \\
Never open door to strangers & .38 & .47 \\
Never show/carry large dollars & .39 & .47 \\
Keep car doors locked when driving & .32 & .43 \\
& & .40 \\
Owner: & .32 & .40 \\
Install peephole in door & & \\
\hline
\end{tabular}


Table XCVI

PERSONAL SECURITY MEASURES

IMPORTANCE OF TECHNIQUES

OPINION BY INCOME

\begin{tabular}{lllll}
\hline & \multicolumn{3}{c}{ Very Important } \\
\cline { 2 - 5 } & \multicolumn{3}{c}{$5000-10000-$} \\
\hline Be suspicious of strangers & $<5000$ & 9999 & $14999>15000$ \\
Leave porch/yard lights on at night & .72 & .66 & .68 & .62 \\
Avoid being alone at night & .59 & .59 & .56 & .45 \\
Never pick up hitchhikers & .83 & .74 & .74 & .72 \\
Never hitchhike & .79 & .77 & .79 & .84 \\
& .80 & .77 & .83 & .84 \\
\hline
\end{tabular}


only the poor, however, displayed any real positive attitudinal changes over time. Elsewhere, the program impact was nonexistent (Table XCVII). The poor also indicated a greater recent behavioral change than did other respondents (Table XCVIII). However, there was little indication that the advertising had any real impact upon citizens' behavior. Only two instances of significant change were reported between the mid and post-surveys. The poor displayed an increased likelihood of installing peepholes in doors. The rich indicated they were more likely to keep their car doors locked even while driving.

Conclusion

The Dallas crime prevention advertising program had a modest impact upon citizens' attitudes concerning the importance of utilizing simple measures to prevent crime against them, their homes, and their personal property. Furthermore, and more importantly, the survey results indicated that the advertising campaign had goaded them into action and such measures were actually being utilized throughout the populace in much greater numbers than before. 
Table XCVII

PERSONAL SECURITY MEASURES

IMPORTANCE OF TECHNIQUES

INCOME OPINION BY PERIOD

\begin{tabular}{lllll}
\hline & \multicolumn{3}{c}{ Very Important } \\
\hline Less than $\$ 5000$ Income: & \multicolumn{3}{c}{ Pre } & Post \\
Insta11 peephole in door & .68 & .76 & .72 \\
Avoid being alone at night & .75 & .88 & .85 \\
Never show/carry large dollars & .83 & .89 & .94 \\
Never pick up hitchikers & .77 & .88 & .72 \\
Greater than \$15000 Income: & & & \\
Never pick up hitchhikers & .81 & .89 & .81 \\
\hline
\end{tabular}

Table XCVIII

PERSONAL SECURITY MEASURES

LIKELIHOOD OF USING TECHNIQUES

OPINION BY INCOME

\begin{tabular}{|c|c|c|c|c|}
\hline & $<5000$ & $\begin{array}{l}\text { ore Lik } \\
5000- \\
9999\end{array}$ & $\frac{\mathrm{kely}}{10000-}$ & $>15000$ \\
\hline Require ID of salesmen & .48 & .45 & .44 & .33 \\
\hline Never open door to strangers & .49 & .47 & .41 & .33 \\
\hline Be suspicious of strangers & .49 & .44 & .45 & .34 \\
\hline Keep car doors locked when driving & .44 & .42 & .40 & .30 \\
\hline Avoid being alone at night & .52 & .47 & .42 & .32 \\
\hline Never show/carry large dollars & .52 & .45 & .40 & .34 \\
\hline Never hitchhike & .48 & .41 & .38 & .32 \\
\hline Never pick up hitchhlkers & .47 & .40 & .40 & .33 \\
\hline
\end{tabular}


APPENDIX D. IMPACT ASSESSMENT

Data

Model Building

Impact Assessment Conclusion 
APPENDIX D

\section{IMPACT ASSESSMENT}

Dat a

To measure the impact of the Dallas Crime Prevention Advertising Program upon reported crime incidences, an interrupted time series quasi-experimental design was employed. The police accumulate data on reported incidences of crime in seven categories: murder, rape, assault, burglary, auto theft, larceny, and robbery. This information is then forwarded to the FBI for publication in the annual Uniform Crime Reports. A tape of the reported crime data fn these seven categories from January 1,1971 through December 31, 1981, was obtained from the Dallas Police Department. A total of 935,257 separate incidences of crime were contained on the tape.

Initially, each crime category was summarized by month and year to ascertain the severity of any miscoding problem and to obtain monthly data for subsequent use in the analyses. As may be seen in Table XCIX, miscoding appeared to be minimal.

However, another problem became evident. Data were missing for January, 1971; January - July, 1974; and January - December, 1976. The tape for these periods contained reported crimes at levels approximately 10 per cent of those 
Tab1e XCIX

REPORTED CRIME - DALLAS

JANUARY 1971 - DECEMBER 1981

\begin{tabular}{|c|c|c|c|c|}
\hline & Total & Tape & Report & $\begin{array}{c}\text { Miscoded } \\
\text { Data }\end{array}$ \\
\hline Murder & 4,458 & 4,110 & 348 & 14 \\
\hline Rape & 10,189 & 9,205 & 984 & 25 \\
\hline Assault & 61,073 & 55,184 & 5,889 & 78 \\
\hline Auto Theft & 94,987 & 85,871 & 9,116 & 161 \\
\hline Burglary & 301,980 & 262,589 & 39,391 & 429 \\
\hline Theft & 557,170 & 475,260 & 81,910 & 874 \\
\hline Robbery & $\begin{array}{r}46,397 \\
\end{array}$ & 41,403 & 4,994 & 54 \\
\hline Total & $1,076,254$ & 933,622 & $\overline{142,632}$ & 1635 \\
\hline
\end{tabular}


of the remaining months. To create a continuous time serles, statistics obtained from the Sumary of Crimes reports submitted monthly to the F.B.I. were inserted in the appropriate periods.

These reports are prepared on the last day of each month and thus do not include any crimes for a particular month reported and processed after that date. Since the residual crimes contained on the master tape would not have been included in the monthly F.B.I. reports, they were added to the data to achieve greater continuity.

The merging of data from two separate sources, particularly for the post-intervention year 1976, may alter the observed trends in crime and thus produce potentially unreliable data. As may be seen in Figures 23-29, average monthly incidences of reported crime dropped in 1976 from prior year totals in all cases but one--laxceny. However, the changes observed between 1976 and 1977 do not appear to differ appreciably from the pattern developed in subsequent years. Therefore, it as decided that the data were homogeneous and adequate for use in a time series analysis.

\section{Mode1 Building}

The model of the stochastic process evident in each time series was bult in an iterative fashion in three steps: identification, estimation and diagnosis. First, based upon the autocorrelation and partial autocorrelation functions (ACF and PACF) derived from the time series, 


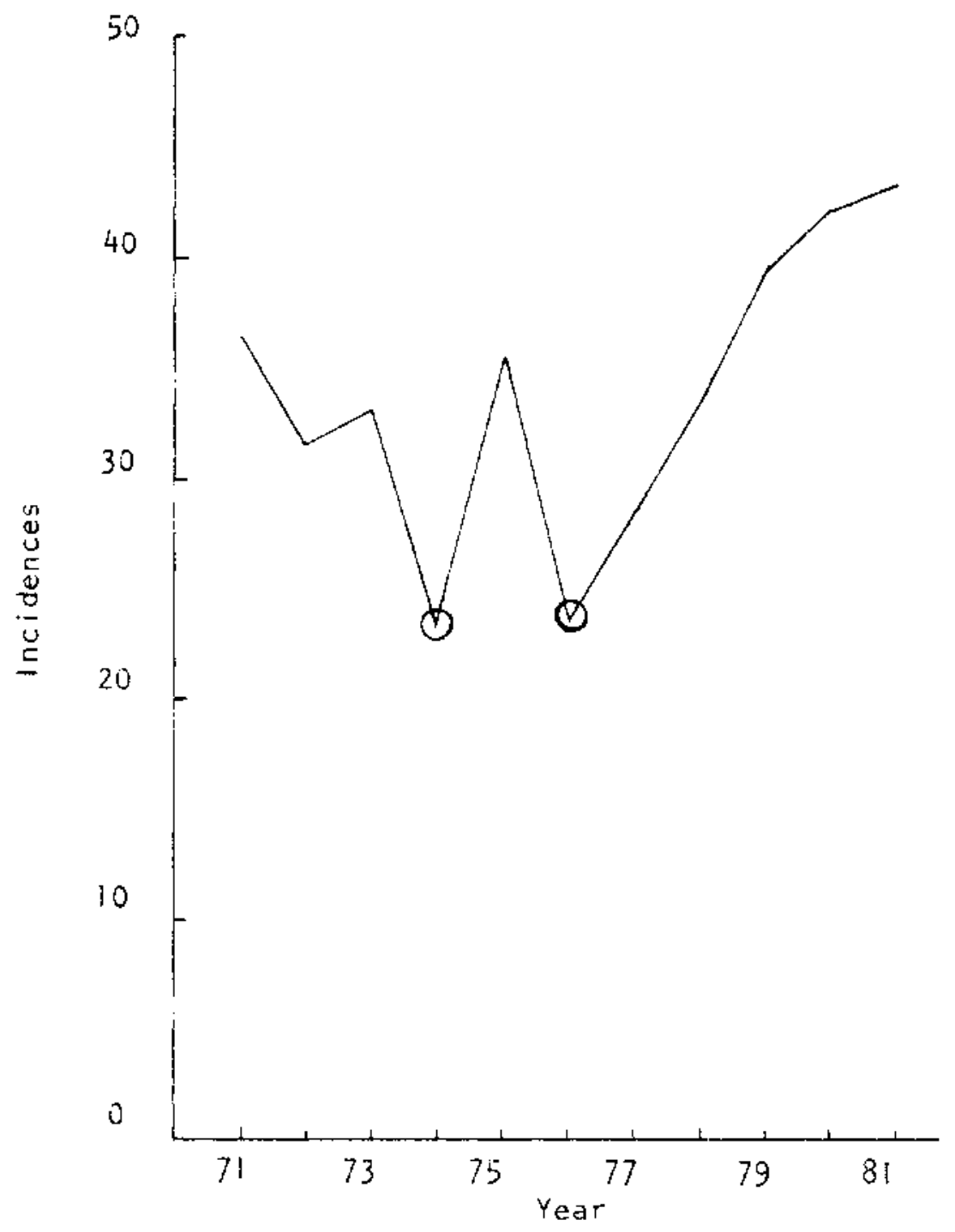

Fig. 23--Dallas Reported Crime-Murder Average Monthly Incidences 1971-1981 


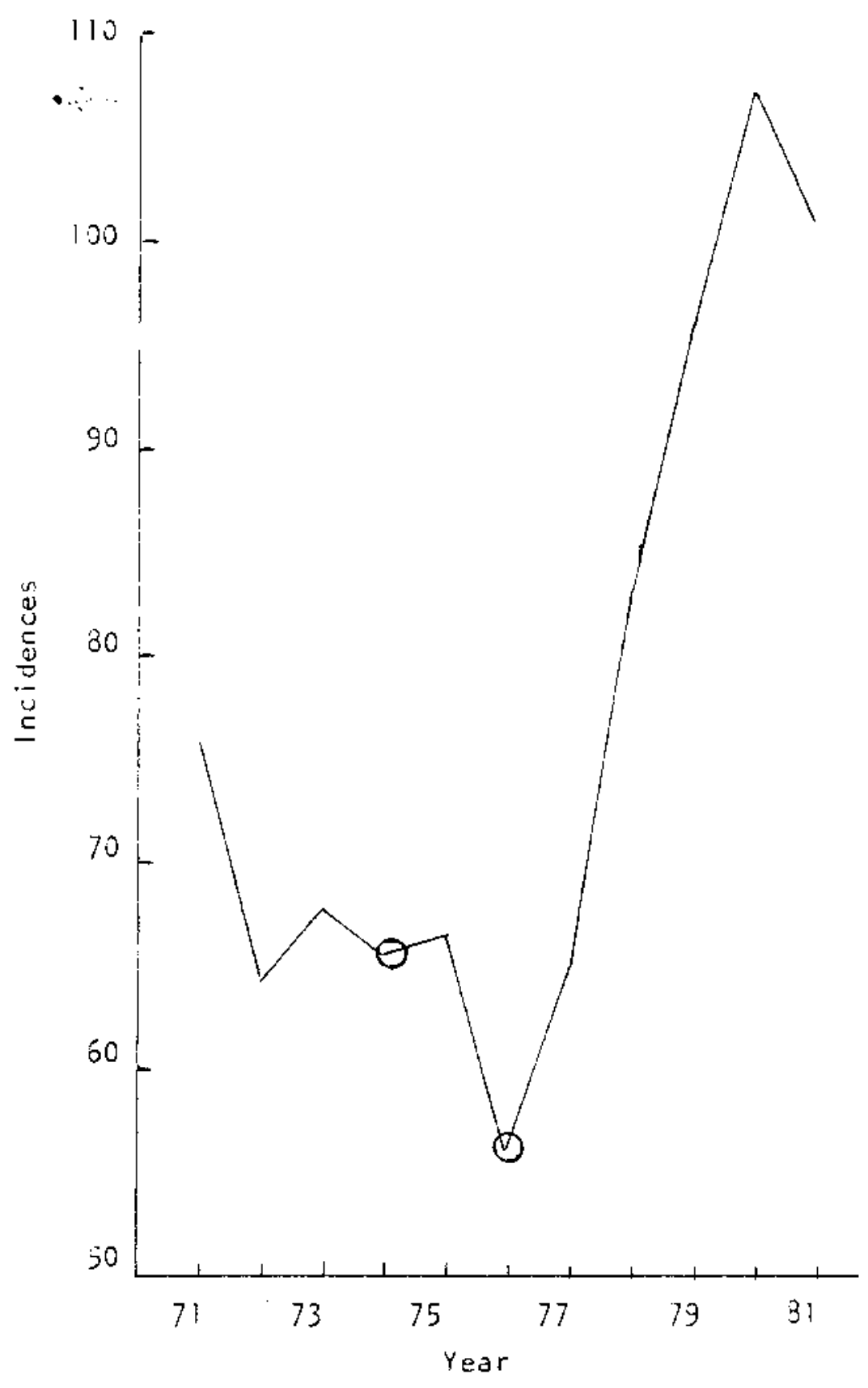

Fig. 24--Dallas Reported Crime - Rape Average Monthly Incidences 1971-1981 


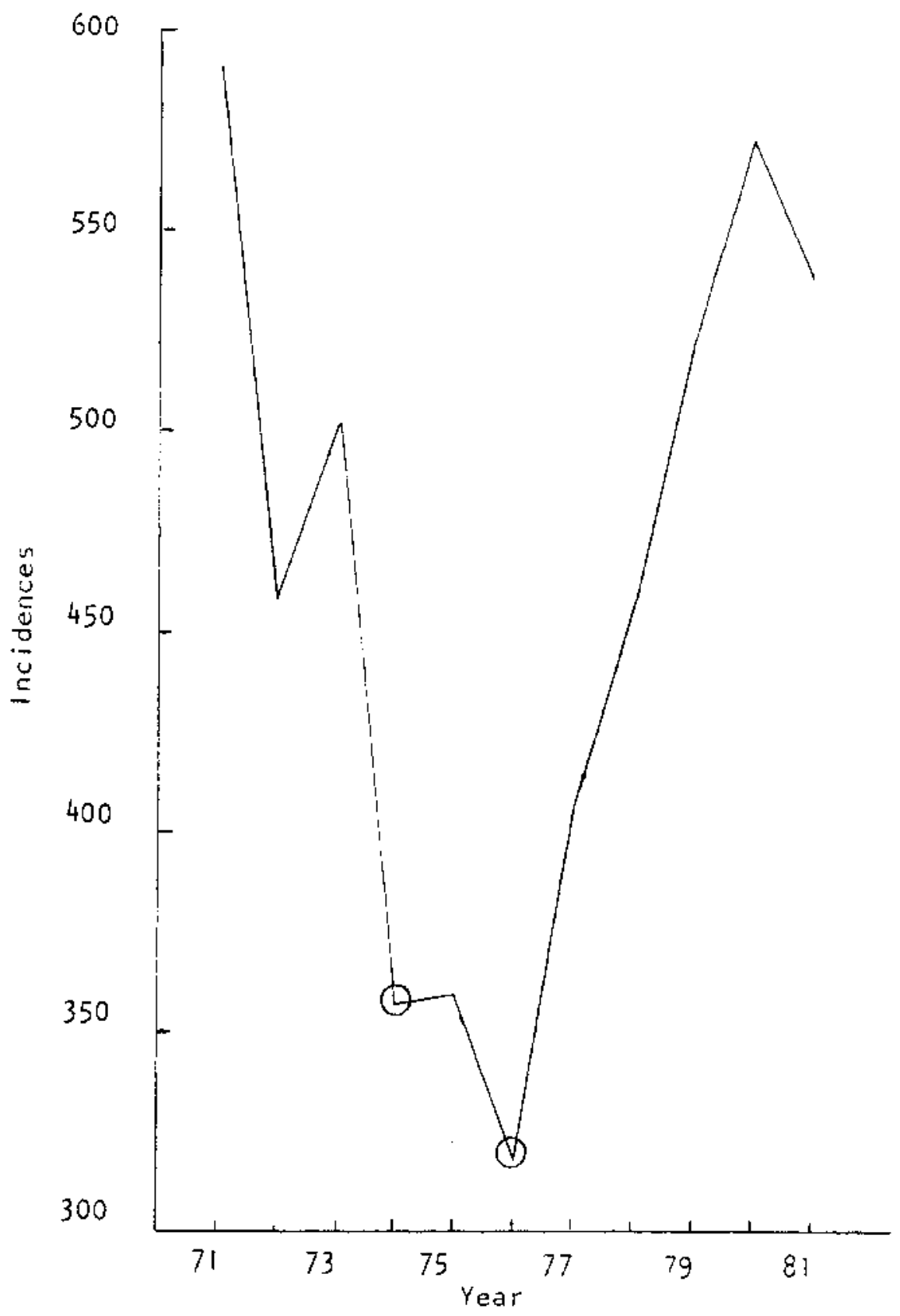

Fig. 25--Dallas Reported Crime - Assault Average Monthly Incidences 1971-1981 


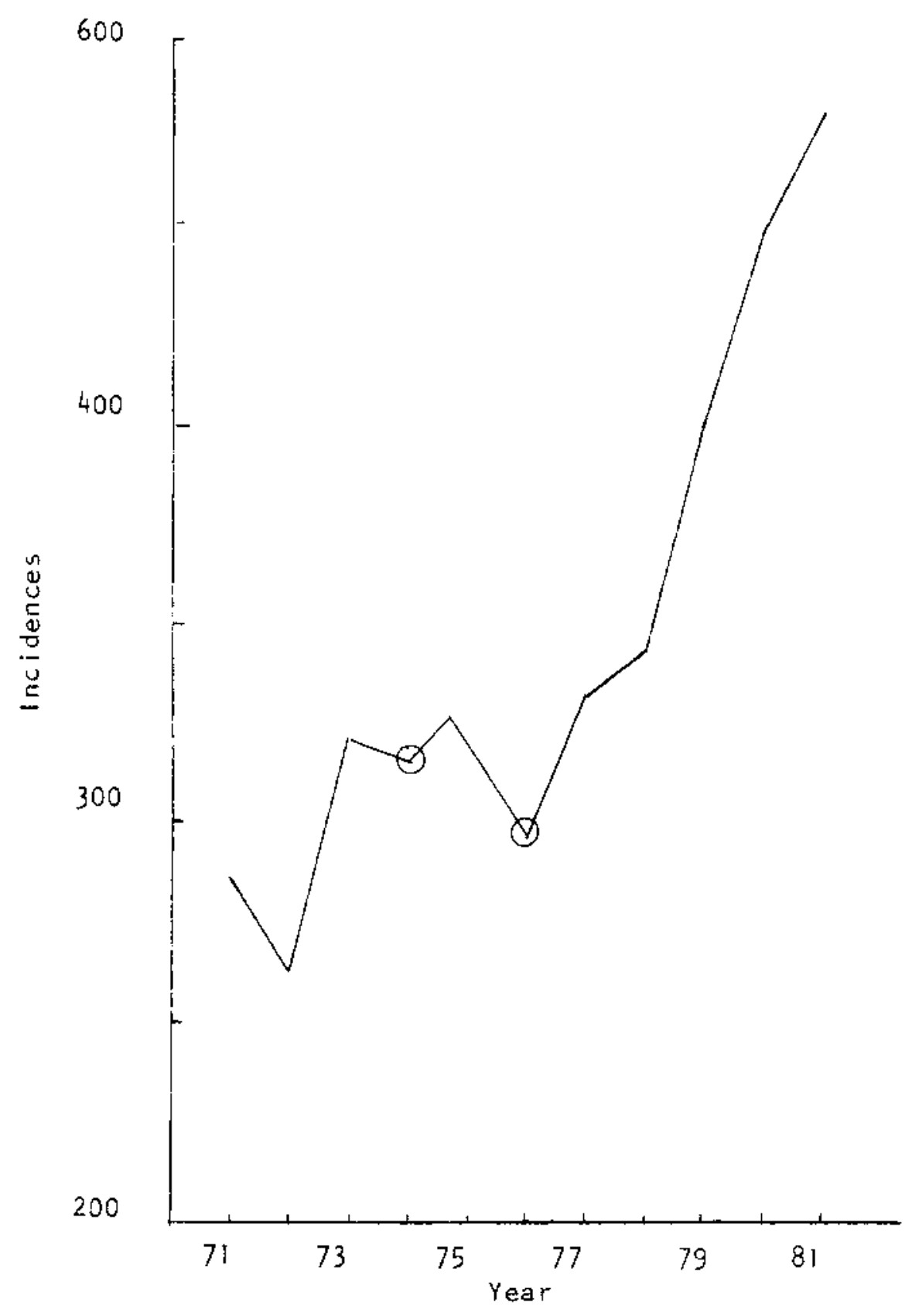

Fig. 26--Dallas Reported Crime - Robbery Average Monthly Incidences 1971-1981 


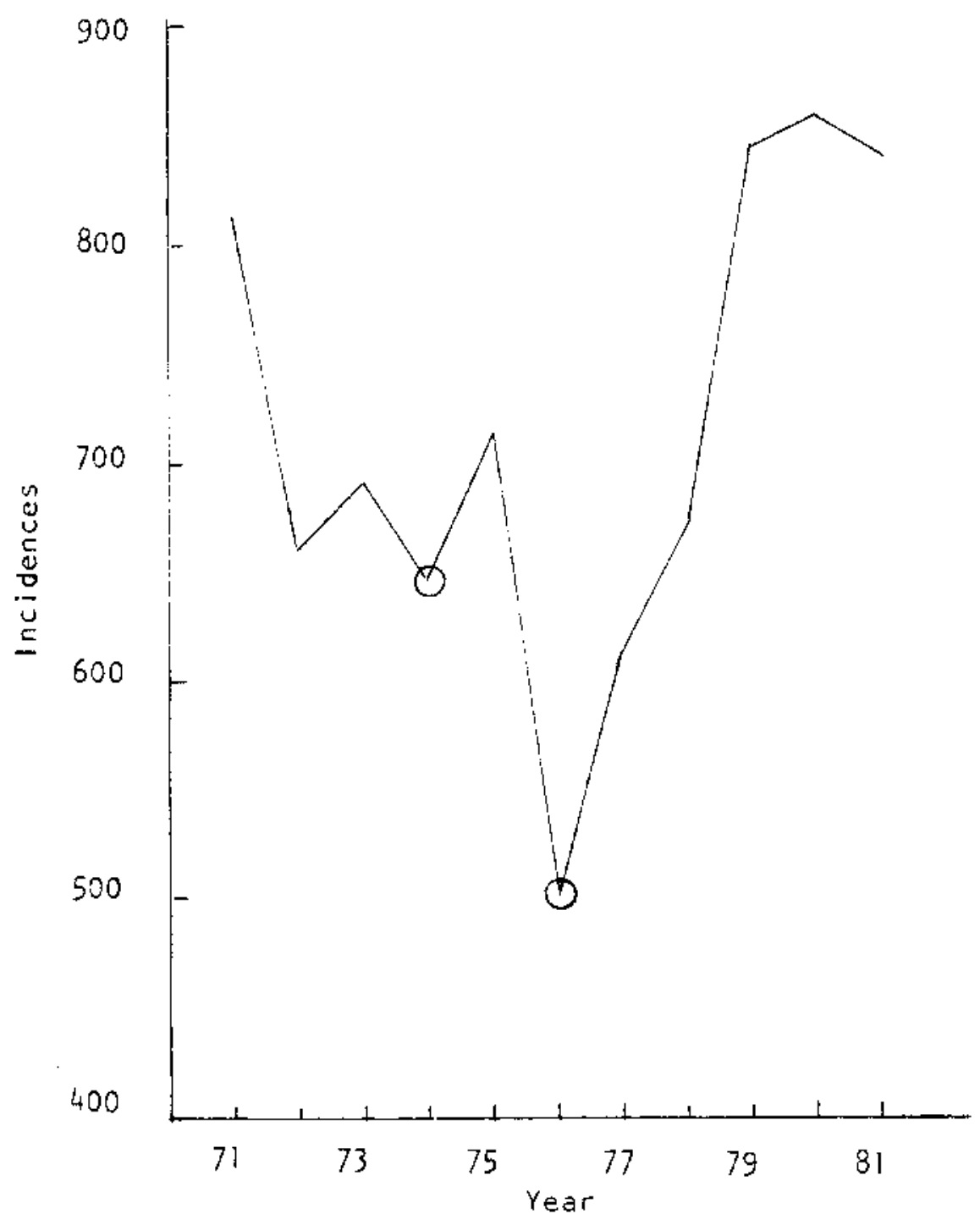

Fig. 27--Dallas Reported Crime - Auto Theft Average Monthly Incidences 1.971-1981 


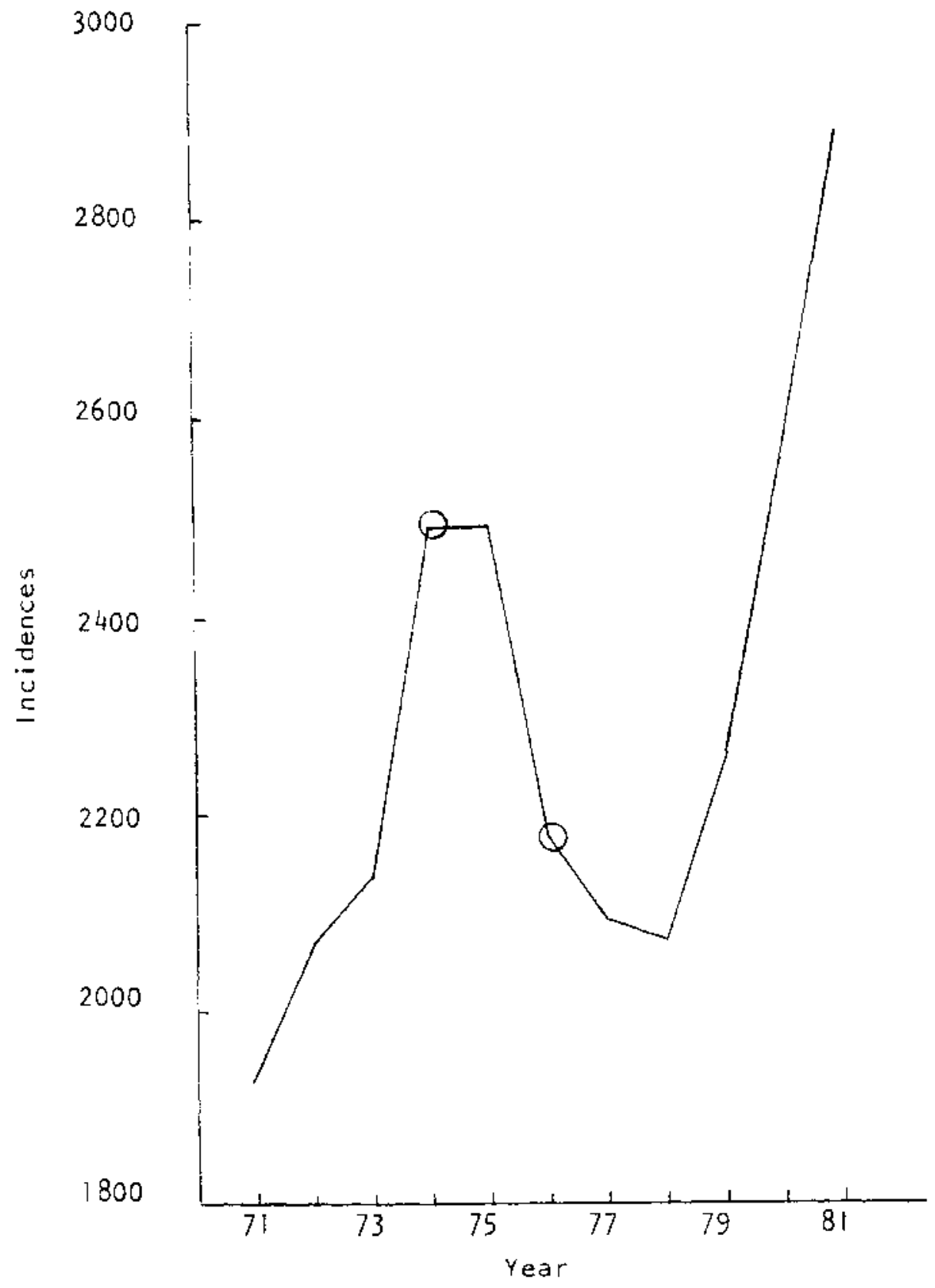

Fig. 28--Dallas Reported Crime - Burglary Average Monthly Incidences $1971-1981$ 


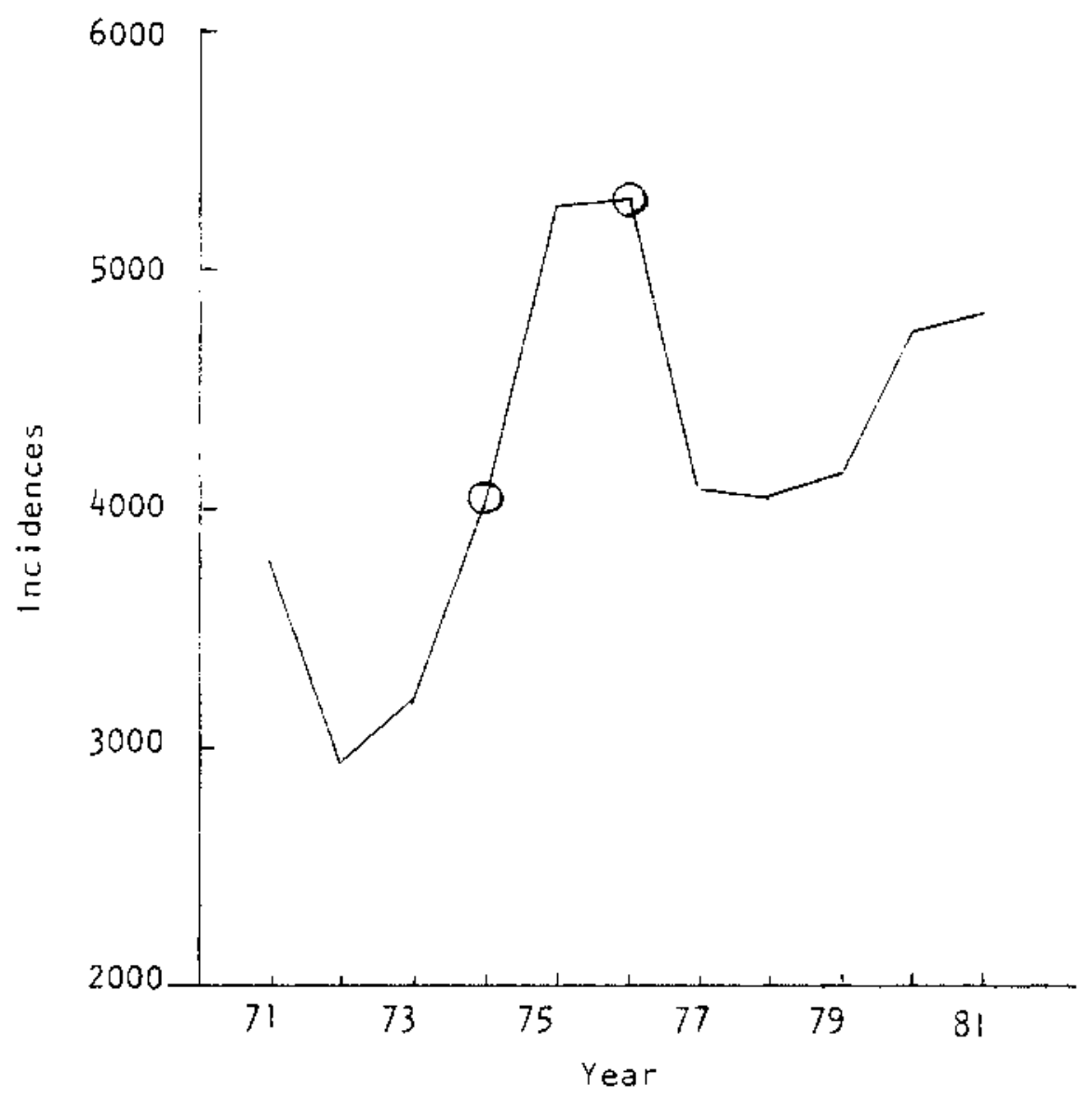

Fig. 29--Dallas Reported Crime - Larceny Average Monthly Incidences $1971-1981$ 
a tentative ARIMA model was identified. Then the model parameters were estimated. An ARIMA model is generally nonlinear. Therefore, the conditional least squares and unconditional least squares methods were used for estimation. Finally, the resultant model residuals were utilized to diagnose the adequacy of the model. A discussion of each crime model follows.

\section{Murder}

Identification (Mode1 1 ).--Comparison of a plot of the raw data with the logged series (Figures 30 and 31 ) indicated that except for the outiyer on December, 1971 , the raw series displayed more constant variance than the logged version. Therefore, the model was bullt using unlogged data. It was not readily evident from the ACF and PACF of the raw time series (Figure 32) that nonstationarity was present. The ARIMA mode1 $(1,0,0)$ was initially investigated. However, a significant spike at lag (1) remafned in the ACF, so the series was differenced. The spike in the $A C F$ and the decay of the $P A C F$ for the regularly differenced series (Figure 33) indicated the presence of a regular moving average. This resulted in a tentative ARIMA $(0,1,1)$ model for the time series. It is denoted as fo11 ow .

D. 1) $\mathrm{Y}_{\mathrm{t}}=\frac{\theta_{0}+1-\theta_{1} \mathrm{~B}}{(1-\mathrm{B})} \mathrm{a}_{\mathrm{t}}$ 


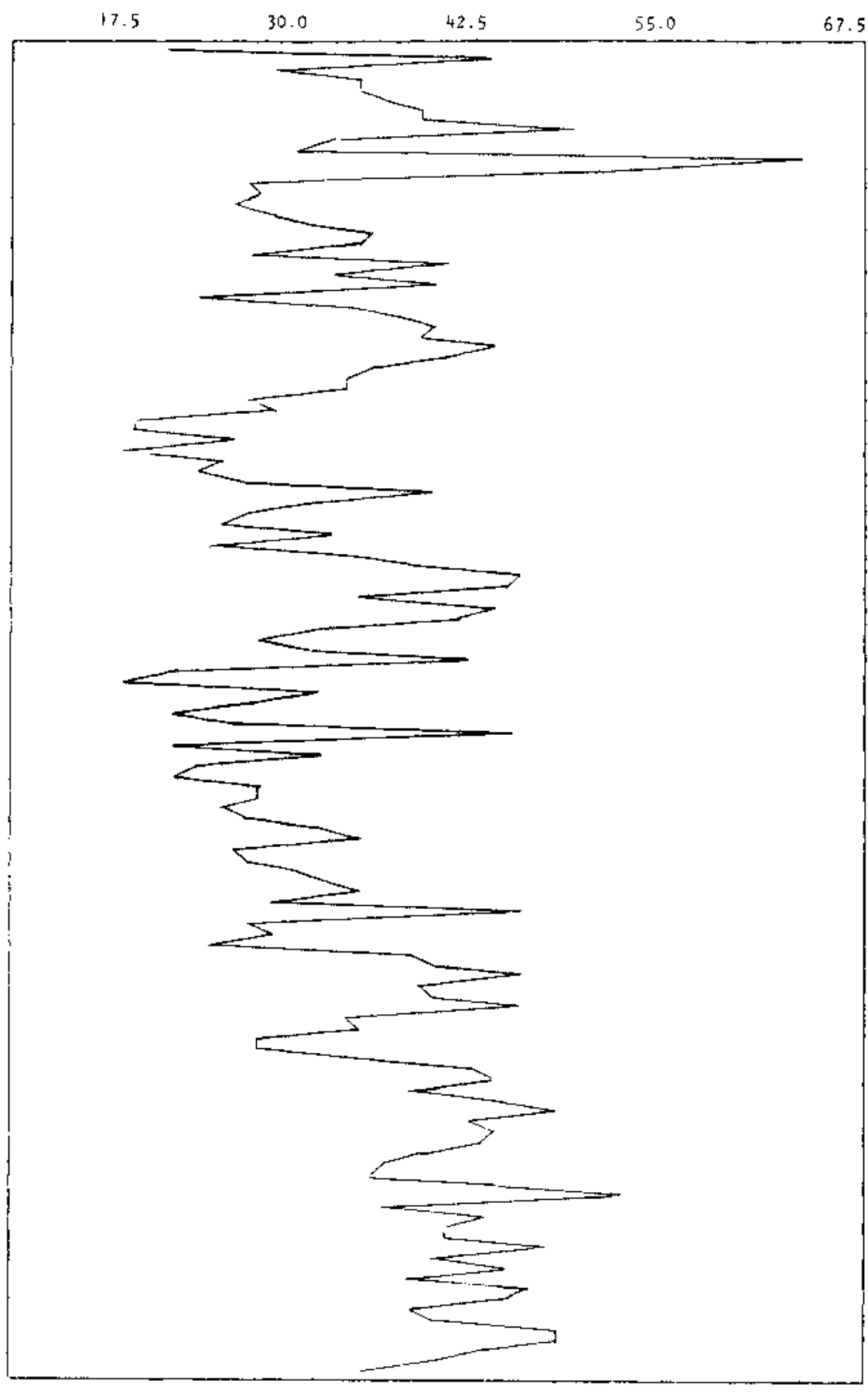

1971

1972

1973

1974

1975

1976

1977

1978

1979

1380

1931

Fig. 30--Murder Time Series

Unlogged Data

$1971-1981$ 


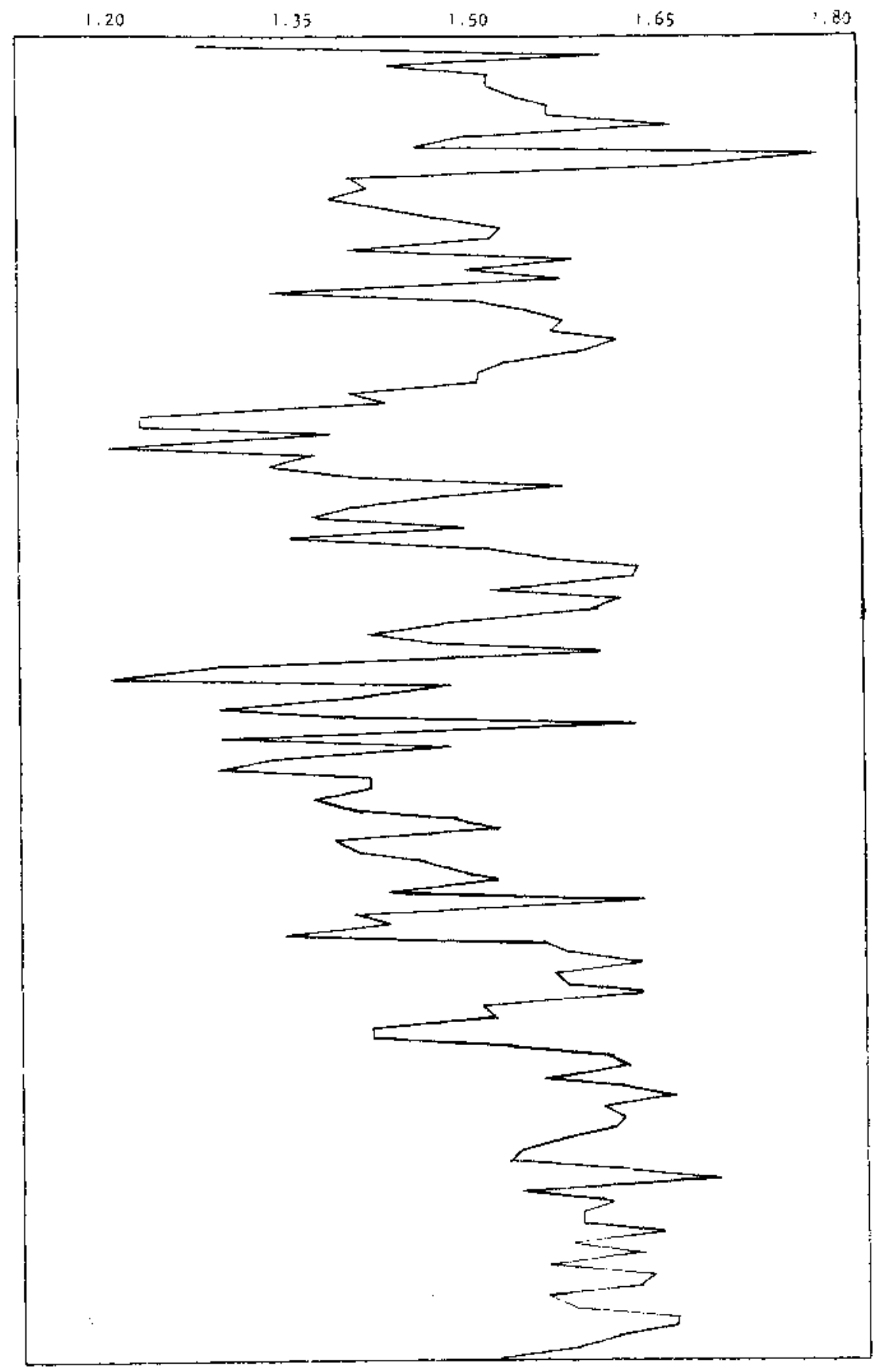

1971

1972

1973

1974

1975

1976

1977

1978

1979

1980

1981

Fig. 31--Murder Time Series

Logged Data

$1971-198 I$ 


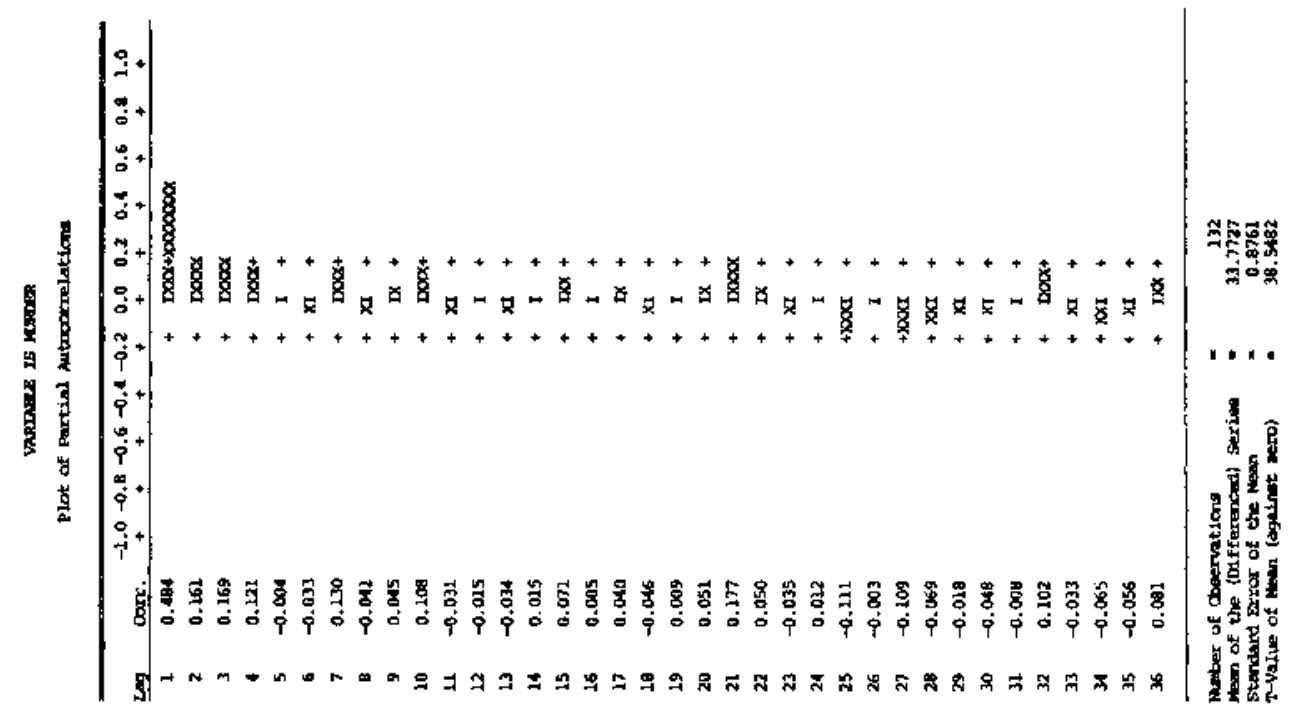

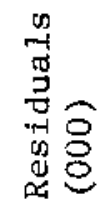

gु

语学

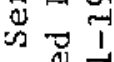

4 a

이의
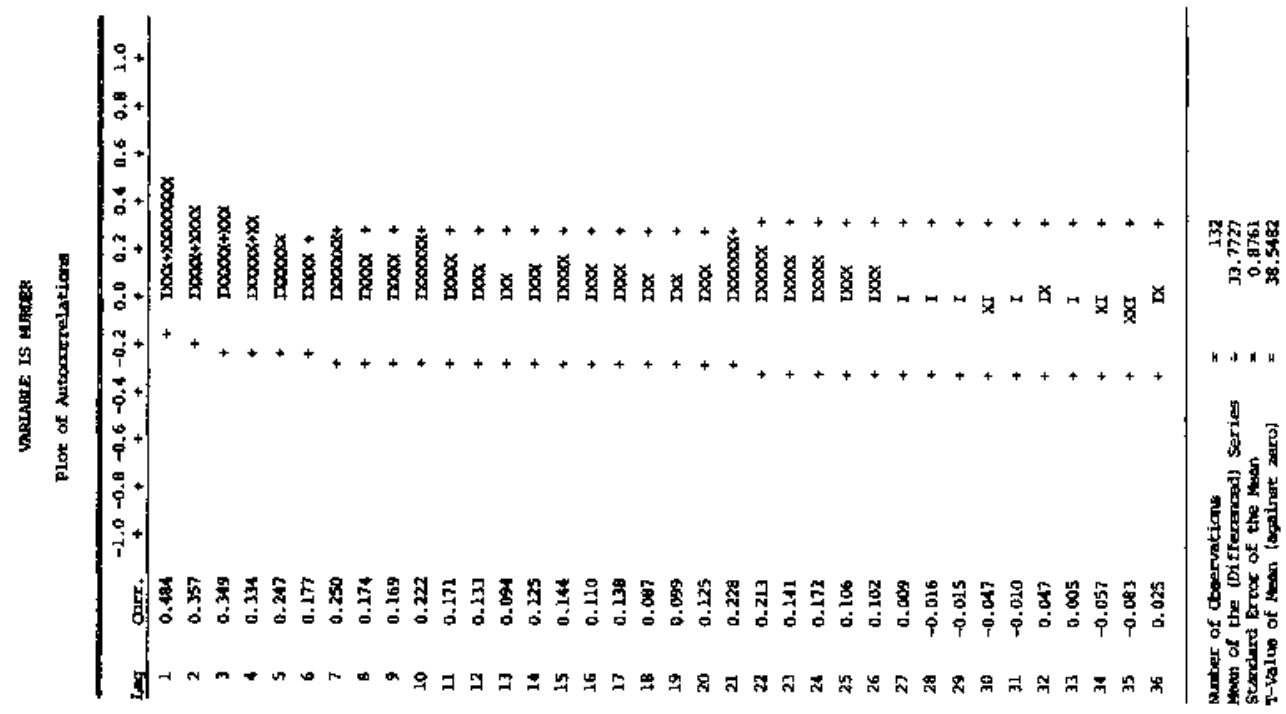

峁 


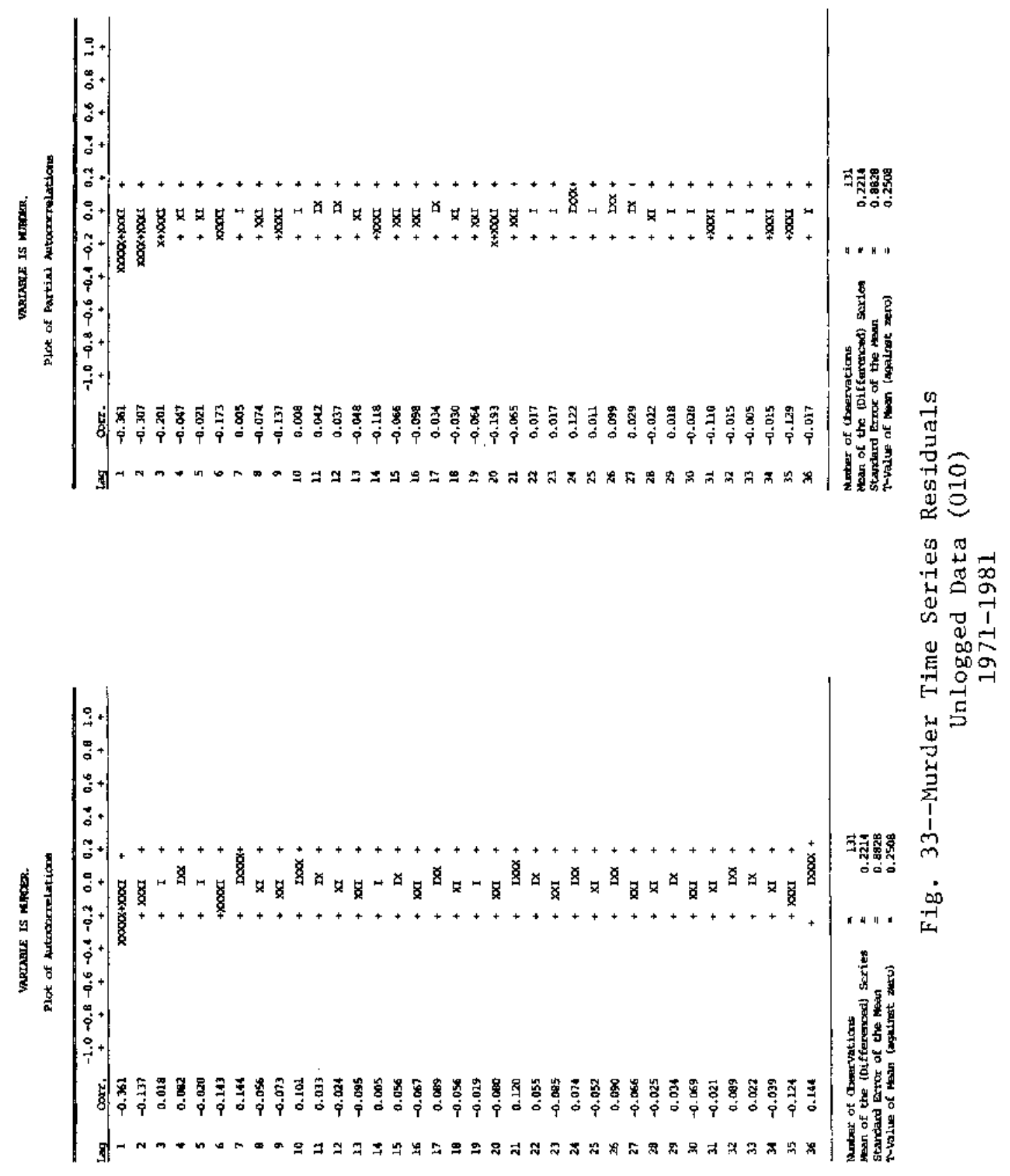


Estimation.--The parameter estimates for this tentative model are:

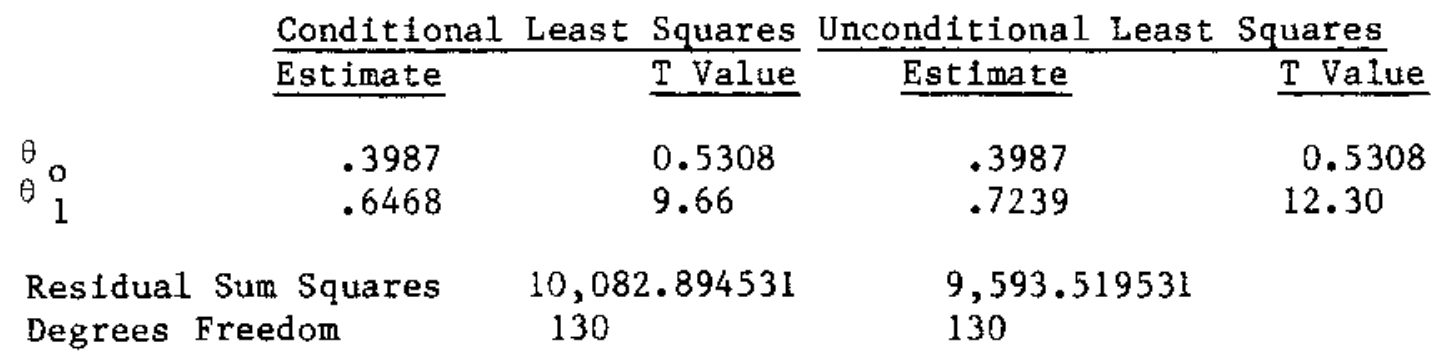

The estimate for $\theta_{0}$ was not statistically significant and was dropped from the model. This indicated that the movement of this time series process was drifting and no trend was present. The estimate for $\theta_{1}$ was statistically significant and lies within the bounds of invertibility. Diagnosis.--Figure 34 contains the ACF and PACF derived from the model residuals. There are no significant spikes in the early lags. The Q statistic for the ACF 1 ag 25 of 23 indicated that the model residuals were not significantly different from white noise. Nevertheless, closer examination of the residuals suggested that seasonallty was present. January and November contained mainly negative pulses, whlle May, JuIy, and August exhibited predominately positive residuals. This implied that reported murders could be more adequately modeled if seasonality was recognized.

Identification (Model 非) -- The ACF and PACF estimated from the regularly and seasonally differenced series (Figure 35) indicated an (011)(011) 12 ARIMA mode1. However, 

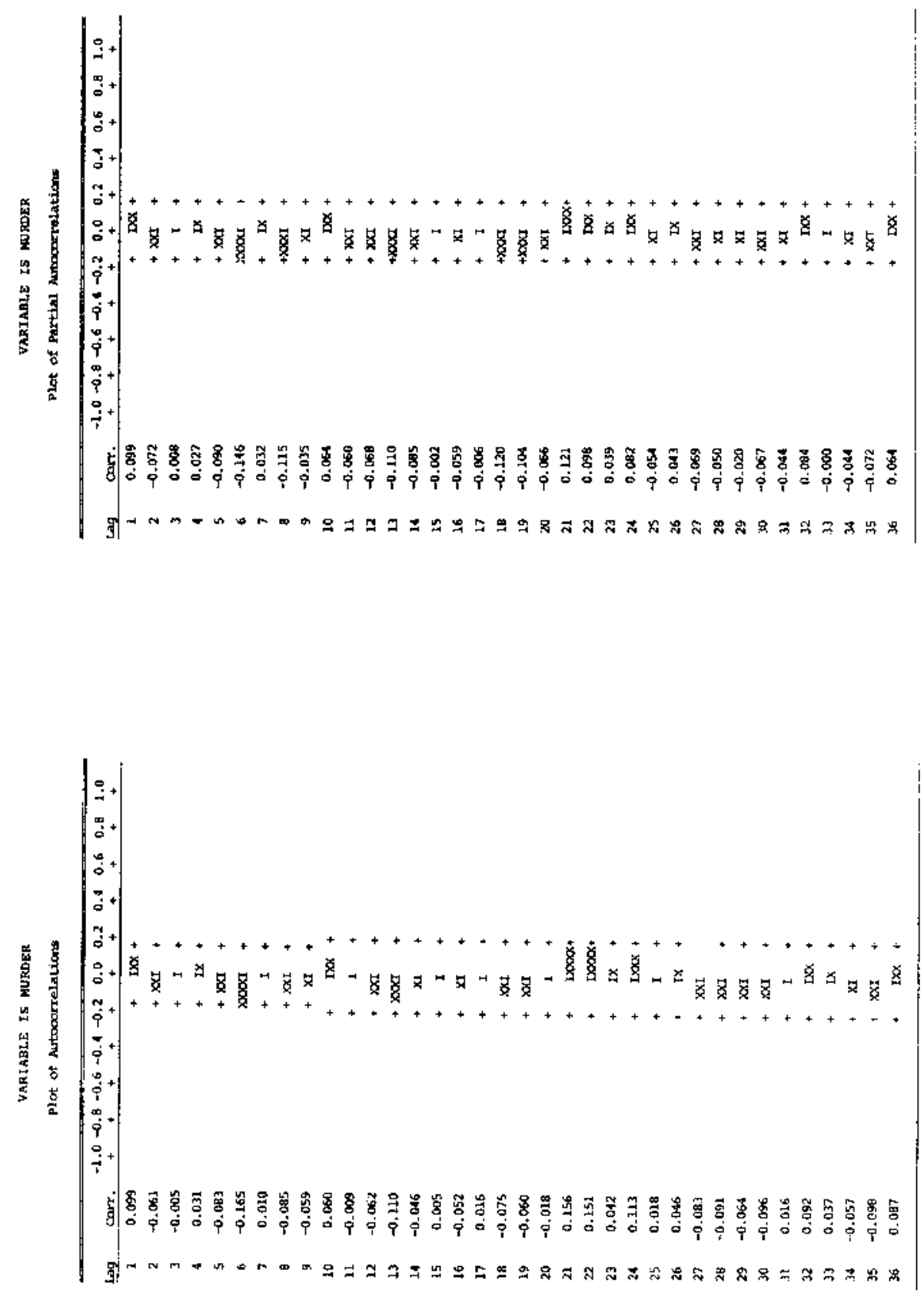


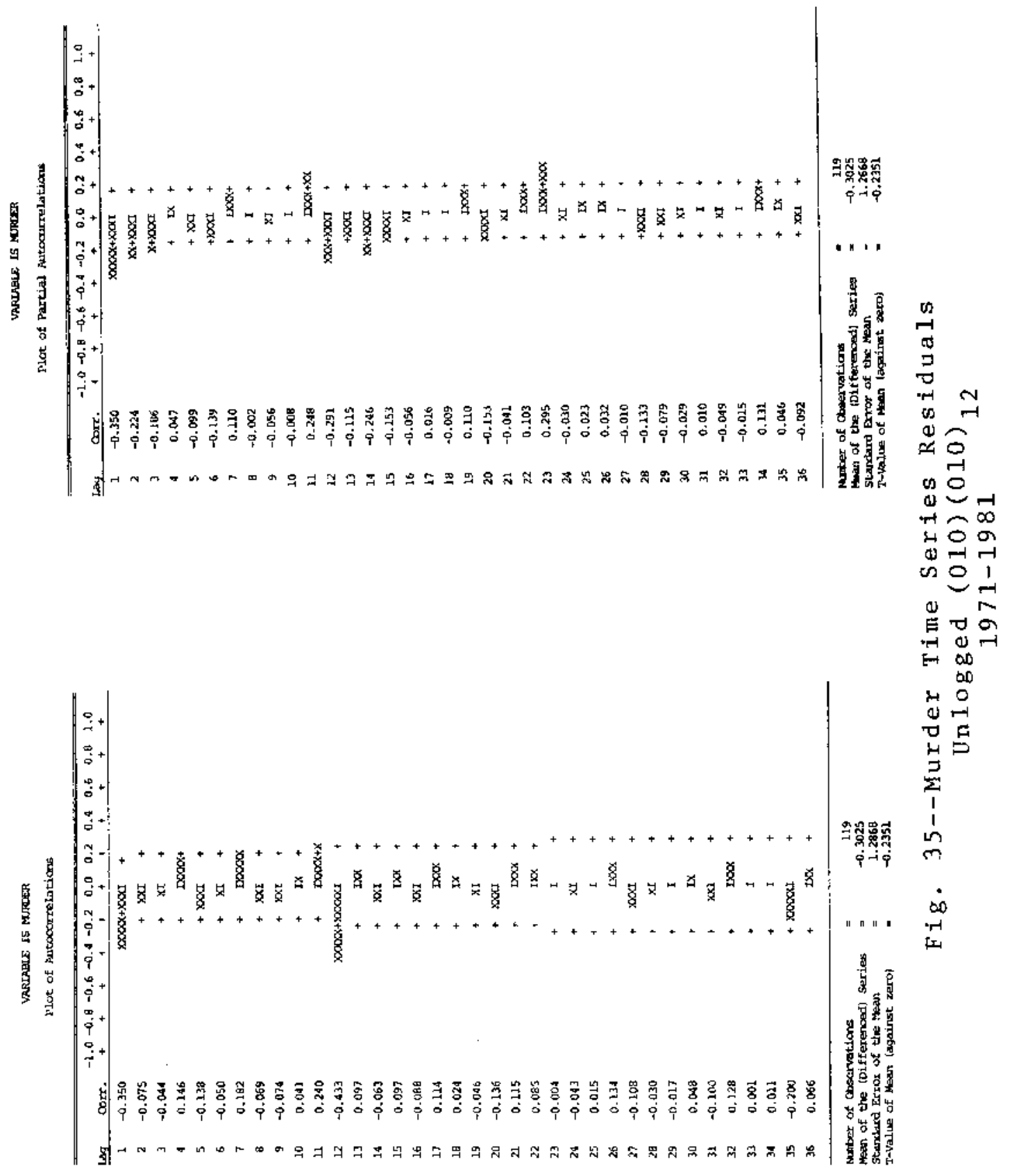


due to the autoregressiveness suggested by the differenced data, it was decided to create an (111)(111)12 ARIMA model. This is denoted as follows:

D.2) $\left(1-\phi_{1} B\right)\left(1-\phi_{12} B^{12}\right) y_{t}=\frac{\theta_{0}+\left(1-\theta_{1} B\right)\left(1-\theta_{12} B^{12}\right)}{(1-B)\left(1-B^{12}\right)} a_{t}$ Estimation.--The parameter estimates for Model \#2 are presented below.

$\frac{\text { Conditional Least Squares }}{\text { Estimate }} \frac{\text { Unconditional Least Squares }}{\text { TValue }}$

$\begin{array}{lrrrr}\theta_{0} & 0.4643 & 0.69 & 0.4643 & 0.69 \\ \theta_{1} & 0.7266 & 9.05 & 0.8595 & 16.83 \\ \theta_{1} & 0.7610 & 9.79 & 0.8779 & 32.92 \\ \phi_{1} & 0.1427 & 1.49 & 0.2515 & 2.57 \\ \phi_{12} & -0.2083 & -2.66 & -0.3588 & -5.12\end{array}$

Residual Sum of Squares $\quad 6465.449219 \quad 5509.968750$ Degrees Freedon $102 \quad 102$

All parameter estimates computed under the unconditional least squares method except ${ }^{\theta}$ o were statistically significant and within the bounds of invertibility and stationarity.

Diagnosis.--Estimation of the ACF and PACE of Model \#2 (Figure 36) indicated that the model residuals were independent at the first and second lags. The $Q$ statistic of 20, with degrees freedom of 21 , provided further evidence that the residuals were distributed as white noise.

Metadiagnosis.--Both murder ARIMA models met all the tests of white noise and were thus acceptable. However, while Model $/ 2$ was not parsimonious, its residual mean square of 54.02 was lower than that of Model 1 (73.80). Thus the ARIMA ( 111$)\left(\begin{array}{lll}1 & 1 & 1\end{array}\right) 12$ model was utilized in the 


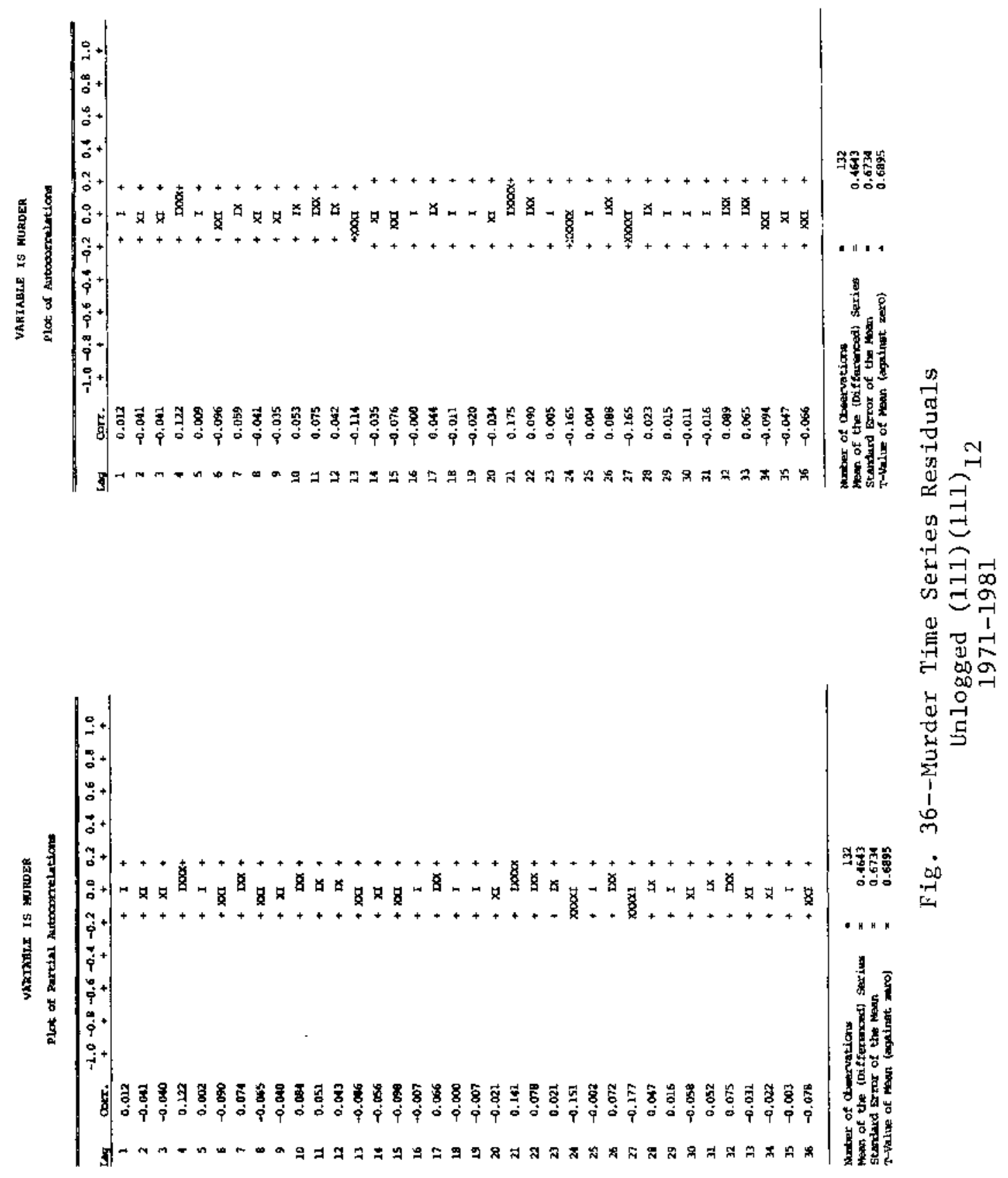


subsequent intervention analysis. A plot of the model residuals is contained in Figure 37.

\section{Rape}

Identification.--The time series of reported rapes in raw and 10 gged forms are presented in Figures 38 and 39 respectively. The raw time series variance was not constant, but increased in later years as rape incidences rose. Therefore, the model was built using log-transformed data where month-to-month fluctuations were roughly the same size throughout the series.

The ACF for the undifferenced series (Figure 40) displayed a pattern of cyclical slowly-decaying autocorrelation and the PACF had spikes at lags (1) and (12). This suggested that the series should be both regularly and seasonally differenced to achieve stationarity. The ACF spikes and PACF decaying patterns depicted in the stationary series (Figure 4l) clearly indicated an ARIMA (011)(011)12 model. This tentative model is written as

$$
\text { D.3) } \quad \operatorname{Ln}\left(y_{t}\right)=\frac{\theta_{0}+\left(1-\theta_{1} B\right)\left(1-\theta_{1} B^{12}\right)}{(1-B)\left(1-B^{12}\right)} a_{t}
$$

Estimation.--The parameter estimates for the tentative model are: 


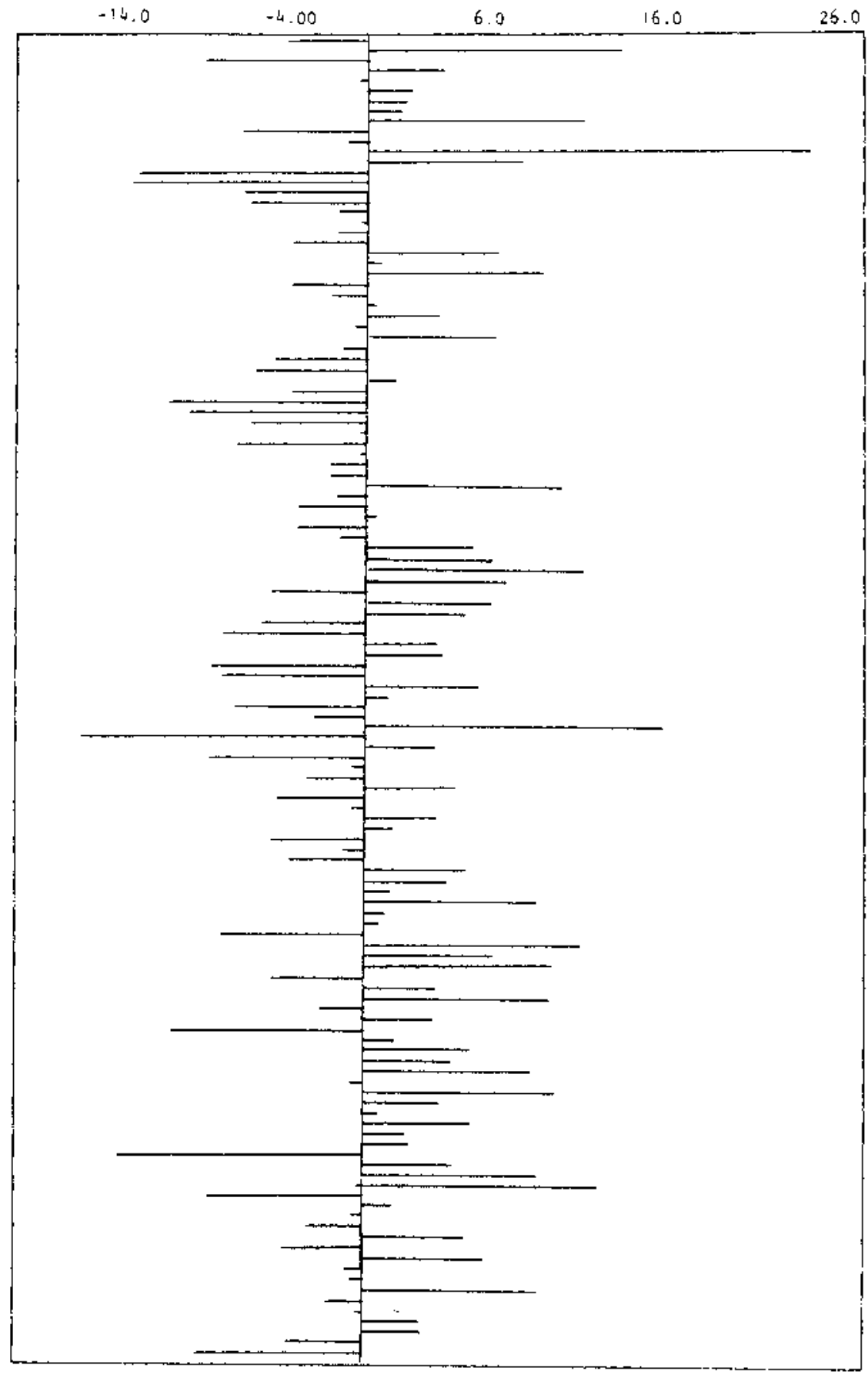

1971

1972

1973

1974

1975

1976

1977

Fig. 37--Murder Time Series Residuals Plot Un $10 \mathrm{gged}(111)(111) 12$
$1971-1981$ 


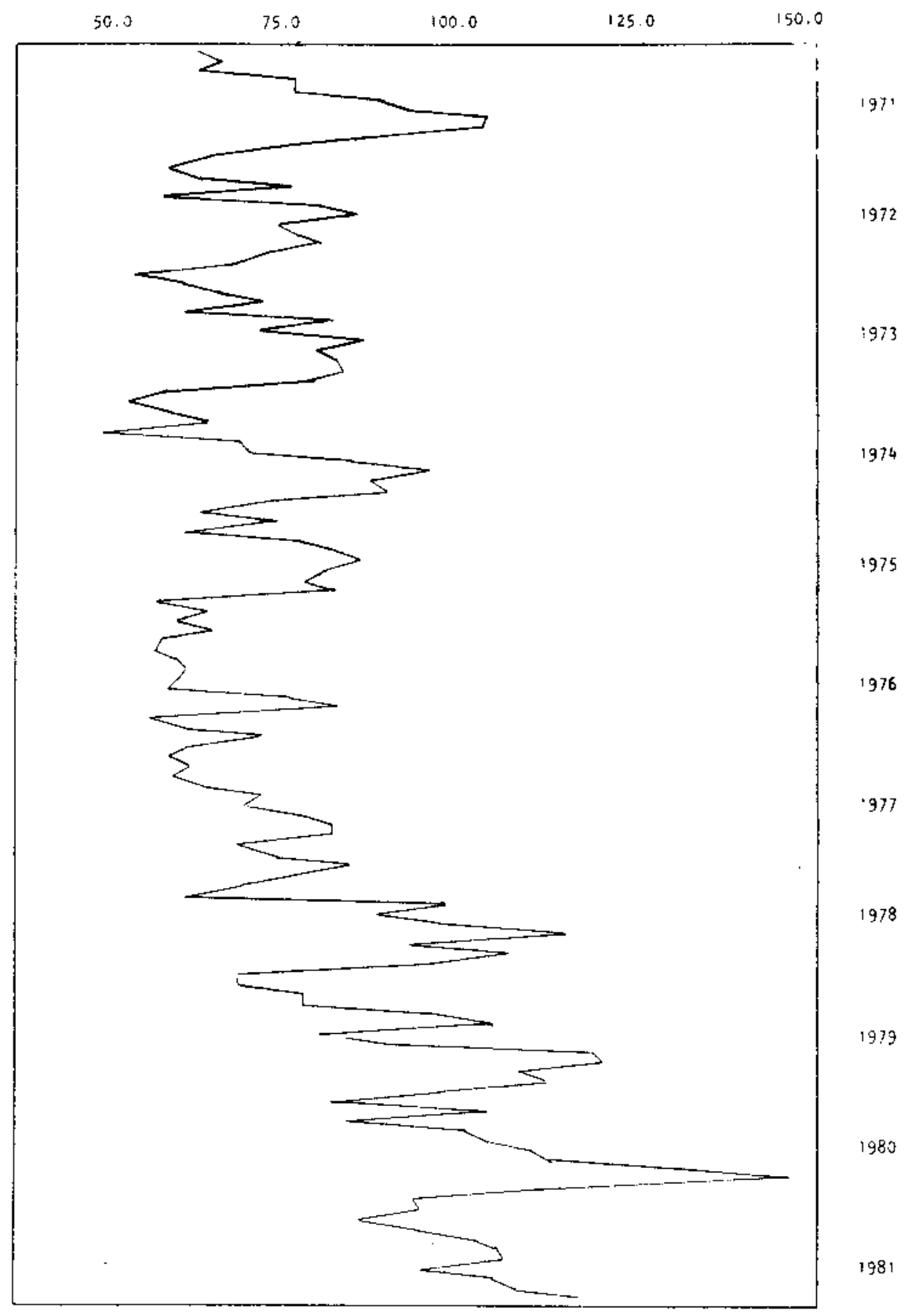

Fig. 38--Rape Time Series

Unlogged Data

$1971-1981$ 


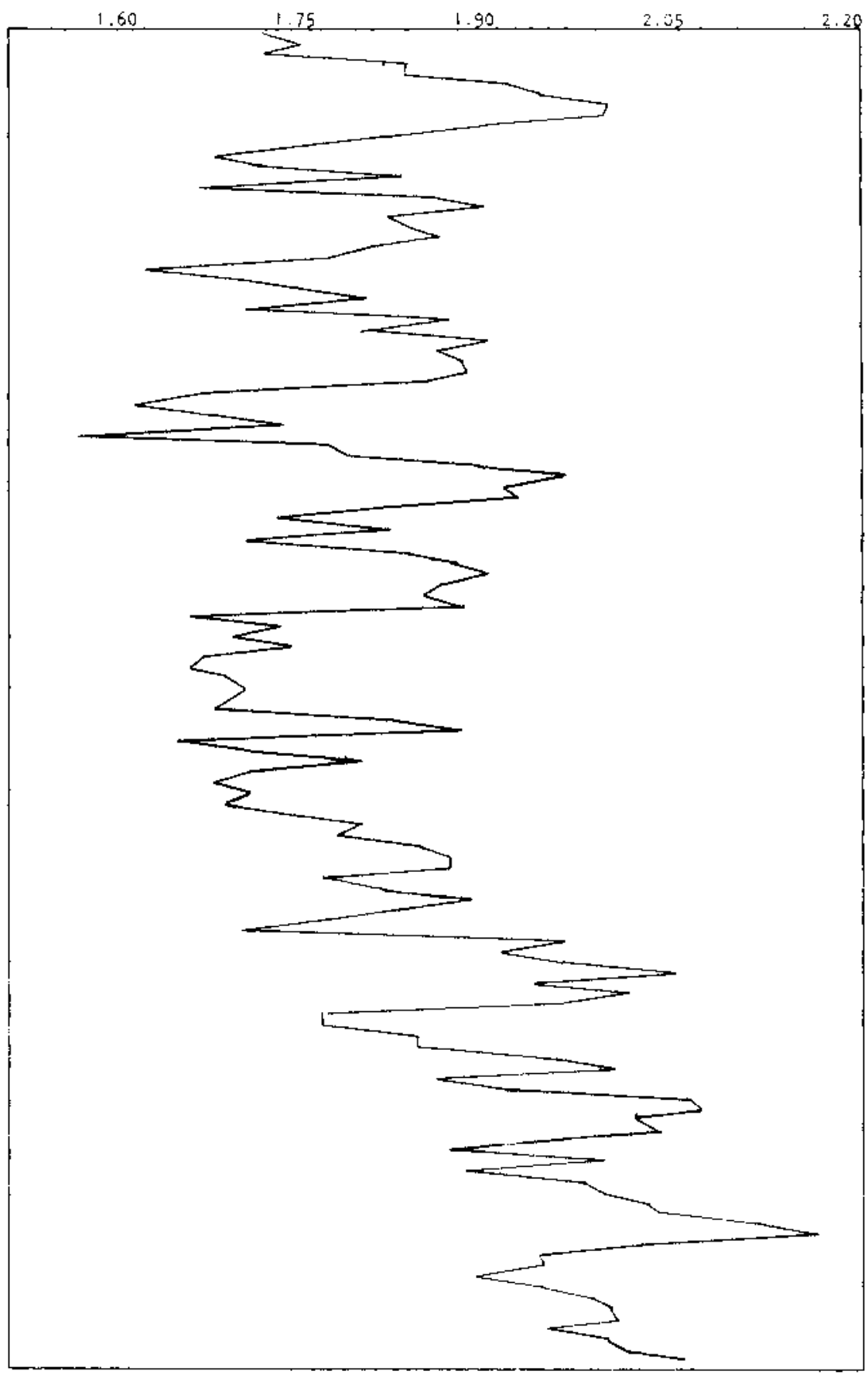

1971

1972

1973

1974

1975

1976

1977

1978

1979

1990

1981

Fig. 39--Rape Time Series

Logged Data

$1971-1981$ 

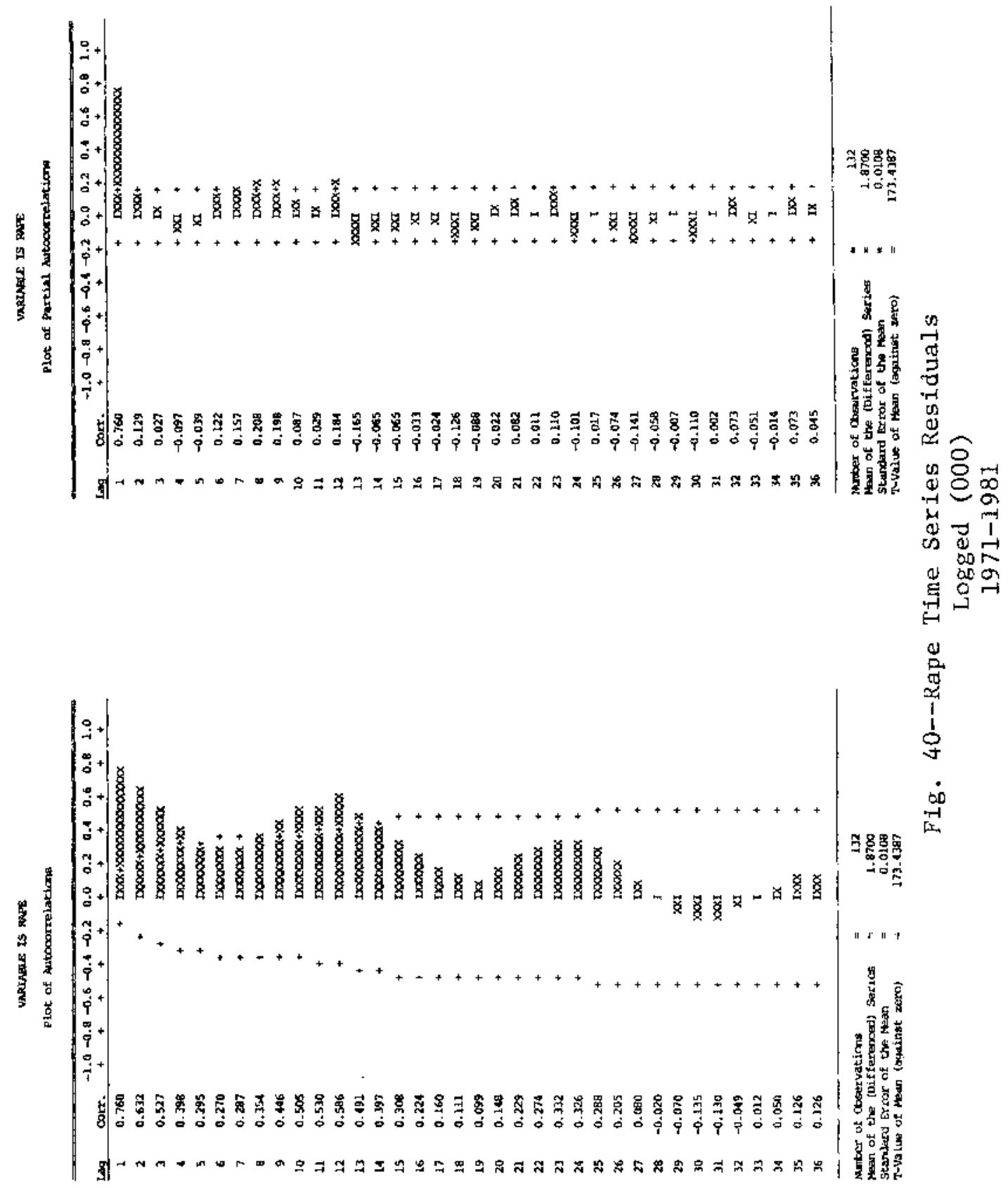

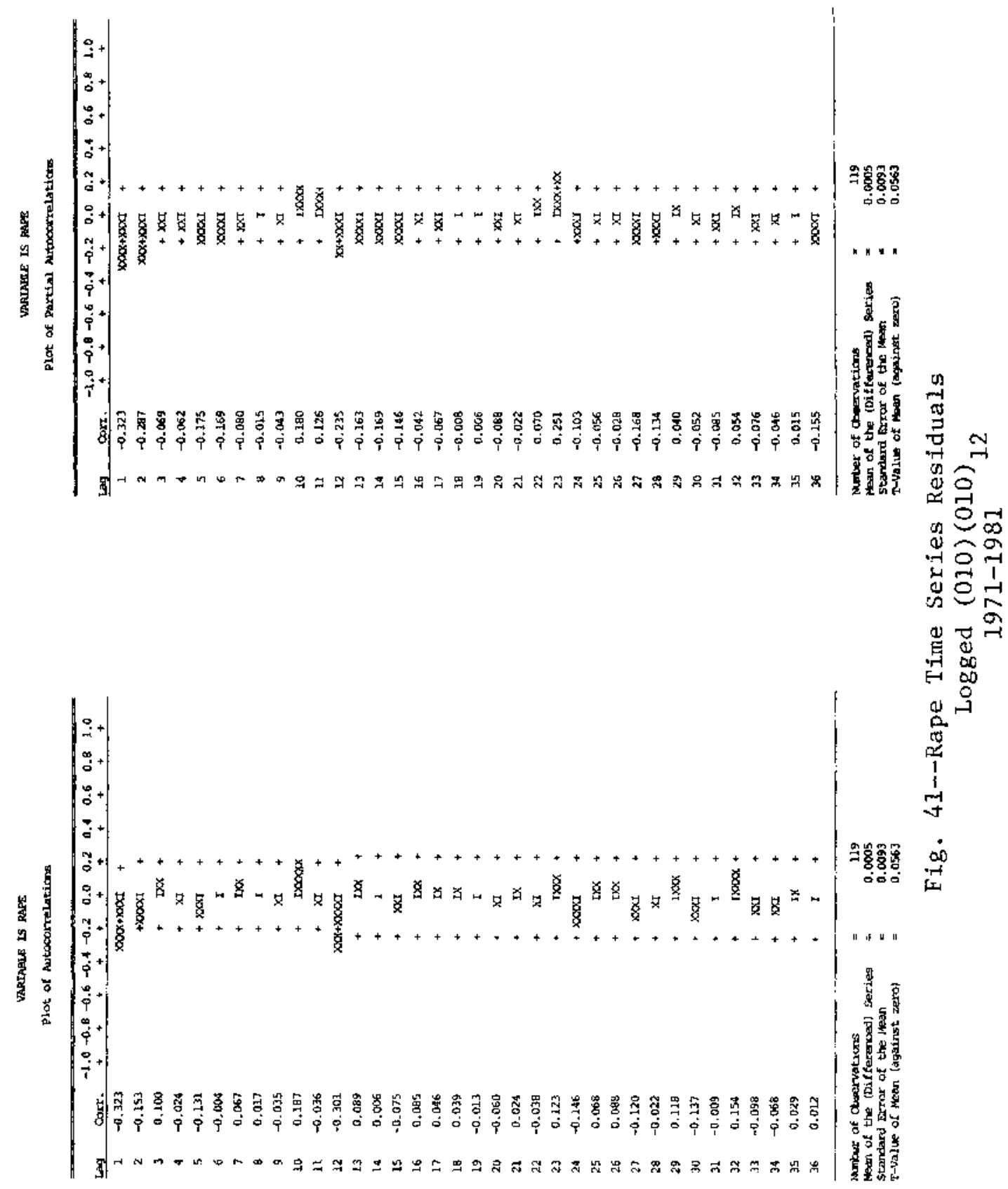


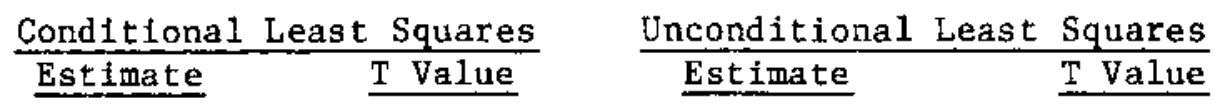

\begin{tabular}{|c|c|c|c|c|}
\hline $\begin{array}{ll}\theta & 0 \\
\theta & 0 \\
\theta & 1\end{array}$ & $\begin{array}{l}0.0008 \\
0.6617 \\
0.7031\end{array}$ & $\begin{array}{r}0.14 \\
9.59 \\
10.29\end{array}$ & $\begin{array}{l}0.0008 \\
0.6654 \\
0.8957\end{array}$ & $\begin{array}{r}0.14 \\
10.23 \\
33.84\end{array}$ \\
\hline${ }^{\theta} 12$ & 0.7031 & 10.29 & 0.8957 & \\
\hline
\end{tabular}

Residual Sun Squares

Degrees Freedom

0.714910

0.566212

117

117

Both $\theta_{1}$ and $\theta_{12}$ lie within the bounds of invertibility for moving average parameters and are acceptable. However, $\theta_{0}$ is not statistically different from zero and must be dropped from the model.

Diagnosis.--The ACF and PACF for the tentative model residuals showed no significant spikes (Figure 42). Furthermore, the $Q$ statistic of 16 for the ACF lag (25) was not statistically significant. Thus, the model was accepted. The residuals plot is contained in Figure 43.

Assault

Identification.--The plot of the log-transformed time series of reported assaults displayed more constant variance than did the raw time series (Figures 44 and 45 ). Therefore, the tentative model was built with logged data. The ACF and PACF estimated from the logged series (Figure 46) indicated a nonstationary process and the series was differenced. While the ACF and PACF estimated from the regularly differenced series (FIgure 47) did not demonstrate seasonality, the plot of the raw data displayed a high 


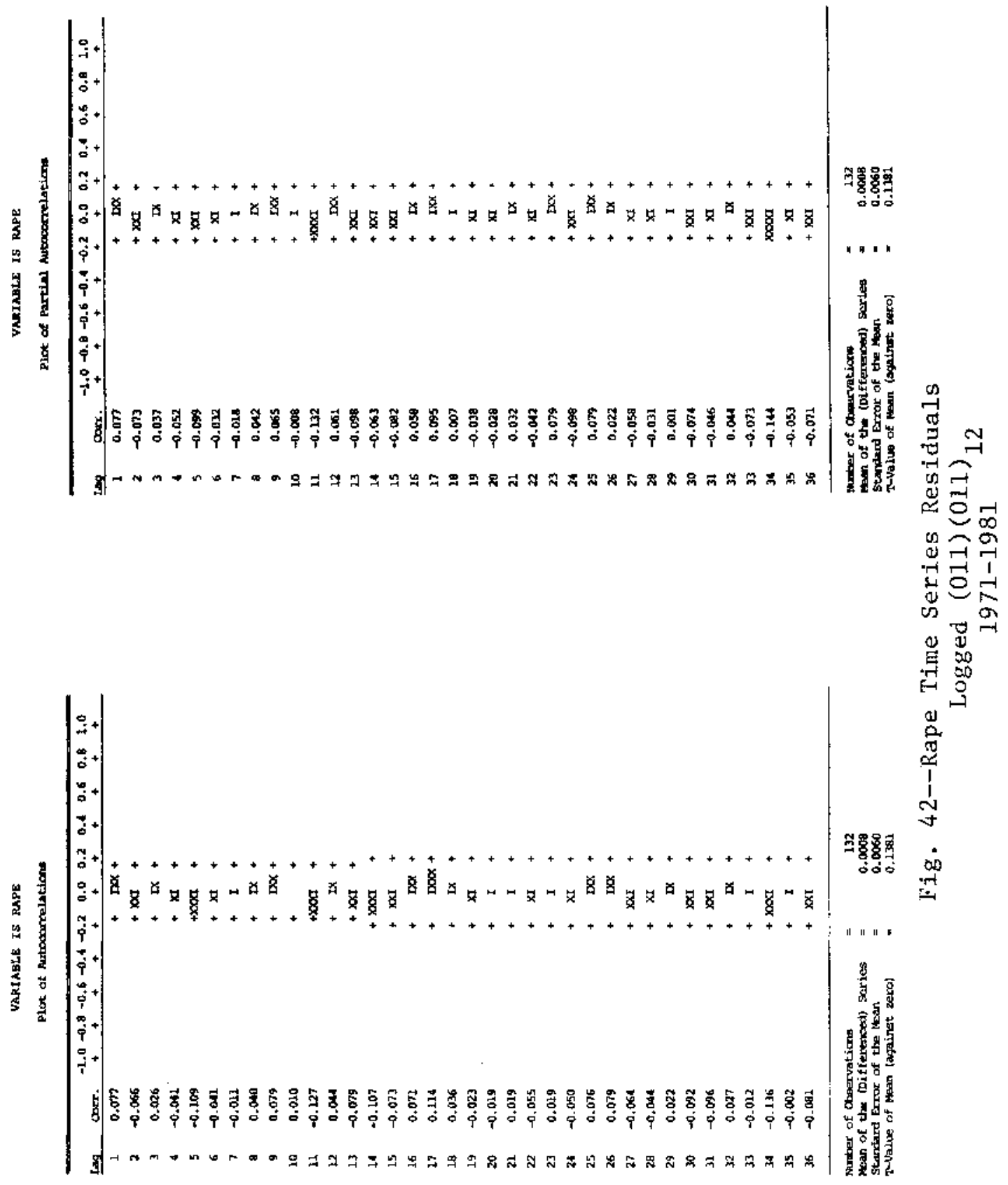




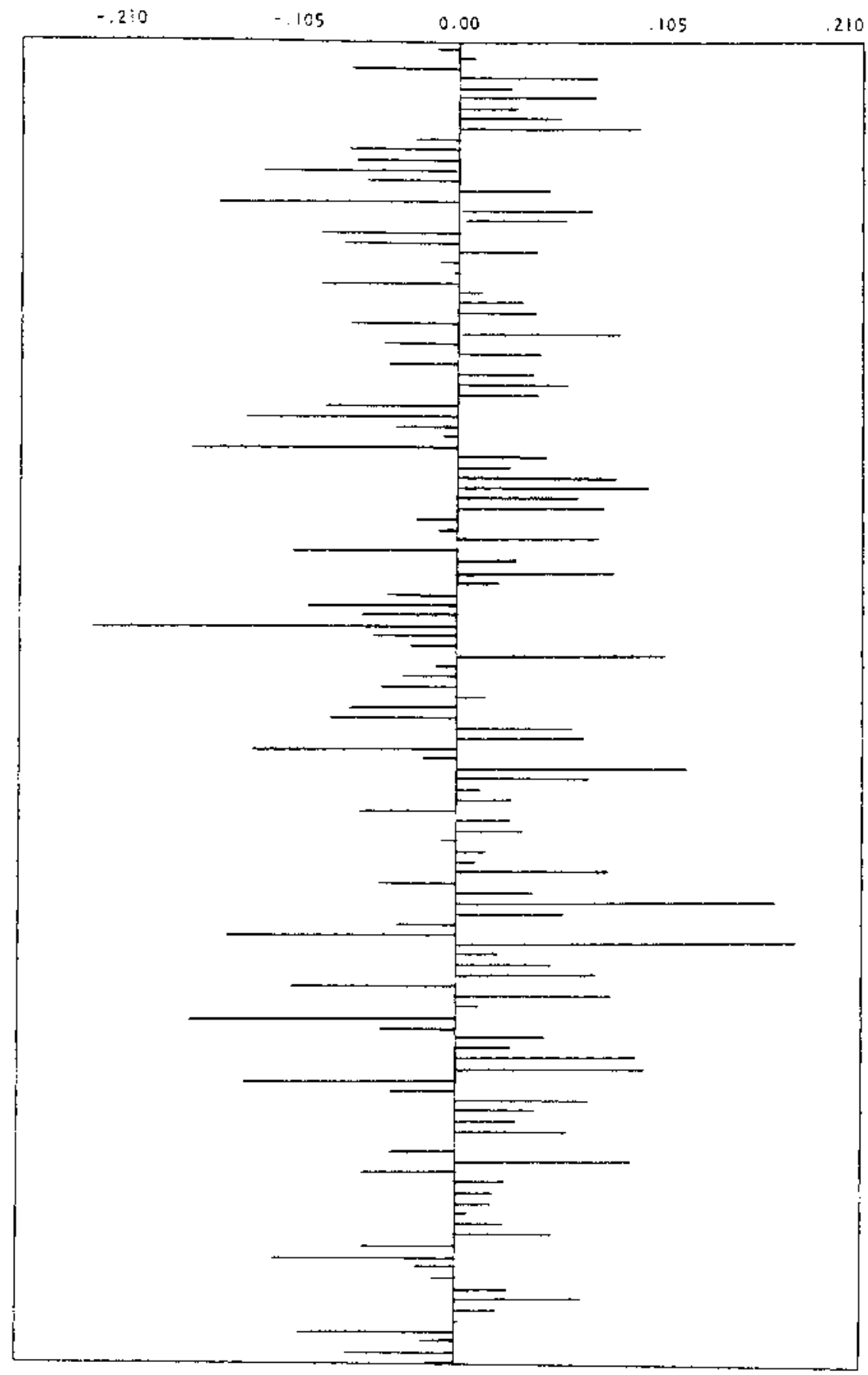

1971

1972

1973

1974

1975

1977

1978

979

Fig. 43--Rape Time Series Residuals Plot

Logged $(011)(011)$
$1971-1981$ 


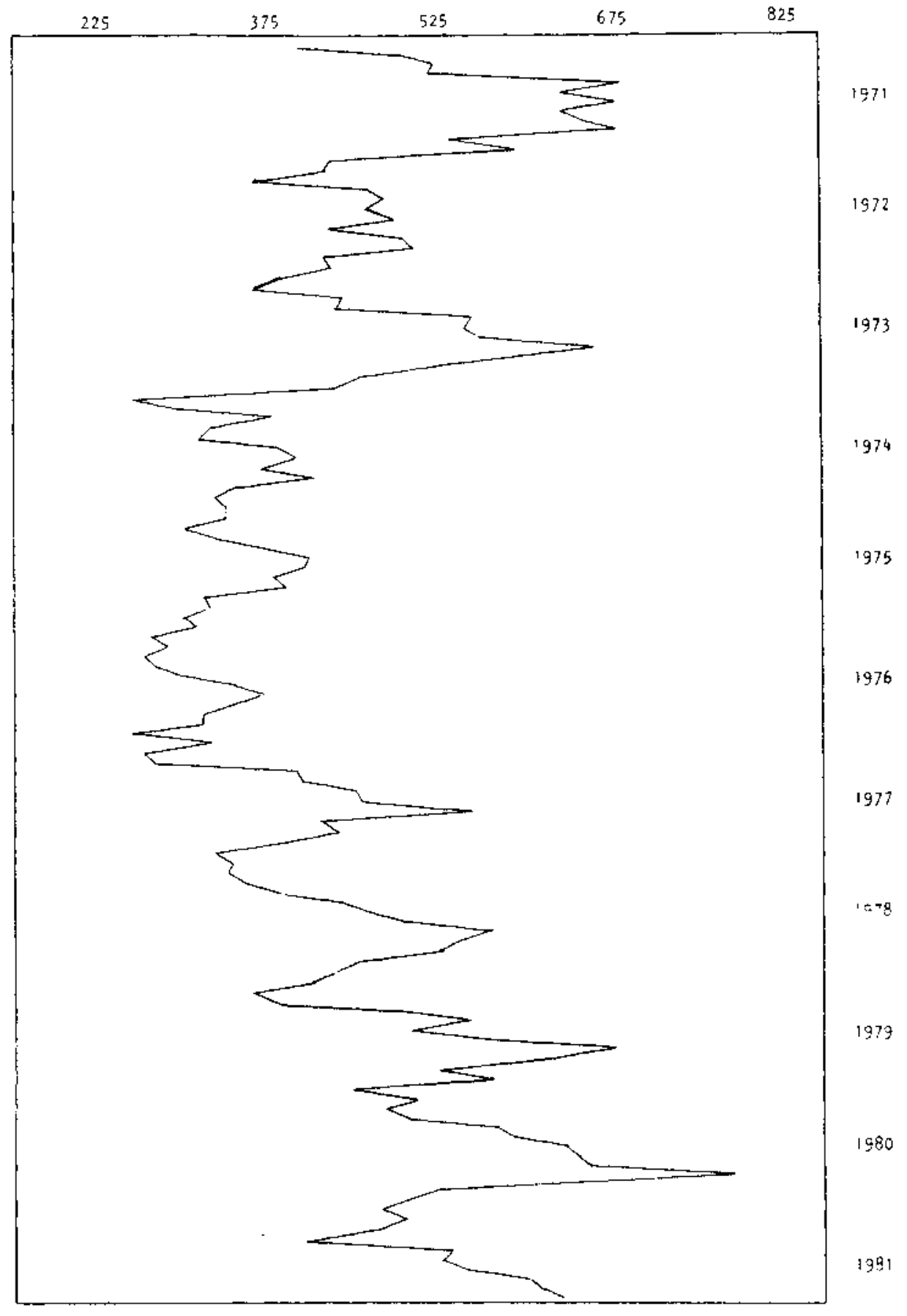

Fig. 44--Assault Time Series Unlogged Data $1971-1981$ 

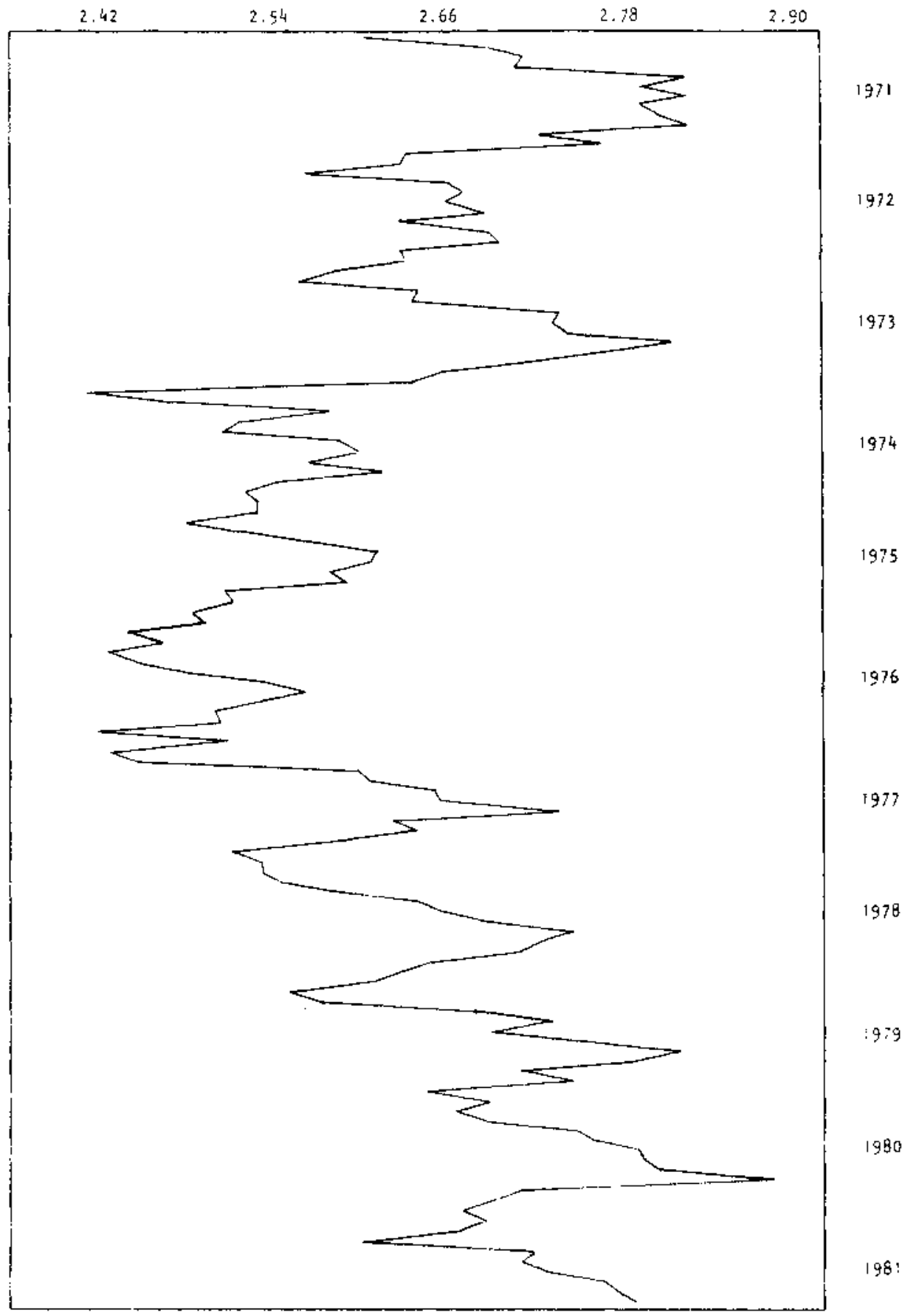

Fig. 45--Assault Time Series

Logged Data

$1971-1981$ 


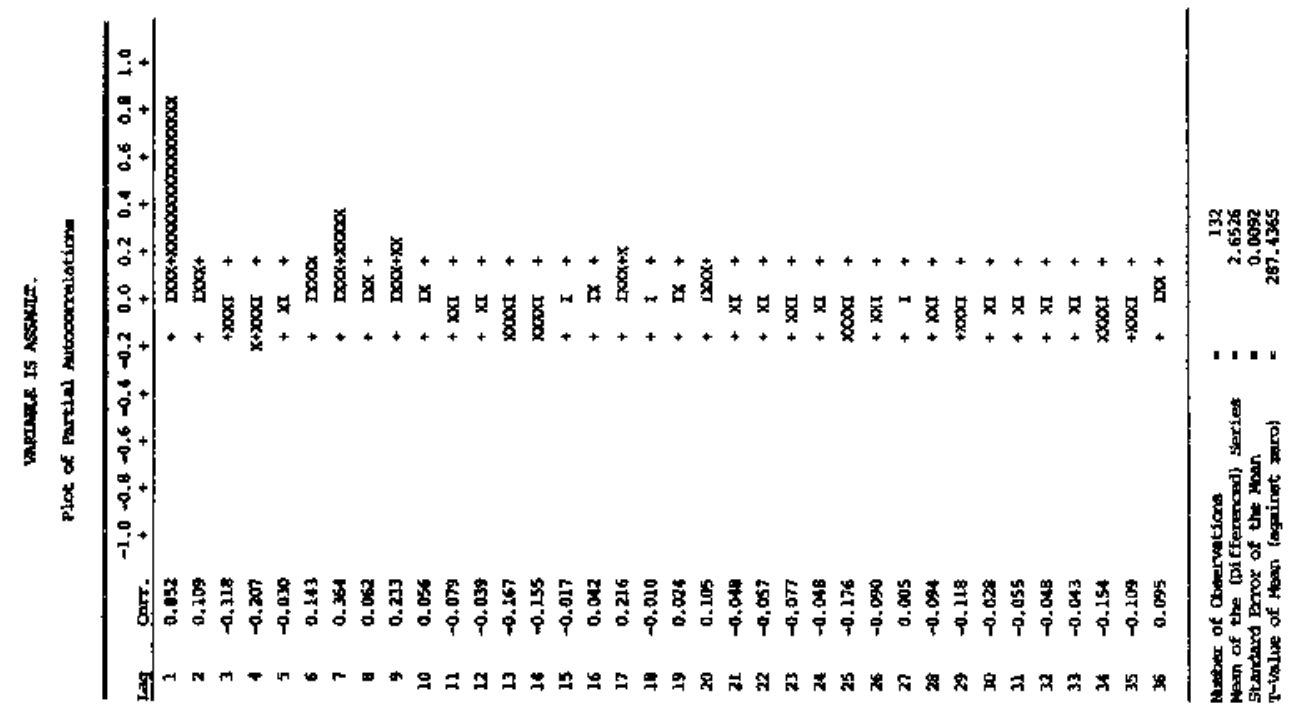

要
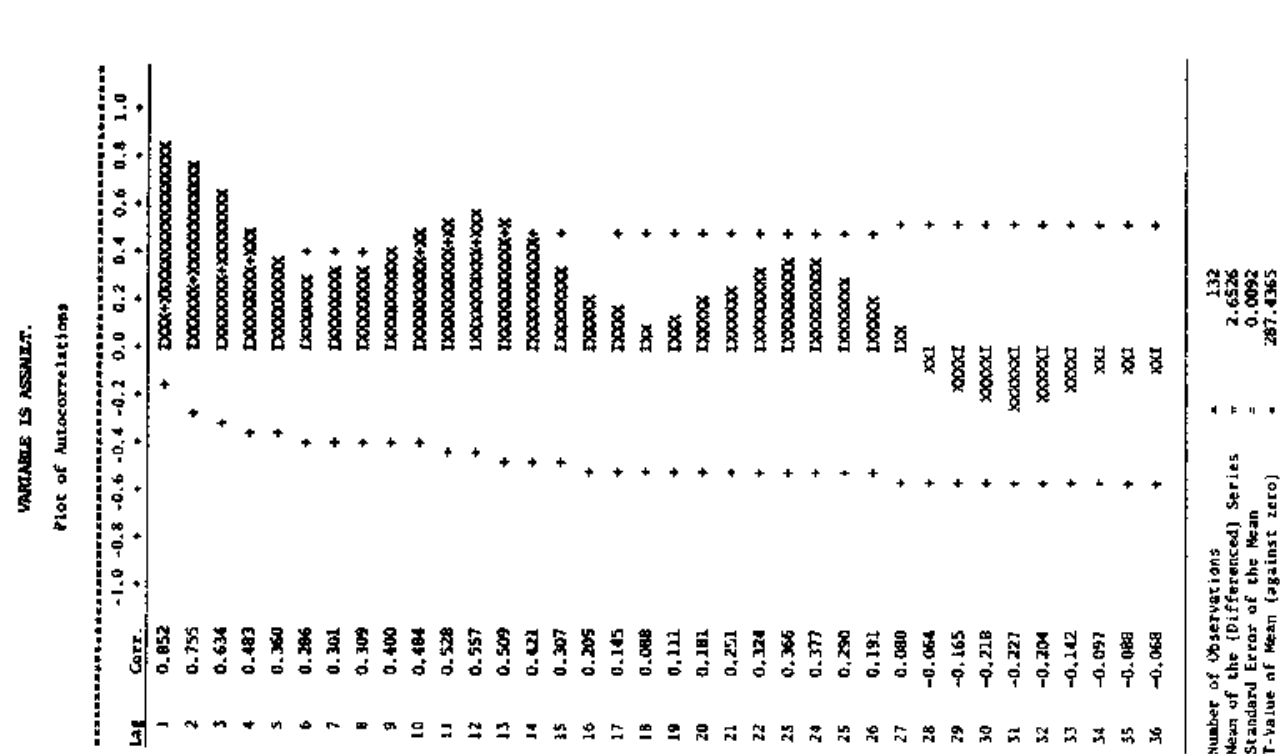

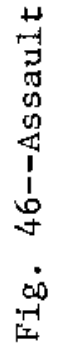




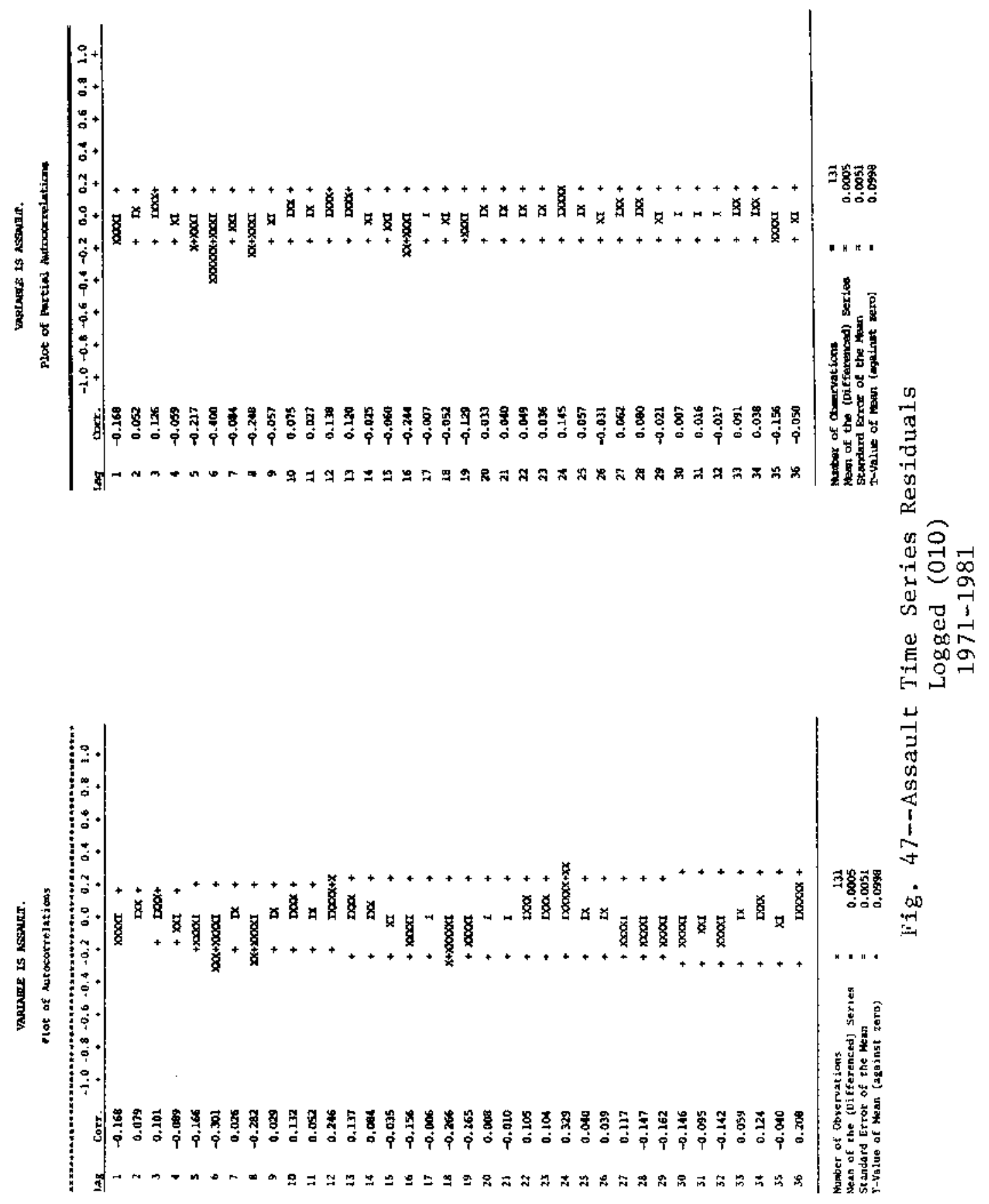


incidence of assault in the summer months and fewer assaults in the winter months. Therefore, it was decided to difference the series both regularly and seasonally.

The ACF and PACF estimated from this series (Figure 48) suggested an ARIMA (011)(011) 12 model. This model, however, proved inadequate because of spikes at lag (8). Thus, the model was expanded to ARIMA $(011)(001)_{8}(011)_{12}$. The regularly differenced PACF displayed signiflcant spikes at eight month intervals indicating that some cyclical process of this duration was in fact occurring. The tentative model can be written as follows:

D.4) Ln $\left(y_{t}\right)=\frac{\theta_{0}+\left(1-\theta_{1} B\right)\left(1-\theta_{B} B^{8}\right)\left(1-\epsilon_{12} B^{12}\right)}{(1-B)\left(1-B^{12}\right)} \quad a_{t}$

Estimation.--The parameter estimates for the assault mode 1 are:

\begin{tabular}{lccccr} 
& \multicolumn{2}{c}{ Conditiona1 Least Squares } & & Unconditional Least Squares \\
\cline { 2 - 3 } & Estimate & T Value & & Estimate & T Value \\
$\theta_{0}$ & 0.0024 & 0.67 & & 0.0024 & 0.67 \\
$\theta_{1}$ & 0.4395 & 5.27 & & 0.4178 & 3.22 \\
$\theta_{8}$ & 0.2759 & 3.03 & 0.3135 & 3.82 \\
12 & 0.7132 & 10.19 & 0.9053 & 32.28
\end{tabular}

Residual Sum Squares

Degrees Freedom
0.259298

116
0.209794

116

The estimate of $\theta_{0}$ was not statistically significant and was dropped from the model. The other estimates are 


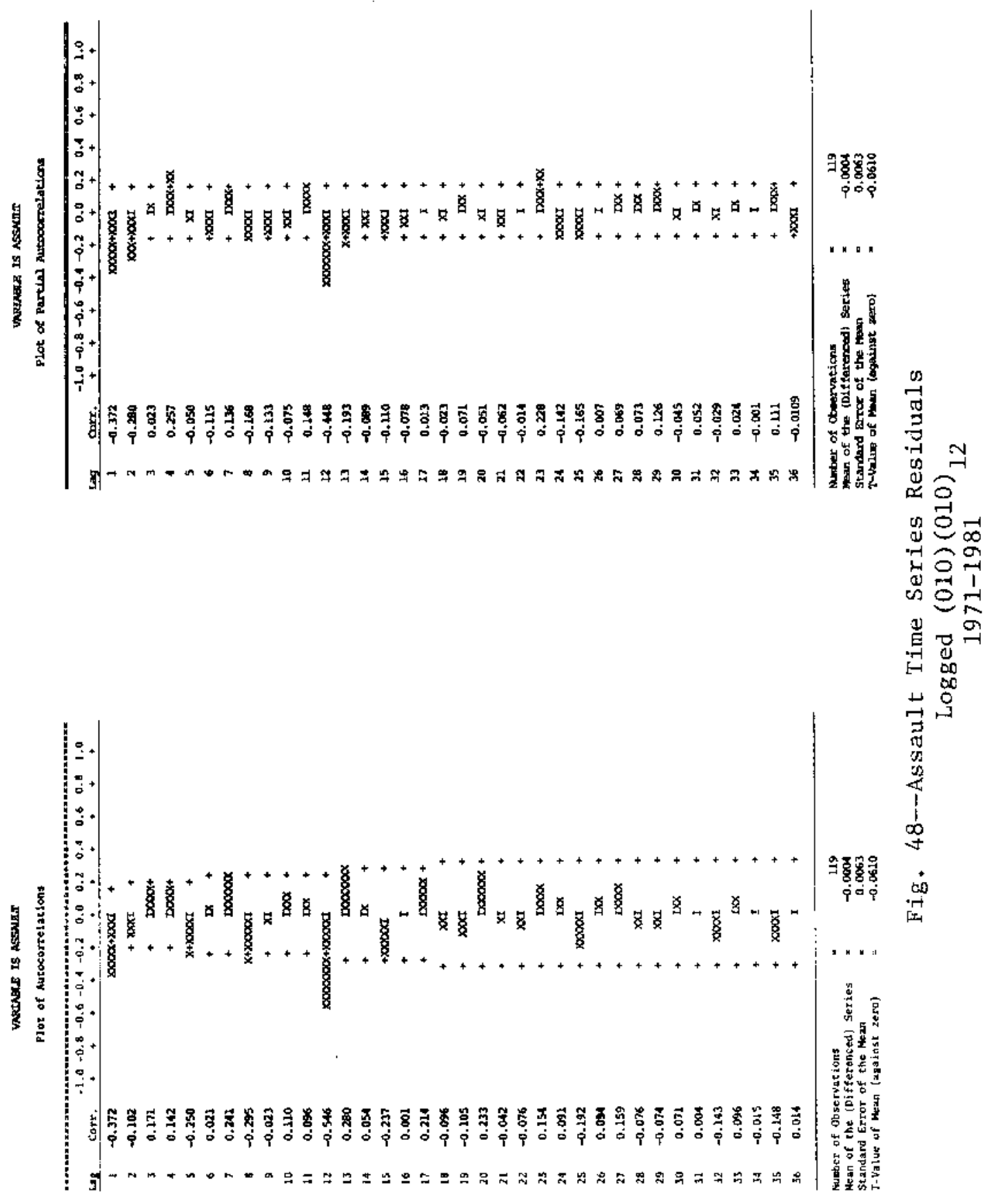


statistically significant and lie within the bounds of invertibility.

Diagnosis.--The resultant ACF and PACF (Figure 49)

indicated that the residuals of this model were not

different from white notse. The Q statistic of 14 with 22

degrees of freedom was not statistically significant.

Therefore, the tentative model was accepted. A plot of these residuals is contained in Figure 50 .

\section{Robbery}

Identification. - The raw data and logged data for the reported robbery incidences are contained in Figures 51 and 52. While neither series indicated complete variance stationarity, the raw series displayed more constant variance than did the logged version. Therefore, the model was built with the raw data.

The ACF and PACF for this serles are shown in Figure 53. The ACF suggested nonstationarity and so the series was differenced. The ACF and PACF for the regularly differenced series (Figure 54) did not indicate seasonal nonstationarity. Therefore, no further differencing was performed.

only this crime ultimately did not exhibit seasonality. This observation compliments an earlier study conducted by the U.S. Department of Justice.l An examination of month1y

1U. S. Department of Justice, Crime and Seasonality, (Washington, D.C., 1980). 


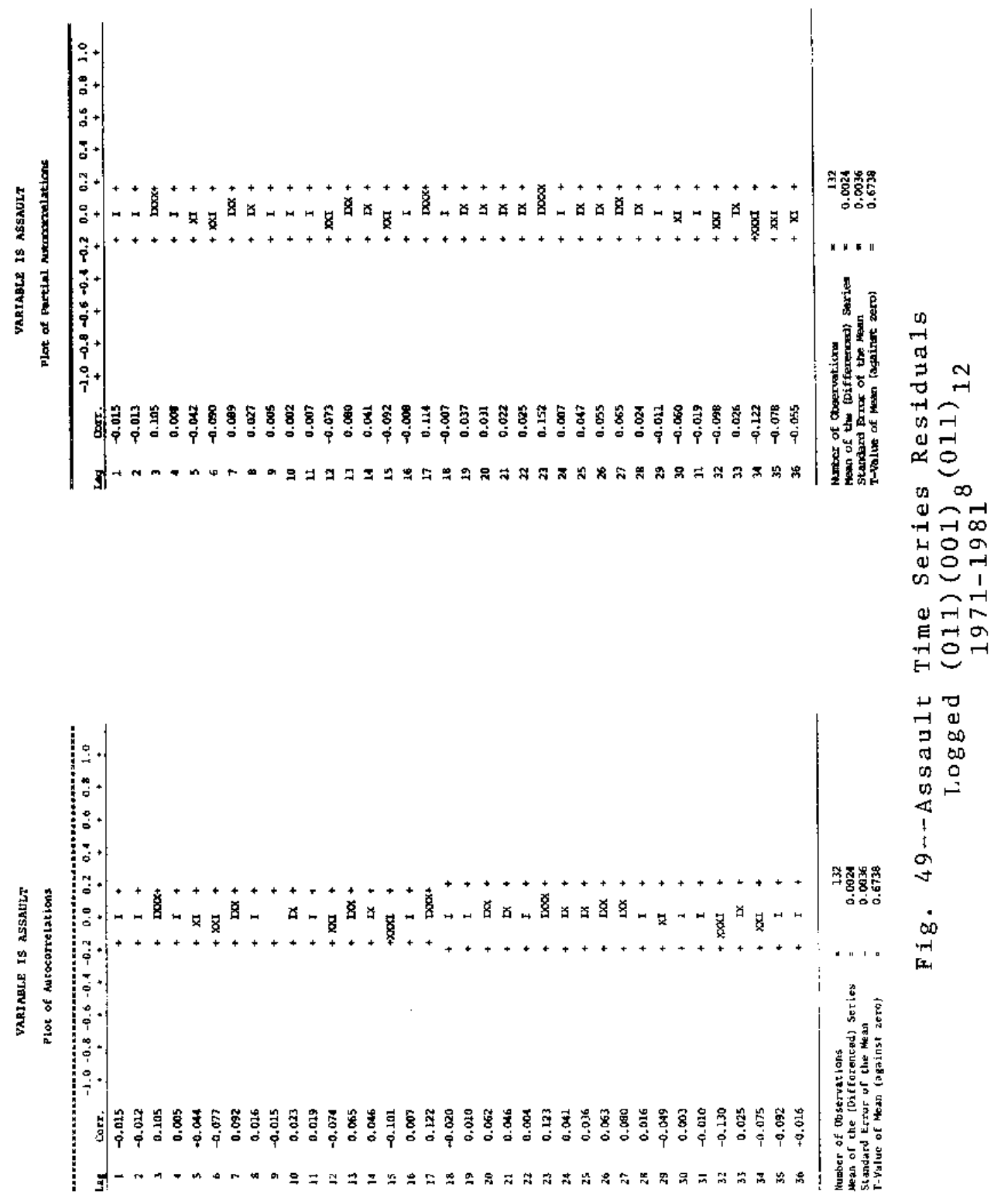




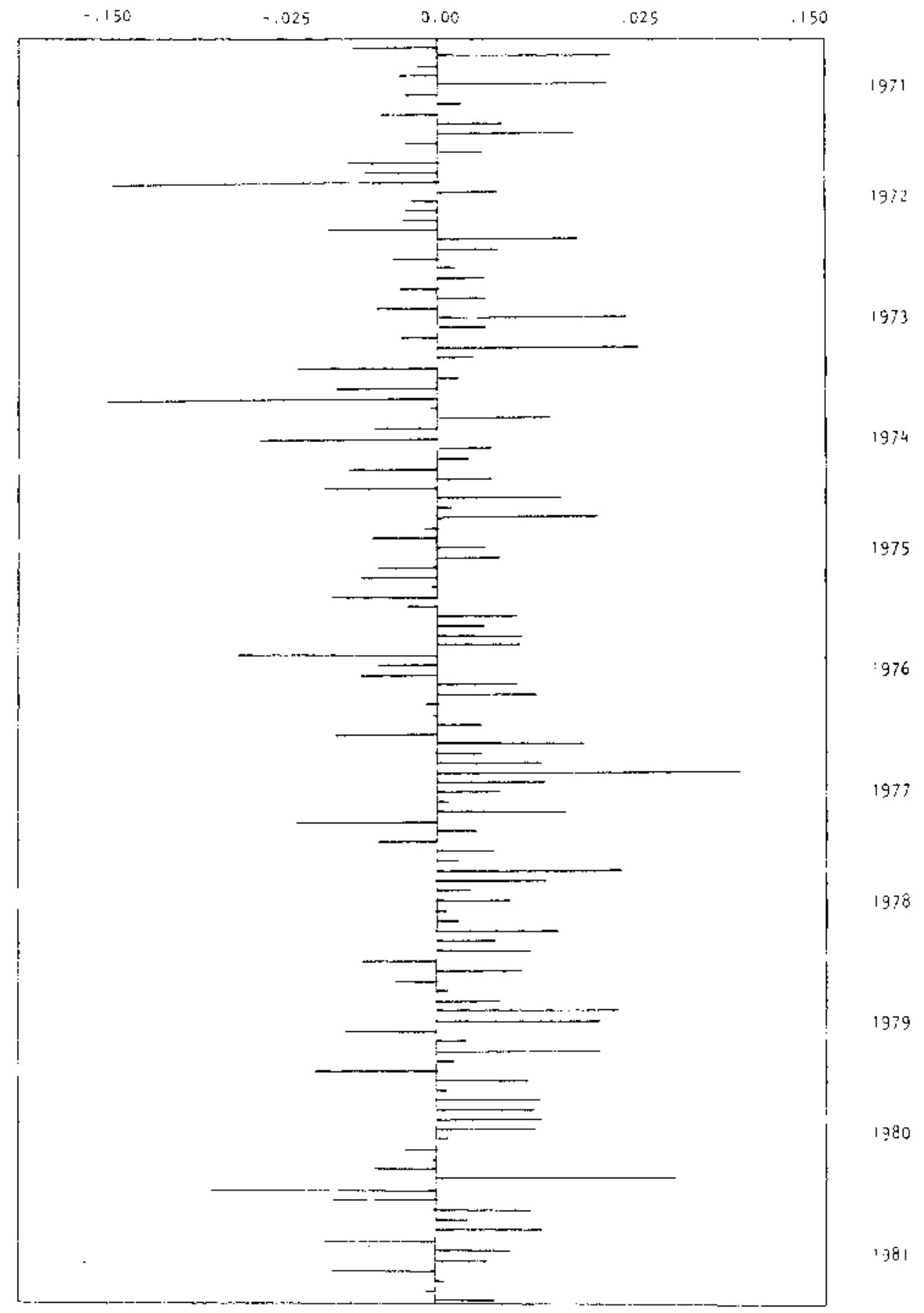

Fig. 50--Assault Time Series Residuals Plot

Logged $\begin{array}{r}(011)(001) 8(011) 12 \\ 1971-1981\end{array}$ 


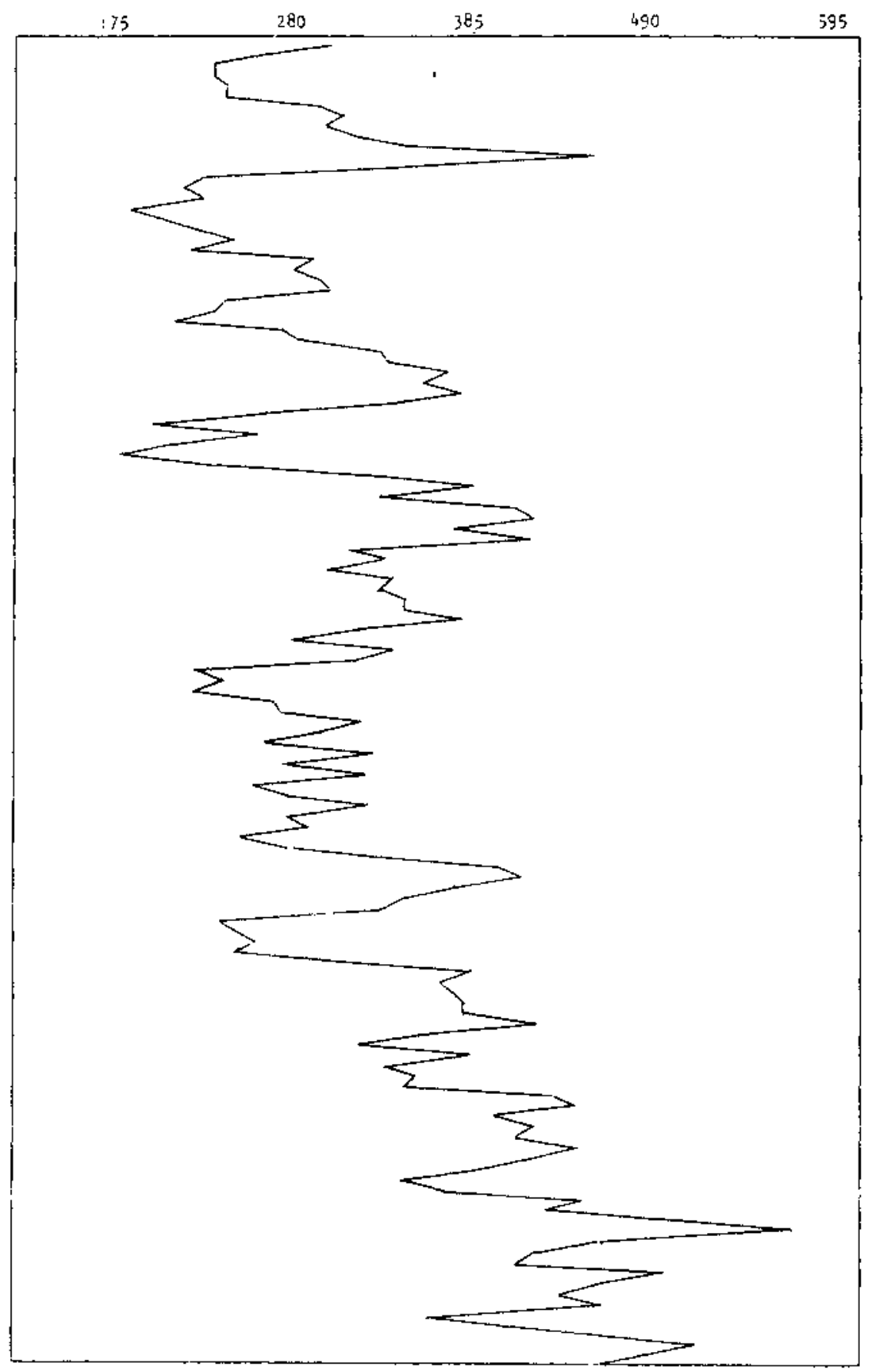

$: 971$

1972

1973

1974

1975

1976

1977

1978

1979

1980

Fig. 51--Robbery Time Series

Unlogged Data

$1971-1981$ 


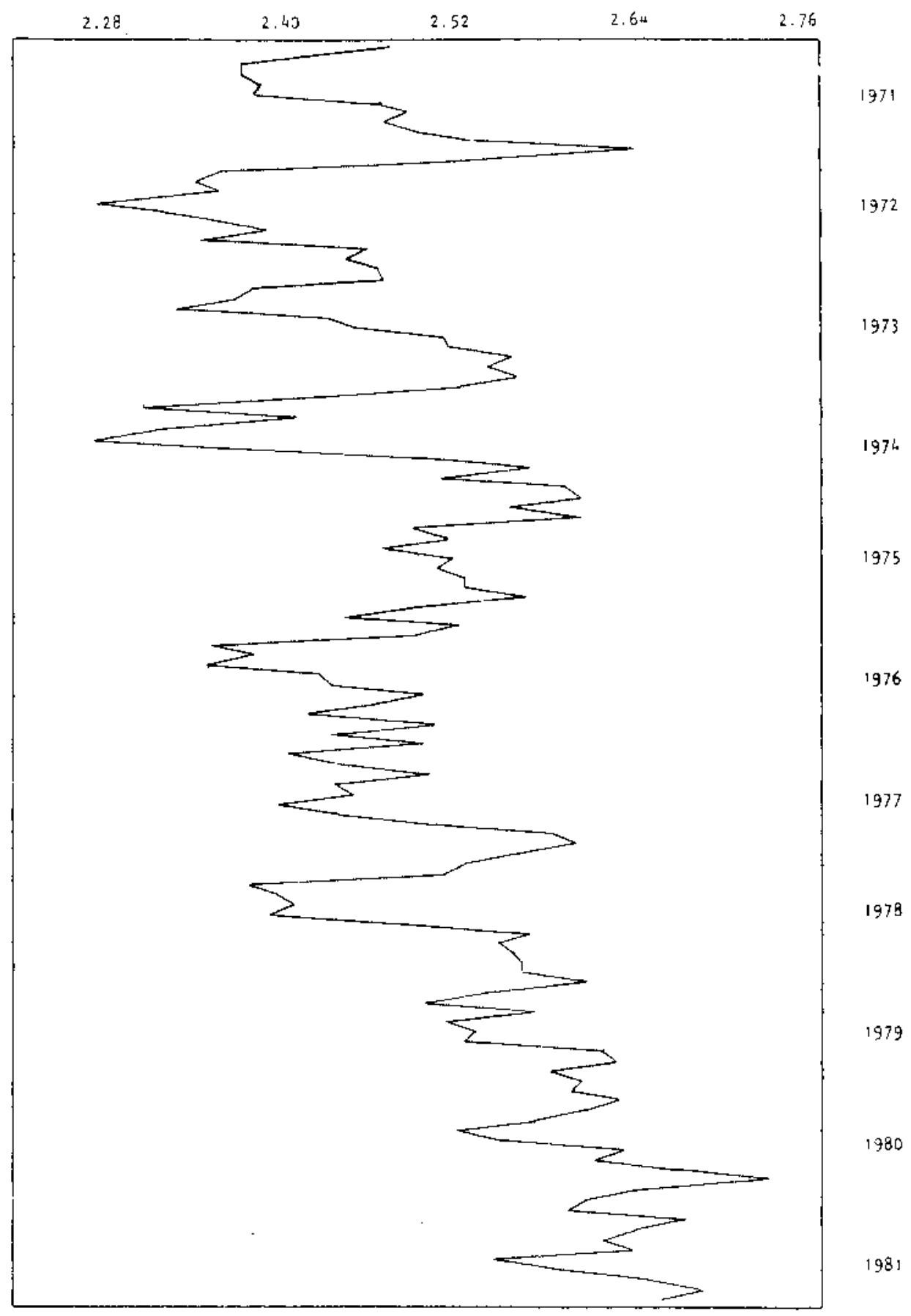

Fig. 52--Robbery Time Series

Logged Data

$1971-1981$ 

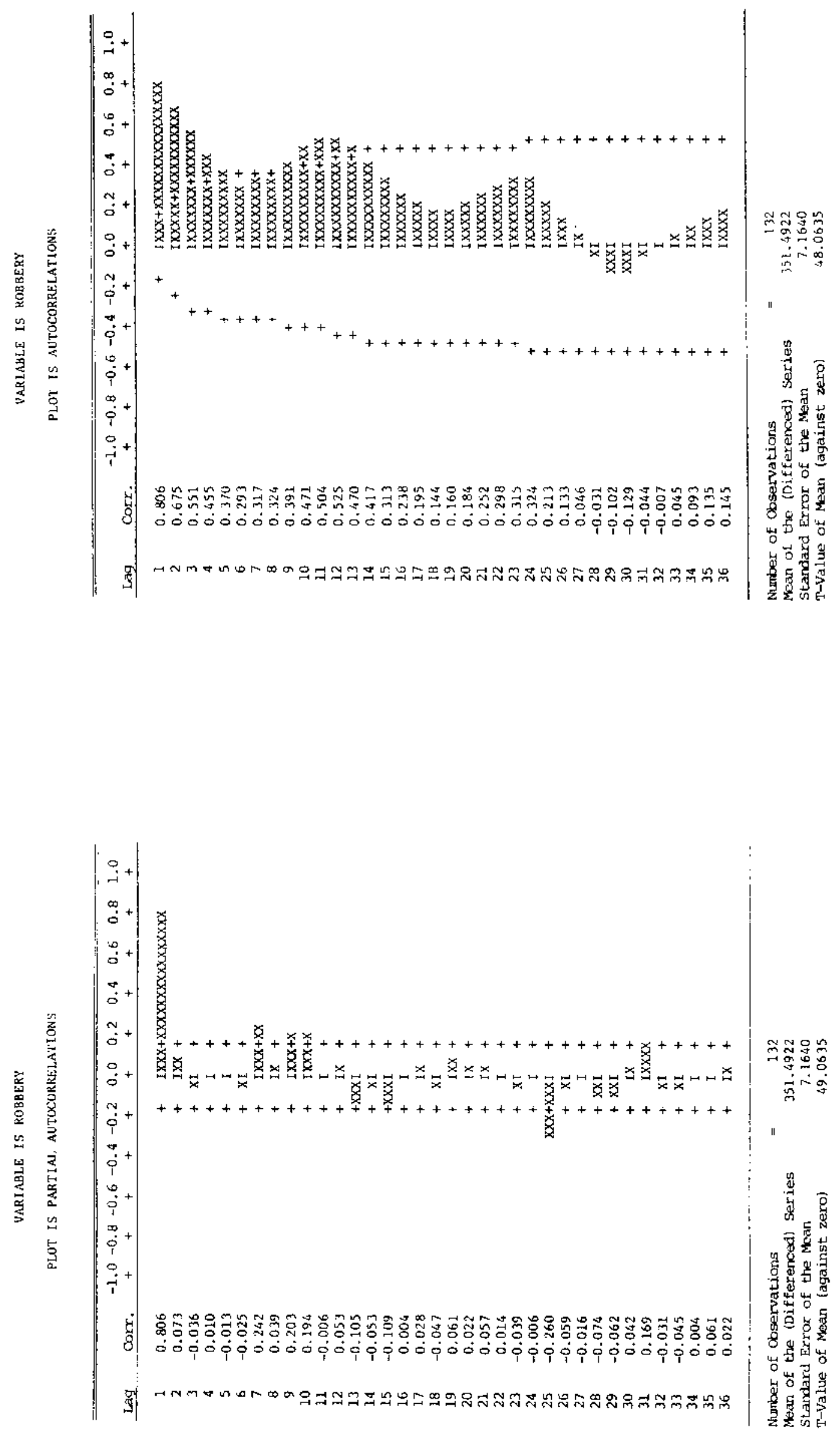


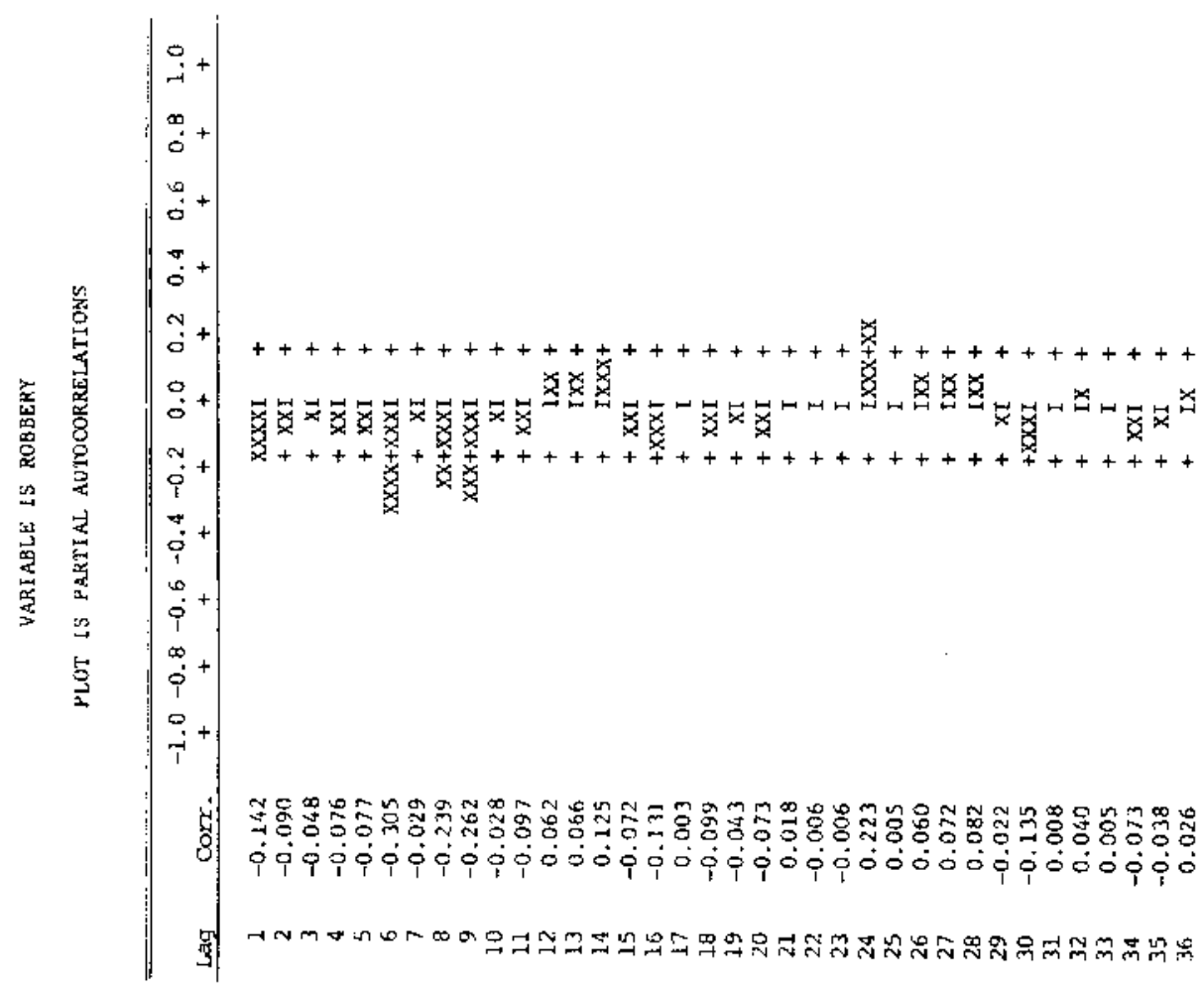

321

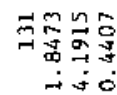

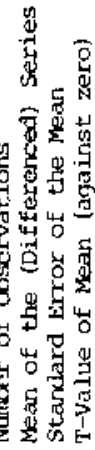

告

0



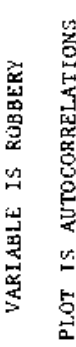

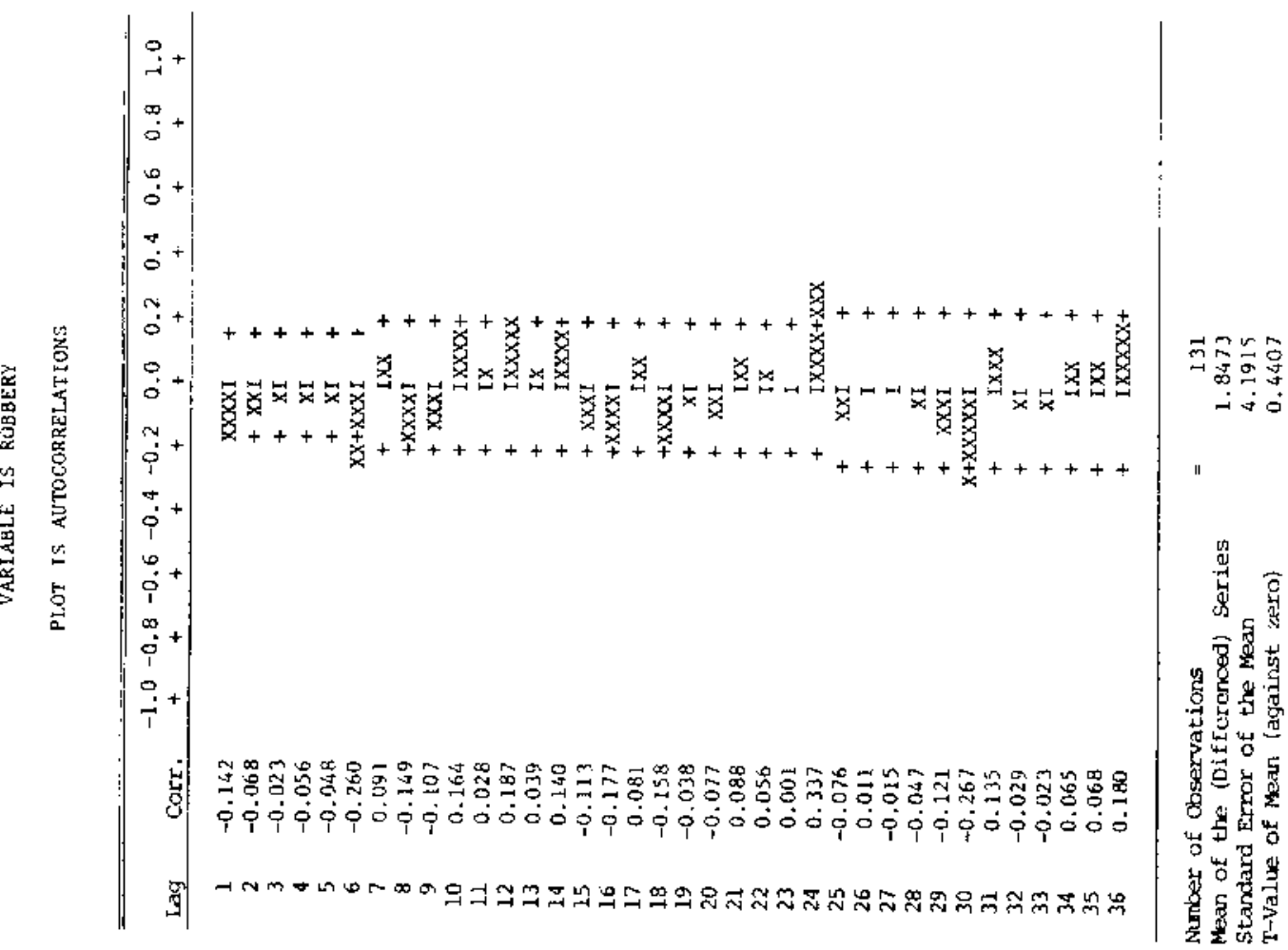


victimlation data for incidences of household and personal larceny, burglary, motor vehicle theft, assault, and personal robbery for the five years ending December 31 , 1977, disclosed seasonal fluctuations in all crimes but robbery. "Most displayed a similar pattern, highlighted by a peak period during the summer months." 2 Robbery, however, "did not exhibit significant regularity of movement within each year to meet the requirements for seasonality." 3

Development of a tentative model proved to be quite difficult. The ACF was significant at six month intervals. The PACF displayed a suggestion of decay at the lag (6). Therefore, the ARIMA model (011)(001)6 was tried. This model was unacceptable. The ACF was significant at eight month intervals and some decay was present at lags (8) and (9).

A second tentative model ARIMA $(011)(001)_{6}(001)_{8}$ was calculated. Again, the model indicated that confounding influences were still present. The ACF was significant at 1 ag ( 3 ) and also at twelve month intervals. The PACF spiked at lags (9), (24), and (30).

To remove the early lag problems, a third tentative model ARIMA ( 111$)(001)_{6}(001)_{8}$ was estimated. While the

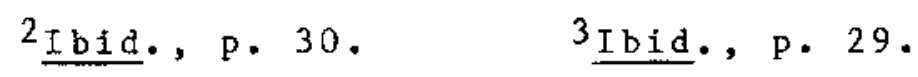


residual sum of squares declined, the model residuals were still not white noise. The ACF and PACF were significant at lags (12) and (24).

No pattern could be discerned in these important lags. Therefore, a fourth model ARIMA (111)(001)6(001)8(101) 12 was estirated. This model is written as follows:

D.5) $\left(1-\phi_{1} B\right)\left(1-\phi_{12}{ }^{1}{ }^{12}\right) y_{t}=\frac{\theta_{0}+\left(1-\theta_{1} B\right)\left(1-\theta_{6} B^{6}\right)\left(1-\theta_{8} B^{8}\right)\left(1-\theta_{12} B\right)}{(1-B)} a_{t}$

Estimation.--The parameters of this model were estimated to be:

Conditional Least Squares Estimate

$\theta_{0}$
$\theta_{1}$
06
$\theta_{8}$
$\theta_{12}$
$\phi_{1}$
$\phi_{12}$

Residual Sum Squares

Degrees Freedom

$\begin{array}{ll}4.7934 & 1.40 \\ 0.5998 & 4.42 \\ 0.1523 & 1.53 \\ 0.1347 & 1.36 \\ 0.5556 & 4.86 \\ 0.1968 & 1.20 \\ 0.7417 & 9.41\end{array}$

4.7934

0.1523

0.1347

0.1968

0.7417

T Value

$194,934.00$ 112

\section{Unconditional Least Squares Estimate \\ T Value}

4.7934

0.8451

0.1794

0.1715

0.7022

0.5288

0.8827
1.40

9.66

1.91

1.89

6.80

3.93

17.05

\section{Since the estimates for $\theta_{0}, \theta_{6}$, and $\theta_{8}$ were at best} only marginally significant, these parameters could have been dropped from the model. However, the residuals of the ARIMA mode1 ( 111$)(101)_{12}$ proved to not be white noise. Thus, the decision was made to retain all parameters in the model utilized in the intervention analysis. 
Diagnosis.--The ACF and PACF for the model residuals (Figure 55) had no spikes at lag (1) or at the seasonal lags. The Q statistic of 20 with 19 degrees of freedom calculated from the ACF indicated that the residuals from the tentative model appeared to be white noise; thus, the model was accepted. Figure 56 presents a plot of these residuals.

\section{Auto Theft}

Identification.--Graphs of the regular and log-transformed auto theft series are contained in Figures 57 and 58. The regular plot displayed more constant variance than the logged version. Therefore, it was unnecessary to log-transform the data prior to building an ARIMA model.

The ACF and PACF estimated from this series (Figure 59) indicated the need to difference. There was a cyclical decaying pattern apparent in the ACF and a spike at the first lag of the PACF. The ACF and PACF estimated from the regularly differenced series (Figure 60) further suggested seasonal nonstationarity. Once this was accomplished, an ARIMA mode1 (011)(011)12 appeared appropriate. The ACF spiked at lags (1) and (12) and the PACF decayed at the corresponding lags (Figure 61). 


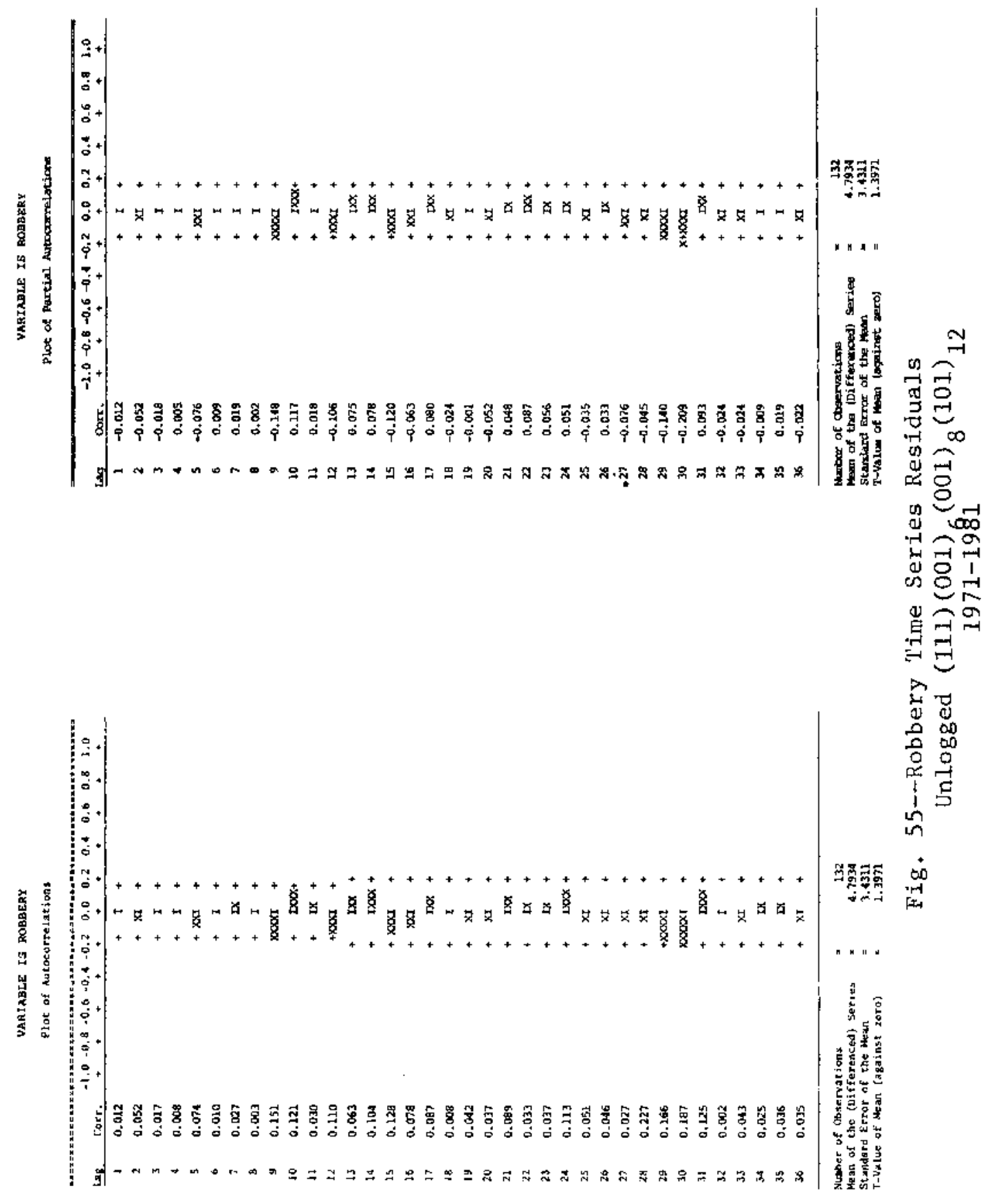




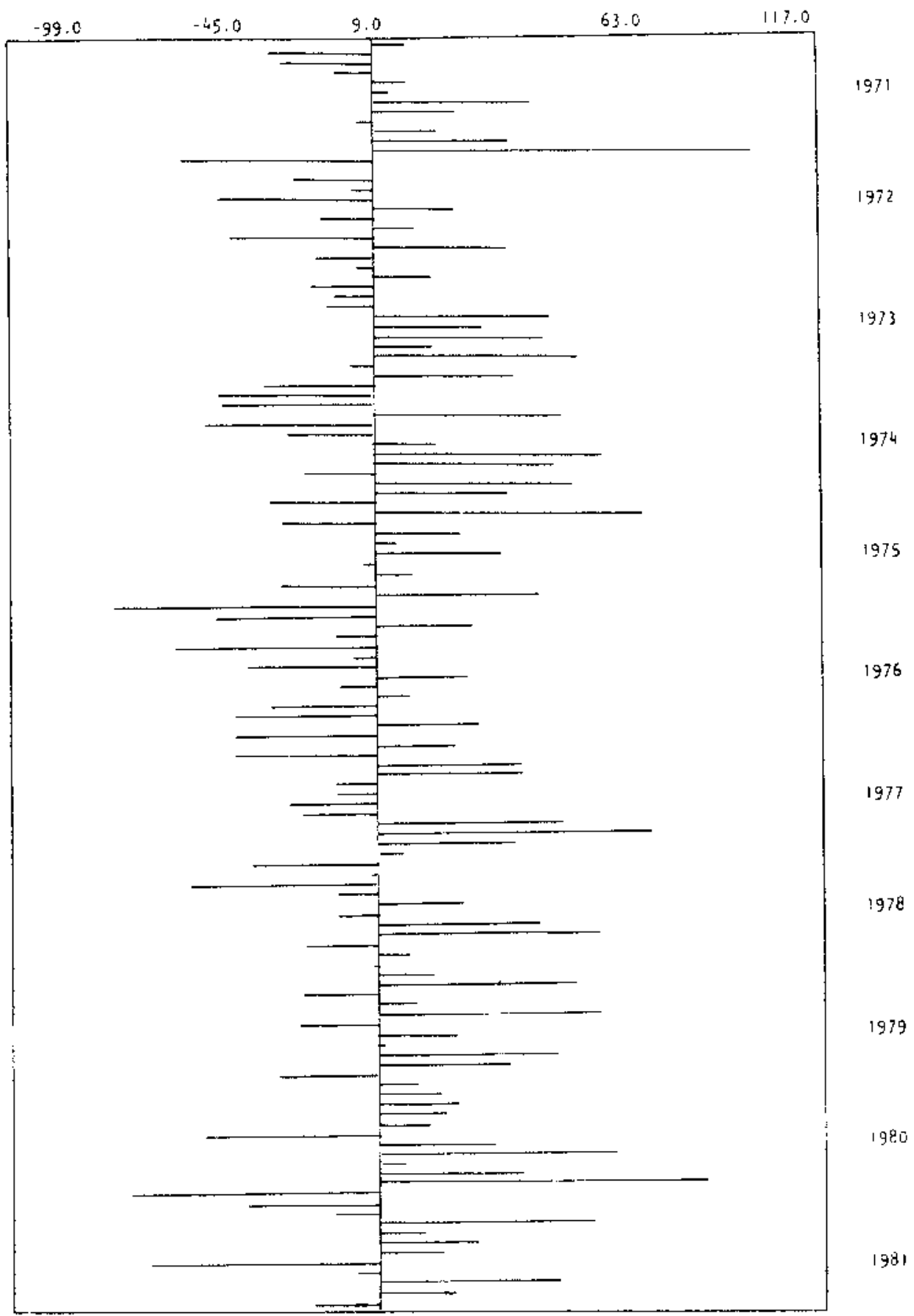

Fig. 56--Robbery Fime Series Residuals plot Unlogged $\begin{gathered}(111)(001) \\ 1971-1981\end{gathered}$ 


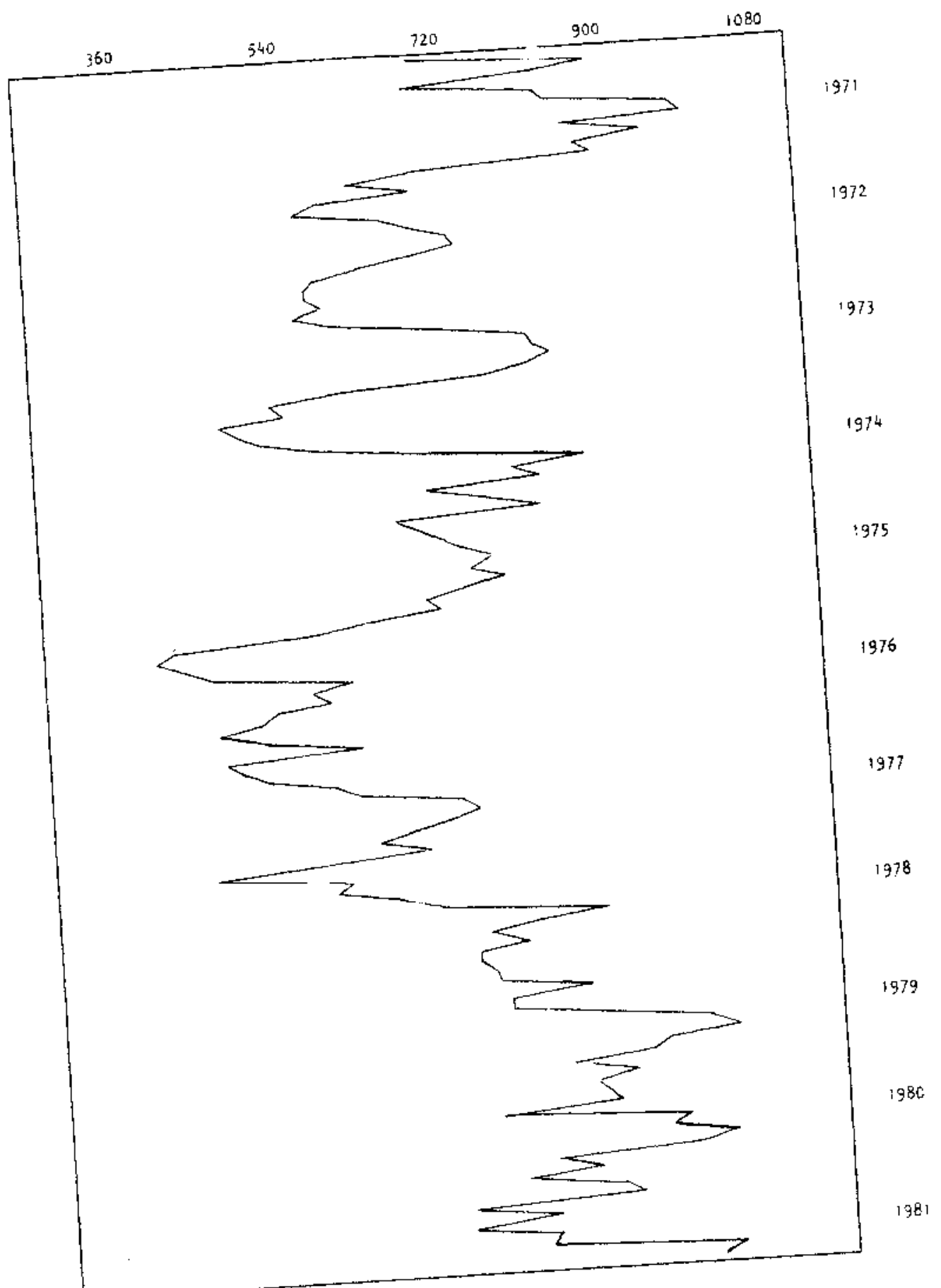

Fig. 57--Auto Theft Time Series Unlogged Data $1971-1981$ 


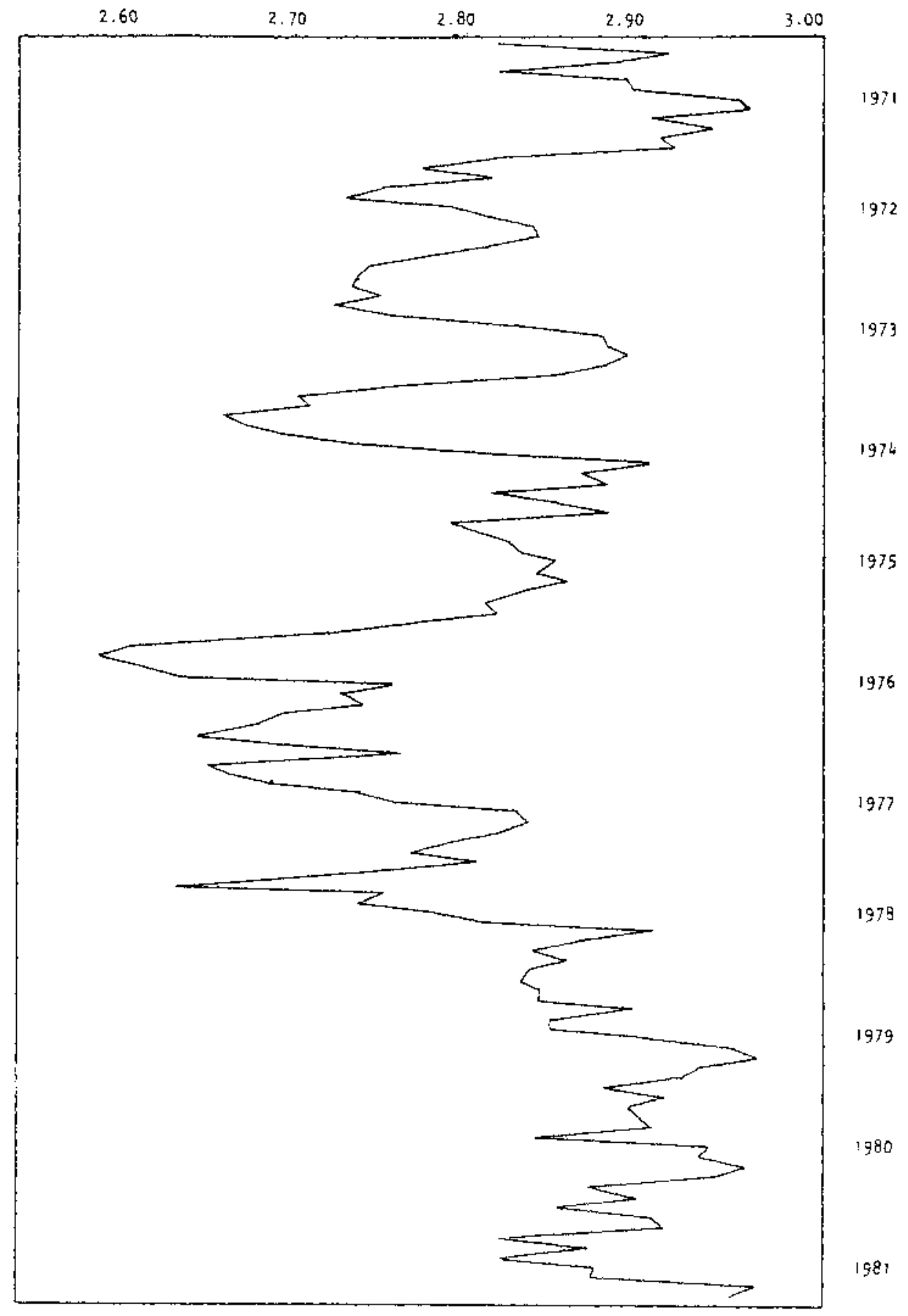

Fig. 58--Auto Theft Time Series

Logged Data

$1971-1981$ 


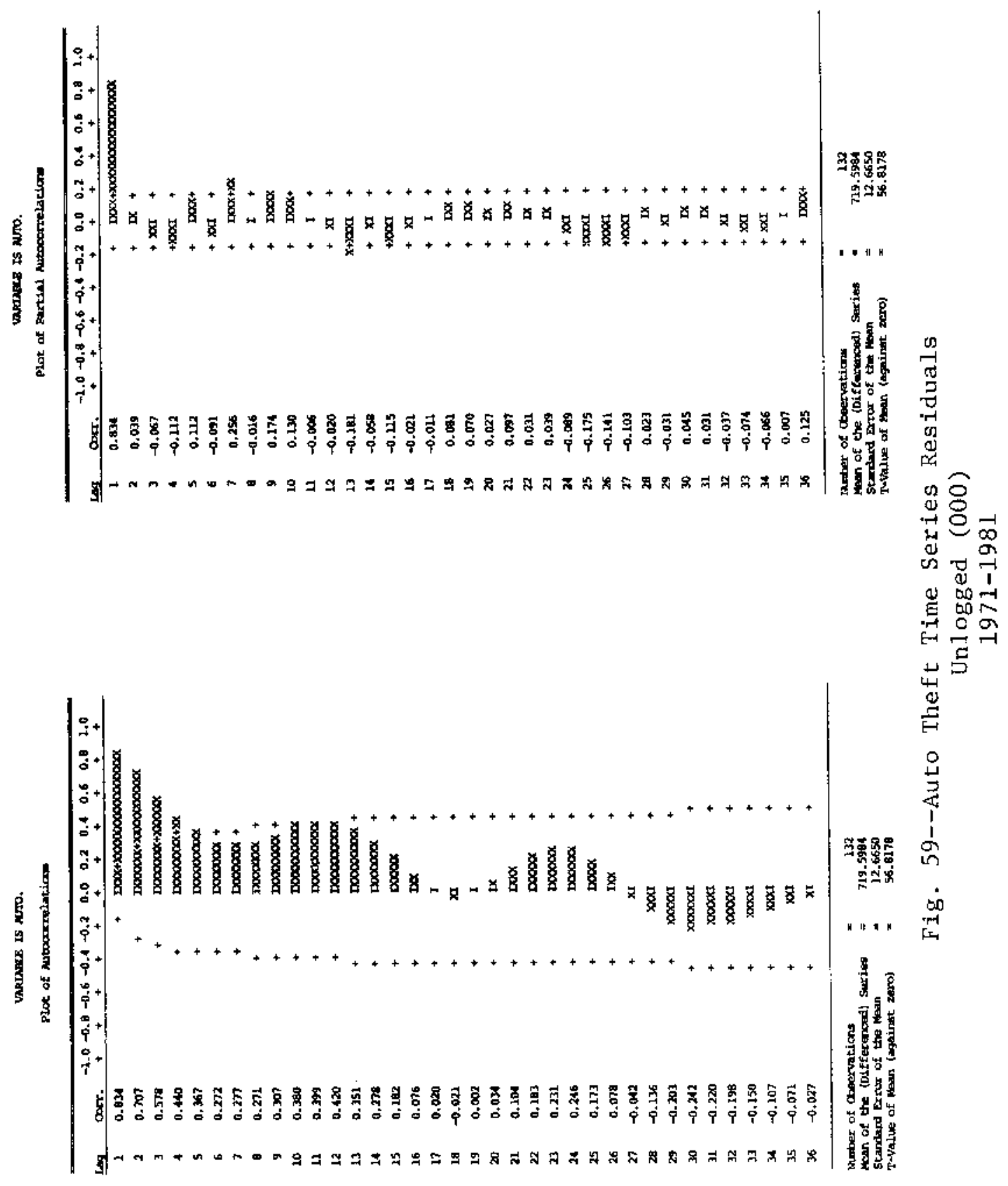




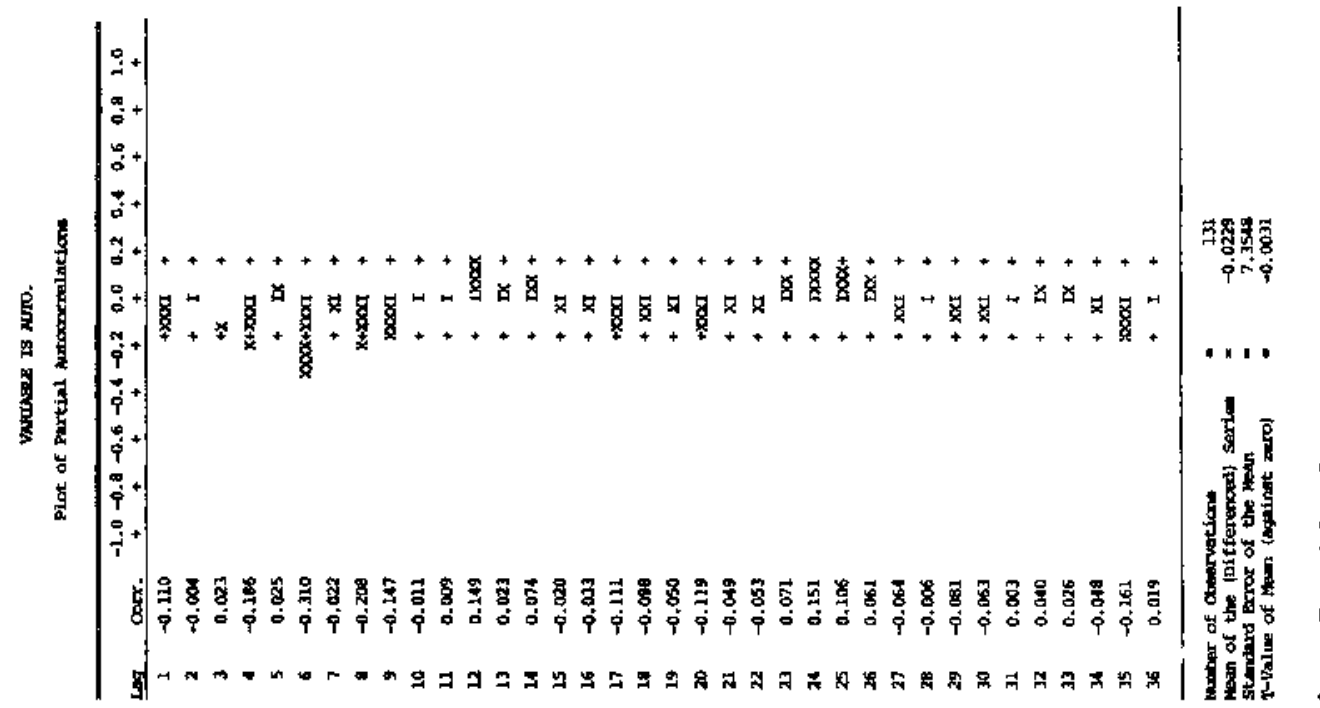



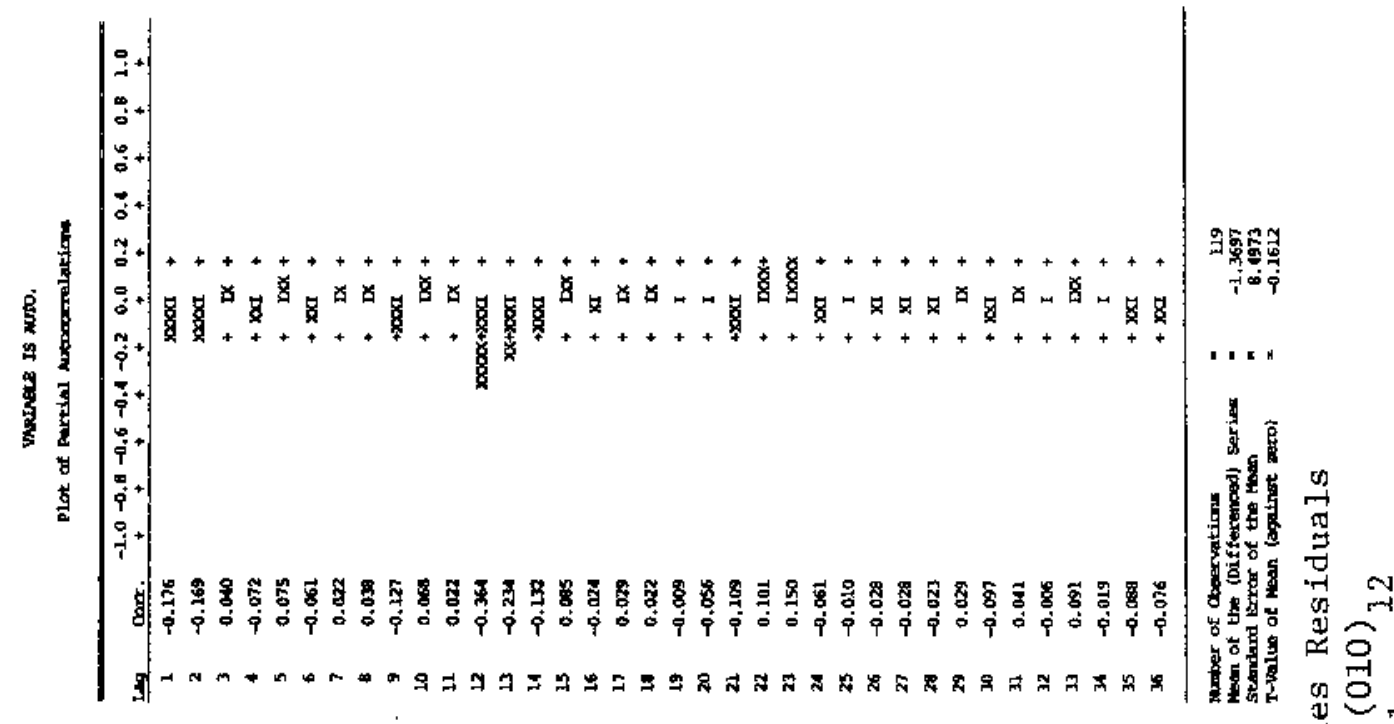

㟧。高

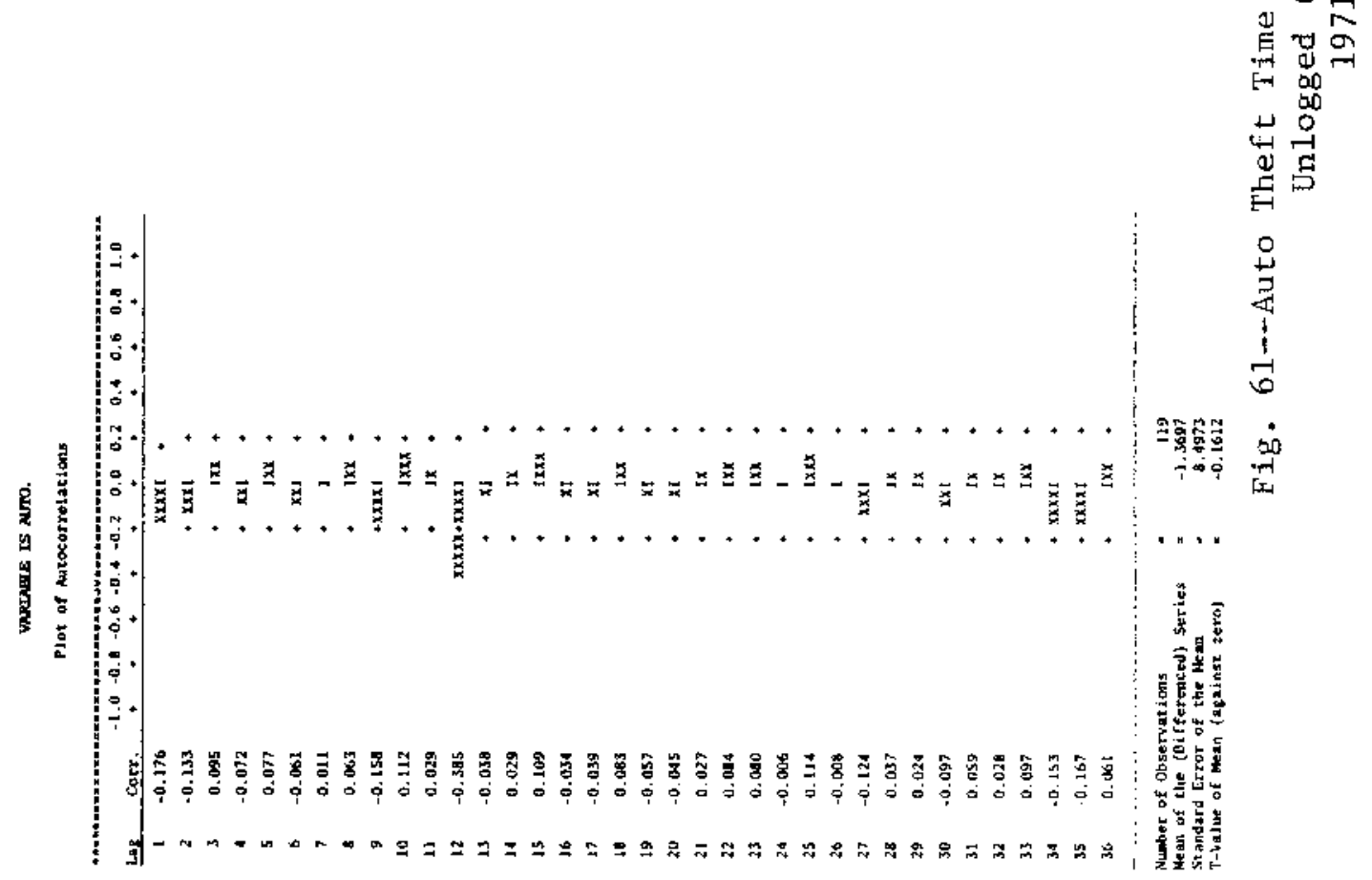


This tentative mode 1 is represented as follows:

D.6)

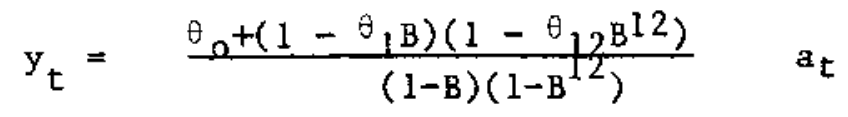

Estimation.--Parameter estimates were:

\begin{tabular}{ccccc}
\multicolumn{2}{c}{ Conditional Least Squares } & & \multicolumn{2}{c}{ Unconditional Least Squares } \\
\cline { 1 - 2 } Estimate & T Value & & Estimate & T Value \\
3.6054 & 0.6103 & & 3.6054 & 0.6103 \\
0.4123 & 4.66 & & 0.3824 & 4.88 \\
0.6050 & 7.65 & & 0.8571 & 27.64
\end{tabular}

Residual Sum Squares

$714,657.6875$

Degrees Freedom

$117 \quad 117$

The estimate for $\theta_{0}$ was not statistically significant. Thus, the series displayed a drift rather than a trend. The remaining estimates for $\theta_{1}$ and $\theta_{12}$ were statistically significant and were within the bounds of invertibility.

Diagnosis.--The residuals depicted in the model ACF and PACF (F1gure 62) were not different from white noise. The Q statistic of 12 with 23 degrees of freedom was not statistically significant, so the tentative model was accepted. The plotted residuals are exhibited in Figure 63 .

\section{Burglary}

Identification (Model \#1). - The plot of raw burglary data (Figure 64) did not display constant variance. The magnitude of change from month to month increased with the level of reported crime. Log-transformed data, as depicted in Figure 65, provided more constant variance. Thus, the tentative ARIMA model was built utilizing this data. 


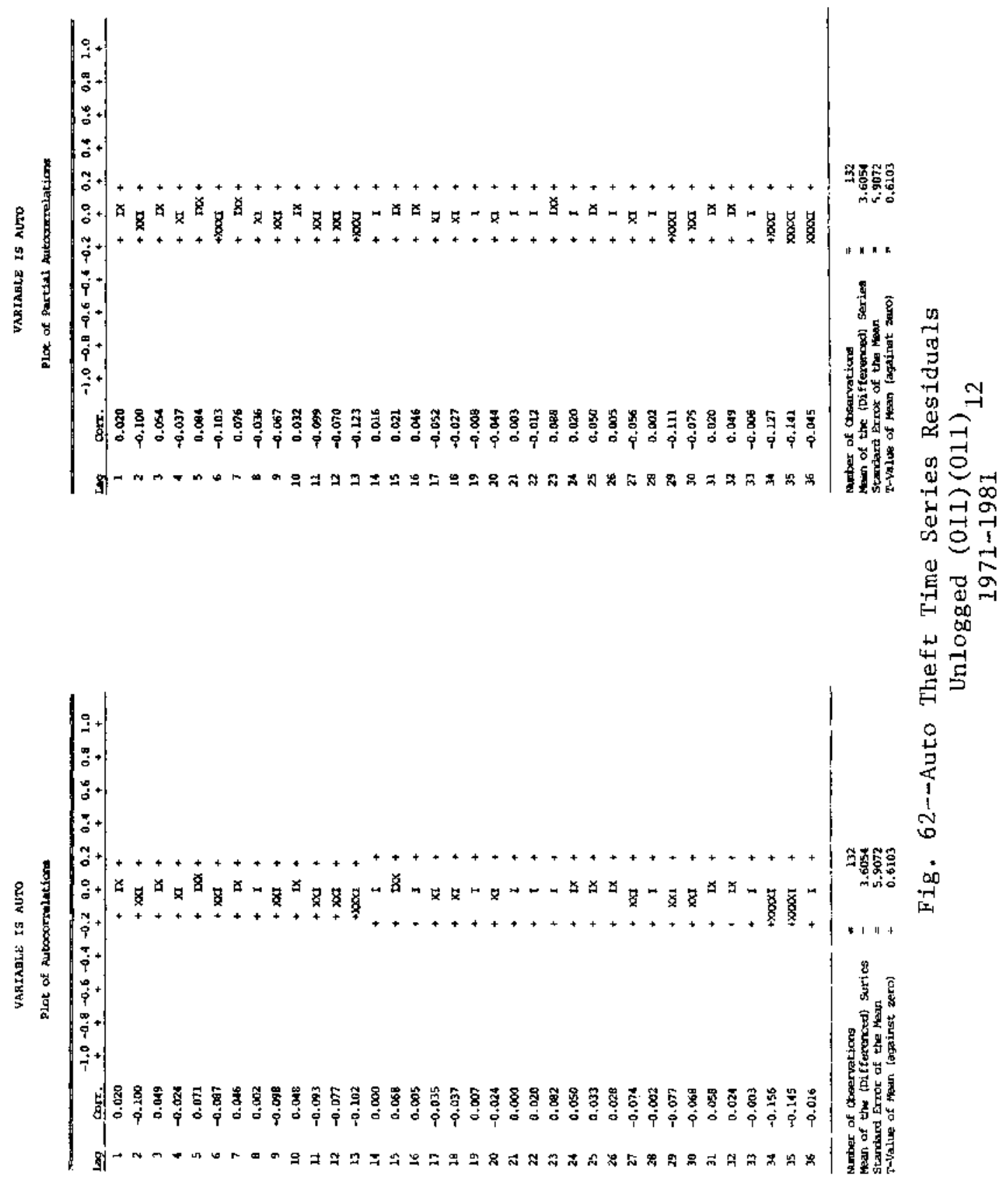




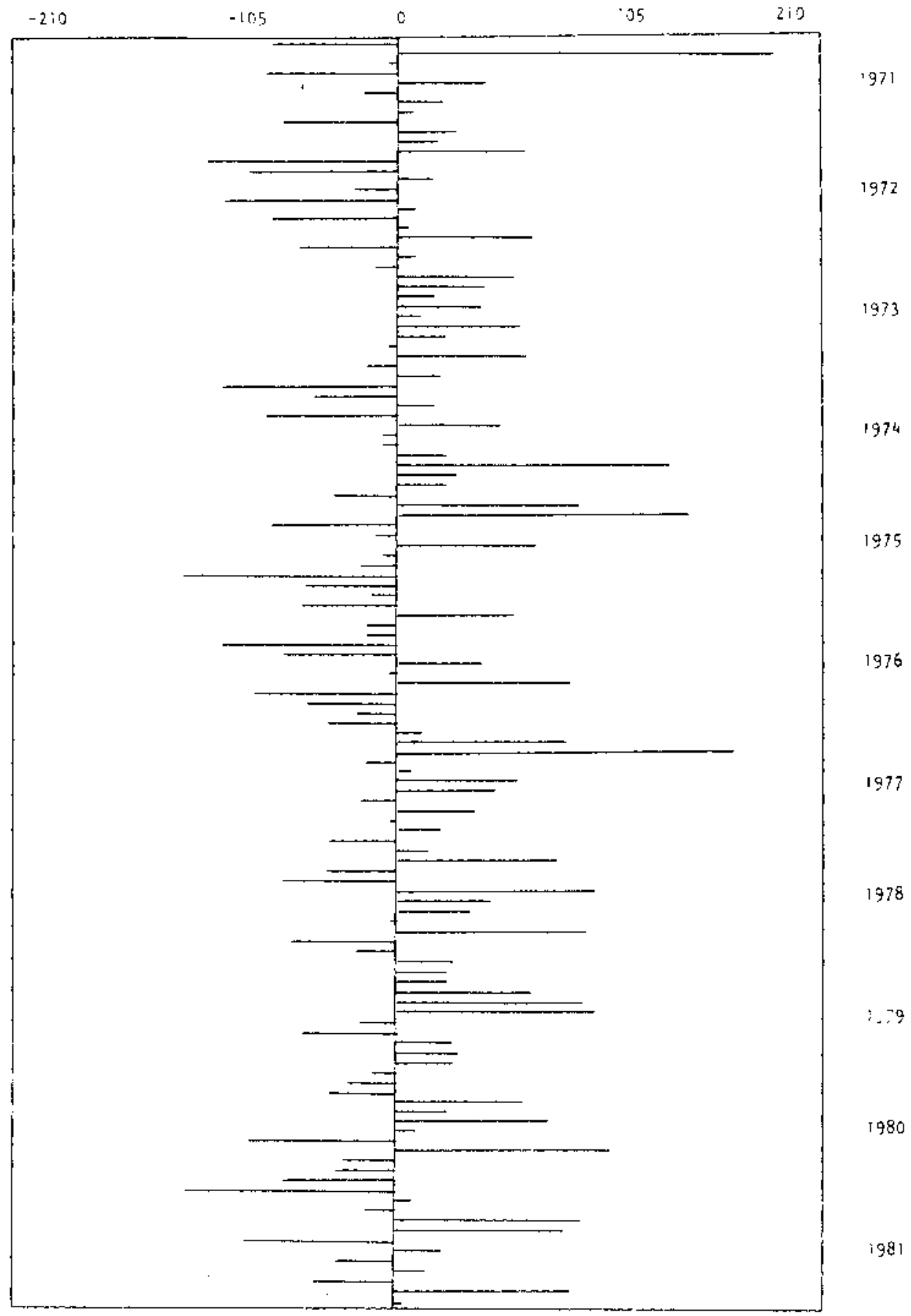

Fig. 63--Auto Theft Time Series Residuals Plot Unlogged $(011)(011) 12$
$1971-1981$ 


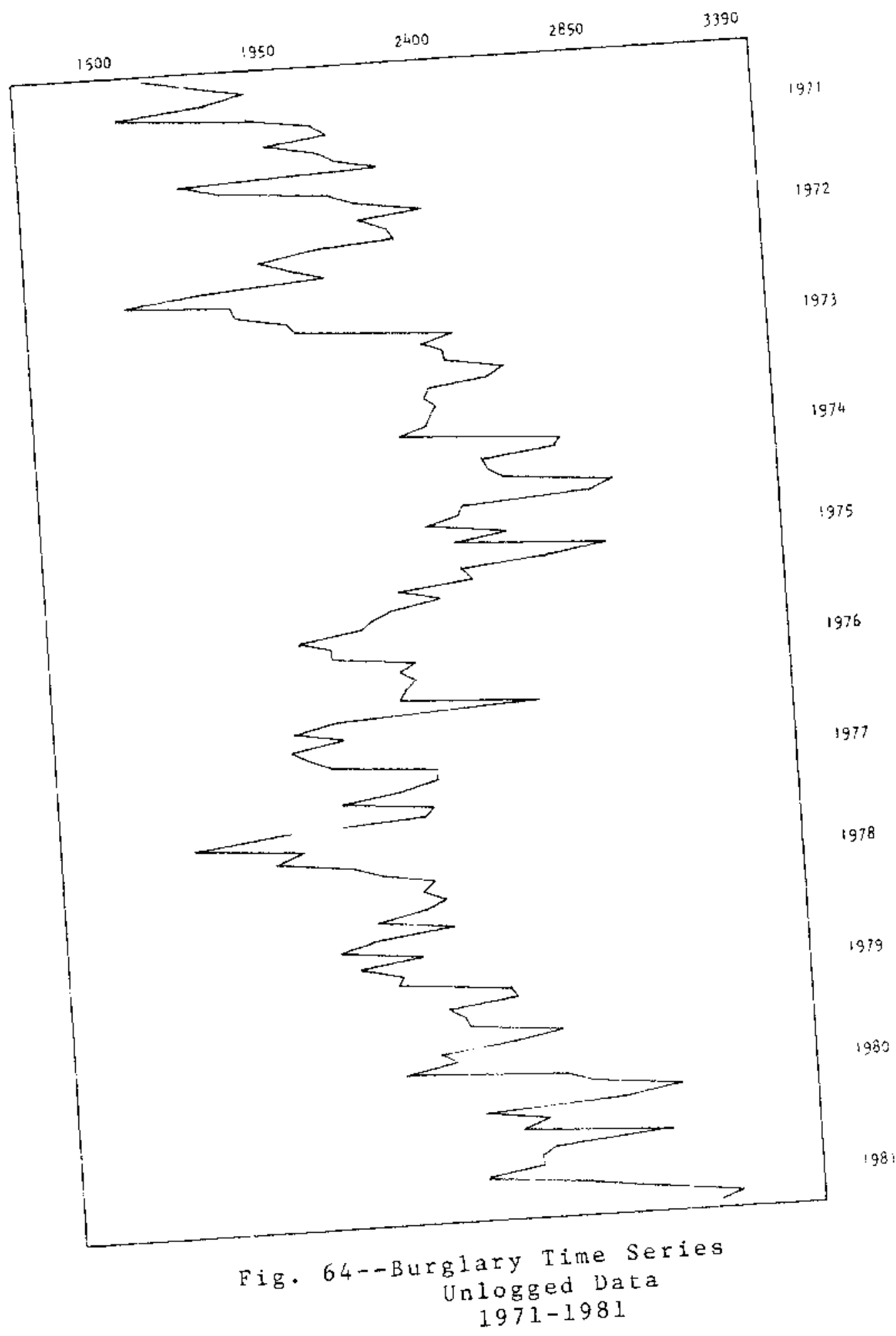




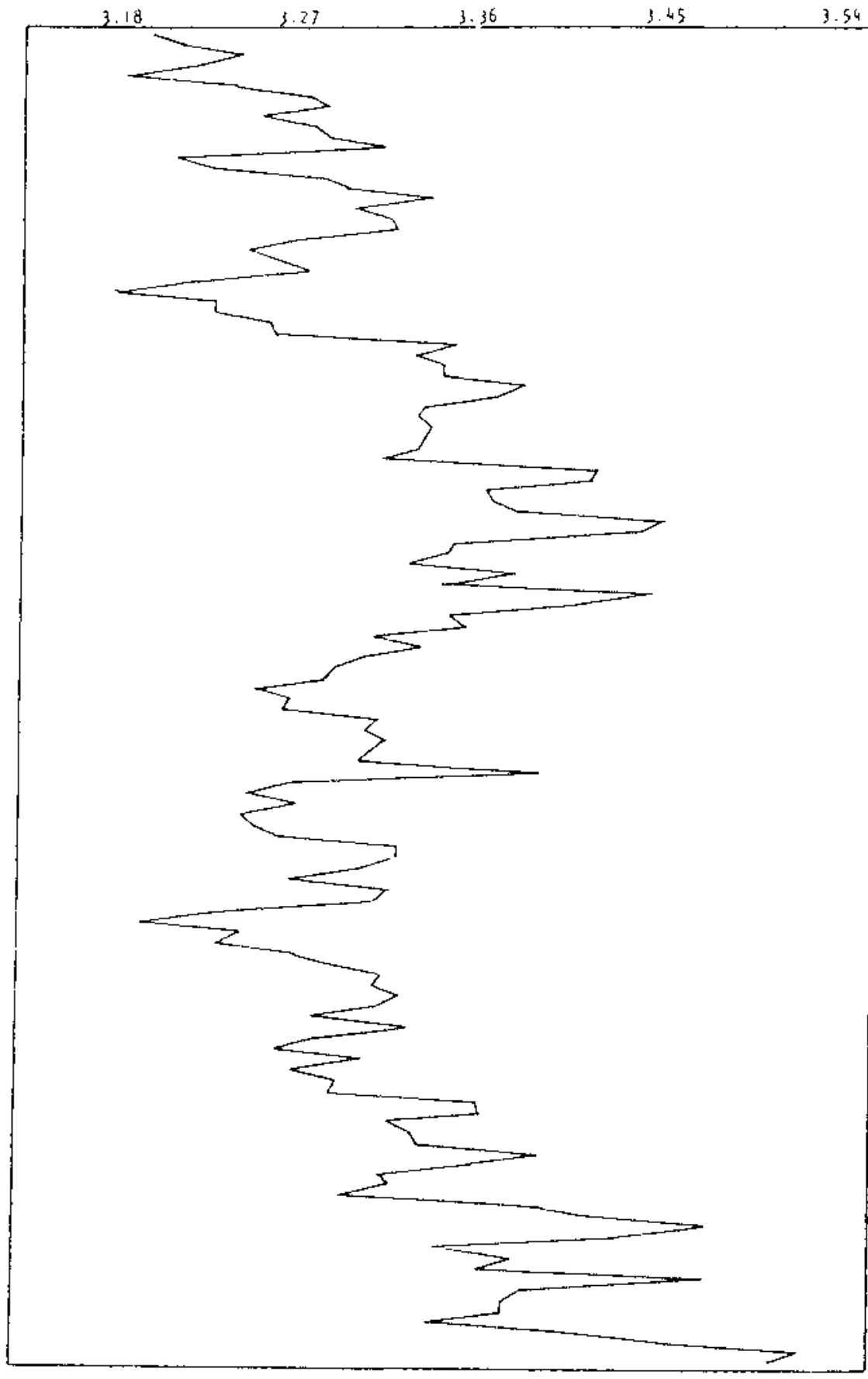

197

1972

1973

1974

1975

1976

1977

1978

1979

1980

1981

Fig. 65--Burglary Time Series Logged Data 1971-1981 
The ACF and PACF of the logged time series (Figure 66) readily indicated that the process was not stationary. One spike at PACF lag (1) suggests that first-differencing was required. The regularly differenced ACF contained spikes at six month intervals and the PACF spiked at lags (6) and (12) (Figure 67.) As may be seen in Figure 68, the regularly and seasonally differenced ACF spiked at lag (12) and the PACF displayed a decaying pattern at the early 1 ags $(1-3)$ and again at lag (12). This suggested an ARIMA (011)(011) 12 mode1. It is written in the following fashion:

D.7) $\operatorname{Ln}\left(y_{t}\right)=\frac{\theta_{0}+\left(1-\theta_{1} B^{1}\right)\left(1-\theta_{12} B^{12}\right)}{(1-B)(1-B) 12} a_{t}$ Estimation.--Parameter estimates were:

\begin{tabular}{lllllc} 
& \multicolumn{2}{c}{ Conditiona1 Least Squares } & & \multicolumn{2}{c}{ Unconditional Least Squares } \\
& Estimate & T Value & & Estimate & T Value \\
$\theta_{0}$ & 0.0003 & 0.1223 & & 0.0003 & 0.1223 \\
$\theta_{1}$ & 0.3210 & 3.58 & 0.2710 & 3.29 \\
$\theta_{12}$ & 0.6473 & 8.76 & 0.8933 & 33.88
\end{tabular}

Residual Sum Squares

0.116325

Degrees Freedom 117 117

All parameter estimates, with the exception of $\theta_{0}$ were signiflcant and were retained in the model. $\theta_{1}$ and $\theta_{12}$ were also within the bounds of invertibility and were thus acceptable.

Diagnosis.--The ACF and PACF plots of the model indicated marginal significance at lag (3) (Figure 69). However, the initial and seasonal lags were not 


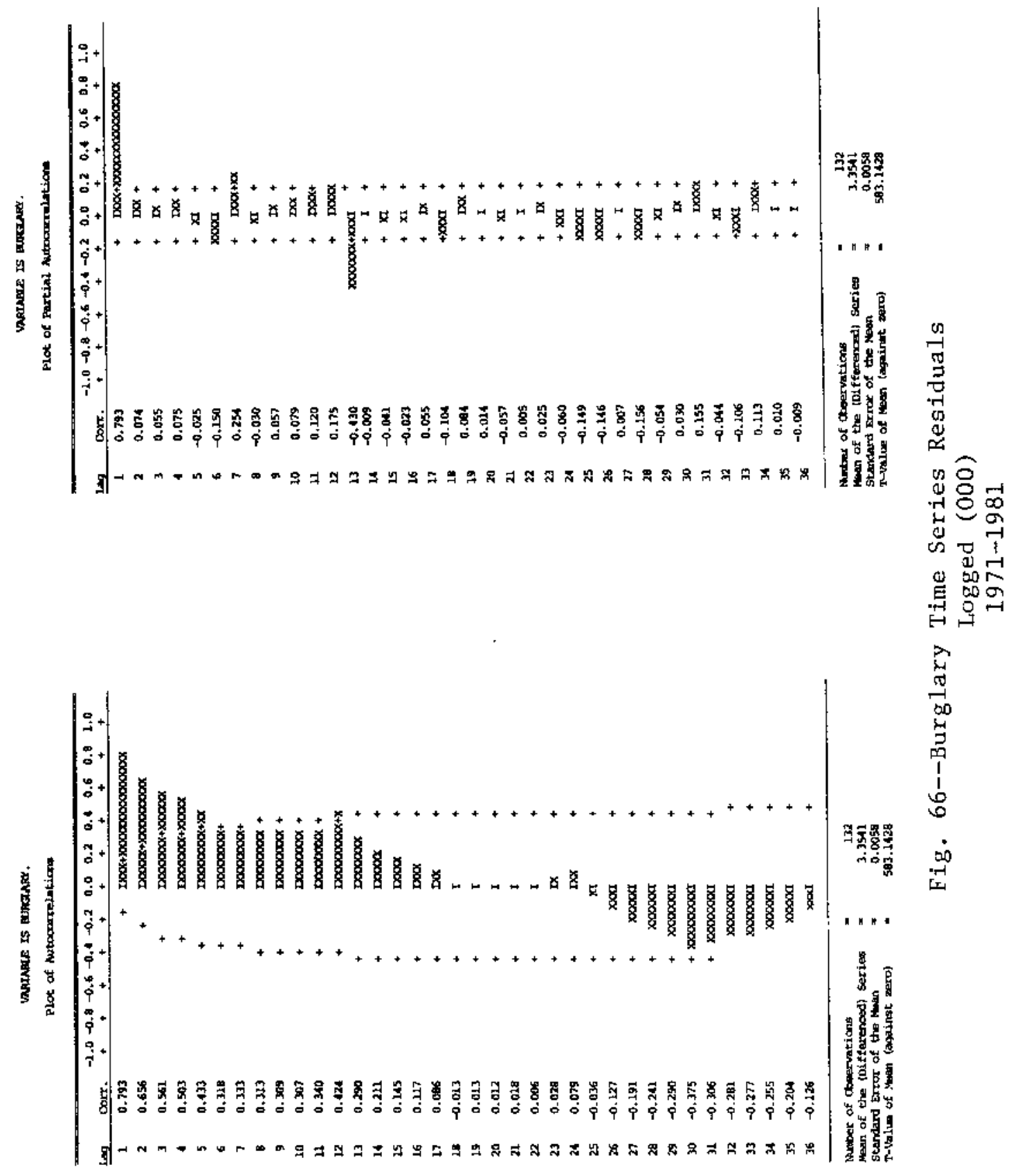



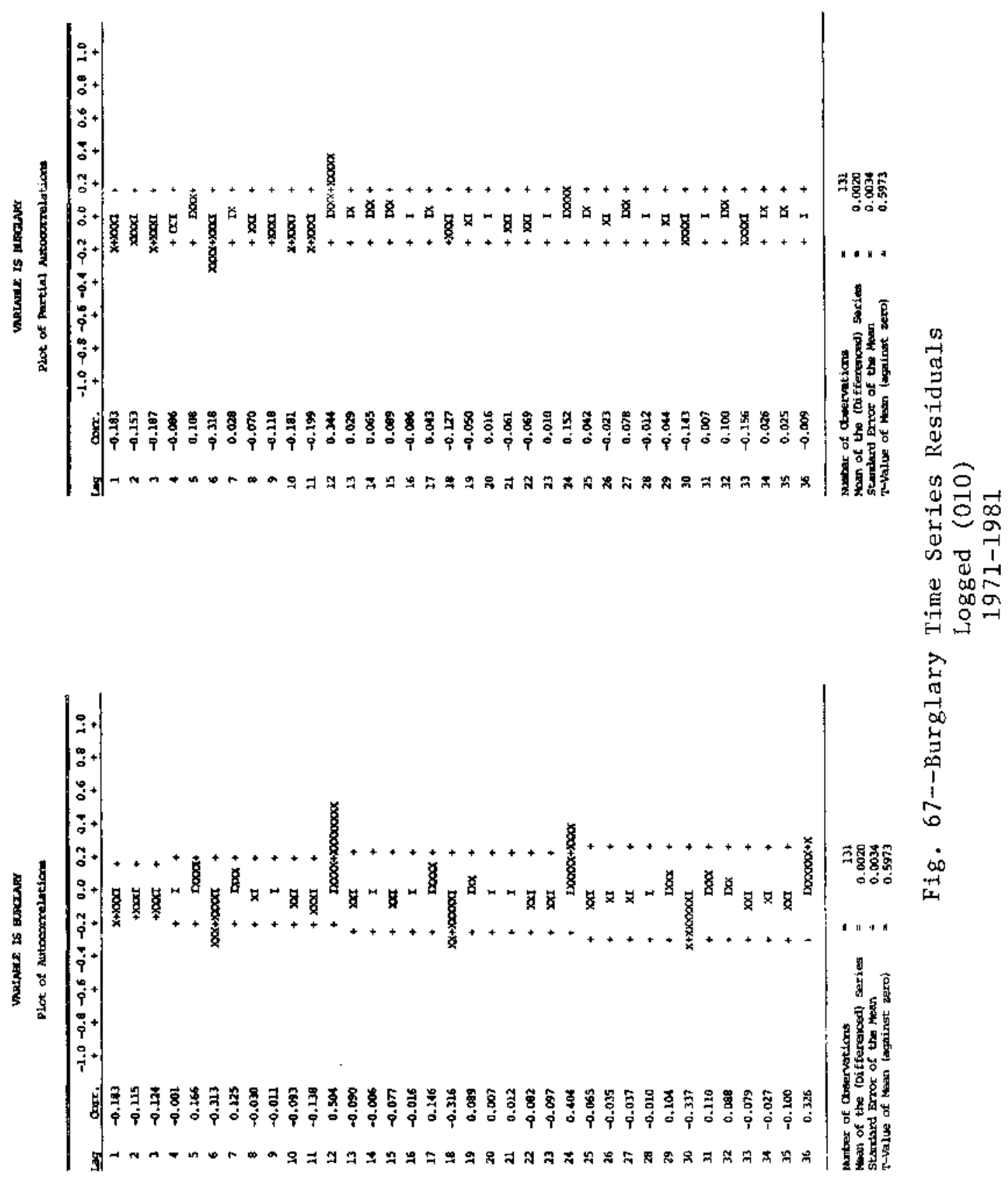

范 


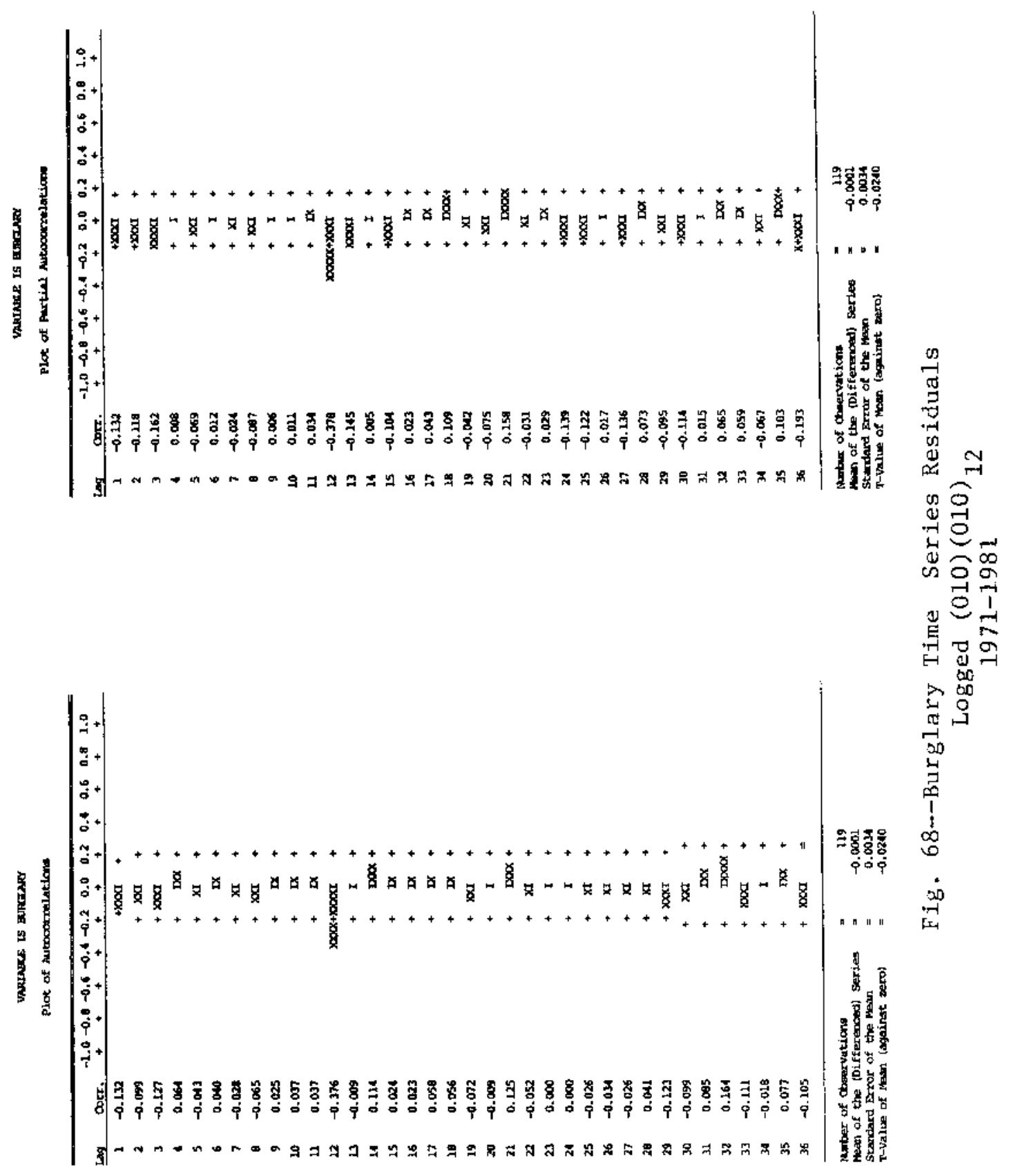




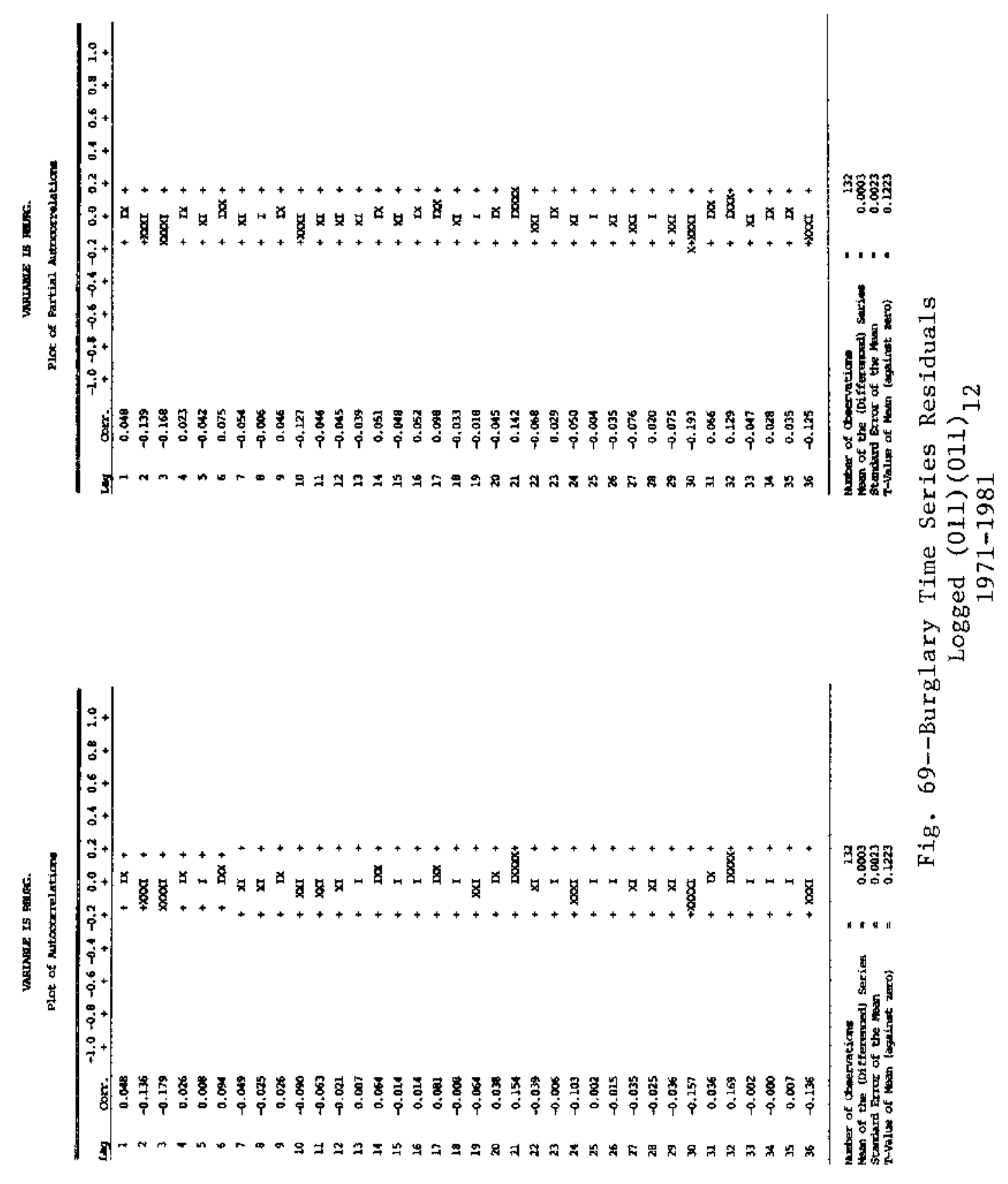


statistically significant. The Q statistic of 19 with 23 degrees of freedom was also not significant. Thus, one could conclude that the model residuals were no different than white noise. Nevertheless, further model building appeared warranted.

Identification (Model \#2) - - The tentative model ARIMA (111)(011)12 was investigated to ascertain if this would eliminate the confounding influences present in the early lags. This model is written as follows:

D.8) $\left(1-\phi_{1} B\right) \operatorname{Ln}\left(y_{t}\right)=\frac{\theta_{0}+\left(1-\theta_{1} B\right)\left(1-\theta_{12}{ }^{12}\right)}{(1-B)\left(1-B^{12}\right)} a_{t}$ Estimation.--The parameter estimates of this model were:

\begin{tabular}{|c|c|c|c|c|}
\hline \multicolumn{3}{|c|}{ Conditional Least Squares } & \multicolumn{2}{|c|}{ Unconditional Least Squares } \\
\hline & Estimate & T Value & Estimate & T Value \\
\hline 0 & -0.0020 & -0.88 & -0.0020 & -0.88 \\
\hline 1 & 0.7252 & 4.83 & 0.6201 & 3.82 \\
\hline 12 & 0.6420 & 8.58 & 0.8756 & 30.34 \\
\hline 1 & 0.4430 & 2.21 & 0.3450 & 1.77 \\
\hline
\end{tabular}

Residual Sum Squares

Degrees Freedom

0.113460

115

0.079892

115

Again, $\theta_{0}$ was not significant and was dropped from the mode1. However, all other parameters were retained, even though $\phi_{1}$ was only marginally significant under the unconditional least squares method.

Diagnosis.--The ACF and PACF of the residuals computed from model 12 (Figure 70) no longer exhibited any significance in the early lags. The Q statistic of 15 


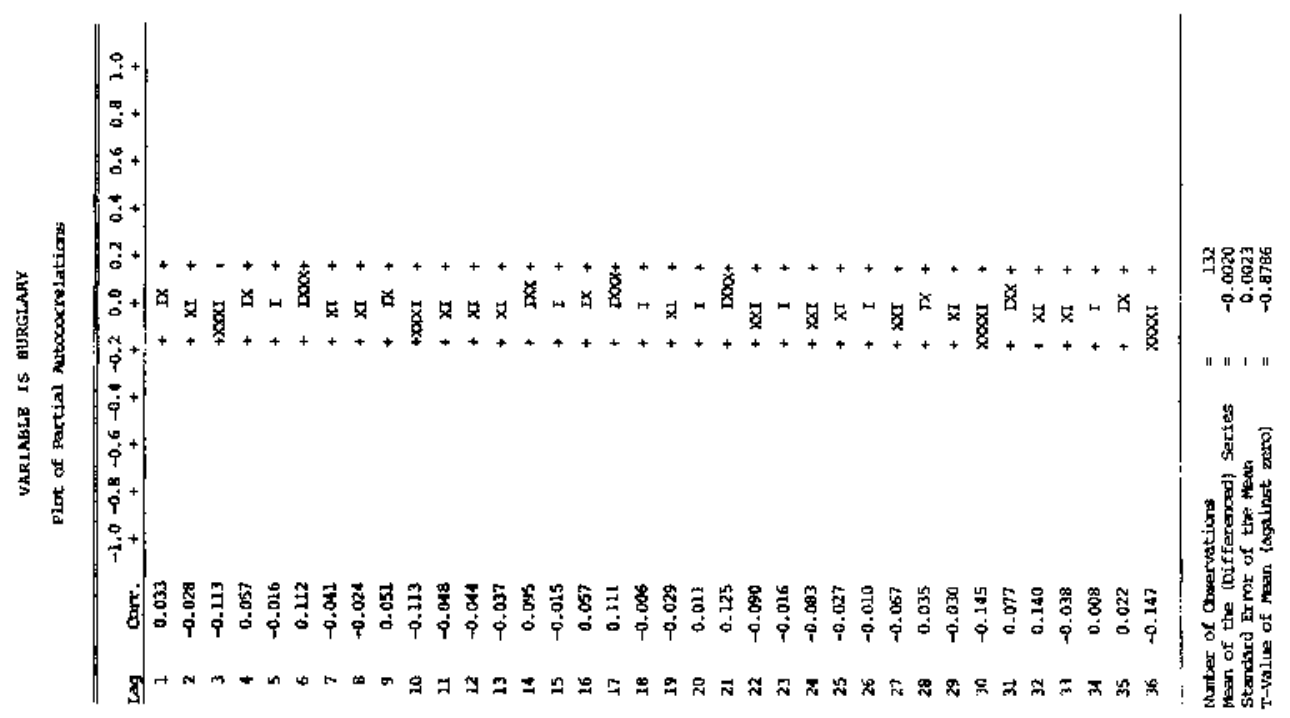

尔 $-\infty$ क 基宁合

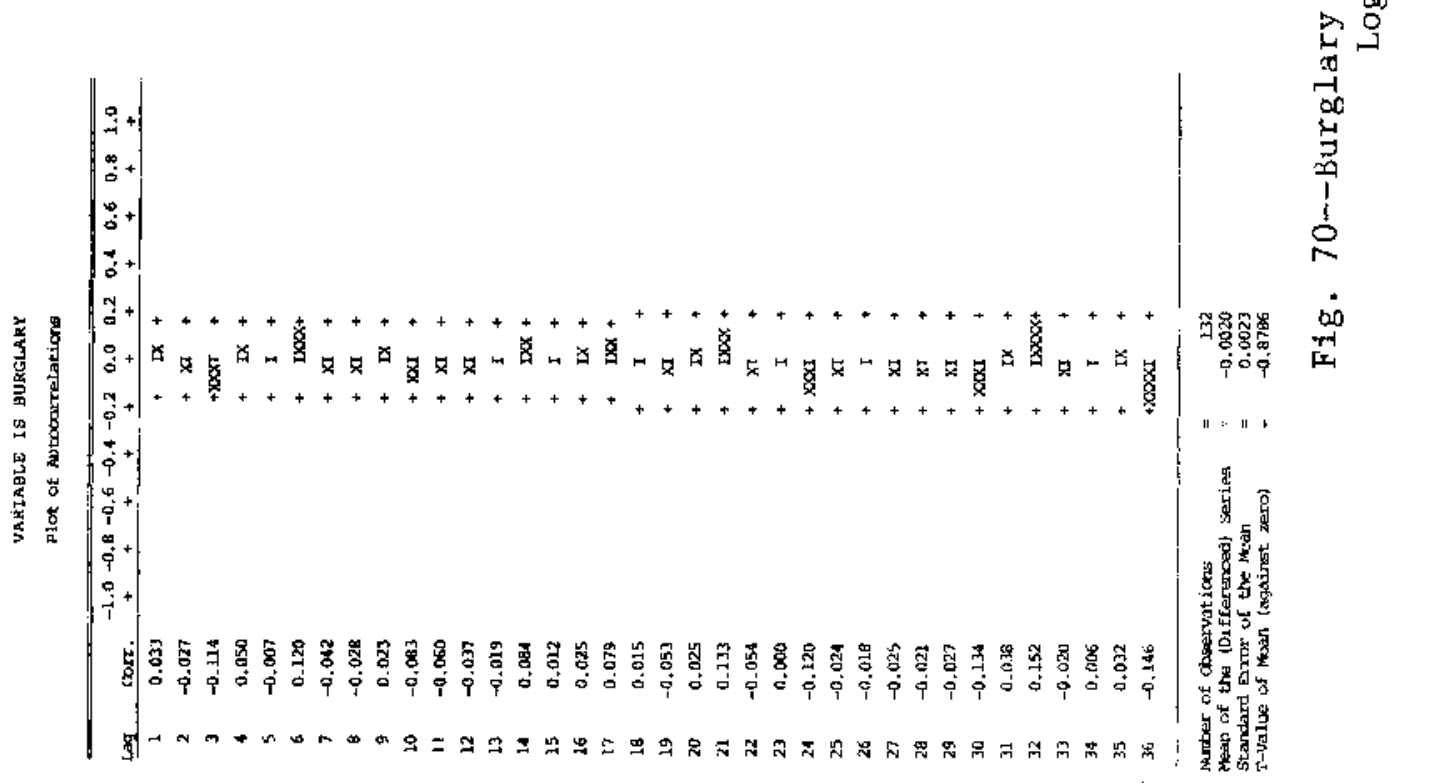


computed for lag (25) further suggested that the series residuals were no different than white noise. Metadiagnosis.--Both models are acceptable. However, the residual sum of squares of Model \#2 declined from 0.081395 to 0.079892 . Thus, it was decided to utilize Model \#2 in the subsequent intervention analysis. Figure 71 provides a plot of the model residuals.

\section{Larceny}

Identification Figures 72 and 73 contain plots of the larceny time series in raw and logged forms. Variance appeared to be proportional to the change in the series level. Therefore, the model was built utilizing the log-transformed data to achieve more uniform variance across the series.

The ACF and PACF of the log-transformed time series (Figure 74) indicated non-stationarity. The ACF and PACF of the differenced series, contained in Figure 75 , suggested that two cycles were operating -- one at six month intervals and a longer one every twelve months. This pattern was also observed in the undifferenced PACF estimations. Thus, it was decided to difference the series regularly once and twice seasonally. Once this was accomplished, the resultant ACE spikes and PACF decays (Figure 76) suggested an ARIMA $(011)(011)_{6}(011) 12$ model. 


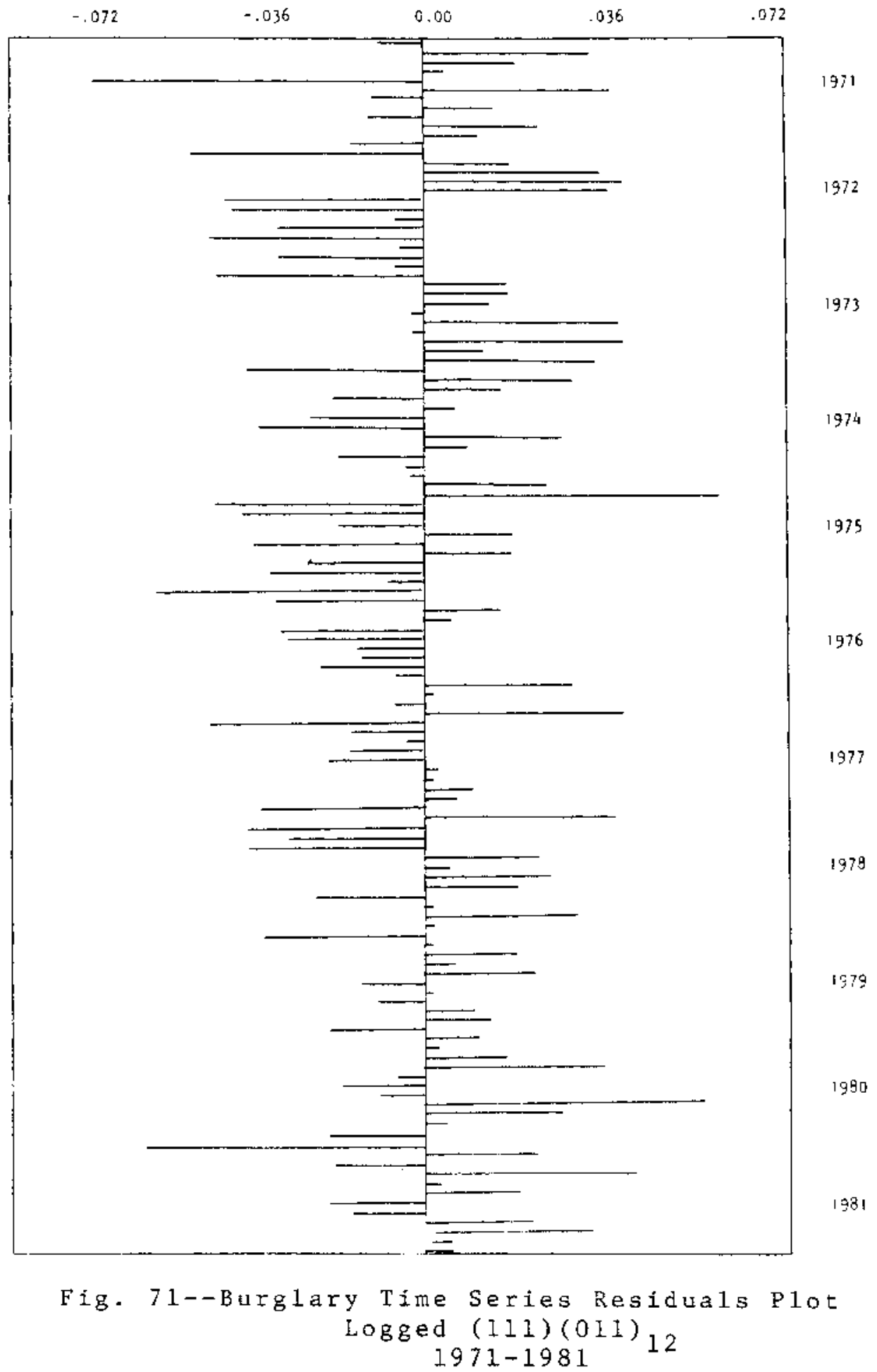




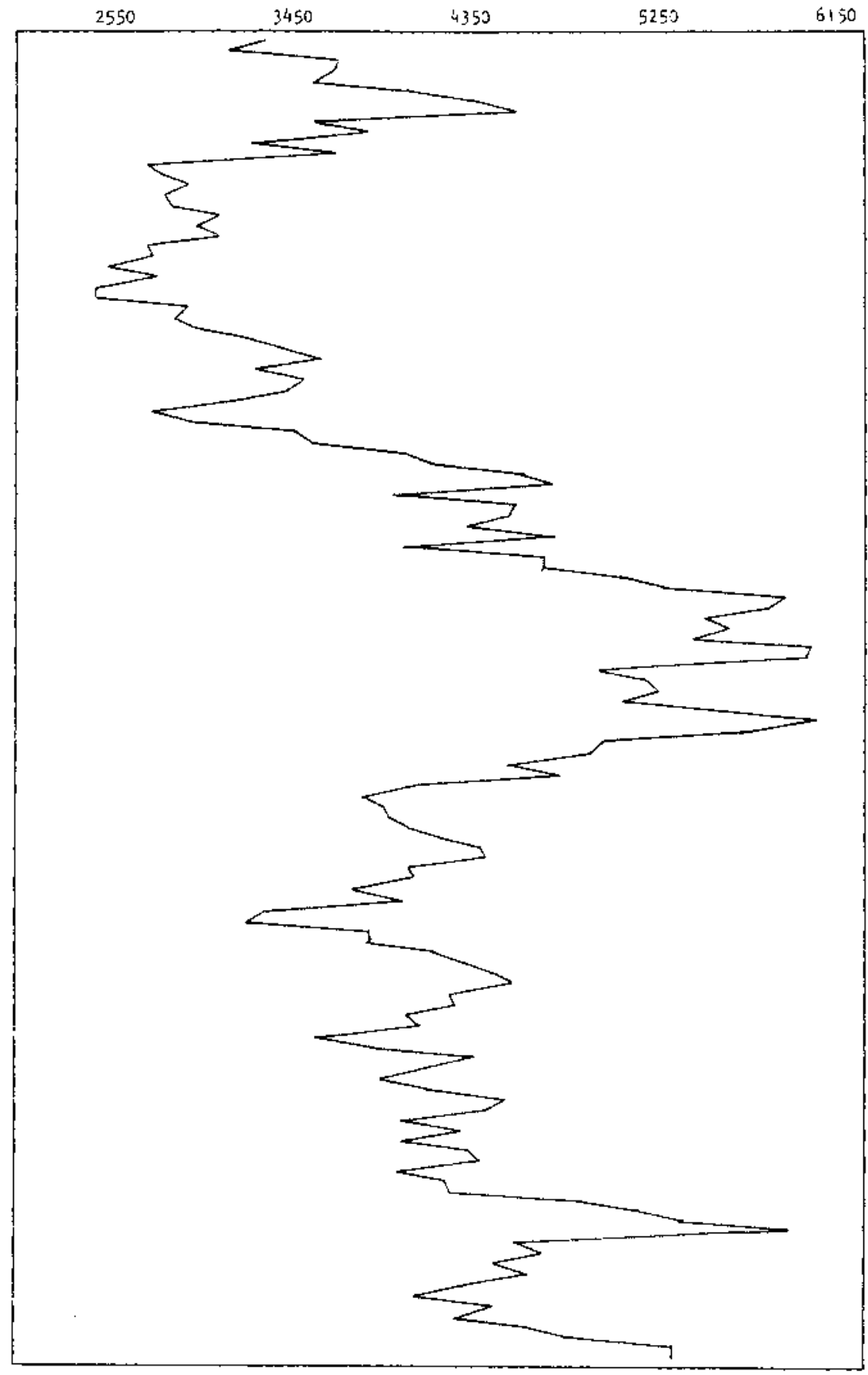

197

1972

1973

1974

1975

1976

1977

1978

1979

1980

Fig. 72--Larceny Time Series

Unlogged Data

$1971-1981$ 


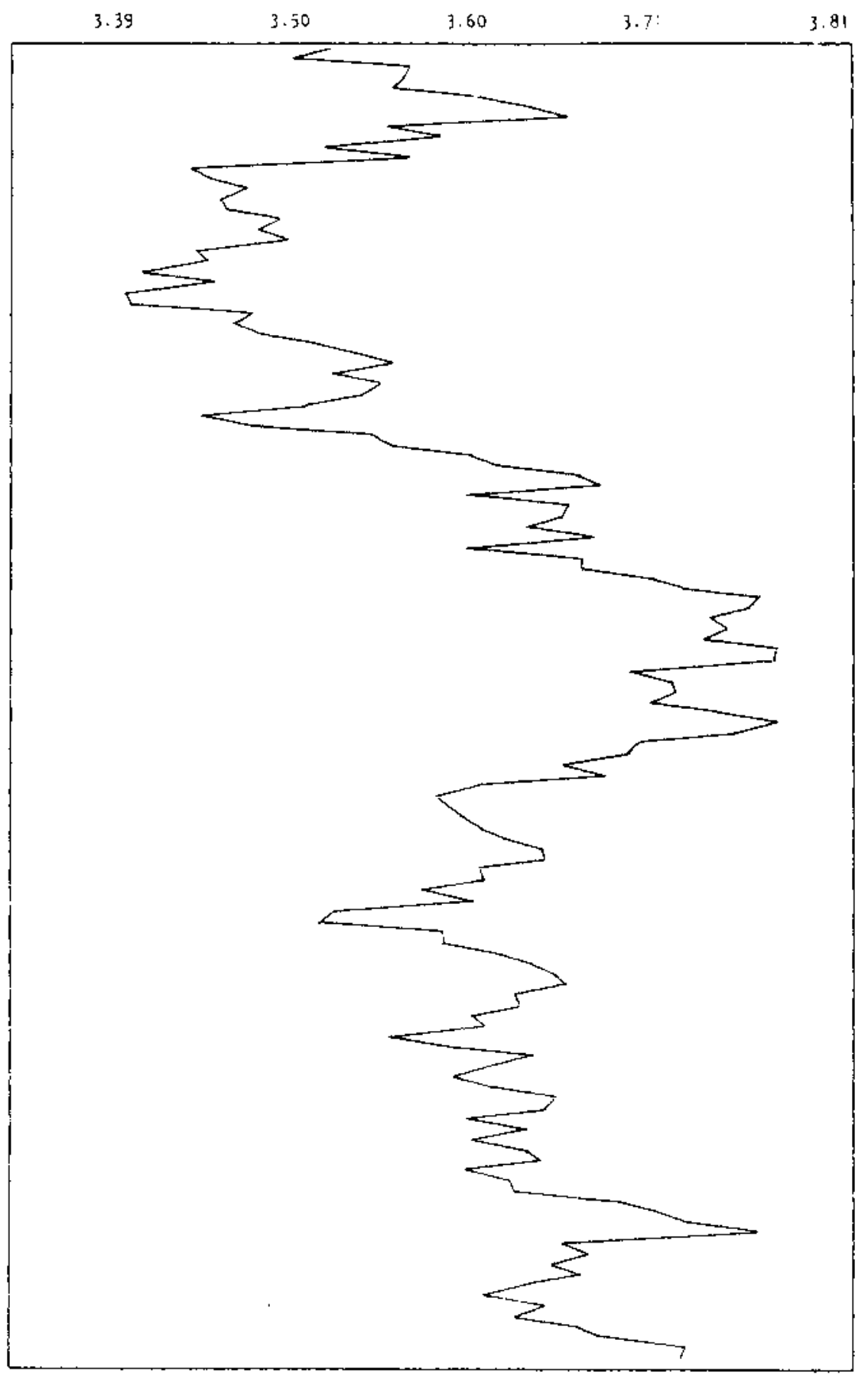

1971

Fig. 73--Larceny Time Series Logged Data $197 \mathrm{~L}-1981$ 


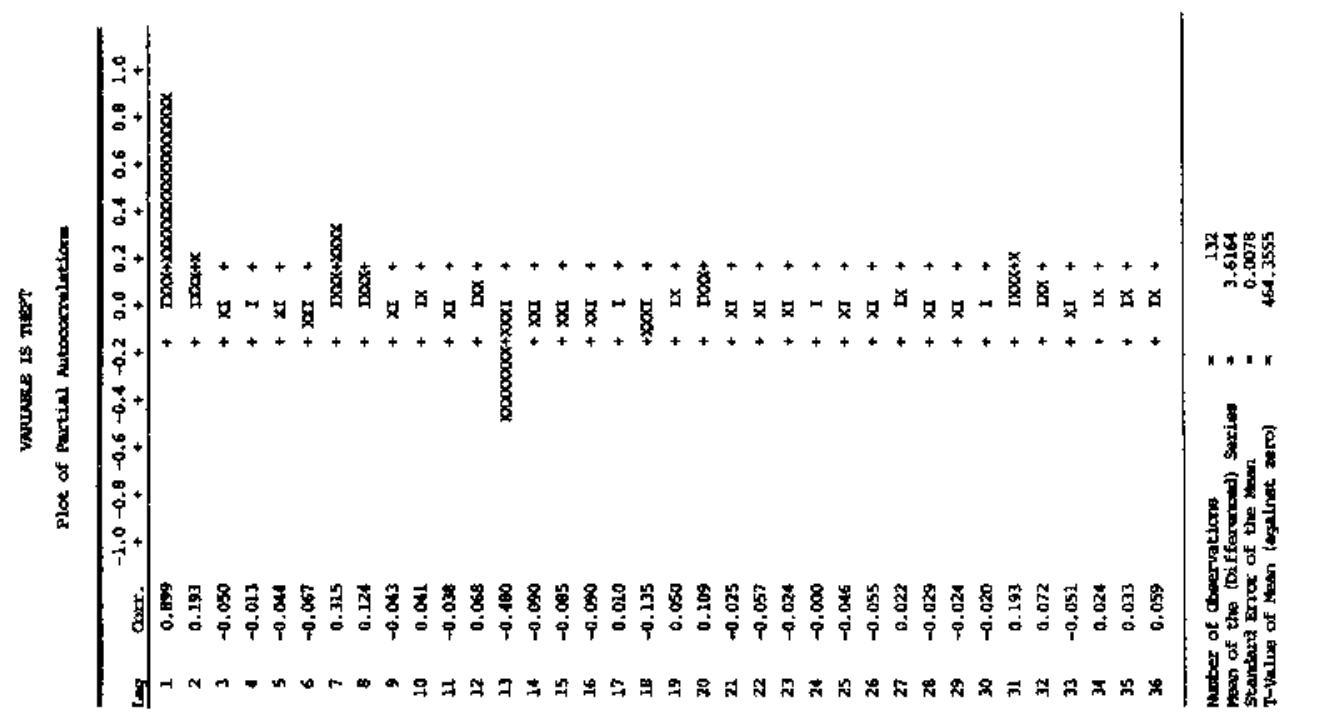

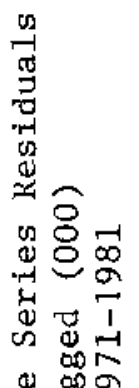
볍
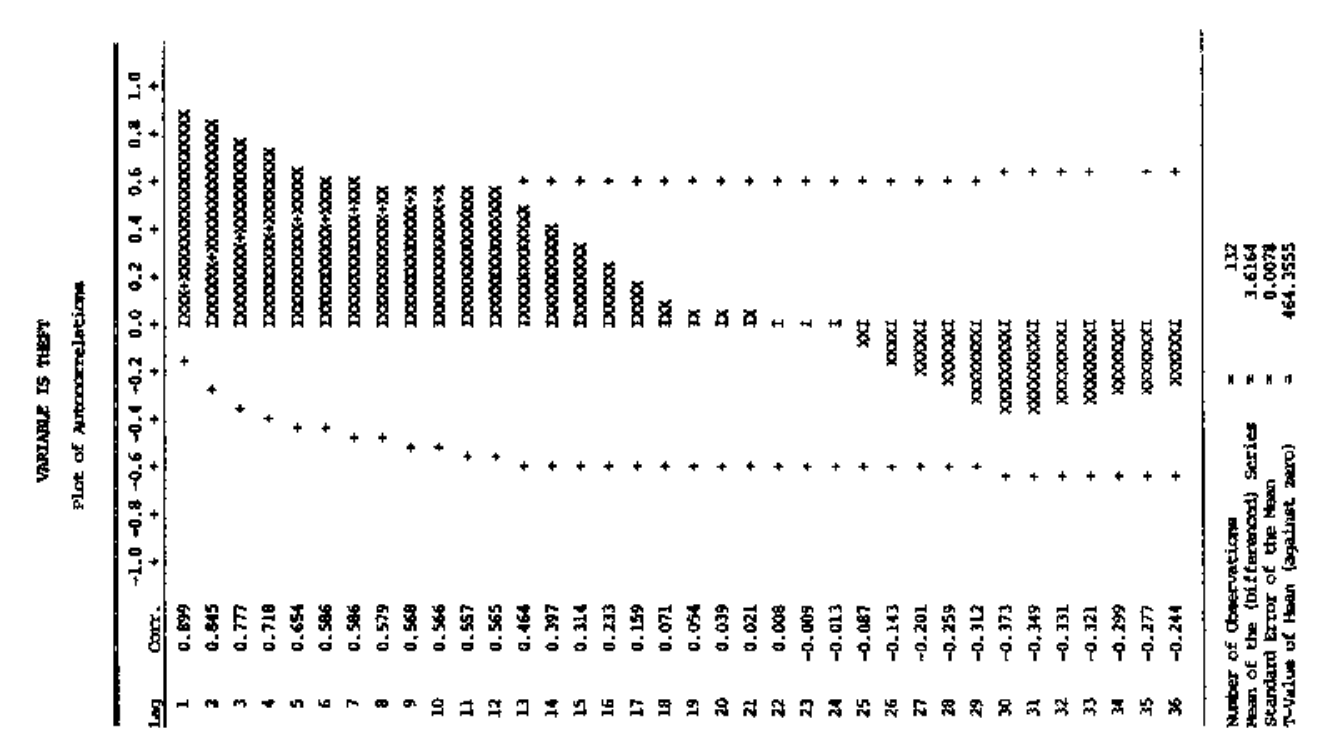

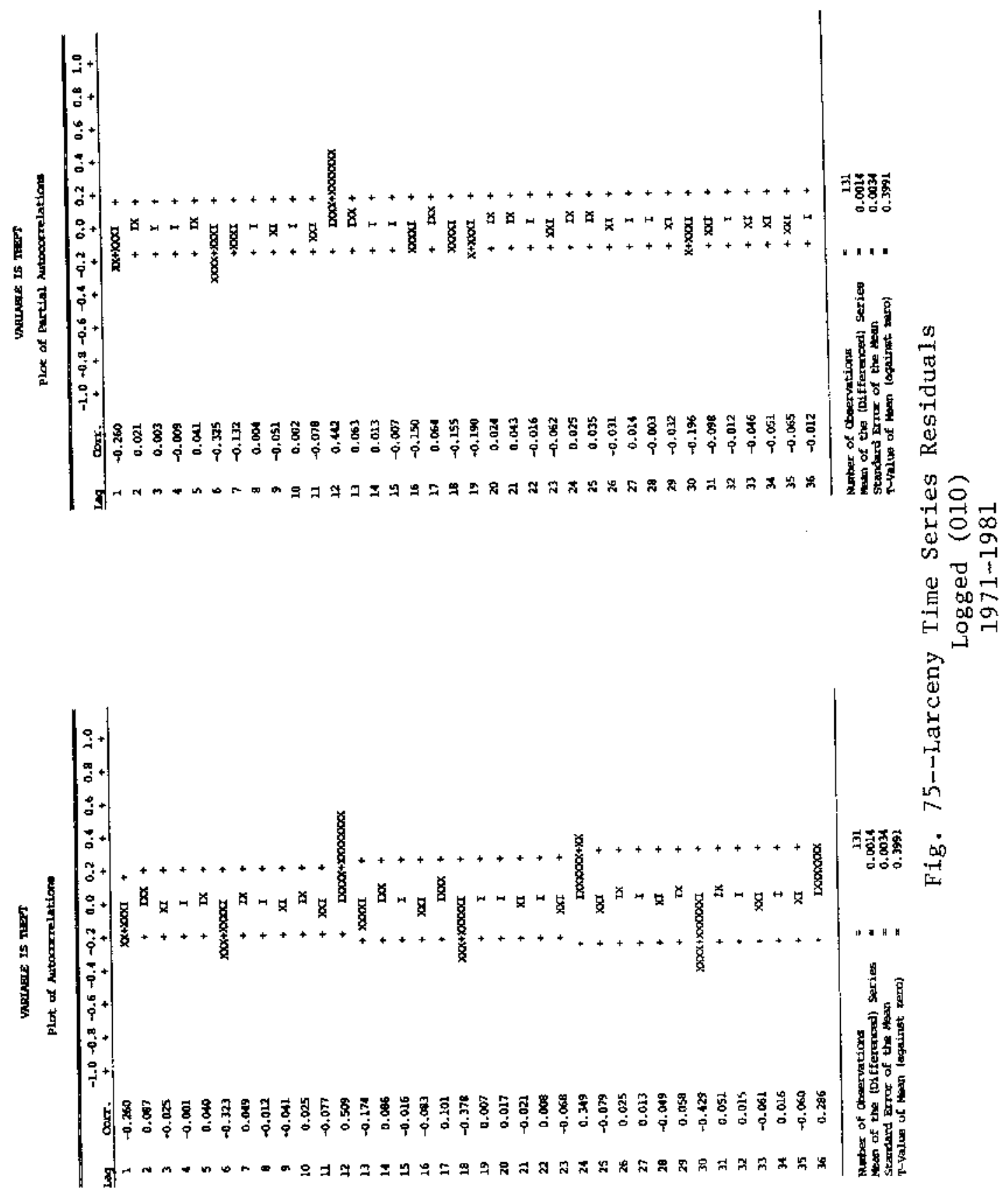

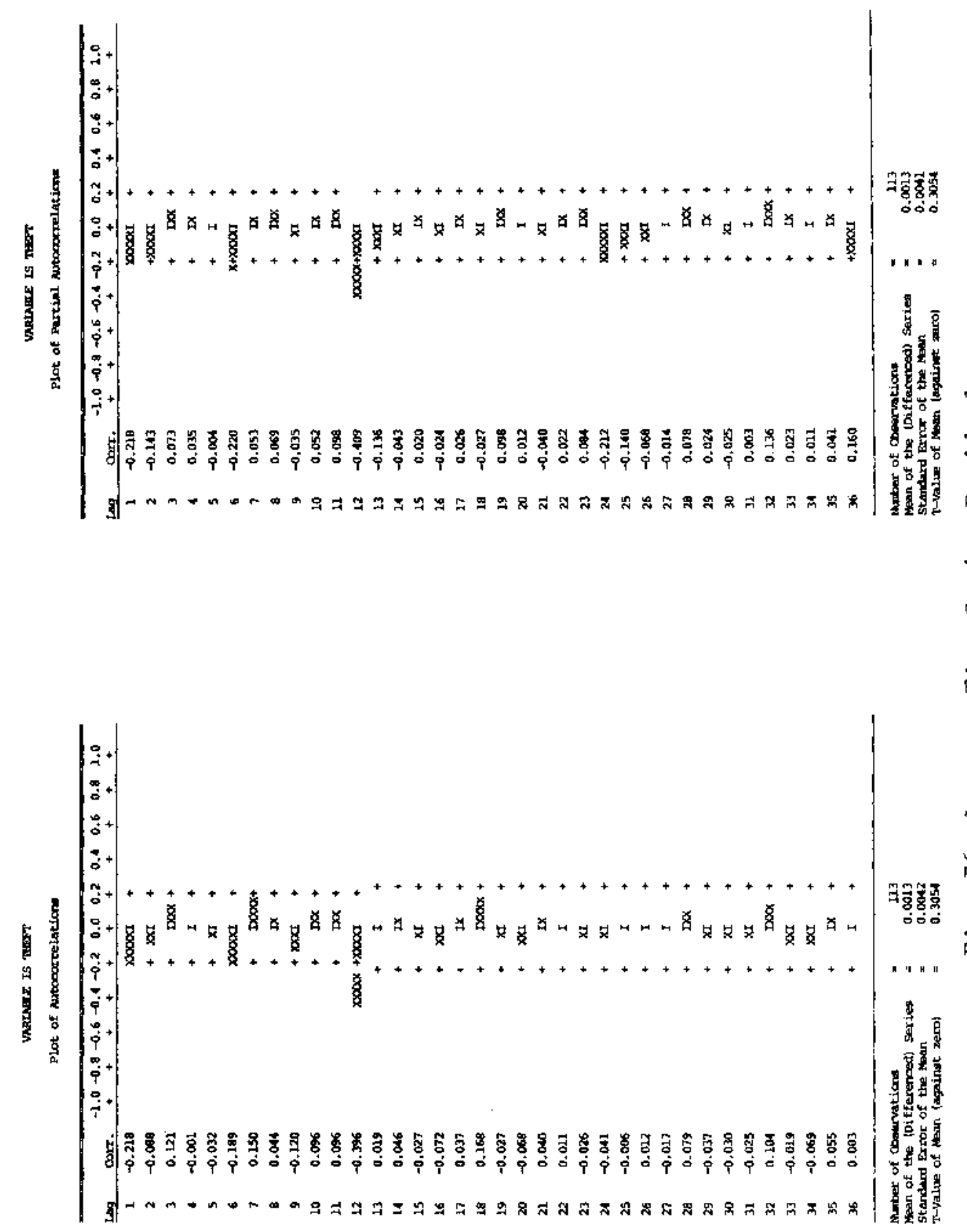
D.9) $\quad \operatorname{Ln}\left(y_{t}\right)=\frac{\theta_{0}+\left(1-\theta_{1} B\right)\left(1-\theta_{6} B^{6}\right)\left(1-\theta_{12} B^{12}\right)}{(1-B)\left(1-B^{6}\right)\left(1-B^{12}\right)} a_{t}$

Estimation.--The parameter estimates were:

\begin{tabular}{lccccc} 
& \multicolumn{2}{c}{ Conditional Least Squares } & & Unconditional Least Squares \\
\cline { 2 - 3 } & Estimate & T Value & & Estimate & T Value \\
$\theta_{0}$ & -0.0017 & -0.6993 & & -0.0017 & -0.6993 \\
$\theta_{1}$ & 0.2644 & 2.87 & 0.2590 & 2.98 \\
$\theta_{1}$ & 0.3765 & 4.05 & 0.5857 & 7.16 \\
$\theta_{12}$ & 0.6940 & 9.60 & 0.8371 & 20.39
\end{tabular}

Residual Sum Squares

Degrees Freedom

0.131328

0.087309

110

110

The t-statistic for $\theta_{0}$ was less than 1.96 ; therefore, this parameter was dropped from the model. However, the remaining parameters were within the bounds of invertibility and were statistically significant.

Diagnosis.--As can be seen in Figure 77 , the model residuals have no significant spikes in the early lags of the ACF or PACF. Furthermore, the $Q$ statistic of 20 with 22 degrees of freedom indicated the resultant series was white noise. Repeated attempts to remove various parameters from this model proved unsuccessful. Thus, the ARIMA $(011)(011)_{6}(011)_{12}$ model was deemed adequate for intervention insertion. The residuals are plotted in Figure 78 . 


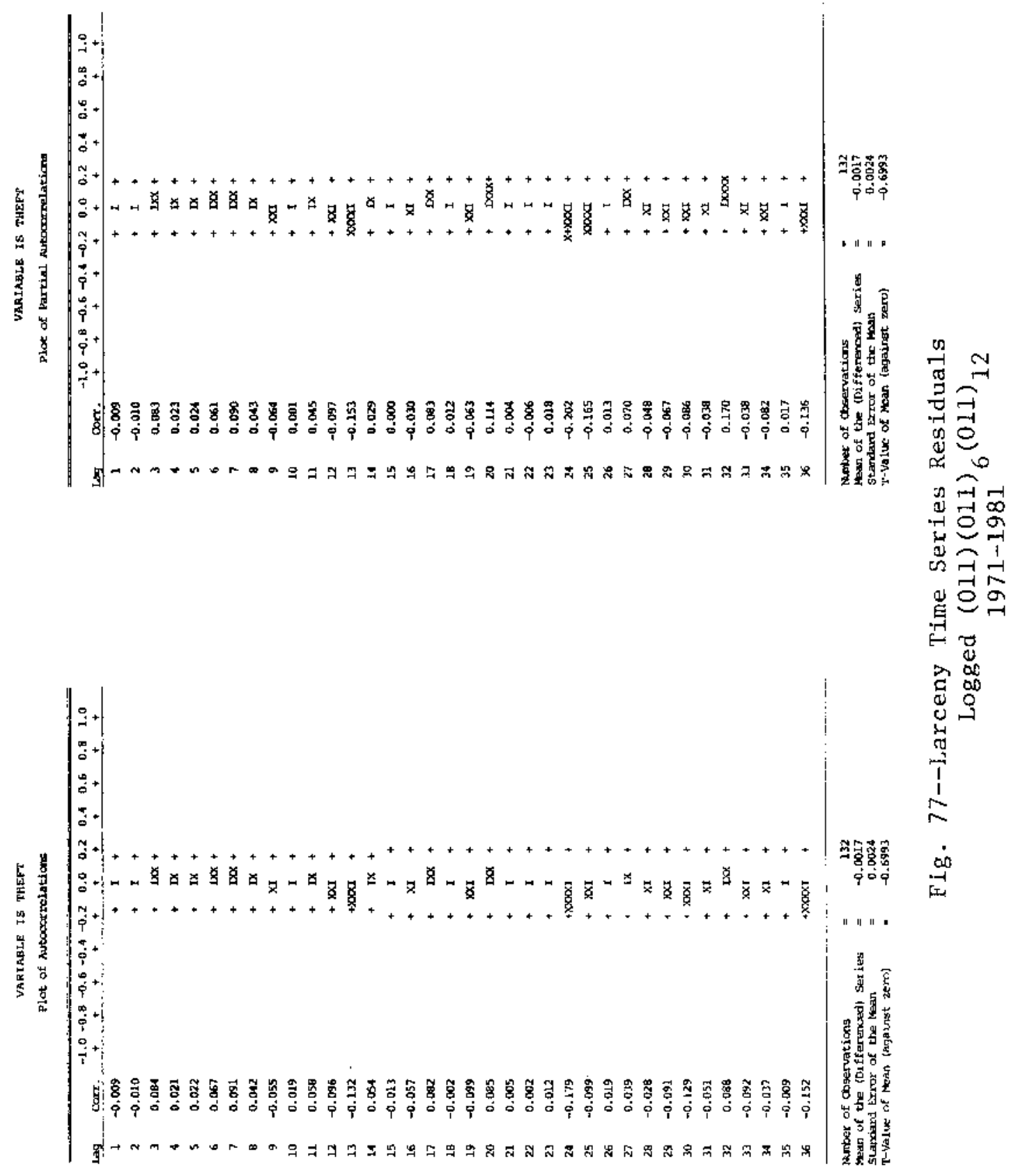




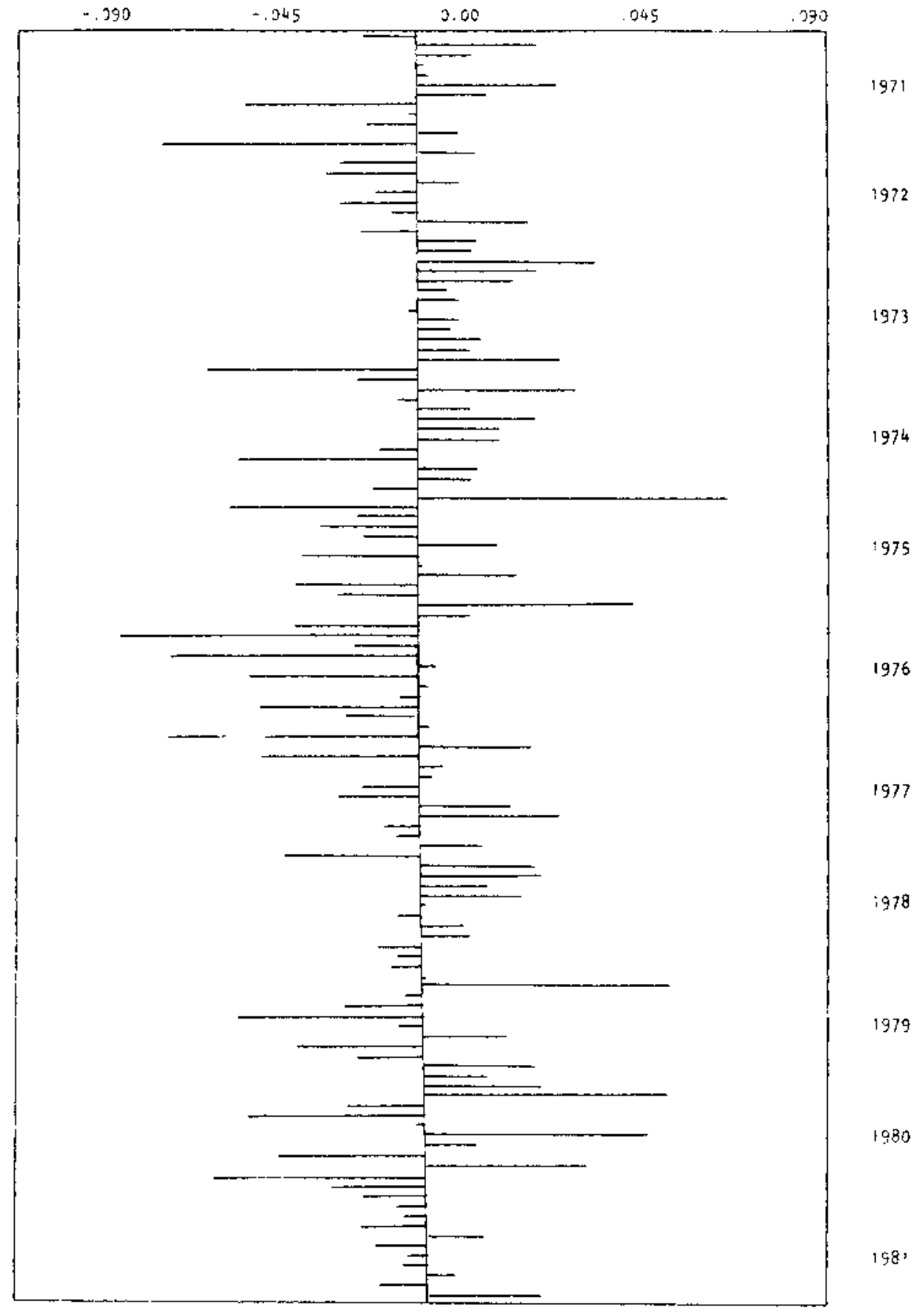

Fig. 78--Larceny Time Series Residuals Plot Logged $\begin{aligned}(011)(011) \\ 1971-1981\end{aligned} 6^{(01 I)} 12$ 
Impact Assessment

The above ARIMA models comprise the noise $\left(N_{t}\right)$

component of the equation

D.10) $Y_{t}=f\left(I_{t}\right)+N t$

By adding an intervention component to the ARIMA models developed of the stochastic process, the impact of the crime prevention advertising program upon reported incidences of major crimes in Dallas was assessed. Three intervention models--abrupt/permanent, gradual/permanent, and abrupt/temporary -- were investigated for each crime. However, only the abrupt/permanent case produced fruitful results.

The unconditional least squares method of model estimation consistently provided better estimations and resulted in significantly lower unexplained variance. Therefore, all reported results were obtained using this wethod. The impact of the program upon each type of crime is discussed individually.

\section{$\underline{\text { Murder }}$}

The full murder impact assessment model was tentatively set as:

$D .11)\left(1-\phi_{1} B\right)\left(1-\phi_{12} B\right)^{12} Y_{t}=\omega_{0} I 5 \frac{\left(1-\theta_{1 B}\right)\left(1-\theta_{12 B} 12\right)}{(1-B)(1-B 12)} a_{t}$ Where: $I_{54}=0$ for the first 53 observations $I_{54}=1$ for the 54 th and subsequent observations 
Parameter estimates for the tentative model are;

$\begin{array}{lcc} & \text { Estimate } & \text { T-Value } \\ \theta_{1} & 0.8703 & 17.80 \\ e_{12} & 0.8771 & 32.53 \\ \phi_{1} & 0.2653 & 2.75 \\ \phi_{12} & -0.3620 & -5.15 \\ \omega_{0} & -4.903 & -1.10\end{array}$

Residual Sum of Squares

5473.02

Degrees of Freedom 101

The intervention estimate was not statistically significant. Therefore, it must be concluded that the crime prevention program had no impact upon murder. This result, however, was not unexpected. Murders are acts of violence committed in the heat of the moment. Once violence has erupted, little could probably be done by the victim to alter the subsequent chain of events.

\section{Rape}

The logged rape noise component was identified as ARIMA (011)(011) 12 model without a trend. This was utilized to create the following abrupt, permanent impact assessment mode 1 .

D.12) $\operatorname{Ln}\left(Y_{t}\right)=\omega_{0} I_{54}+\frac{\left(1-\theta_{1} B\right)\left(1-\theta_{12} B^{12}\right)}{(1-B)\left(1-B^{12}\right)}$ at 
Parameter estimates for this model were:

\begin{tabular}{lrr} 
& Estimate & \multicolumn{1}{c}{ T-Value } \\
$\theta_{1}$ & .7295 & 12.11 \\
$\theta_{12}$ & .8888 & 32.68 \\
$\omega_{0}$ & -.1195 & -2.54
\end{tabular}

Residual Sum of Squares

.541876

Degrees of Freedom

The estimates of $\theta_{1}$ and $\theta_{12}$ were statistically significant and within the bounds of invertibility. The intervention estimate $\omega_{0}$ was also statistically significant at the .05 level for a one-tail test. The ACF of this model (Figure 79) indicated that the residuals were no different than white noise. Thus, the model was acceptable.

The introduction of the intervention component into the time series also causeda signiflcant decline in the model unexplained variance. The calculated $F$ statistic for the change in the residual sum of squares is 5.21 with $1 / 116$ degrees of freedom. 4

It was concluded that the crime prevention advertising program was associated with an 11.26 per cent abrupt and permanent decline in reported rapes.5 The preintervention monthly mean for rapes was 68.6 . Therefore, this percentage change represents a reduction of approximately eight rapes per month.

$$
\begin{aligned}
& { }^{4} \mathrm{~F}=\frac{\operatorname{SSE}(\mathrm{R})-\operatorname{SSE}(\mathrm{F}) /(\mathrm{N}-\mathrm{Q})-(\mathrm{N}-\mathrm{P})}{\operatorname{SSE}(\mathrm{F}) / \mathrm{N}-\mathrm{P}}=\frac{(.566212-.541876) /(117-116)}{.541876 / 116}=5.21 \\
& 5 e^{-1 t} ; e^{-.1195}=.88736 ; \% \text { change }=.88736-1.0=11.26 \%
\end{aligned}
$$


VARTABLE IS RAPE

PLOT OF AUTOCORRELATIONS

\begin{tabular}{|c|c|c|c|c|c|c|c|c|c|c|c|c|}
\hline Iag & Corr. & $\begin{array}{c}-1.0 \\
+ \\
\end{array}$ & $\begin{array}{c}-0.8 \\
+ \\
\end{array}$ & $\begin{array}{c}-0.6 \\
+\quad \\
\end{array}$ & $\begin{array}{r}-0.4 \\
+ \\
\end{array}$ & $\begin{array}{c}-0.2 \\
+ \\
\end{array}$ & $\begin{array}{c}0.0 \\
+ \\
\end{array}$ & $\begin{array}{c}0.2 \\
+ \\
\end{array}$ & $\begin{array}{c}0.4 \\
+ \\
\end{array}$ & $\begin{array}{c}0.6 \\
+ \\
\end{array}$ & $\begin{array}{c}0.8 \\
+ \\
\end{array}$ & $\begin{array}{c}1.0 \\
+ \\
\end{array}$ \\
\hline I & 0.085 & & & & & + & IXX - & + & & & & \\
\hline 2 & -0.058 & & & & & + & $\mathrm{XI}$ & + & & & & \\
\hline 3 & 0.016 & & & & & + & $I$ & + & & & & \\
\hline 4 & 0.042 & & & & & + & XI & + & & & & \\
\hline 5 & -0.093 & & & & & & $\mathrm{XXI}$ & + & & & & \\
\hline 6 & -0.030 & & & & & + & XI & + & & & & \\
\hline 7 & -0.027 & & & & & + & $X I$ & + & & & & \\
\hline 8 & 0.042 & & & & & + & IX & + & & & & \\
\hline 9 & 0.089 & & & & & + & IXX + & + & & & & \\
\hline 10 & 0.032 & & & & & + & IX & + & & & & \\
\hline 11 & -0.110 & & & & & & XXXI & + & & & & \\
\hline 12 & 0.052 & & & & & + & IX & + & & & & \\
\hline 13 & -0.050 & & & & & & XI & + & & & & \\
\hline 14 & -0.131 & & & & & & $\mathrm{XXXI}$ & + & & & & \\
\hline 15 & -0.103 & & & & & & XXXI & + & & & & \\
\hline 16 & 0.075 & & & & & + & IXX & + & & & & \\
\hline 17 & 0.114 & & & & & + & IXXX & $x+$ & & & & \\
\hline 18 & 0.007 & & & & & + & I & + & & & & \\
\hline 19 & -0.043 & & & & & + & $X I$ & + & & & & \\
\hline 20 & -0.021 & & & & & + & $\mathrm{XI}$ & + & & & & \\
\hline 21 & 0.017 & & & & & + & I & + & & & & \\
\hline 22 & -0.056 & & & & & + & $X I$ & + & & & & \\
\hline 23 & 0.028 & & & & & + & IX & + & & & & \\
\hline 24 & -0.056 & & & & & + & $X I$ & + & & & & \\
\hline 25 & 0.095 & & & & & + & IXX & + & & & & \\
\hline 26 & 0.090 & & & & & + & IXX & + & & & & \\
\hline 27 & -0.031 & & & & & + & $X I$ & + & & & & \\
\hline 28 & -0.017 & & & & & + & $I$ & + & & & & \\
\hline 29 & 0.065 & & & & & + & IXX & + & & & & \\
\hline 30 & -0.071 & & & & & + & $X X I$ & + & & & & \\
\hline 31 & -0.188 & & & & & $+x$ & $\mathrm{XXXI}$ & + & & & & \\
\hline 32 & 0.003 & & & & & + & I & + & & & & \\
\hline 33 & -0.019 & & & & & + & I & + & & & & \\
\hline 34 & -0.113 & & & & & $+x$ & $\mathrm{XXXI}$ & + & & & & \\
\hline 35 & -0.021 & & & & & + & $X I$ & + & & & & \\
\hline 36 & -0.079 & & & & & & $X X I$ & + & & & & \\
\hline
\end{tabular}

Fig. 79--Rape Interrupted Time Series Residuals Abrupt, Permanent Intervention

Logged (011) (011) 12 1971-1981 
Assault

A logged ARIMA $(011)(001)_{8}(011) 12$ model was built for the noise component of the assault time series. The full impact assessment model for an abrupt permanent change is

D.13) $\operatorname{Ln}\left(y_{t}\right)=\omega_{0} I_{54}+\frac{\left(1-\theta_{1} B\right)\left(1-\theta_{8} B^{8}\right)\left(1-\theta_{12} B^{12}\right)}{(1-B)\left(1-B^{12}\right)}$ at

parameter estimates of this model are:

$\begin{array}{lcc} & \text { Estimate } & \text { T-Value } \\ \theta_{1} & .4299 & 5.36 \\ \theta_{8} & .3244 & 3.95 \\ { }_{12}^{12} & .9052 & 32.17 \\ { }_{0}^{0} & -.04914 & -1.34\end{array}$

Residual Sum of Squares

Degrees of Freedom .206771

115

The noise model parameter estimates were acceptable and the residuals of this model indicated that they were not different from white noise (Figure 80). The .003023 decline in the residual sum of squares from .209794 to .206771 was not particularly large. The calculated F Ratio is 1.68 with $1 / 115$ degrees of freedom. It is only significant at the .25 level of probability. However, stnce the parameter estimate for $\omega_{0}$ was statistically significant at the .10 level for a one-tail test, the model was accepted.

The parameter estimates indicate that at the outset of the advertising program, there was a 4.8 per cent abrupt and permanent decline in reported assalits. This equates to roughly 22 fewer assaults per month. 
PLOT OF AUTOCORRELATIONS

\begin{tabular}{|c|c|c|c|c|c|c|c|c|c|c|c|}
\hline Lag. & Corr. & $\begin{array}{c}-1.0 \\
+ \\
\end{array}$ & $\begin{array}{c}-0.8 \\
+ \\
\end{array}$ & $\begin{array}{cc}-0.6 & -0.4 \\
+ & + \\
\end{array}$ & $\begin{array}{c}-0.2 \\
+ \\
\end{array}$ & $\begin{array}{c}0.0 \\
+ \\
\end{array}$ & $\begin{array}{c}0.2 \\
+\quad \\
\end{array}$ & $\begin{array}{c}0.4 \\
+ \\
\end{array}$ & $\begin{array}{c}0.6 \\
+ \\
\end{array}$ & $\begin{array}{c}0.8 \\
+ \\
\end{array}$ & $\begin{array}{c}1.0 \\
+ \\
\end{array}$ \\
\hline 1 & -0.017 & & & & + & I & + & & & & \\
\hline 2 & -0.009 & & & & + & I & + & & & & \\
\hline 3 & 0.095 & & & & + & IXX & + & & & & \\
\hline 4 & 0.004 & & & & + & $I$ & + & & & & \\
\hline 5 & -0.026 & & & & + & $+\quad X I$ & + & & & & \\
\hline 6 & -0.074 & & & & + & $+\mathrm{XXI}$ & + & & & & \\
\hline 7 & 0.099 & & & & + & $+\quad I X X$ & + & & & & \\
\hline 8 & 0.015 & & & & + & I & + & & & & \\
\hline 9 & -0.037 & & & & + & $+\quad X I$ & + & & & & \\
\hline 10 & 0.011 & & & & + & $+I$ & + & & & & \\
\hline 11 & 0.014 & & & & + & $I I$ & + & & & & \\
\hline 12 & $-0.06 I$ & & & & + & $+X X I$ & + & & & & \\
\hline 13 & 0.064 & & & & + & IX & + & & & & \\
\hline 14 & 0.032 & & & & + & IX & + & & & & \\
\hline 15 & -0.090 & & & & + & XXI & + & & & & \\
\hline 16 & 0.007 & & & & + & $+\quad I$ & + & & & & \\
\hline 17 & 0.084 & & & & + & IXX & + & & & & \\
\hline 18 & -0.037 & & & & + & $\mathrm{XI}$ & + & & & & \\
\hline 19 & 0.006 & & & & + & I & + & & & & \\
\hline 20 & 0.063 & & & & + & IXX & + & & & & \\
\hline 21 & 0.069 & & & & + & IXX & + & & & & \\
\hline 22 & 0.033 & & & & + & IX & + & & & & \\
\hline 23 & 0.141 & & & & + & IXXX & $\mathrm{xX}+$ & & & & \\
\hline 24 & 0.046 & & & & + & IX & + & & & & \\
\hline 25 & 0.050 & & & & + & IX & + & & & & \\
\hline 26 & 0.042 & & & & + & IX & + & & & & \\
\hline 27 & 0.884 & & & & + & IXX & + & & & & \\
\hline 28 & 0.886 & & & & + & I & + & & & & \\
\hline 29 & -0.040 & & & & + & XI & + & & & & \\
\hline 30 & 0.016 & & & & + & I & + & & & & \\
\hline 31 & 0.002 & & & & + & I & + & & & & \\
\hline 32 & -0.120 & & & & + & XXXI & + & & & & \\
\hline 33 & 0.089 & & & & + & IX & + & & & & \\
\hline 34 & -0.082 & & & & + & $\mathrm{XXI}$ & + & & & & \\
\hline 35 & -0.086 & & & & + & I & + & & & & \\
\hline 36 & -0.020 & & & & + & I & + & & & & \\
\hline
\end{tabular}

Fig. 80--Assault Interrupted Time Series Residuals Abrupt, Permanent Intervention

$$
\begin{aligned}
\text { Logged } & (011)(011) \\
1971-1981 & 8^{(011)} 12
\end{aligned}
$$




\section{Robbery}

The stochastic ARIMA model developed for the robbery time series had moving average parameters operating at lags $(1,6,8$, and 12$)$ and autoregressive components at lags ( 1 and 12 ). The mean of the differenced series was 4.8 with a t-value of 1.4. Since it was marginally significant, it was retained in the full model.

An abrupt, permanent change is modeled as:

D.14)

$$
\begin{aligned}
& \left(1-{ }_{1} \mathrm{~B}\right)\left(1-{ }_{\left.12 B^{12}\right) y_{t}}={ }^{w_{0}}{ }_{54}+\frac{\theta_{0}+\left(1-\theta_{1} B\right)\left(1-\theta_{6} B^{6}\right)\left(1-\theta_{8} B^{8}\right)\left(1-\theta_{12} B^{12}\right)}{(1-B)} a_{t}\right. \\
& \text { Parameter estimates were computed to be: }
\end{aligned}
$$

$\begin{array}{lcr} & \underline{\text { Estimate }} & \underline{\text { T-Value }} \\ \theta_{0} & 0.1131 & 1.41 \\ \theta_{1} & 0.9047 & 15.32 \\ \theta_{6} & 0.1874 & 1.99 \\ \theta_{8} & 0.1722 & 1.85 \\ \theta_{12} & 0.6993 & 6.45 \\ \phi_{1} & 0.5517 & 5.13 \\ \phi_{12} & 0.8757 & 15.61 \\ \omega_{0} & -49.70 & -1.76\end{array}$

Residual Sum of Squares Degrees of Freedom

$170,136.4375$ 110

The model residuals (Figure 81 ) were not different from white noise and all nolse parameters were within the bounds of invertibility and stationarity. The estimates for $\theta_{0}, \theta_{6}$ and ${ }_{8} 8$ were again only marginally significant, but it was decided not to eliminate them from thr nodel. The estimate of the parameter $\omega_{0}$ was statistically significant at a .05 
VARIABLE IS ROBBERY

PLOT OF AUTOCORRELATIONS

\begin{tabular}{|c|c|c|c|c|c|c|c|c|c|c|c|c|}
\hline Ixag & Corr. & $\begin{array}{c}-1.0 \\
+ \\
\end{array}$ & $\begin{array}{c}-0.8 \\
+ \\
\end{array}$ & $\begin{array}{c}-0.6 \\
+ \\
\end{array}$ & $\begin{array}{c}-0.4 \\
+ \\
\end{array}$ & $\begin{array}{c}-0.2 \\
+ \\
\end{array}$ & $\begin{array}{c}0.0 \\
+ \\
\end{array}$ & $\begin{array}{c}0.2 \\
+\quad \\
\end{array}$ & $\begin{array}{c}0.4 \\
+ \\
\end{array}$ & $\begin{array}{c}0.6 \\
+ \\
\end{array}$ & $\begin{array}{c}0.8 \\
+ \\
\end{array}$ & $\begin{array}{c}1.0 \\
+ \\
\end{array}$ \\
\hline 1 & 0.001 & & & & & + & $I$ & + & & & & \\
\hline 2 & -0.046 & & & & & + & $\mathrm{XI}$ & + & & & & \\
\hline 3 & 0.009 & & & & & + & I & + & & & & \\
\hline 4 & -0.011 & & & & & + & $I$ & + & & & & \\
\hline 5 & -0.047 & & & & & + & $\mathrm{XI}$ & + & & & & \\
\hline 6 & 0.019 & & & & & + & $I$ & + & & & & \\
\hline 7 & 0.041 & & & & & + & IX & + & & & & \\
\hline 8 & 0.014 & & & & & + & I & + & & & & \\
\hline 9 & -0.146 & & & & & & XXXI & + & & & & \\
\hline 10 & 0.134 & & & & & + & $\operatorname{IXXX}$ & & & & & \\
\hline 11 & 0.062 & & & & & + & IXX & + & & & & \\
\hline 12 & -0.091 & & & & & + & $X X I$ & + & & & & \\
\hline 13 & 0.065 & & & & & + & IXX & + & & & & \\
\hline 14 & 0.087 & & & & & + & IXX & + & & & & \\
\hline 15 & -0.119 & & & & & $+x$ & XXXI & + & & & & \\
\hline 16 & -0.071 & & & & & + & XXI & + & & & & \\
\hline 17 & 0.068 & & & & & + & IXX & + & & & & \\
\hline 18 & 0.003 & & & & & + & I & + & & & & \\
\hline 19 & 0.035 & & & & & + & $X I$ & + & & & & \\
\hline 20 & -0.027 & & & & & + & $\mathrm{XI}$ & + & & & & \\
\hline 21 & 0.107 & & & & & + & IXXX & $x+$ & & & & \\
\hline 22 & 0.023 & & & & & + & IX & + & & & & \\
\hline 23 & 0.035 & & & & & + & IX & + & & & & \\
\hline 24 & 0.105 & & & & & + & IXXX & $x+$ & & & & \\
\hline 25 & 0.042 & & & & & + & $\mathrm{XI}$ & + & & & & \\
\hline 26 & -0.032 & & & & & + & $X I$ & + & & & & \\
\hline 27 & -0.011 & & & & & + & I & + & & & & \\
\hline 28 & -0.025 & & & & & + & $X I$ & + & & & & \\
\hline 29 & -0.164 & & & & & $+X X$ & $\mathrm{XXXI}$ & + & & & & \\
\hline 30 & -0.205 & & & & & $\mathrm{XXX}$ & XXXI & + & & & & \\
\hline 31 & 0.112 & & & & & + & IXXX & $x+$ & & & & \\
\hline 32 & -0.013 & & & & & + & I & + & & & & \\
\hline 33 & -0.057 & & & & & + & XI & + & & & & \\
\hline 34 & 0.024 & & & & & + & IX & + & & & & \\
\hline 35 & 0.017 & & & & & + & I & + & & & & \\
\hline 36 & -0.023 & & & & & + & XI & + & & & & \\
\hline
\end{tabular}

Fig. 81--Robbery Interrupted Time Series Residuals Abrupt, Permanent Intervention

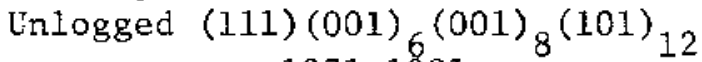


level of probability for a one-tail test. Thus the model as shown was accepted. However, the decline in the residual sum of squares was only 3.4 per cent or 5955 . This resulted in a calculated F Ratio of 1.93 with $2 / 110$ degrees of freedom which is significant at the .25 level of probability.

This model suggested that the crime prevention advertising program was associated with an abrupt and permanent decline in the level of reported robberies. The impact was estimated to be approximately 50 robberies per month.

\section{Auto Theft}

An ARIMA (011)(011) 12 model was created to describe the stochastic component of the auto theft time series. The full model of an abrupt, permanent intervention is denoted as follows.

$$
\begin{aligned}
& \text { D.15) } y_{t}=\omega_{0} I_{54}+\frac{\left(1-\theta_{1} B\right)\left(1-\theta_{12} B^{12}\right)}{(1-B)\left(1-B^{12}\right)} \text { at } \\
& \text { The parameter estimates are: }
\end{aligned}
$$

$\begin{array}{lcr} & \text { Estimate } & \text { T-Value } \\ \theta_{1}^{1} & 0.4057 & 5.19 \\ 12 & 0.8553 & 27.04 \\ 0 & -78.43 & -1.31\end{array}$

Residual Sum of Squares Degrees of Freedom
513,736 116

The residual decline in unexplained variance from 518,718 to 513,736 was not statistically significant. The calculated F-Ratio was only 1.13 with $1 / 116$ degrees of 
freedom. Nevertheless, the noise component parameter estimates were statistically significant at the .05 level of probabiltty for a two-tail test and o was statistically significant at the . 10 level for a one-tail test. Model residuals depicted in Figure 82 were no different than white noise. Thus, the abrupt, permanent impact model was deemed appropriate. Using this model it is estinated that the level of auto thefts dropped by over 78 per month after the implementation of the crime prevention program.

\section{Burglary}

The logged burglary time series was tentatively estimated to be an ARIMA (111)(011) l2 Mode1 with no trend. Utilizing this as the stochastic component, a full abrupt, permanent impact model would be depicted as follows:

$$
\begin{aligned}
& \left(I-\phi_{1} B\right) \operatorname{Ln}(y)=\omega_{0} I_{54}+\frac{\left(1-\theta_{1} B\right)\left(1-\theta_{12} B^{12}\right)}{(1-B)\left(1-B^{12}\right)} \text { at } \\
& \text { Parameter estimates were calculated to be: }
\end{aligned}
$$

$\begin{array}{lcr} & \text { Estimate } & \text { T-Value } \\ 11 & .6817 & 4.81 \\ \theta_{1}^{12} & .8707 & 28.73 \\ \omega_{0}^{1} & .4093 & 2.31 \\ 0 & -.03946 & -1.64\end{array}$

Residual Sum of Squares

Degrees of Freedom

0.077144

114

The wo estimate was significant at the .10 level of probability for a one-tail test. The other parameters were statistlcally significant and otherwise acceptable. Model 
VARIABLE IS AUTO THEFT

PLOT OF AUTOCORRELATIONS

\begin{tabular}{|c|c|c|c|c|c|c|c|c|c|c|c|c|}
\hline Lag & Corr. & $\begin{array}{c}-1.0 \\
+\end{array}$ & $\begin{array}{c}-0.8 \\
+\end{array}$ & $\begin{array}{c}-0.6 \\
+\end{array}$ & $\begin{array}{c}-0.4 \\
+\end{array}$ & $\begin{array}{c}-0.2 \\
+\end{array}$ & $\begin{array}{c}0.0 \\
+ \\
\end{array}$ & $\begin{array}{c}0.2 \\
+ \\
\end{array}$ & $\begin{array}{c}0.4 \\
+ \\
\end{array}$ & $\begin{array}{c}0.6 \\
+ \\
\end{array}$ & $\begin{array}{c}0.8 \\
+ \\
\end{array}$ & $\begin{array}{c}1.0 \\
+ \\
\end{array}$ \\
\hline 1 & 0.017 & & & & & + & I & + & & & & \\
\hline 2 & -0.089 & & & & & + & $\mathrm{XXI}$ & + & & & & \\
\hline 3 & 0.050 & & & & & + & IX & + & & & & \\
\hline 4 & -0.036 & & & & & + & XI & + & & & & \\
\hline 5 & 0.088 & & & & & + & IXX & + & & & & \\
\hline 6 & -0.085 & & & & & + & $\mathrm{XXI}$ & + & & & & \\
\hline 7 & 0.028 & & & & & + & IX & + & & & & \\
\hline 8 & -0.010 & & & & & + & I & + & & & & \\
\hline 9 & -0.103 & & & & & & XXXI & + & & & & \\
\hline 10 & 0.074 & & & & & + & IXX & + & & & & \\
\hline 11 & -0.082 & & & & & & $X X I$ & + & & & & \\
\hline 12 & -0.072 & & & & & & $X X I$ & + & & & & \\
\hline 13 & -0.122 & & & & & & $\mathrm{XXXI}$ & + & & & & \\
\hline 14 & -0.006 & & & & & + & I & + & & & & \\
\hline 15 & 0.054 & & & & & + & IX & + & & & & \\
\hline 16 & 0.002 & & & & & + & I & + & & & & \\
\hline 17 & -0.041 & & & & & + & $X I$ & + & & & & \\
\hline 18 & -0.046 & & & & & + & $\mathrm{XI}$ & + & & & & \\
\hline 19 & 0.016 & & & & & + & I & + & & & & \\
\hline 20 & -0.025 & & & & & + & $X I$ & + & & & & \\
\hline 21 & 0.009 & & & & & + & I & + & & & & \\
\hline 22 & 0.034 & & & & & + & IX & + & & & & \\
\hline 23 & 0.095 & & & & & + & IXX & + & & & & \\
\hline 24 & 0.059 & & & & & + & IX & + & & & & \\
\hline 25 & 0.042 & & & & & + & IX & + & & & & \\
\hline 26 & 0.033 & & & & & + & IX & + & & & & \\
\hline 27 & -0.067 & & & & & + & XXI & + & & & & \\
\hline 28 & -0.001 & & & & & + & I & + & & & & \\
\hline 29 & -0.067 & & & & & + & XXI & + & & & & \\
\hline 30 & -0.066 & & & & & + & XXI & + & & & & \\
\hline 31 & 0.042 & & & & & + & IX & + & & & & \\
\hline 32 & 0.012 & & & & & + & I & + & & & & \\
\hline 33 & 0.014 & & & & & + & I & + & & & & \\
\hline 34 & -0.150 & & & & & $+\mathrm{Xx}$ & $\mathrm{XXXI}$ & + & & & & \\
\hline 35 & -0.153 & & & & & & XXXI & + & & & & \\
\hline 36 & -0.023 & & & & & + & $X I$ & + & & & & \\
\hline
\end{tabular}

Fig. 82--Auto Theft Interrupted Time Series Residuals Abrupt, Permanent Intervention Unlogged (011)(011) 12

1971-1981 
residuals displayed in Figure 83 indicated that they were no different from white noise and thus the model was acceptable.

The decline in unexplained variance of .002748 was likewise significant. The calculated F ratio was 4.06 with $1 / 114$ degrees of freedom. These results suggested that a 3.9 per cent decline occurred in reported burglaries when the advertising program was implemented. This equates to an average of 85 burglaries per month.

\section{Larceny}

The ARIMA (011)(011)6(011)12 untrended model of the logged data was used in the assessment of the program impact upon reported larceny. An abrupt, permanent intervention is modeled as follows.

D.17) Ln $\left(Y_{t}\right)=\omega_{0} \operatorname{I5} \frac{\left(1-e_{1} B\right)\left(1-\theta_{6} B^{6}\right)\left(1-\theta_{12} B^{12}\right)}{(1-B)(1-B) 6(1-B 12)} \quad a_{t}$

$\begin{array}{lcc} & \text { Estimate } & \text { T-Value } \\ { }_{\theta}^{\theta} 1 & .2592 & 2.97 \\ { }_{0} & .5825 & 7.04 \\ { }_{6}^{12} & .8381 & 20.26 \\ \omega_{0}^{12} & .0005 & 0.03\end{array}$

Residual sum of Squares

Degrees of Freedom

.087273

109

This model indicated that the crime prevention program had no impact upon the occurrence of larceny. This result was unexpected considering its apparent impact upon other forms of major crime. Further investigation into the nature 
VARIABLE IS BURGLARY

PLOT OF AUTOCORRELATIONS

\begin{tabular}{|c|c|c|c|c|c|c|c|c|c|c|c|c|}
\hline Lag & Corr. & $\begin{array}{c}-1.0 \\
+ \\
\end{array}$ & $\begin{array}{c}-0.8 \\
+ \\
\end{array}$ & $\begin{array}{c}-0.6 \\
+ \\
\end{array}$ & $\begin{array}{c}-0.4 \\
+ \\
\end{array}$ & $\begin{array}{c}-0.2 \\
+ \\
\end{array}$ & $\begin{array}{c}0.0 \\
+ \\
\end{array}$ & $\begin{array}{c}0.2 \\
+ \\
\end{array}$ & $\begin{array}{c}0.4 \\
+ \\
\end{array}$ & $\begin{array}{c}0.6 \\
+ \\
\end{array}$ & $\begin{array}{c}0.8 \\
+ \\
\end{array}$ & $\begin{array}{c}1.0 \\
+ \\
\end{array}$ \\
\hline 1 & 0.047 & & & & & + & I & + & & & & \\
\hline 2 & -0.034 & & & & & + & $\mathrm{XI}$ & + & & & & \\
\hline 3 & -0.113 & & & & & & $X X I$ & + & & & & \\
\hline 4 & 0.003 & & & & & + & $I$ & + & & & & \\
\hline 5 & -0.004 & & & & & + & I & + & & & & \\
\hline 6 & 0.119 & & & & & + & IXXX & & & & & \\
\hline 7 & -0.031 & & & & & + & $\mathrm{XI}$ & + & & & & \\
\hline 8 & -0.036 & & & & & + & XI & + & & & & \\
\hline 9 & 0.002 & & & & & + & $I$ & + & & & & \\
\hline 10 & -0.100 & & & & & + & XXI & + & & & & \\
\hline 11 & -0.039 & & & & & + & $X I$ & + & & & & \\
\hline 12 & -0.073 & & & & & + & XXI & + & & & & \\
\hline 13 & -0.054 & & & & & + & $X I$ & + & & & & \\
\hline 14 & 0.082 & & & & & + & IXX & + & & & & \\
\hline 15 & 0.029 & & & & & + & IX & + & & & & \\
\hline 16 & 0.058 & & & & & + & IX & + & & & & \\
\hline 17 & 0.120 & & & & & + & $\operatorname{IXXX}$ & $x+$ & & & & \\
\hline 18 & 0.019 & & & & & + & I & + & & & & \\
\hline 19 & -0.059 & & & & & + & $\mathrm{XI}$ & + & & & & \\
\hline 20 & 0.041 & & & & & + & IX & + & & & & \\
\hline 21 & 0.153 & & & & & + & IXXXI & $x x+$ & & & & \\
\hline 22 & -0.050 & & & & & + & $\mathrm{XI}$ & + & & & & \\
\hline 23 & 0.017 & & & & & + & I & + & & & & \\
\hline 24 & -0.112 & & & & & $+y$ & XXI & + & & & & \\
\hline 25 & -0.033 & & & & & + & XI & + & & & & \\
\hline 26 & -0.006 & & & & & + & I & + & & & & \\
\hline 27 & -0.029 & & & & & + & $\mathrm{XI}$ & + & & & & \\
\hline 28 & -0.054 & & & & & + & XI & + & & & & \\
\hline 29 & -0.028 & & & & & + & XI & + & & & & \\
\hline 30 & -0.172 & & & & & $+X$ & XXI & + & & & & \\
\hline 31 & -0.003 & & & & & + & I & + & & & & \\
\hline 32 & 0.122 & & & & & + & IXXX & $x+$ & & & & \\
\hline 33 & -0.049 & & & & & + & $X I$ & + & & & & \\
\hline 34 & 0.019 & & & & & + & I & + & & & & \\
\hline 35 & 0.007 & & & & & + & I & + & & & & \\
\hline 36 & -0.181 & & & & & $\mathrm{XXX}$ & XXI & + & & & & \\
\hline
\end{tabular}

Fig. 83--Burglary Interrupted Time Series Residuals Abrupt, Permanent Intervention Logged (111)(011) 12 
of the reported thefts suggested that perhaps the time series intervention results were being confounded by a second event that had occurred prior to the inception of the advertising campatgn.

Civilian band radios experienced an explosion in popularity in the mid $1970^{\prime} \mathrm{s}$. The C.B. sales boom began with the Arab oil embargo. One million units were sold in 1973. Sales then more than doubled in each subsequent year until 1976, when the sales volume reached its highest level of $11 \mathrm{mill}$ ion. 6

As C.B.'s galned consumer popularity, there was also a significant increase in their theft. Thus, it was decided to include a second intervention variable modeled in the gradual permanent manner to depict this phenomena. The resultant model is

D.18)

$$
\begin{aligned}
& \operatorname{Ln}\left(Y_{t}\right)=\omega_{O_{1}} I_{54}+\frac{\omega o_{x 2}}{1-f_{1_{x}} B} I_{40}+\frac{\left(1-\theta_{1} B\right)\left(1-\theta_{6} B^{6}\right)\left(1-\theta_{12} B\right)^{12}}{(1-B)\left(1-B^{6}\right)\left(1-B^{12}\right)} \text { at } \\
& \text { Parameter estimates for this model were }
\end{aligned}
$$

$\begin{array}{lrr} & \text { Estimate } & \text { T-Value } \\ { }^{\theta} \theta_{6} & .2981 & 3.38 \\ { }^{6} & .6784 & 8.17 \\ \omega^{\circ} & .8118 & 16.48 \\ \omega^{\circ} \times 1 & .0029 & 0.12 \\ f_{1 \times 2}^{\circ} & .0189 & 1.74 \\ 1 \times 2 & .8927 & 8.69\end{array}$

Residual Sum of Squares Degrees of Freedom 
These parameter estimates confirmed the fact that C.B. radios did have a positive impact upon reported thefts. The increased popularity of C.B.'s was associated with a full 19.3 per cent increase in larceny. However, the crime prevention program intervention still proved inconsequential.

$$
\text { Since the C.B. radio sales boom occurred just prior to }
$$
the program implementation, it was hypothesized that additional time was needed for potential victims to percelve the new threat and to alter their behavior. Thus, a third model was created in which the program intervention was modeled to only occur after the full impact of the advertising campaign had been experienced. This model was writen in the following fashion.

D.19)

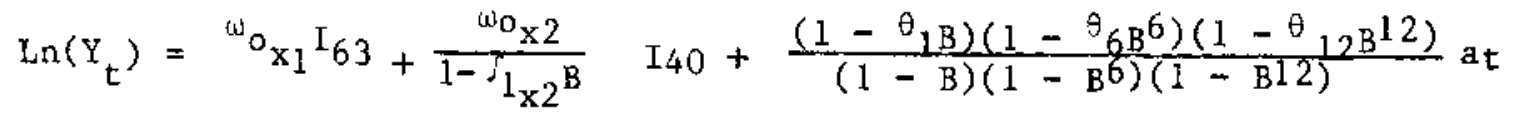

$$
\begin{aligned}
& \text { Parameter estimates for this model were }
\end{aligned}
$$

$\begin{array}{lcr} & \text { Estimate } & \text { T-Value } \\ \theta_{1} & .3206 & 3.68 \\ \theta_{6} & .6739 & 8.15 \\ { }_{12} & .8126 & 16.49 \\ \omega_{0} \times 1 & -.0455 & -1.97 \\ \omega^{0} \times 2 & .01781 & 1.81 \\ f_{1 \times 2}^{0} & .9034 & 10.30\end{array}$

Residual Sum of Squares

Degrees of Freedom

$$
\begin{gathered}
0.082444 \\
107
\end{gathered}
$$


All parameter estimates were statistically significant and the model appeared to be stationary. The ACF for this model indicated that the residuals were no different than white noise (Figure 84 ). The F Ratio for the change in unexplained variance was 2.10 and was significant at the .25 1.evel of probability.

The model suggested that the C.B. radio fad created a 20.2 per cent gradual but permanent increase in reported thefts and the ad campaign was associated with a 4.5 per cent decline. This decline amounted to a reduction in reported larcenies of 175 per month.

Conclusion

Research results indicated that the crime prevention advertising program was assoclated with an abrupt and permanent reduction in all types of major crime in Dallas except murder. Thus, alteration of a potential victim's pattern of behavior through repeated advertising apparenty resulted in less situations occurring where the potential criminal located a suitable target and consumated the illegal act.

The implications of this conclusion are significant. If this is the case, crime could be reduced not only through public efforts aimed at the criminal element of society, but also through programs directed at the potential victim. Further testing of this hypothesis through program replication certainly seems warranted. 
VARIABLE IS LARCENY

PLOT OF AUTOCORRELATIONS

\begin{tabular}{|c|c|c|c|c|c|c|c|c|c|c|c|c|}
\hline Lag & Corr. & $\begin{array}{r}-1.0 \\
+ \\
\end{array}$ & $\begin{array}{c}-0.8 \\
+ \\
\end{array}$ & $\begin{array}{c}-0.6 \\
+ \\
\end{array}$ & $\begin{array}{c}-0.4 \\
+ \\
\end{array}$ & $\begin{array}{c}-0.2 \\
+ \\
\end{array}$ & $\begin{array}{c}0.0 \\
+ \\
\end{array}$ & $\begin{array}{c}0.2 \\
+ \\
\end{array}$ & $\begin{array}{r}0.4 \\
+ \\
\end{array}$ & $\begin{array}{c}0.6 \\
+ \\
\end{array}$ & $\begin{array}{c}0.8 \\
+ \\
\end{array}$ & $\begin{array}{c}1.0 \\
+ \\
\end{array}$ \\
\hline 1 & -0.002 & & & & & + & I & + & & & & \\
\hline 2 & -0.027 & & & & & + & $X I$ & + & & & & \\
\hline 3 & 0.053 & & & & & + & IX & + & & & & \\
\hline 4 & 0.016 & & & & & + & I & + & & & & \\
\hline 5 & 0.009 & & & & & + & $\mathrm{I}+$ & + & & & & \\
\hline 6 & 0.099 & & & & & + & $\mathrm{IXX}+$ & + & & & & \\
\hline 7 & 0.047 & & & & & + & $I X+$ & + & & & & \\
\hline 8 & 0.030 & & & & & + & IX & + & & & & \\
\hline 9 & -0.082 & & & & & & $\mathrm{XXI}$ & + & & & & \\
\hline 10 & -0.006 & & & & & + & I & + & & & & \\
\hline 11 & 0.035 & & & & & + & IX & + & & & & \\
\hline 12 & -0.100 & & & & & & XXXI & + & & & & \\
\hline 13 & -0.176 & & & & & & XXXI & + & & & & \\
\hline 14 & 0.032 & & & & & + & $I$ & + & & & & \\
\hline 15 & -0.050 & & & & & + & $\mathrm{XI}$ & + & & & & \\
\hline 16 & -0.093 & & & & & + & XXI & + & & & & \\
\hline 17 & 0.053 & & & & & + & IX & + & & & & \\
\hline 18 & -0.017 & & & & & + & I & + & & & & \\
\hline 19 & -0.121 & & & & & $+Y$ & XXXI & + & & & & \\
\hline 20 & 0.101 & & & & & + & IXXX & + & & & & \\
\hline 21 & 0.043 & & & & & + & IX & + & & & & \\
\hline 22 & 0.045 & & & & & + & IX & + & & & & \\
\hline 23 & 0.045 & & & & & + & IX & + & & & & \\
\hline 24 & -0.159 & & & & & & $\mathrm{XXXI}$ & + & & & & \\
\hline 25 & -0.066 & & & & & + & $\mathrm{XXI}$ & + & & & & \\
\hline 26 & 0.071 & & & & & + & IXX & + & & & & \\
\hline 27 & 0.091 & & & & & + & $\operatorname{IXX}$ & + & & & & \\
\hline 28 & 0.031 & & & & & + & IX & + & & & & \\
\hline 29 & -0.033 & & & & & & $X I$ & + & & & & \\
\hline 30 & -0.104 & & & & & & XXXI & + & & & & \\
\hline 31 & 0.006 & & & & & + & I & + & & & & \\
\hline 32 & 0.138 & & & & & + & IXXX & $x+$ & & & & \\
\hline 33 & -0.055 & & & & & + & $\mathrm{XI}$ & + & & & & \\
\hline 34 & -0.020 & & & & & + & $X I$ & + & & & & \\
\hline 35 & -0.004 & & & & & + & I & + & & & & \\
\hline 36 & -0.171 & & & & & & XXXI & + & & & & \\
\hline
\end{tabular}

Fig. 84--Larceny Interrupted Time Series Residuals Abrupt, Permanent Intervention Logged (011) (011) $6{ }^{(011)} 12$ 
B I BL I OGRAPHY 


\section{BI BL I OGRAPHY}

\section{Books}

Ashton, Robert H., Human Information Processing in Accounting, Sarasota, American Accounting Association, 1982 .

Babbie, Earl R., Survey Research Methods, Belmont, Wadsworth Publishing Co., 1973.

Banfield, Edward $C$, The Unheavenly City Revisited, Boston, Little, Brown and Company, 1974 .

Burkhead, Jesse, Governmental Budgeting, New York, John Wiley and Sons, 1956.

Campbe11, Donald T. and Julian C. Stanley, Experimental and Quasi-Experimental Designs for Research, Chicago, Rand McNaIIy College Pub ishing Co., 1963.

Carmines, Edward G. and Richard A. Ze1ler, Reliability and Validity Assessuent, Beverly Hills, Sage Publications, 1979 .

Cook, Thomas D. and Donald T. Campbell, QuasiExperimentation, Chicago, Rand MoNaliy Publishing Co., 1979 .

Dentler, Robert A., Urban Problems: Perspectives and Solutions, Chicago, Rand McNally Publishing Co., 1977.

Gordon, David M., Problems 1n Political Econory: An Urban Perspective, i976.

Haveman, Robert $H$, The Economics of the Public Sector, Santa Barbara, John Wiley and Sons, $\overline{1976 .}$

Henkel, Ramon, Tests of Significance, Beverly Hills, Sage Publications, $19 \overline{76}$.

Hirshleifer, Jack, Prlce Theory and Applications, Englewood Cliff, Prentice-Hali, 1976.

Kerlinger, Fred N., Foundations of Behavioral Research, New York, Holt, Rinehart and Winston, 1973.

Leftwich, Richard H., The Price System and Resource Allocation, New York, Holt, Rinehart and Winston, 1961. 
Leloup, Lance T., Budgetary Politics, Brunswick, King's Court Communications, 1980 .

Libby, Robert, Accounting and Human Information Processing: Theory and Applications, Englewood Cliffs, Prentec-Hall, 1981 .

Lindblom, Charles E., Politics and Markets, New York, Basic Books, 1977 .

Lyden, Fremont $J$. and Ernest G. Miller, Public Budgeting Program Planning and Implementation, Englewood Cliffs, Prentice $\overline{-H a 11,1982 \text {. }}$

Lynch, Thomas D, Public Budgeting in America, Englewood Cliffs, Prentice-Hall, 1979 .

McCleary, Richard and Richard A. Hay, Jr., Applied Time Series Analysis for the Social Sciences, Beverly Hills, Sage Publications, 1980 .

McDowa11, David, Richard McCleary, Errol E. Meidinger, and Richard A. Hay, Jr., Interrupted Time Series Analysis, Beverly Hills, Sage Publications, 1980 .

Mock, Theodore $J$. , Measurement and Accounting Information Criteria, Sarasota, American Accounting Association, 1976 .

Rossi, Peter H., Howard E. Freeman, and Sonia R. Wright, Evaluation, A Systematic Approach, Beverly Hills, Sage Publications, 1979 .

Schick, Allen, perspectives on Budgeting, Washington, D.C., American Society for Public Administration, 1980 .

Schreiber, Arthur F., Paul Gatons, and Richard Clemmer, Economics and Urban Problems, Boston, Houghton Miffin Co., 1976 .

Schultze, Charles L., The Public Use of Private Interest, Washington, D.C., The Brookings Tnstitute, 1977 .

Spector, Paul E., Research Designs, Beverly Hills, Sage Qublications, I98I.

Sterling, Robert R., Theory of the Measurement of Enterprise Income, Lawrence, The University Press of Kansas, 1970. 
Texas Crime Prevention Institute, Principles and Practices of crime Prevention, San Marcos, Southwest Texas state University.

Jrban Institute, Measuring the Effectiveness of Basic Municipal Services, Washington, D.C., February, 1974.

Weisbrod, Burton A., "Conceptual Perspective on the Public Interest: An Economic Analysis", in Public Interest Law, University of California Press, $1982, \overline{4-29}$.

Weiss, Carol H., Evaluation Research, Englewood Cliffs, Prentice-Ha11, 1972 .

Wildavsky, Aaron, The Politics of the Budgetary Process, Boston, Little, Brown and Co., 1979 .

Wilson, James $Q$, and Barbara Boland, "Crime", in The Urban Predicament, Edited by William Gorhat and Nathan Glazer, The Urban Institute, Washington, D.C., 1976, $179-230$.

Articles

Alchian, Armen A. and Harold Demsetz, "Production, Information Costs, and Economic organization", The American Economic Review, LXII (December, 1972), $777-795$.

Balkin, Steven, "Victimization Rates, Safety and Fear of Crime", Social Problems, XXVI (February, 1979), 343-358.

Becker, Gary S., "Crime and Punishment: An Economic Approach", Journal of Political Economy, LXXVI (March/Apri1, 1968), 169-217.

Boggs, Sarah L., "Urban Crime Patterns", American Sociological Review, XXX (1965), 899-908.

Burkhead, Jesse and P.J. Hennlgan, "Productivity Analysis: A Search for Definition and Order", Public Administration Review, (Jan/Feb., 1978), 34-40.

Cameron, K., "Construct Space and Subjectivity Problems in Organizational Effectiveness", Public Productivity Review, (June, 1981), 105-121.

Chapman, Jeffrey $I$., "An Economic Model of Crime and Police: Some Enpirical Results", Journal of Research In Crime and Delinquency, XIII (January, 1976), 48-63. 
Churchman, C. West, "On the Facility, Felicity and Morality of Measuring Social Change", Accounting Review, XLVI (January, 1971), 30-35.

Clotfelter, Charles T., "Public Services, Private Substitutes, and the Demand for Protection Agatnst Crime", The American Economic Review, LXVII (December, $1977), 9 \overline{67-877}$.

Cohen, Lawrence E. and Marcus Felson, "Social Change and Crime Rate Trends: A Routine Activity Approach", American Sociological Review, XLIV (August, 1979), 588-608.

Cohen, Lawrence E., Marcus Felson, and Kenneth C. Land, "property Crime Rates in the United States: A Macrodynamic Analysis, 1947-1977: With Ex Ante Forecasts for the Mid-1980's", American Journal of Sociology, LXXXVI $(1980), 90-11 \overline{8}$.

Cohen, Lawrence E., David Cantor and James R. Kluegel, "Robbery Victimization in the U.S.: An Analysis of a Nonrandon Event", Social Science Quarterly, LXII (December, 1981), $\overline{644-657}$.

Conyers, John, "Criminology, Economics, and Public Policy", Crime and De1inquency, XXV (Apri1, 1979), 137-144.

Danziger, Sheldon and David Wheeler, "The Economics of Crime: Punishment or Income Redistribution", Review of Social Economy, XXXIII (October, 1975), 113-131.

Erskine, Haze1, "The Polls: Fear of Violence and Crime", The Public opinion Quarterly, XXXVIII (1974), 131-145.

Friedlander, Frank and Hal Pickle, "Components of Effectiveness in Small organizations", Administrative Science Quarterly, XIII (1968), 289-304.

Haas, Emanuel, "The Supply and Demand for Municipal Crime Prevention", American Economist, XXIV (Spring, 1980), 10-17.

Hakim, Simon, "The Attraction of Property Crimes to Suburban Localities: A Revised Economic Model", Urban Studies, XVII $(1980), 265-276$.

Harris, Anthony R., "Imprisonment and the Expected Value of Criminal Choice: A Specification and Test of Aspects of the Labeling Perspective", American Sociological Review, XL (February, 1975), 71-87. 
Hatry, Harry P., "Performance Measurement Principles and Techniques", Public productivity Review, IV (December, $1980), 312-339$.

Hatry, Harry P., The Status of Productivity Measurement in the Public Sector", Public Administration Review, ( January/February, $1 \overline{978}$ ), 28-33.

Hemley, David D. and Lee R. McPheters, "Crime as an Externality of Economic Growth", American Economist, XIX (February, 1978), 93-109.

Hurst, E. Gerald, "Attributes of Performance Measures", Public Productivity Review, IV (March, 1980), 43-49.

Jensen, Michael C. and William H. Meckling, "Theory of the Firm: Managerial Behavior, Agency Costs and Ownership Structure", Journal of Financial Economics, III

(october, 1976), 305-360.

Kasarda, John D., "The Impact of Suburban Population Growth on Central City Service Functions", American Journal of Sociology, LXXVII (1972), 1111-1124.

Katzman, Martin T., "The Contribution of Crime and Urban Decline", Urban Studies, XVII (1980), 277-286.

Kennett, David, "The Distribution of Unpriced Public Goods, A Frame with some Enpirical Results for Police Services", American Economist, XXIII (Spring, 1979), $22-27$.

King, Barry G., "Cost-Effectiveness Analysis: Implications for Accountants", The Journal of Accountancy, (March, $1970), 43-49$.

Lavrakas, Paul J. and Dan A. Lewis, "The Conceptualization and Measurement of Citizens' Crime Prevention Behaviors", Journal of Research in Crime and De1inquency, XVII (Ju1y, 1980), $254-272$.

Lee, Barrett A., "The Urban Unease Revisited: Perceptions of Local Safety and Neighborhood Satisfaction Anong Metropolitan Residents", Soctal Sciences quarterly, LXII (December, 1981), 61 $1-629$.

Lewis, Dan A. and Michael G. Manfield, "Fear in the Neighborhoods: An Investigation of the Impact of Crime", Journal of Research in Crime and Delinquency, XVII ( Juî, 1980), $\overline{160-189 .}$ 
Lindblom, Charles E., "Still Muddling, Not Yet Through", Public Administration Review, (November/December, 1979), 517-526.

Mahoney, Thomas A., "Managerial Perceptions of

Organizational Effectiveness", Management Science, XIV $(1967), B 76-91$.

Merry, Sal1y E., "Defensible Space Undefended", Urban Affairs Quarterly, XVI (June, 1981), 397-422.

Mitnick, Barry M., "Regulation and the Theory of Agency", Orbis, $(1982), 442-453$.

Nelson, James F., "Multiple Victimization in American Cities: A Statistical Analysis of Rare Events", American Journal of Sociology, LXXXV (1980), 870-891.

Quinn, Robert E., "Productivity and the Process of Organizational Improvement: Why We Cannot Talk to Each Other", Public Administration Review, ( January/February, 1978), 41-45.

Shichor, David, David Decker, and Robert o'Brien, "Population Density and Criminal Victimization", Criminology, XVII (August, 1979), 184-193.

Sizer, John, "Performance Assessment in Instjtutions of Higher Education Under Conditions of Financial Strengency, Contraction, and Changing Needs: A Management Accounting Perspective", Accounting and Business Research, (Summer, 1981), $2 \overline{27-242}$.

Sorenson, James E, and Hugh D. Grove, "Cost-outcome and Cost-Effectiveness Analysis", The Accounting Review, LII ( Ju1y, 1977), 658-675.

Stafford, Mark C. and Jack Gibbs, "Crime Rates in an Ecological Context: Extension of a Proposition", Social Science Quarter1y, LXI (December, 1980),653-665.

Stahura, John M., Rona1d Huff, and Brent Smith, "Crime in the Suburbs", Urban Affairs Quarterly, XV (March, $1980), 291-315$.

Steers, Richard M. "Problems in the Measurement of Organizational Effectiveness", Administrative Science Quarter1y, XX (December, 1975), 546-557. 
Steinberg, Harold I, and Paul K. Brace, "Financial

Accounting Standards Board Study of Service Efforts and Accomplishments", Government Accountants Journal, XXX (Spring, 1981), $1-10$.

Stipak, Brian, "Citizen Satisfaction with Urban Services: Potential Misuse as a Performance Indlcator", Public Administration Review, (January/February, 1979), 46-52.

Webb, Ronald J., "Organizational Effectiveness and the Voluntary Organization", Academy of Management Journa1, (December, 1974), 663-677.

Whetten, David A., "Coping with Incomplete Expectations: An Integrated View of Role Conflict", Administrative Science Quarterly, XXIII (June, 1978), 254-268.

\section{Reports}

Committee on Measures of Effectiveness for Social Programs, Committee Report, Accounting Review, XLVII (1972), $339-396$.

Committee on Non-Financial Measures of Effectiveness, Comittee Report, Accounting Review, XLVI (1971), 165-211.

Louis, Bowles and Grove, Inc., Tabulations of Replies to Crime Prevention Survey, A Report of a Public opinion Survey conducted for the Dallas Police Department, Dallas, March, 1976.

\section{Publications of professional organizations}

American Institute of Certified Public Accountants, "objectives of Financial Reporting by Business Enterprises", Statement of Financial Accounting Concepts No. 1 , New York, ATCPA, November, 1978.

American Institute of Certifled Public Accountants, "Qualitative Characteristics of Accounting Information", Statement of Financial Accounting Concepts No. 2, New York, A $\overline{\mathrm{ICPA}}$, May, 1980 .

American Institute of Certified Public Accountants, "Objectives of Financial Reporting by Nonbusiness organizations", Statement of Financial Accounting Concepts No. 4, New York, AICPA, December, 1980 . 
Anthony, Robert N., Financial Accounting in Nonbusiness Organizations, Financial Accounting Standards Board, 1978 .

Financial Accounting Standards Board, Objectives of Financial Reporting by Nonbusiness Organizations, December, I 980 .

\section{Public Documents}

Duncan, J. T., Citizen Crime Prevention Tactics, U.S. Department of Justice, National Institute of Justice, Apr11, 1980 .

Dunn, Christopher, The Patterns and Distribution of Assaut Incident Characteristics Among Social Areas, U.S. Department of Justice, Law Enforcement Assistance Administration, National Criminal Justice Information and Statistics Service, 1976.

Gibbs, John, Crime Against Persons- In Urban, Suburban and Rural Areas: A Comparative Ana1ysis of Victimization Rates, U.S. Department of Justice, Law Enforcement Assistance Administration, National Criminal Justice Information and Statistical Service, 1979.

Heller, Nelson B., William W. Stenzel, Allen D. Gill, Richard A. Kolde, Stanley R. Schimermar, Operation Identification Projects: Assessment of Effectiveness, U.S. Department of Justice, Law Enforcement Assistance Administration, National Institute of $L_{a}$ aw Enforcement and Criminal Justice, August, 1975.

Hellman, Daryl A. and Joel Naroff, The Urban Public Sector and Urban Crime: A Simultaneous System Approach, U.S. Department of Justice, National Institute of Justice, November, 1980 .

Sagalyn, Arnold, Restdential Security, U.S. Department of Justice, Law Enforcement Assistance Administration, National Institute of Law Enforcement and Criminal Justice, December, 1973.

U.S. Department of Justice, Crime and Seasonality, National Institute of Law Enforcement and Criminal Justice, 1980 .

U.S. Department of Justice, Crime Prevention Security Surveys, Phase I Report, National Institute of Law Enforcement and Criminal Justice, Law Enforcement Assistance Administration, January, 1977 . 
U.S. Department of Justice, Criminal Victimization in the U. December, 1980 .

U.S. Department of Justice, Criminal Victimization Surveys in Elght American Cities, National Institute of Law Enforcement and Criminal Justice, 1976.

U.S. Department of Justice, Reducing Residertial Crime and Fear: The Hartford Neighborhood Crime Prevention Program, National Institute of Law Enforcement and Criminal Justice.

U.S. Department of Justice, The Cost of Negligence: Losses from Preventable Household Burglaries, Law Enforcement Assistance Administration, 1979.

Yin, Robert, Mary Vogel, Jan Charken and Deborah Both, Citizen Patrol Projects, National Institute of Law Enforcement and Criminal Justice, Law Enforcement Assistance Administration, U.S. Department of Justice, January, 1979 . 